Supporting Information for:

\title{
Direct, Catalytic $\alpha$-Alkylation of $N$-Heterocycles by Hydroaminoalkylation: Substrate Effects for Regiodivergent Product Formation
}

Rebecca C. DiPucchio, Karst E. Lenzen, Pargol Daneshmand, Maria B. Ezhova, Laurel L. Schafer Department of Chemistry, The University of British Columbia, 2036 Main Mall, Vancouver, British Columbia, Canada V6T 1Z1

\section{Table of Contents}

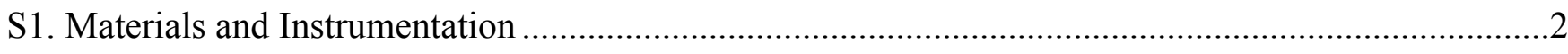

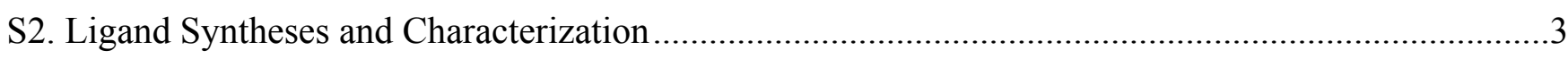

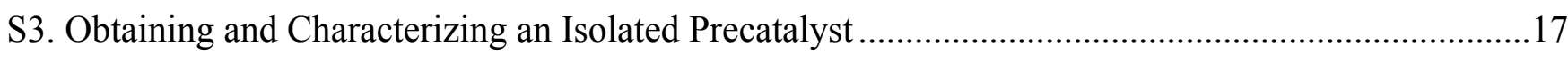

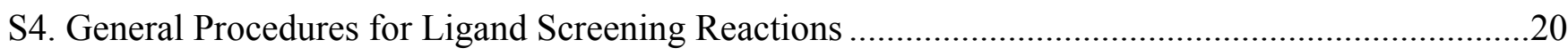

S5. General Procedures for Qualitative and Quantitative Catalysis .....................................................20

S6. Synthesis and Characterization of Amine Scope Products ...............................................................36

S7. Synthesis and Characterization of Alkene Scope Products ..........................................................61

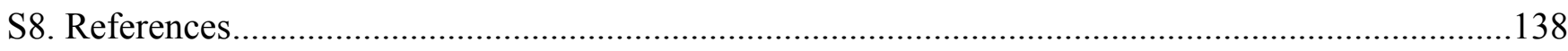




\section{S1. Materials and Instrumentation}

All reactions were performed under a $\mathrm{N}_{2}$ atmosphere using Schlenk or glovebox techniques, unless otherwise stated. $\mathrm{TaCl}_{5}$ (Strem), $\mathrm{Ta}\left(\mathrm{NMe}_{2}\right)_{5}$ (Strem), (chloromethyl)trimethylsilane (Aldrich), $N, N$ diphenylamine (Alfa), $N$-isopropylaniline (Combi-Blocks), triphosgene (Oakwood), 2,6-dimethylaniline (Aldrich), 2,6-diisopropylaniline (Alfa), $N$-methyl-1-phenylethan-1-amine (CombiBlocks), $N$-methyl1,1-diphenylmethanamine (CombiBlocks), $N$-methylpropan-2-amine (CombiBlocks), 2,4,6trimethylaniline (Aldrich), 4-bromo-2,6-dimethylaniline (Aldrich), and 4-chloro-2,6-dimethylaniline (Aldrich) were used as received. All amines and alkenes were commercially available, dried over $\mathrm{CaH}_{2}$ and distilled and degassed prior to use in catalytic experiments. $\left[\mathrm{Ta}\left(\mathrm{NMe}_{2}\right)_{3} \mathrm{Cl}_{2}\right]_{2},{ }^{1} \mathrm{Ta}\left(\mathrm{CH}_{2} \mathrm{CMe}_{3}\right)_{3} \mathrm{Cl}_{2},{ }^{2}$ and $\mathrm{Ta}\left(\mathrm{CH}_{2} \mathrm{SiMe}_{3}\right)_{3} \mathrm{Cl}_{2}{ }^{3}$ were synthesized according to literature protocols. The proteo-ligands and their corresponding ligand salts $\mathbf{L 1}-\mathbf{L 3}^{4}, \mathbf{L 4}^{5}, \mathbf{L 5}^{6}, \mathrm{TaMe}_{3} \mathrm{Cl}_{2},{ }^{7}$ can be prepared as previously described. All glassware was dried in a $180{ }^{\circ} \mathrm{C}$ oven overnight before use. Toluene, and hexanes were dried over activated alumina columns and stored over activated molecular sieves $(4 \AA)$. $d_{8}$-Toluene was dried over sieves, sparged, and freeze/pump/thawed prior to use. Experiments conducted on an NMR tube scale were performed in J. Young NMR tubes ( 8 " x $5 \mathrm{~mm}$ ) sealed with screw-type Teflon caps.

${ }^{1} \mathrm{H}$ and ${ }^{13} \mathrm{C}$ NMR spectra were recorded on Bruker $300 \mathrm{MHz}$ and $400 \mathrm{MHz}$ Avance spectrometers at ambient temperature. Chemical shifts $(\delta)$ are given relative to the corresponding residual protio solvent and are reported in parts per million ( $\mathrm{ppm})$. Coupling constants $J$ are given in Hertz (Hz). The following abbreviations are used to indicate signal multiplicity: $\mathrm{s}=$ singlet, $\mathrm{d}=$ doublet, $\mathrm{t}=$ triplet, $\mathrm{q}=$ quartet, $\mathrm{m}$ $=$ multiplet, and $\mathrm{br}=$ broad. Assignment of the signals was carried out using $1 \mathrm{D}\left({ }^{1} \mathrm{H},{ }^{13} \mathrm{C}\left\{{ }^{1} \mathrm{H}\right\}\right)$ and $2 \mathrm{D}$ (COSY, HSQC and HMBC) NMR experiments. High resolution mass-spectra (HRMS) were measured by the mass spectrometry services at University of British Columbia, UBC on a Kratos MS-50 spectrometer using a Bruker maXis Ultra-High Resolution tandem TOF (UHR-Qq-TOF) mass spectrometer using a positive electrospray ionization source. Fragment signals are given in mass per charge number $(\mathrm{m} / \mathrm{z})$. GC/MS analyses were conducted on an Agilent 7890B GC with an Agilent 5977 inert CI mass detector, utilizing methane as the ionization gas. Note that the peak at 6.294 represents residual internal standard in any cases where this is present. Single-crystal X-ray structure determination was performed on a APEX II diffractometer at the Department of Chemistry, University of British Columbia, by Pargol Daneshmand. 


\section{S2. Ligand Syntheses and Characterization}

General procedure for the synthesis of urea based proteoligands: Prepared following a modified literature procedure ${ }^{1}$ in which a chosen primary amine (1 equiv.) was dissolved in dichloromethane and the solution was cooled to $0{ }^{\circ} \mathrm{C}$. Triphosgene ( 0.35 equiv.) was added in portions as a solid. The solution was stirred for five minutes after which $N, N$-diisopropylethylamine DIPEA ( 2 equiv.) was added and the cold bath removed. The solution was stirred for 1 hour and then the appropriate amine (1 equiv.) and a second portion of DIPEA ( 1 equiv.) was added. The solution was stirred for an additional hour, and then diluted with $1 \mathrm{M} \mathrm{HCl}$. The organic phase was washed three times with $1 \mathrm{M} \mathrm{HCl}$ dried over $\mathrm{MgSO}_{4}$, filtered, and concentrated by rotary evaporation to give the crude product. Product was then recrystallized using ethyl acetate, all ligand yields reported are recrystallized yields.<smiles>Cc1cccc(C)c1NC(=O)N(C)C(C)c1ccccc1</smiles>

Synthesis of 3-(2,6-dimethylphenyl)-1-methyl-1-(1-phenylethyl)urea (L4-H): Prepared following the general procedure outlined above: 2,6-dimethylaniline $(2.25$ $\mathrm{g}, 18.5 \mathrm{mmol})$, triphosgene (1.81 g, $6.10 \mathrm{mmol})$, DIPEA $(7.2 \mathrm{~g}, 55.5 \mathrm{mmol}), \mathrm{N}$ methyl-1-phenylethan-1-amine $(2.5 \mathrm{~g}, 18.5 \mathrm{mmol})$. Recrystallization from a concentrated ethyl acetate solution provided the desired compound as a white solid $(3.48 \mathrm{~g}, 66.9 \%)$. All characterization data matched a previous report from our group. ${ }^{6}$

Synthesis of 1-benzhydryl-3-(2,6-dimethylphenyl)-1-methylurea (L5-H):<smiles>Cc1cccc(C)c1NC(=O)N(C)C(c1ccccc1)c1ccccc1</smiles>
Prepared following the general procedure outlined above: 2,6-dimethylaniline (307 $\mathrm{mg}, 2.53 \mathrm{mmol}$ ), triphosgene (250.2 $\mathrm{mg}, 0.843 \mathrm{mmol})$, DIPEA (981 mg, $7.59 \mathrm{mmol}$ ), $\mathrm{N}$-methyl-1,1-diphenylmethanamine (500 mg, $2.53 \mathrm{mmol}$ ). Recrystallization from a concentrated ethyl acetate solution provided the desired compound as a white solid (750 mg, $86 \%$ ): ${ }^{1} \mathrm{H} \mathrm{NMR}\left(\mathrm{CDCl}_{3}, 400 \mathrm{MHz}, 298 \mathrm{~K}\right): \delta$ 7.41-7.27 (overlapping $\mathrm{m}$, $\left.10 \mathrm{H}, o, m, p-\mathrm{C}_{6} H_{5}\right), 7.04\left(\mathrm{~s}, 3 \mathrm{H}, m, p-\mathrm{C}_{6} H_{5}\right), 6.70(\mathrm{~s}, 1 \mathrm{H}, \mathrm{NHCH}), 5.78($ br s, $1 \mathrm{H}, \mathrm{NH}), 2.88\left(\mathrm{~s}, 3 \mathrm{H}, \mathrm{CH}_{3}\right)$, $2.16\left(\mathrm{~s}, 6 \mathrm{H}, 2,6-\left(\mathrm{CH}_{3}\right)_{2} \mathrm{C}_{6} \mathrm{H}_{3}\right) \mathrm{ppm} .{ }^{13} \mathrm{C} \mathrm{NMR}\left(\mathrm{CDCl}_{3}, 101 \mathrm{MHz}, 298 \mathrm{~K}\right): \delta 156.57(\mathrm{C}=\mathrm{O}), 139.66,135.47$, $135.30,128.80,128.77,128.25,127.80,126.49,63.30,32.05,28.48 \mathrm{ppm}$. HRMS (ESI): $\mathrm{m} / z$ calcd for $\mathrm{C}_{23} \mathrm{H}_{25} \mathrm{~N}_{2} \mathrm{O}\left[\mathrm{M}+\mathrm{H}^{+}\right]: 345.1967$ Found: 345.1964. Anal. Calcd. for $\mathrm{C}_{23} \mathrm{H}_{25} \mathrm{~N}_{2} \mathrm{O}: \mathrm{C}, 80.20 ; \mathrm{H}, 7.02 ; \mathrm{N}, 8.13$; Found: C, 80.50; H, 7.12; N, 8.18. 


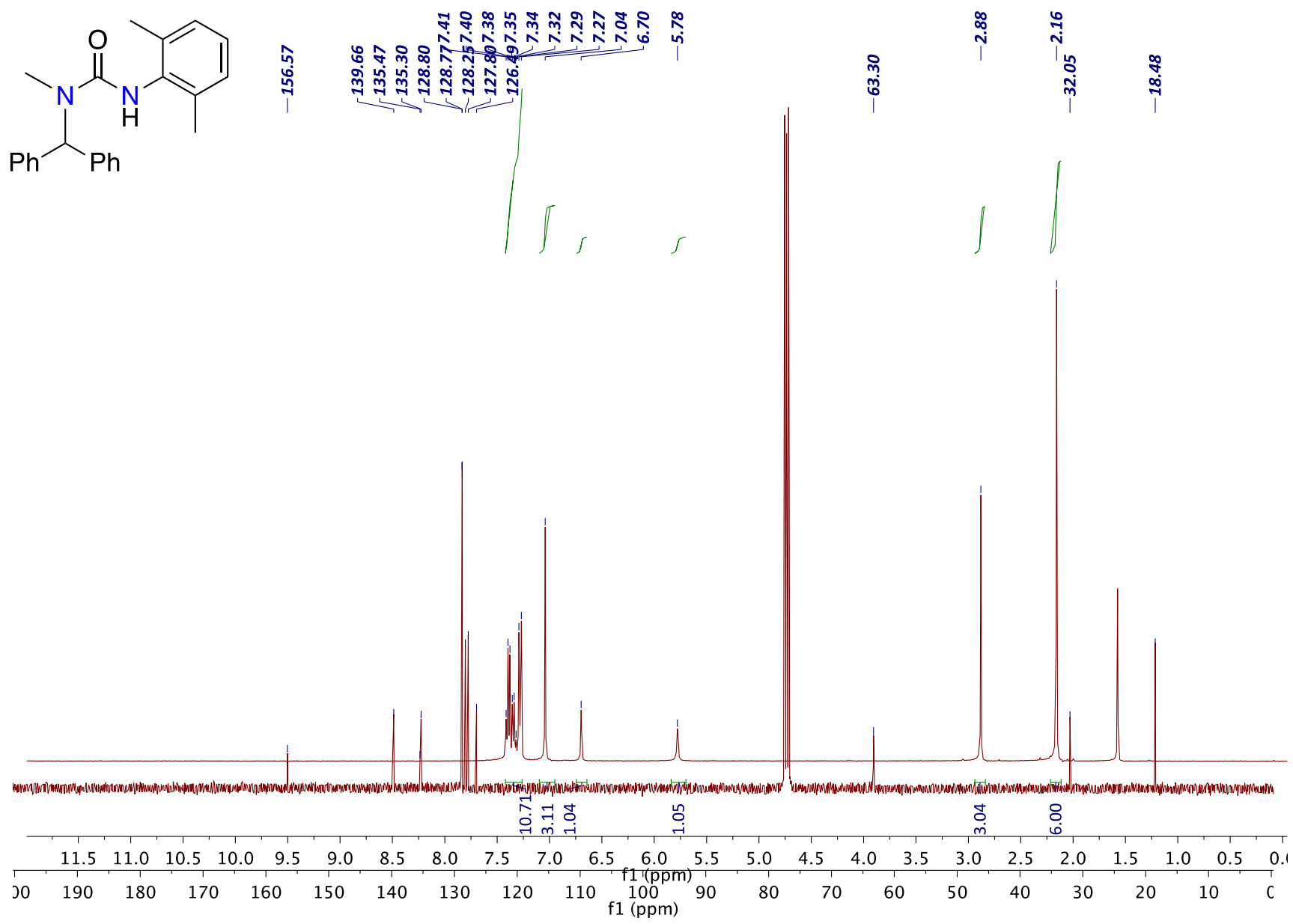

Figure S1. ${ }^{1} \mathrm{H}$ NMR spectrum (400 MHz, $\mathrm{CDCl}_{3}, 298 \mathrm{~K}$ ) of 1-benzhydryl-3-(2,6-dimethylphenyl)-1methylurea.<smiles>Cc1cccc(C)c1NC(=O)N(C)C(c1ccccc1)c1ccccc1</smiles>

Figure S2. ${ }^{13} \mathrm{C}$ NMR spectrum $\left(101 \mathrm{MHz}, \mathrm{CDCl}_{3}, 298 \mathrm{~K}\right)$ of 1-benzhydryl-3-(2,6dimethylphenyl)-1-methylurea. 
Synthesis of 3-(2,6-dimethylphenyl)-1-isopropyl-1-phenylurea (L6-H): Prepared $\mathrm{C}_{\mathrm{H}}$ following the general procedure outlined above: 2,6-dimethylaniline $(1.5 \mathrm{~g}, 20.5$ mmol), triphosgene $(2.02 \mathrm{~g}, 7.41 \mathrm{mmol})$, DIPEA $(7.95 \mathrm{~g}, 61.5 \mathrm{mmol}), \mathrm{N}$ isopropylaniline $(2.5 \mathrm{~g}, 20.5 \mathrm{mmol})$. Recrystallization from a concentrated ethyl acetate solution provided the desired compound as a white solid $(3.20 \mathrm{~g}, 65 \%):{ }^{1} \mathrm{H}$ NMR $\left(\mathrm{CDCl}_{3}, 400 \mathrm{MHz}, 298 \mathrm{~K}\right): \delta 7.05\left(\mathrm{~s}, 3 \mathrm{H}, o, m, p-\mathrm{C}_{6} H_{5}\right), 5.69$ (br s, $\left.1 \mathrm{H}, \mathrm{NH}\right)$, 4.56-4.49 (m, $\left.1 \mathrm{H}, \mathrm{CH}\left(\mathrm{CH}_{3}\right)_{2}\right), 2.86\left(\mathrm{~s}, 3 \mathrm{H}, \mathrm{CH}_{3}\right), 2.24\left(\mathrm{~s}, 6 \mathrm{H}, 2,6-\left(\mathrm{CH}_{3}\right)_{2} \mathrm{C}_{6} \mathrm{H}_{3}\right), 1.17\left(\mathrm{~d}, J_{\mathrm{H}-\mathrm{H}}=1.7 \mathrm{~Hz}\right.$, $\left.6 \mathrm{H}, \mathrm{CH}\left(\mathrm{CH}_{3}\right)_{2}\right)$ ppm. ${ }^{13} \mathrm{C} \mathrm{NMR}\left(\mathrm{CDCl}_{3}, 101 \mathrm{MHz}, 298 \mathrm{~K}\right): \delta 156.00(\mathrm{C}=\mathrm{O}), 135.70,135.57,128.20$, 126.40, 45.89, 27.45, 20.21, 18.56 ppm. HRMS (ESI): $m / z$ calcd for $\mathrm{C}_{13} \mathrm{H}_{21} \mathrm{~N}_{2} \mathrm{O}\left[\mathrm{M}+\mathrm{H}^{+}\right]: 221.1654$. Found: 221.1656. Anal. Calcd. for $\mathrm{C}_{13} \mathrm{H}_{21} \mathrm{~N}_{2} \mathrm{O}$ : C, 70.87; H, 9.15; N, 12.72; Found: C, 70.89; H, 9.14; N, 12.63 . 


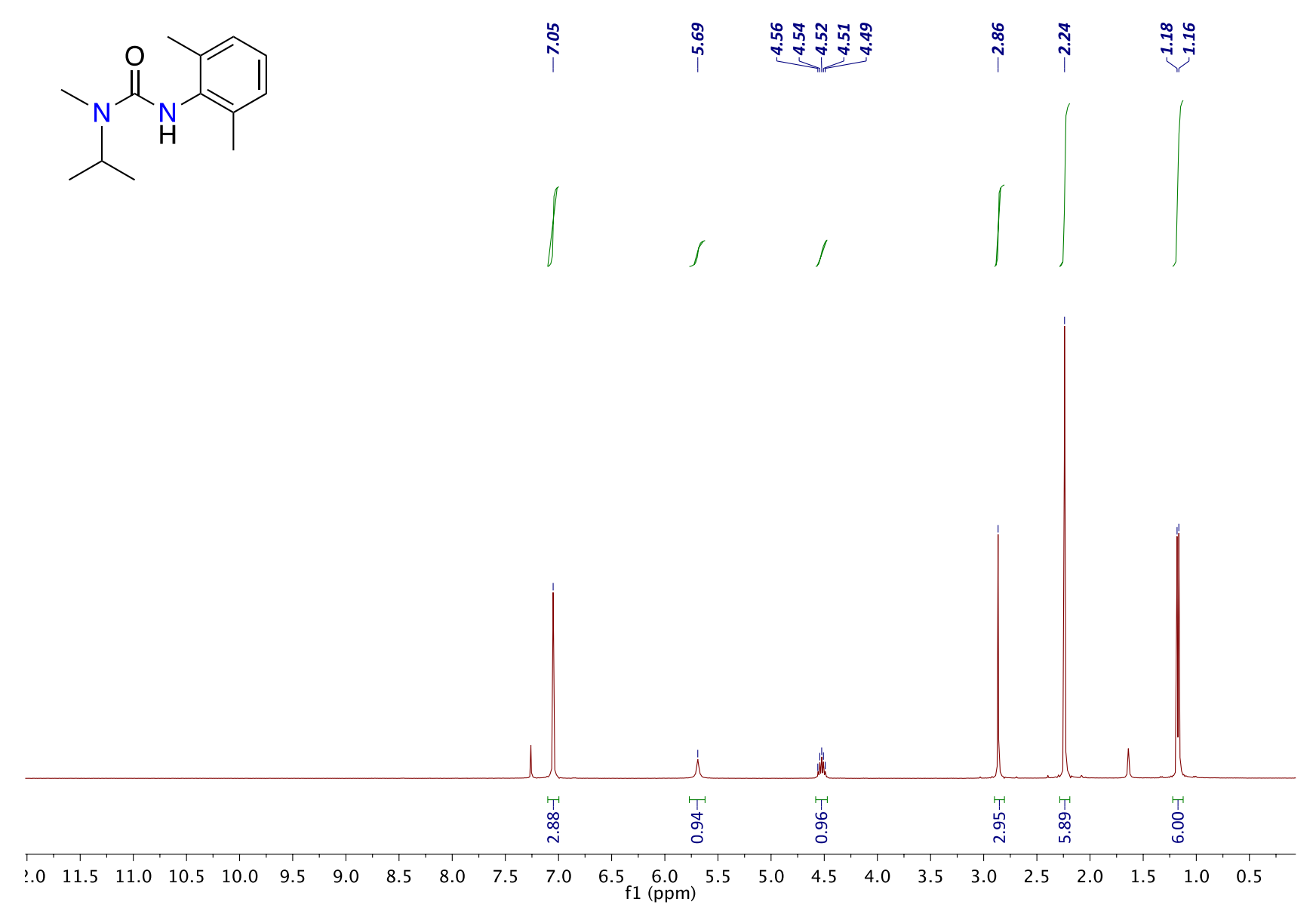

Figure S3. ${ }^{1} \mathrm{H}$ NMR spectrum $\left(400 \mathrm{MHz}, \mathrm{CDCl}_{3}, 298 \mathrm{~K}\right.$ ) of 3-(2,6-dimethylphenyl)-1-isopropyl-1phenylurea. 


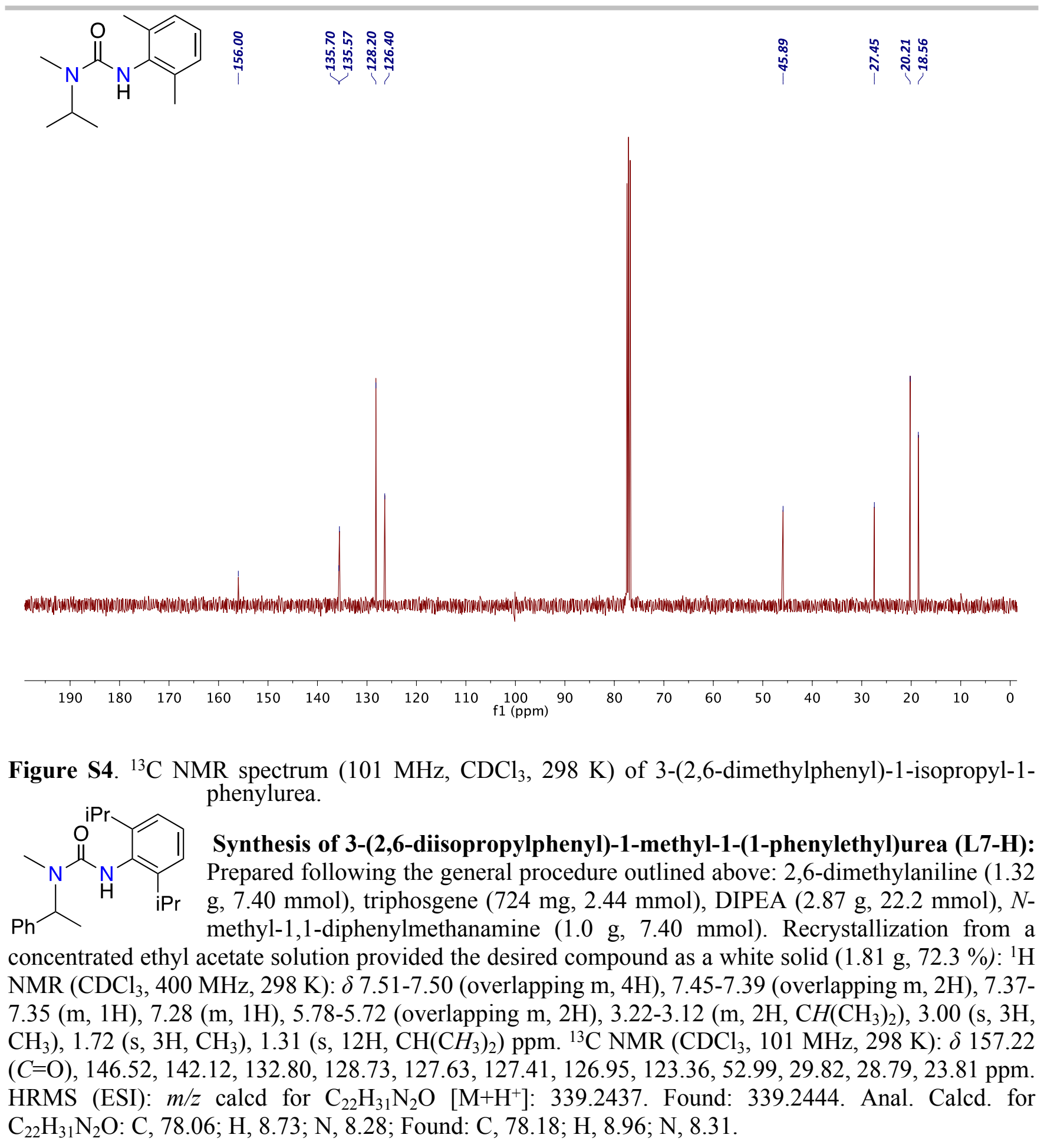




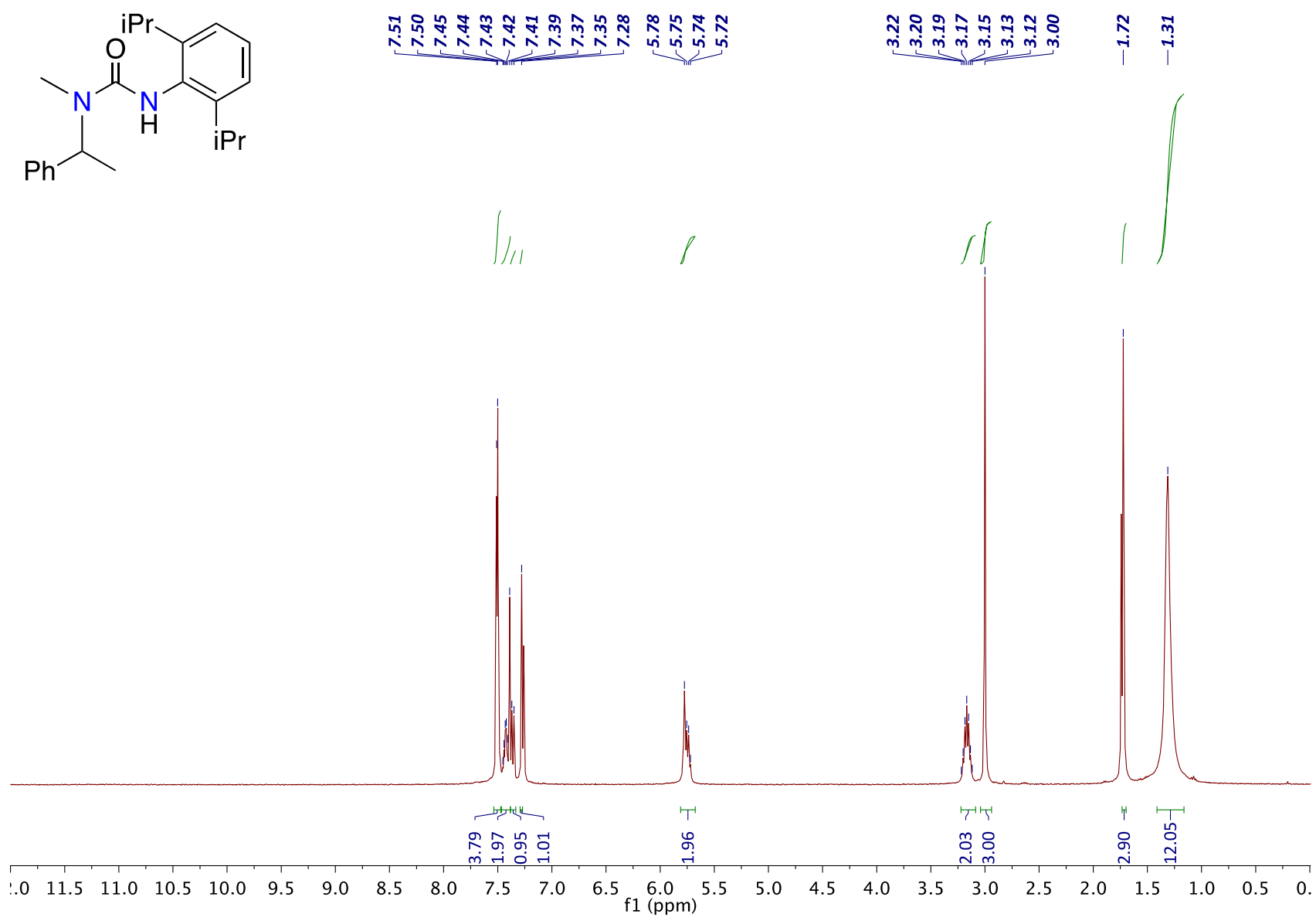

Figure S5. ${ }^{1} \mathrm{H}$ NMR spectrum $\left(400 \mathrm{MHz}, \mathrm{CDCl}_{3}, 298 \mathrm{~K}\right)$ of 3-(2,6-diisopropylphenyl)-1-methyl-1-(1phenylethyl)urea. 

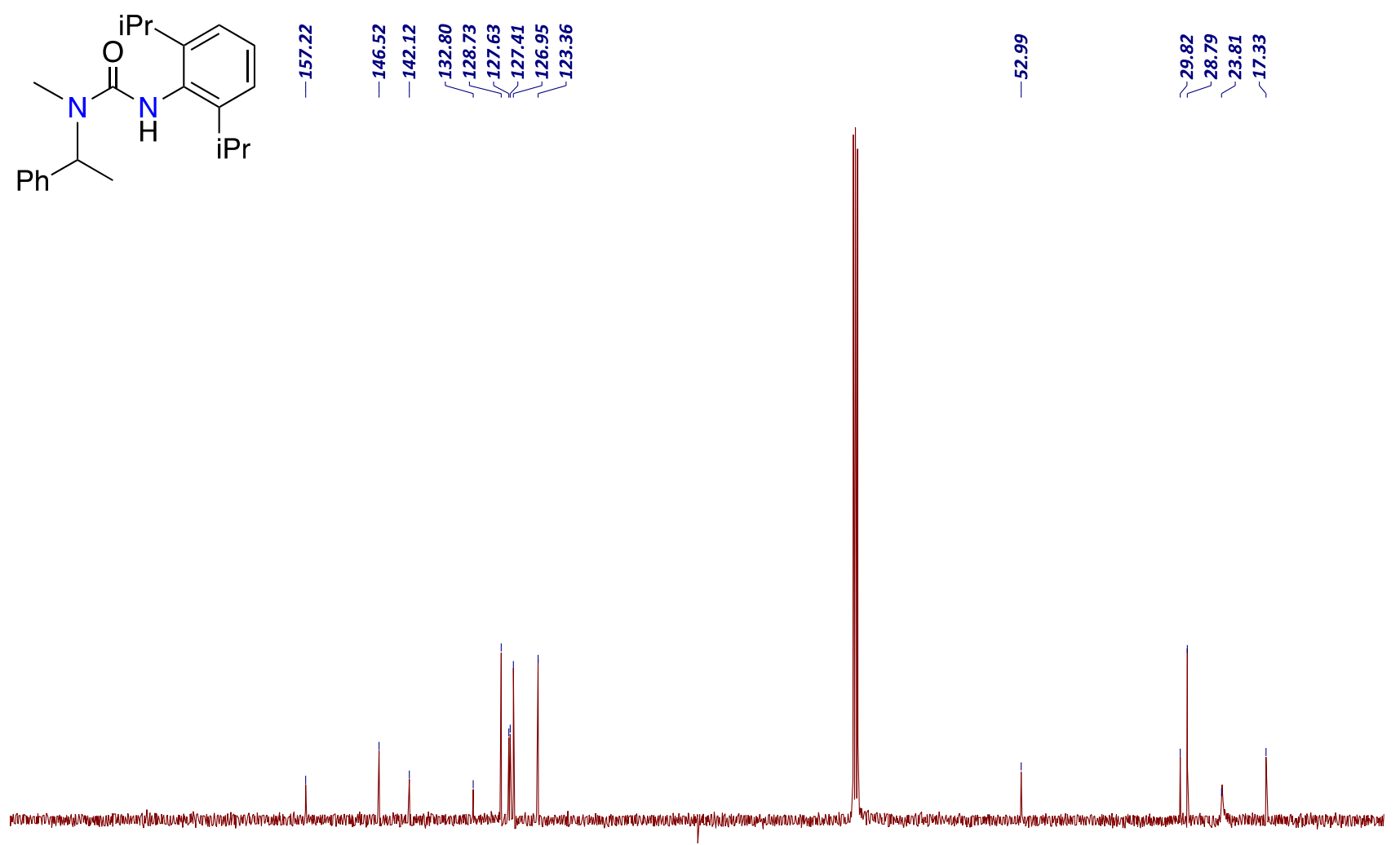

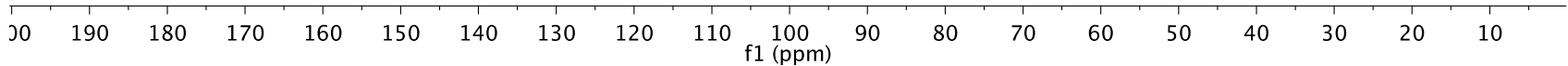

Figure S6. ${ }^{13} \mathrm{C}$ NMR spectrum (101 MHz, $\left.\mathrm{CDCl}_{3}, 298 \mathrm{~K}\right)$ of 3-(2,6-diisopropylphenyl)-1-methyl-1-(1phenylethyl)urea.<smiles>Cc1cc(Cl)cc(C)c1NC(=O)N(C)C(C)c1ccccc1</smiles>

\section{Synthesis of 3-(4-chloro-2,6-dimethylphenyl)-1-methyl-1-(1-} phenylethyl)urea (L8-H): Prepared following the general procedure outlined above: 4-chloro-2,6-dimethylaniline $(2.50 \mathrm{~g}, 15.8 \mathrm{mmol})$, triphosgene $(1.30 \mathrm{~g}$, $5.26 \mathrm{mmol})$, DIPEA (12.3 mL, $68.0 \mathrm{mmol}), N$-methyl-1-phenylethan-1-amine $(2.34 \mathrm{~g}, 15.8 \mathrm{mmol})$. Recrystallization from a concentrated ethyl acetate solution provided the desired compound as a white solid $(0.94 \mathrm{~g}, 38 \%):{ }^{1} \mathrm{H} \mathrm{NMR}\left(\mathrm{CDCl}_{3}, 400 \mathrm{MHz}, 298 \mathrm{~K}\right): \delta$ $7.36\left(\mathrm{~m}, 4 \mathrm{H}, \mathrm{o}, \mathrm{m}_{-} \mathrm{C}_{6} \mathrm{H}_{5}\right), 7.31\left(\mathrm{~m}, 1 \mathrm{H}, \mathrm{p}-\mathrm{CH}_{3}\right), 7.03(\mathrm{~s}, 2 \mathrm{H}, \mathrm{CH}), 5.84($ br s, $1 \mathrm{H}, \mathrm{NH}), 5.56(\mathrm{~m}, 1 \mathrm{H}$, $\left.\mathrm{CH}\left(\mathrm{CH}_{3} \mathrm{Ph}\right)\right), 2.84\left(\mathrm{~s}, 3 \mathrm{H}, \mathrm{CH}_{3}\right), 2.14\left(\mathrm{~s}, 6 \mathrm{H}, 2,6-\left(\mathrm{CH}_{3}\right) 2 \mathrm{C}_{6} \mathrm{H}_{3}\right), 1.60\left(\mathrm{~d}, 3 \mathrm{H}, \mathrm{CH}_{3}\right) \mathrm{ppm} .{ }^{13} \mathrm{C} \mathrm{NMR}\left(\mathrm{CDCl}_{3}\right.$, $101 \mathrm{MHz}, 298 \mathrm{~K}): \delta 156.12(\mathrm{C}=\mathrm{O}), 141.69,137.36,134.23,131.59,128.87,128.01,127.58,126.95$, 53.23, 29.92, 18.48, 17.29 ppm. HRMS (ESI): $\mathrm{m} / \mathrm{z}$ calcd for $\mathrm{C}_{18} \mathrm{H}_{21} \mathrm{ClN}_{2} \mathrm{O}[\mathrm{M}+\mathrm{H}+]: 317.1419$. Found: 317.1421 . 


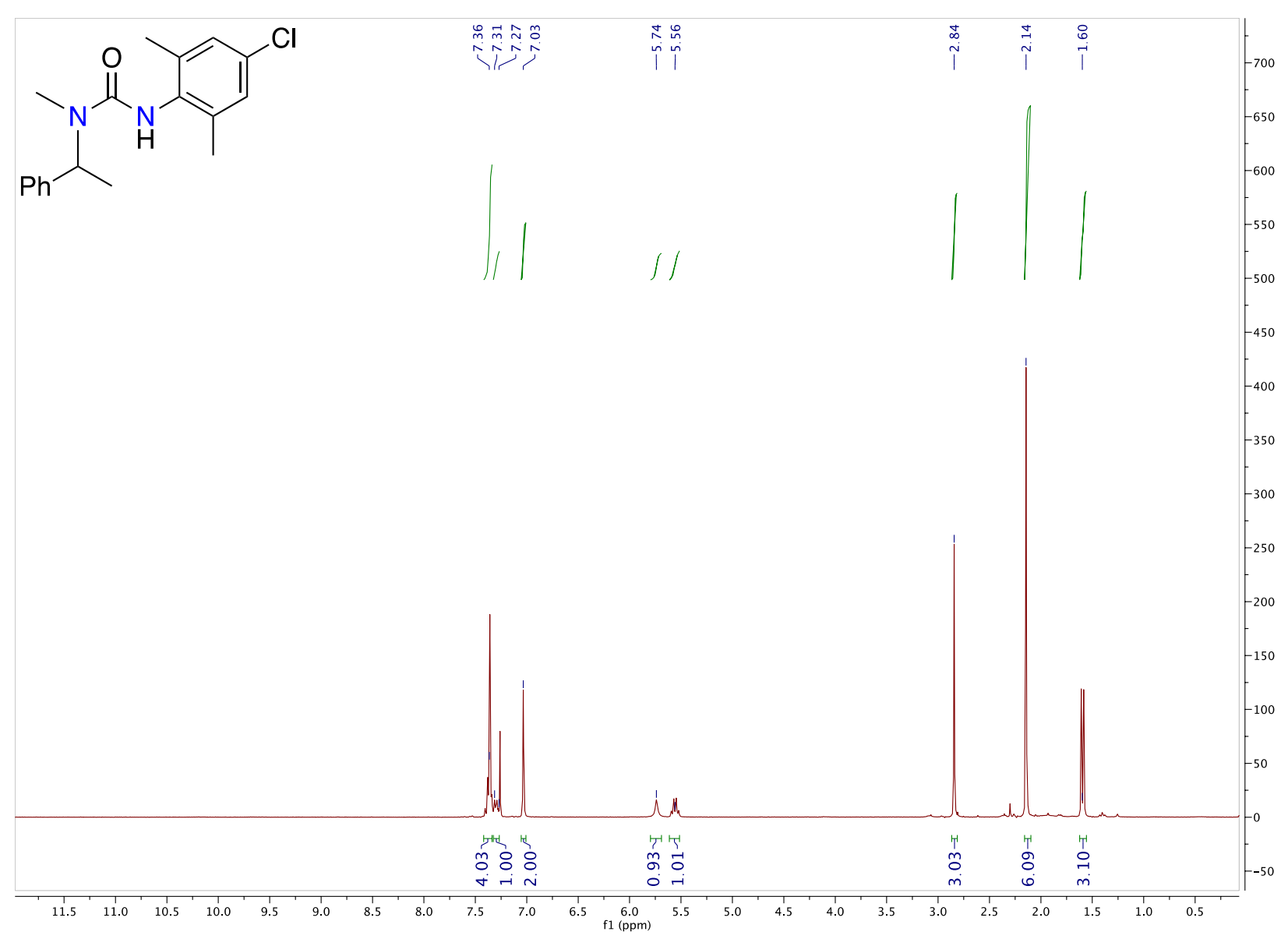

Figure S7: ${ }^{1} \mathrm{H}$ NMR spectrum (400 MHz, $\mathrm{CDCl}_{3}, 298 \mathrm{~K}$ ) of 3-(4-chloro-2,6-dimethylphenyl)-1-methyl1-(1-phenylethyl)urea. 


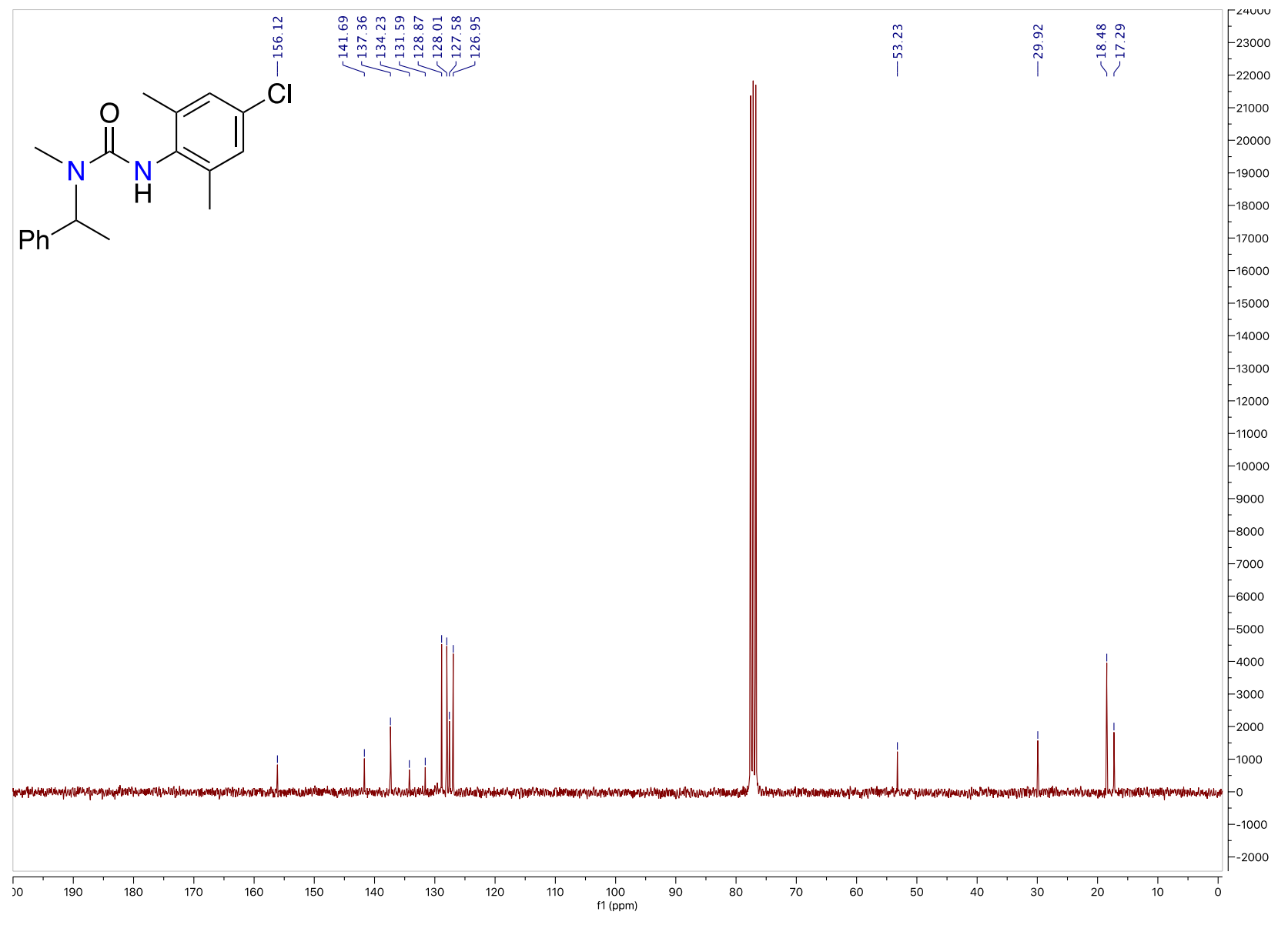

Figure S8: ${ }^{13} \mathrm{C}$ NMR spectrum $\left(101 \mathrm{MHz}, \mathrm{CDCl}_{3}, 298 \mathrm{~K}\right)$ of of 3-(4-chloro-2,6-dimethylphenyl)-1methyl-1-(1-phenylethyl)urea.<smiles>Cc1cc(C)c(NC(=O)N(C)C(C)c2ccccc2)c(C)c1</smiles>

Synthesis of 3-mesityl-1-methyl-1-(1-phenylethyl)urea (L9-H): Prepared following the general procedure outlined above: 2,4,6-trimethylaniline $(2.28 \mathrm{~g}$, $15.8 \mathrm{mmol})$, triphosgene $(1.39 \mathrm{~g}, 7.40 \mathrm{mmol})$, DIPEA (12.3 mL, $68.0 \mathrm{mmol}), \mathrm{N}-$ methyl-1-phenylethan-1-amine (2.5 g, $15.8 \mathrm{mmol})$. Recrystallization from a concentrated ethyl acetate solution provided the desired compound as a white solid (4.53 g, $91 \%):{ }^{1} \mathrm{H} \mathrm{NMR}\left(\mathrm{CDCl}_{3}, 400 \mathrm{MHz}, 298 \mathrm{~K}\right): \delta 7.37$ (m, 4H, o,m- $\left.\mathrm{C}_{6} \mathrm{H}_{5}\right)$, $7.30\left(\mathrm{~m}, 1 \mathrm{H}, \mathrm{p}-\mathrm{C}_{6} \mathrm{H}_{5}\right), 6.86(\mathrm{~S}, 2 \mathrm{H}), 5.72(\mathrm{br} \mathrm{s}, 1 \mathrm{H}, \mathrm{NH}), 5.59\left(\mathrm{~m}, 1 \mathrm{H}, \mathrm{CH}\left(\mathrm{CH}_{3}\right)_{2}\right), 2.81\left(\mathrm{~s}, 3 \mathrm{H}, \mathrm{CH}_{3}\right), 2.25$ $\left(\mathrm{s}, 3 \mathrm{H}, \mathrm{CH}_{3}\right), 2.15\left(\mathrm{~s}, 6 \mathrm{H}, \mathrm{CH}_{3}\right), 1.59\left(\mathrm{~d}, \mathrm{~J}_{\mathrm{H}-\mathrm{H}}=1.6 \mathrm{~Hz}, 3 \mathrm{H}, \mathrm{CH}_{3}\right)$ ppm. ${ }^{13} \mathrm{C} \mathrm{NMR}\left(\mathrm{CDCl}_{3}, 101 \mathrm{MHz}, 298\right.$ $\mathrm{K}): \delta 156.57(\mathrm{C}=\mathrm{O}), 141.92,136.01,135.36,132.89,128.90,128.72,127.36,126.97,52,90,29.68,20.98$, 18.42, 17.13 ppm. HRMS (ESI): m/z calcd for $\mathrm{C}_{19} \mathrm{H}_{24} \mathrm{~N}_{2} \mathrm{O}[\mathrm{M}+\mathrm{H}+]$ : 297.1967. Found: 297.1963. 


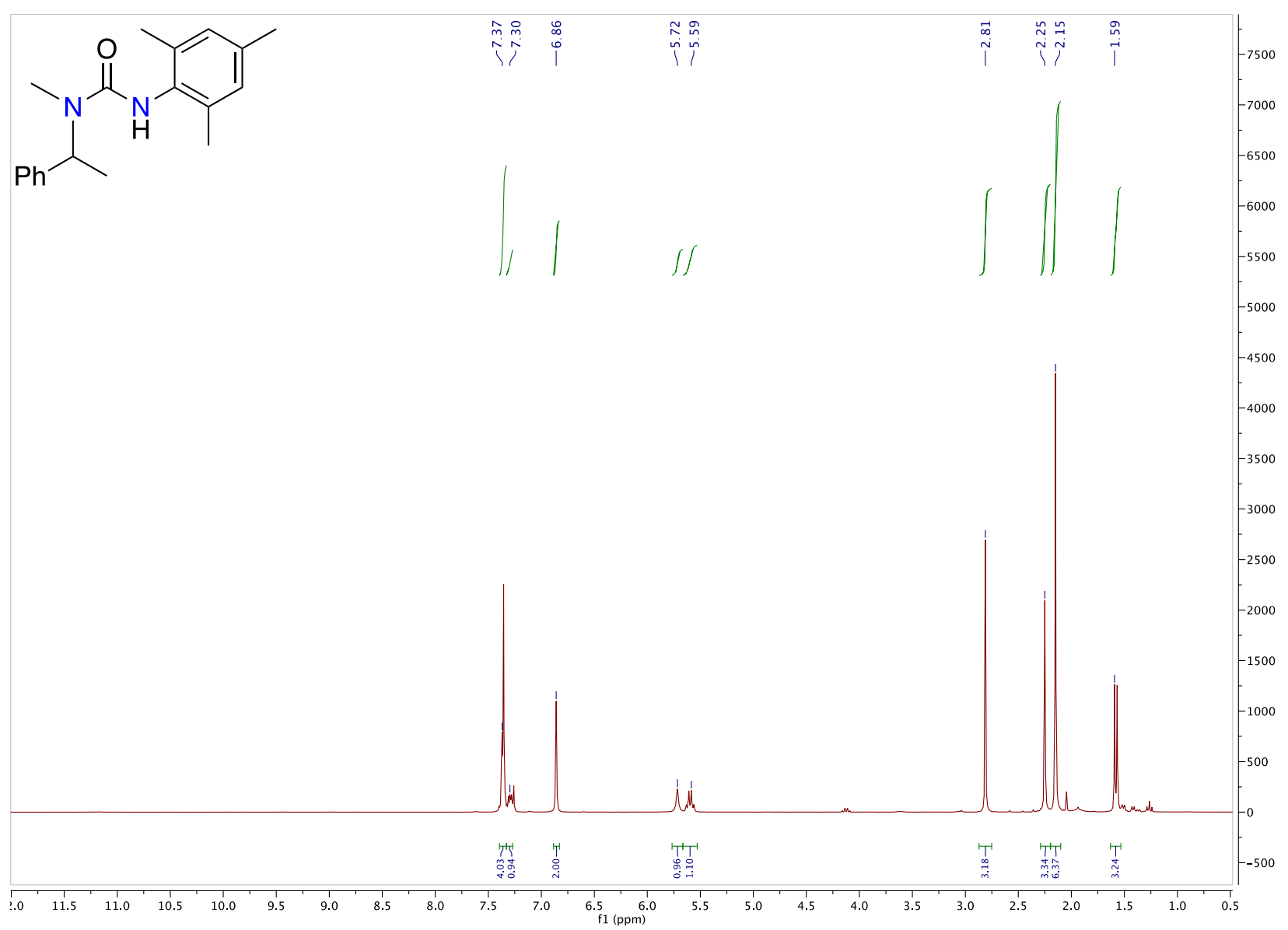

Figure S9: ${ }^{1} \mathrm{H}$ NMR spectrum $\left(400 \mathrm{MHz}, \mathrm{CDCl}_{3}, 298 \mathrm{~K}\right)$ of 3-mesityl-1-methyl-1-(1-phenylethyl)urea. 


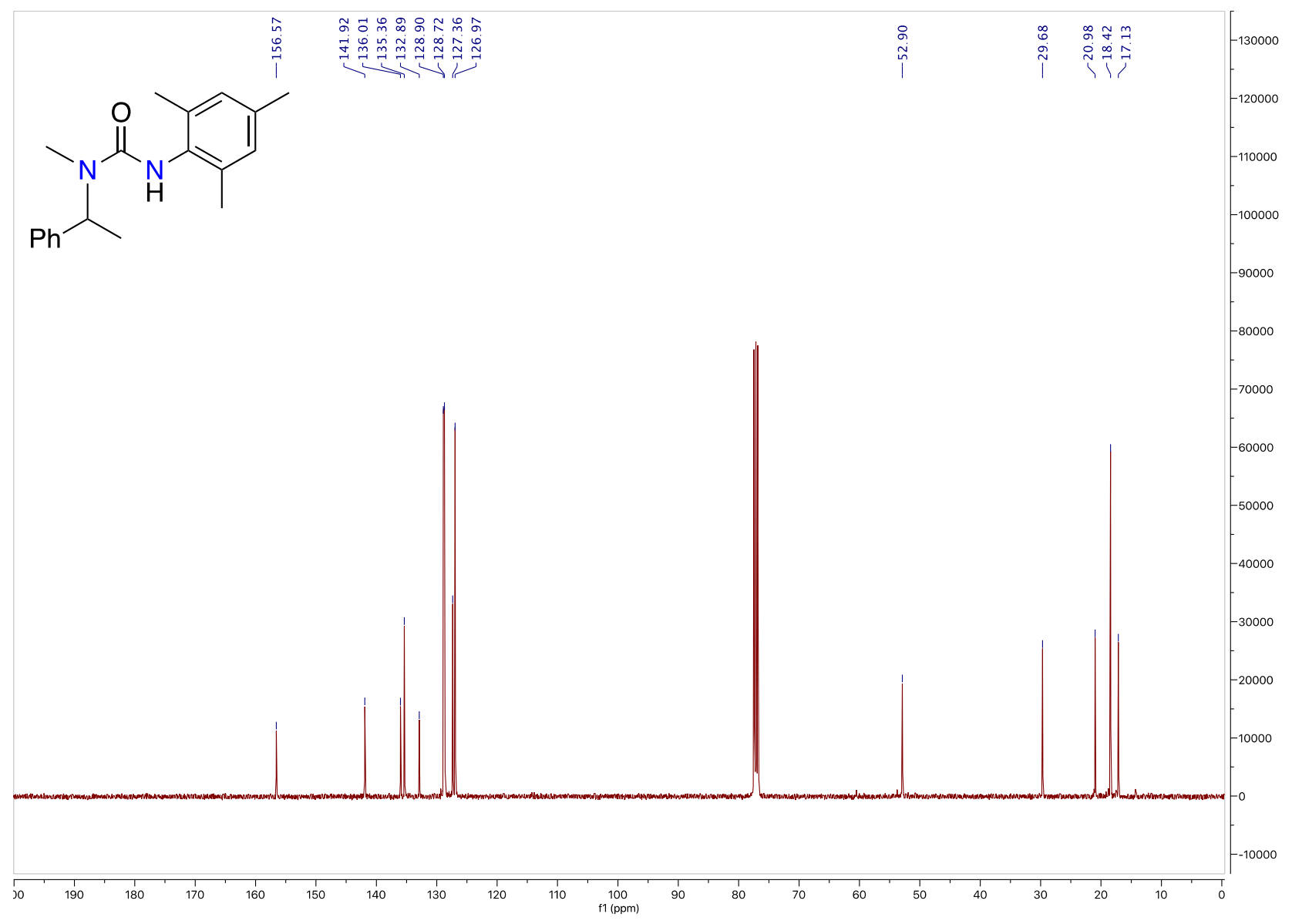

Figure S10: ${ }^{13} \mathrm{C}$ NMR spectrum $\left(101 \mathrm{MHz}, \mathrm{CDCl}_{3}, 298 \mathrm{~K}\right)$ of 3-mesityl-1-methyl-1-(1-phenylethyl)urea.<smiles>Cc1cc(Br)cc(C)c1NC(=O)N(C)C(C)c1ccccc1</smiles>

\section{Synthesis of}

of

3-(4-bromo-2,6-dimethylphenyl)-1-methyl-1-(1phenylethyl)urea (L10-H): Prepared following the general procedure outlined above: 4-bromo-2,6-dimethylaniline $(2.34 \mathrm{~g}, 11.7 \mathrm{mmol})$, triphosgene $(0.96 \mathrm{~g}$, $3.89 \mathrm{mmol})$, DIPEA (9.15 mL, $52.5 \mathrm{mmol}), \mathrm{N}$-methyl-1-phenylethan-1-amine $(1.58 \mathrm{~g}, 11.7 \mathrm{mmol})$. Recrystallization from a concentrated ethyl acetate solution provided the desired compound as a white solid $(2.36 \mathrm{~g}, 56 \%):{ }^{1} \mathrm{H} \mathrm{NMR}\left(\mathrm{CDCl}_{3}, 400 \mathrm{MHz}, 298 \mathrm{~K}\right): \delta$ $7.37\left(\mathrm{~m}, 4 \mathrm{H}, \mathrm{o}, \mathrm{m}-\mathrm{C}_{6} \mathrm{H}_{5}\right), 7.30\left(\mathrm{~m}, 1 \mathrm{H}, \mathrm{p}-\mathrm{C}_{6} \mathrm{H}_{5}\right), 6.86(\mathrm{~s}, 2 \mathrm{H}, m-\mathrm{CH}), 5.72($ broad s, $1 \mathrm{H}, \mathrm{NH}), 5.99(\mathrm{~m}, 1 \mathrm{H}$, $\left.\mathrm{CH}\left(\mathrm{CH}_{3} \mathrm{Ph}\right)\right), 2.81\left(\mathrm{~s}, 3 \mathrm{H}, \mathrm{CH}_{3}\right), 2.25\left(\mathrm{~s}, 3 \mathrm{H}, \mathrm{CH}_{3}\right), 2.15\left(\mathrm{~s}, 6 \mathrm{H}, \mathrm{CH}_{3}\right), 1.59\left(\mathrm{~d}, 3 \mathrm{H}, \mathrm{CH}_{3}\right)$ ppm. ${ }^{13} \mathrm{C} \mathrm{NMR}$ $\left(\mathrm{CDCl}_{3}, 101 \mathrm{MHz}, 298 \mathrm{~K}\right): \delta 156.57(\mathrm{C}=\mathrm{O}), 141.92,136.01,135.36,132.89,128.90,128.72,127.36$, 126.97, 52.90, 29.68, 20.98, 18.42, 17.13 ppm. Anal. Calcd. for $\mathrm{C}_{18} \mathrm{H}_{21} \mathrm{BrN}_{2} \mathrm{O}: \mathrm{C}, 59.84 ; \mathrm{H}, 5.86 ; \mathrm{N}, 7.75$; Found: C, 59.91; H, 5.89; N, 7.73. 


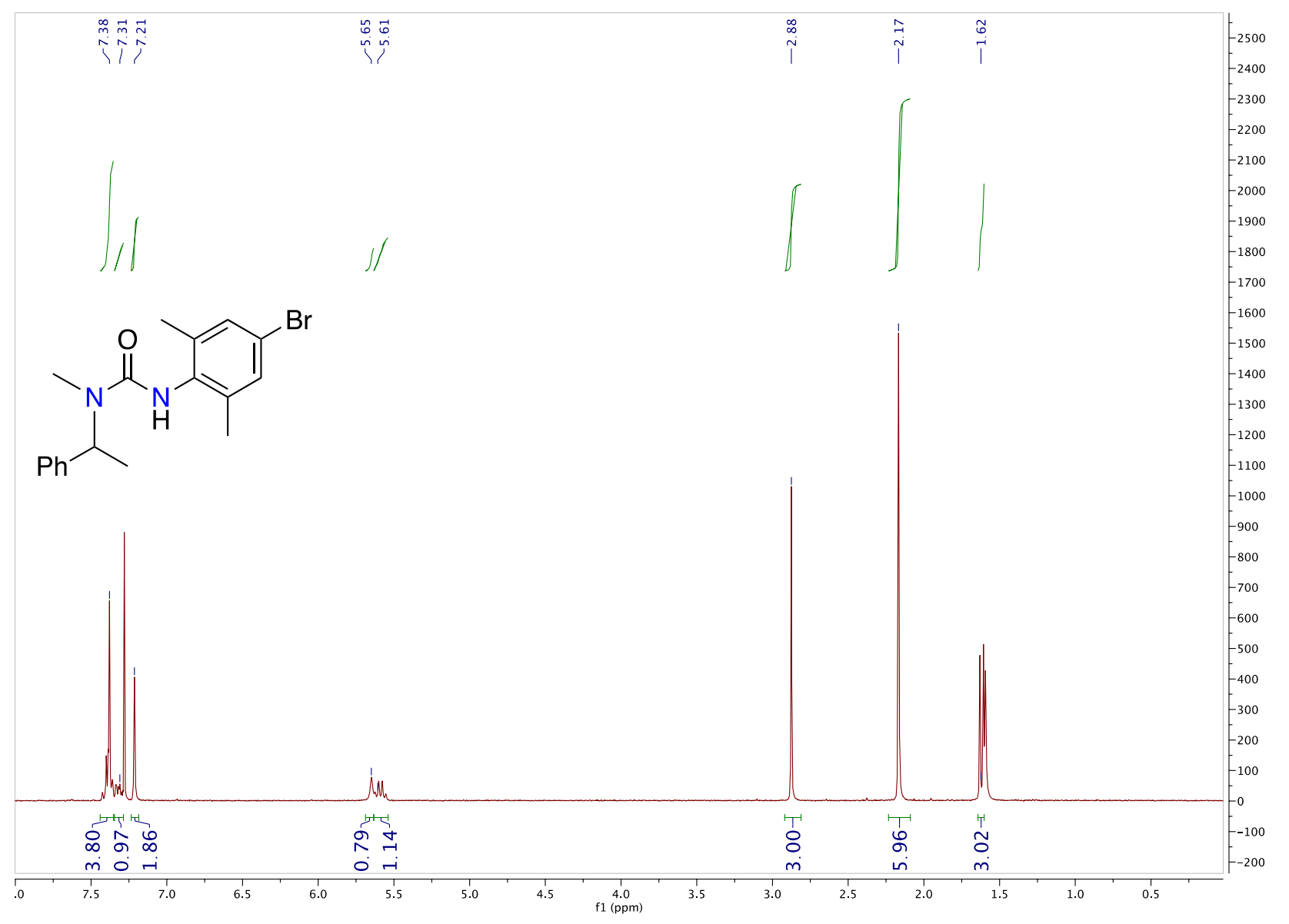

Figure S11: 1H NMR spectrum (400 MHz, CDCl3, $298 \mathrm{~K})$ of 3-(4-bromo-2,6-dimethylphenyl)-1methyl-1-(1-phenylethyl)urea. 


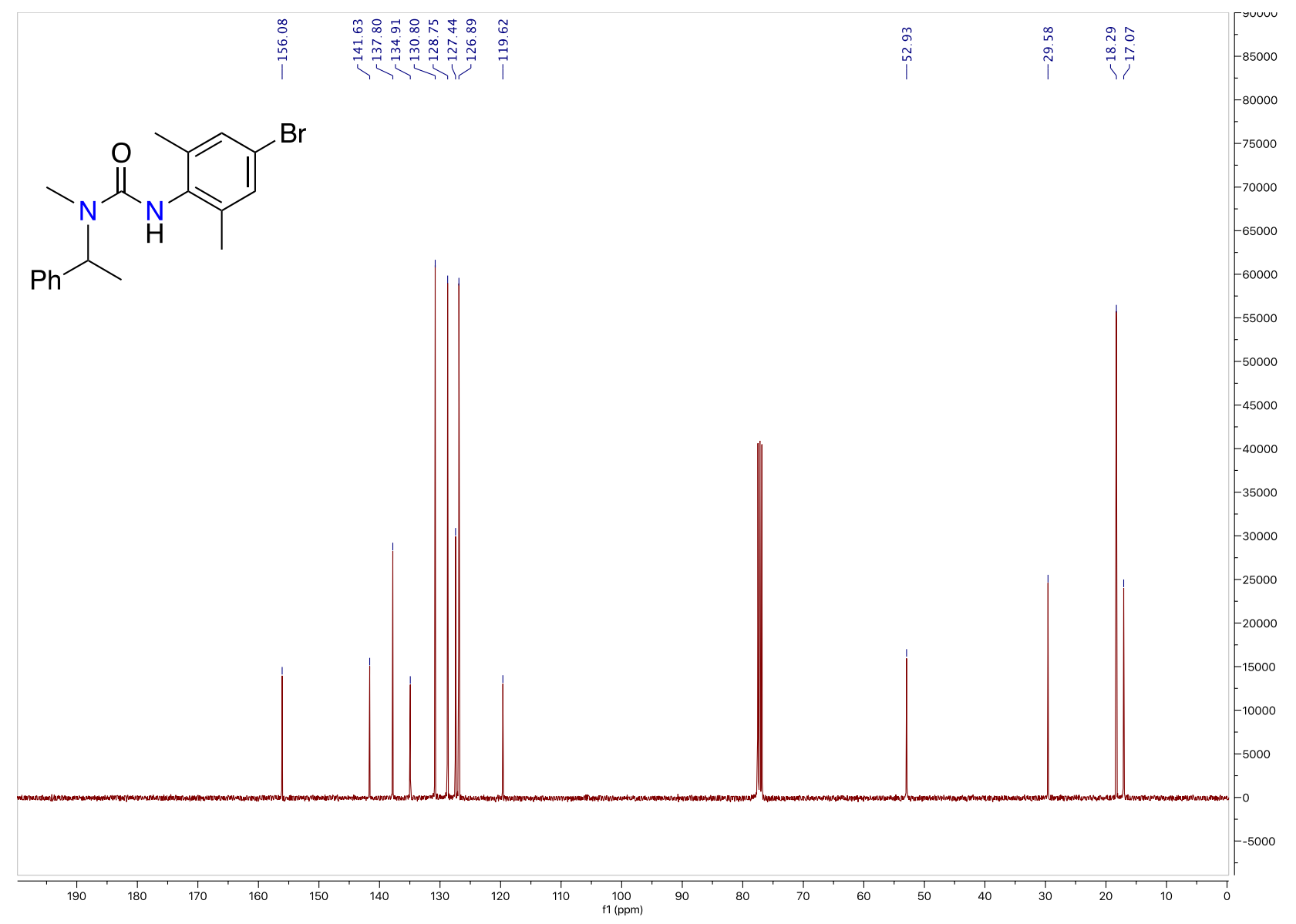

Figure S12: ${ }^{13} \mathrm{C}$ NMR spectrum $\left(101 \mathrm{MHz}, \mathrm{CDCl}_{3}, 298 \mathrm{~K}\right)$ of 3-(4-bromo-2,6-dimethylphenyl)-1methyl-1-(1-phenylethyl)urea. 
General procedure for the synthesis of all ureate ligand salts: $\mathrm{NaN}\left(\mathrm{SiMe}_{3}\right)_{2}$ (1 equiv.) was added in portions to a suspension of the corresponding proteoligand (1 equiv.) in hexanes $(\sim 10 \mathrm{~mL})$ and stirred overnight at room temperature. The volatiles were then removed at low pressure and the resulting solid was thoroughly washed with hexanes $(3 \times 5 \mathrm{~mL})$ and dried to give the sodium salt in quantitative yield as a colorless powder. The resulting ligand salts were used directly without further purification and were stored in a glovebox. NMR characterization was precluded due to poor solubility in common NMR solvents (e.g. $d_{6}$-benzene or $d_{8}$-toluene).

Synthesis of sodium (2,6-dimethylphenyl)(diphenylcarbamoyl)amide (L5): Prepared following the general procedure outlined above: 3-(2,6-dimethylphenyl)-1,1-diphenylurea (0.68 g, $2.17 \mathrm{mmol})$, $\mathrm{NaN}\left(\mathrm{SiMe}_{3}\right)_{2}(0.40 \mathrm{~g}, 2.17 \mathrm{mmol})$.

Synthesis of sodium (2,6-dimethylphenyl)(isopropyl(phenyl)carbamoyl)amide (L6): Prepared following the general procedure outlined above: 3-(2,6-dimethylphenyl)-1-isopropyl-1-phenylurea (1.81 $\mathrm{g}, 2.64 \mathrm{mmol}), \mathrm{NaN}\left(\mathrm{SiMe}_{3}\right)_{2}(0.48 \mathrm{~g}, 2.64 \mathrm{mmol})$.

Synthesis of sodium (2,6-diisopropylphenyl)(methyl(1-phenylethyl)carbamoyl)amide (L7): Prepared following the general procedure outlined above: 3-(2,6-diisopropylphenyl)-1-methyl-1-(1phenylethyl)urea $(0.74 \mathrm{~g}, 5.35 \mathrm{mmol}), \mathrm{NaN}\left(\mathrm{SiMe}_{3}\right)_{2}(0.98 \mathrm{~g}, 5.35 \mathrm{mmol})$.

Synthesis of sodium (4-chloro-2,6-dimethylphenyl)(methyl(1-phenylethyl)carbamoyl)amide (L8): Prepared following the general procedure outlined above: 3-(4-chloro-2,6-dimethylphenyl)-1-methyl-1(1-phenylethyl)urea $(0.94 \mathrm{~g}, 6.00 \mathrm{mmol}), \mathrm{NaN}\left(\mathrm{SiMe}_{3}\right)_{2}(1.10 \mathrm{~g}, 6.00 \mathrm{mmol})$.

Synthesis of sodium mesityl(methyl(1-phenylethyl)carbamoyl)amide (L9): Prepared following the general procedure outlined above: 3-mesityl-1-methyl-1-(1-phenylethyl)urea (4.53 g, $14.37 \mathrm{mmol})$, $\mathrm{NaN}\left(\mathrm{SiMe}_{3}\right)_{2}(2.64 \mathrm{~g}, 14.37 \mathrm{mmol})$.

Synthesis of sodium (4-bromo-2,6-dimethylphenyl)(methyl(1-phenylethyl)carbamoyl)amide (L10): Prepared following the general procedure outlined above: 3-(4-bromo-2,6-dimethylphenyl)-1-methyl-1(1-phenylethyl)urea $(2.36 \mathrm{~g}, 6.55 \mathrm{mmol}), \mathrm{NaN}\left(\mathrm{SiMe}_{3}\right)_{2}(1.20 \mathrm{~g}, 6.55 \mathrm{mmol})$. 


\section{S3. Obtaining and Characterizing an Isolated Precatalyst}

\section{$\operatorname{Mono}(N-$ (2,6-dimethylphenyl)- $N$-methyl- $N$-(1-phenylethyl)carbamoylamidate)-}

tris(methylenetrimethylsilane)chlorotantalum (1): In a glovebox, to a stirring suspension of $\mathrm{Ta}\left(\mathrm{CH}_{2} \mathrm{SiMe}_{3}\right)_{3} \mathrm{Cl}_{2}(0.169 \mathrm{~g}, 0.33 \mathrm{mmol})$ in toluene $(\sim 3 \mathrm{~mL})$ in a $20 \mathrm{~mL}$ vial, a suspension of sodium (2,6-dimethylphenyl)(methyl(1-phenylethyl)carbamoyl)amide (L4, $0.100 \mathrm{~g}, 0.33 \mathrm{mmol})$ in toluene ( 3 $\mathrm{mL}$ ) was added dropwise over 5 minutes. The mixture was stirred at ambient temperature for one hour, filtered through Celite ${ }^{\mathrm{TM}}$, and concentrated in vacuo overnight. The resulting crude residue was dissolved in minimal hexanes $(\sim 2 \mathrm{~mL})$, storage at $-35^{\circ} \mathrm{C}$ overnight produced a yellow precipitate. The supernatant was decanted and the white crystals $(0.0813 \mathrm{~g}, 31 \%)$ were obtained and dried in vacuo overnight. A sample from these crystals was used for single crystal X-ray structure analysis: ${ }^{1} \mathrm{H}$ NMR $\left(\mathrm{CDCl}_{3}, 400 \mathrm{MHz}, 298 \mathrm{~K}\right): \delta 7.18(\mathrm{~m}, 3 \mathrm{H}), 7.05(\mathrm{~m}, 2 \mathrm{H}), 6.84(\mathrm{~m}, 3 \mathrm{H}), 6.05(\mathrm{~m}, 1 \mathrm{H}), 2.22(\mathrm{~s}, 3 \mathrm{H}), 2.17$ $(\mathrm{s}, 3 \mathrm{H}), 2.13(\mathrm{~m}, 4 \mathrm{H}), 1.72(\mathrm{~s}, 3 \mathrm{H}), 1.45(\mathrm{~m}, 6 \mathrm{H}), 1.22(\mathrm{~m}, 3 \mathrm{H}), 0.38(\mathrm{~s}, 27 \mathrm{H}) \mathrm{ppm} .{ }^{13} \mathrm{C} \mathrm{NMR}\left(\mathrm{CDCl}_{3}\right.$, $101 \mathrm{MHz}, 298 \mathrm{~K}): \delta 164.71,142.01,139.17,135.23,135.05,126.82,93.17,86.58,52.71,35.02,32.06$, 28.16, 23.12, 15.74, $2.96 \mathrm{ppm}$.

Table S1: List of crystallographic parameters for mono(N-(2,6-dimethylphenyl)-N-methyl-N-(1phenylethyl)carbamoylamidate)-tris(methylenetrimethylsilane)chlorotantalum

\begin{tabular}{|c|c|}
\hline Identification code & ls806 - AAU10Na \\
\hline Empirical formula & $\mathrm{C}_{30} \mathrm{H}_{54} \mathrm{ClN}_{2} \mathrm{OSi}_{3} \mathrm{Ta}$ \\
\hline Formula weight & 759.42 \\
\hline Temperature/K & 273.15 \\
\hline Crystal system & monoclinic \\
\hline Space group & $\mathrm{P} 22_{1} / \mathrm{n}$ \\
\hline $\mathrm{a} / \AA$ & $12.6561(8)$ \\
\hline $\mathrm{b} / \AA$ & $16.2013(10)$ \\
\hline $\mathrm{c} / \AA$ & $17.5797(11)$ \\
\hline$\alpha /^{\circ}$ & 90 \\
\hline$\beta /^{\circ}$ & $90.103(2)$ \\
\hline $\mathrm{Y} /{ }^{\circ}$ & 90 \\
\hline Volume $/ \AA^{3}$ & $3604.6(4)$ \\
\hline $\mathrm{Z}$ & 4 \\
\hline$\rho_{\text {calc }} g / \mathrm{cm}^{3}$ & 1.399 \\
\hline$\mu / \mathrm{mm}^{-1}$ & 3.247 \\
\hline $\mathrm{F}(000)$ & 1552.0 \\
\hline Crystal size $/ \mathrm{mm}^{3}$ & $0.15 \times 0.12 \times 0.09$ \\
\hline Radiation & $\operatorname{MoK} \alpha(\lambda=0.71073)$ \\
\hline
\end{tabular}


$2 \Theta$ range for data collection/ ${ }^{\circ}$

Index ranges

Reflections collected

Independent reflections

Data/restraints/parameters

Goodness-of-fit on $\mathrm{F}^{2}$

Final R indexes $[\mathrm{I}>=2 \sigma(\mathrm{I})]$

Final R indexes [all data]

Largest diff. peak/hole / e $\AA^{-3}$
3.418 to 59.178

$-17 \leq \mathrm{h} \leq 9,-22 \leq \mathrm{k} \leq 20,-24$

$\leq 1 \leq 24$

28395

$10122\left[R_{\text {int }}=0.0546, R_{\text {sigma }}=\right.$

0.0685]

$10122 / 0 / 361$

0.981

$\mathrm{R}_{1}=0.0345, \mathrm{wR}_{2}=0.0612$

$\mathrm{R}_{1}=0.0556, \mathrm{wR}_{2}=0.0673$

$0.89 /-0.78$

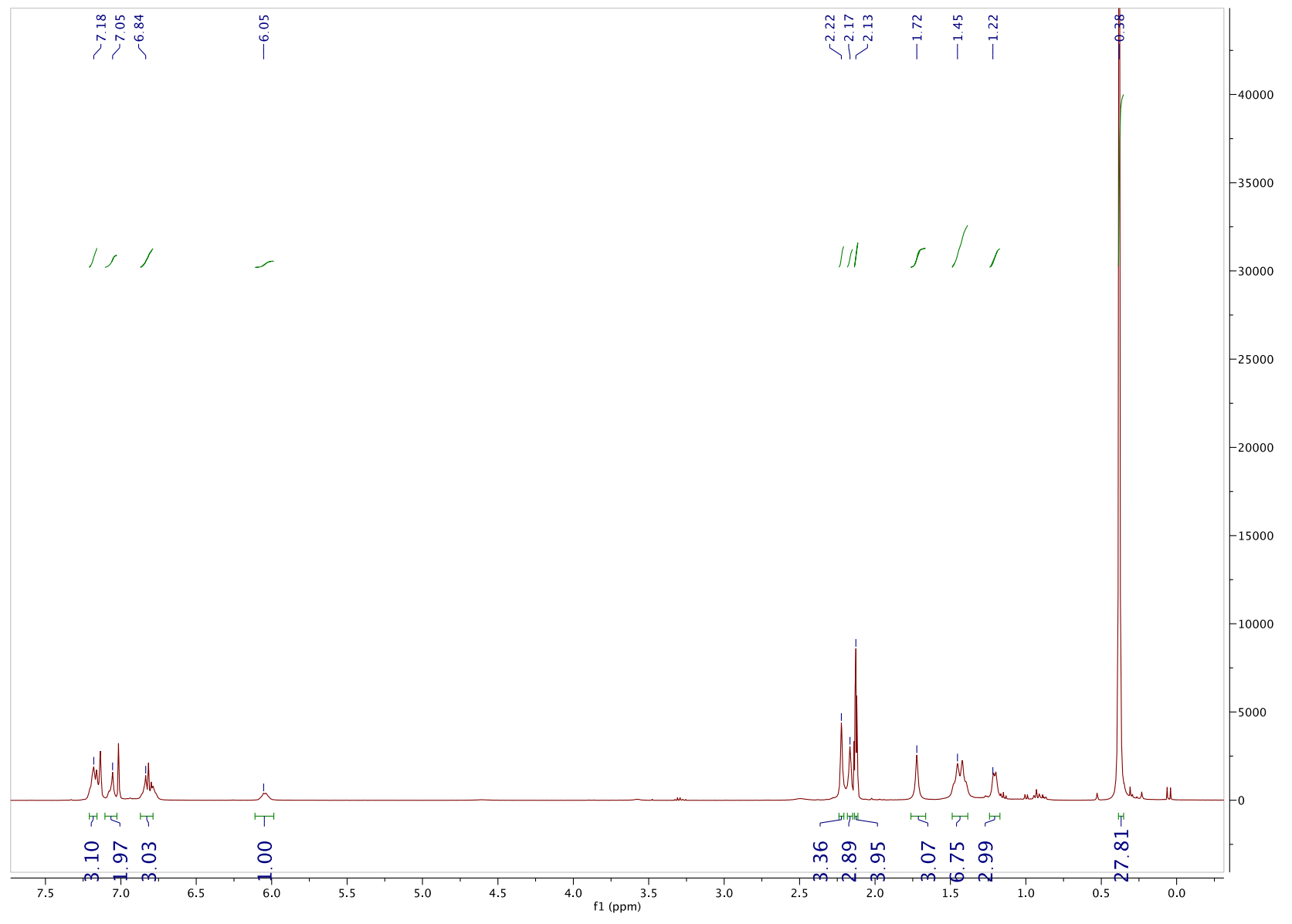

Figure S13: ${ }^{1} \mathrm{H}$ NMR spectrum $(400 \mathrm{MHz}$, Tol-d 8 , $298 \mathrm{~K})$ for mono( $N$-(2,6-dimethylphenyl)- $N$-methyl- $N-(1-$ phenylethyl)carbamoylamidate)-tris(methylenetrimethylsilane)chlorotantalum 


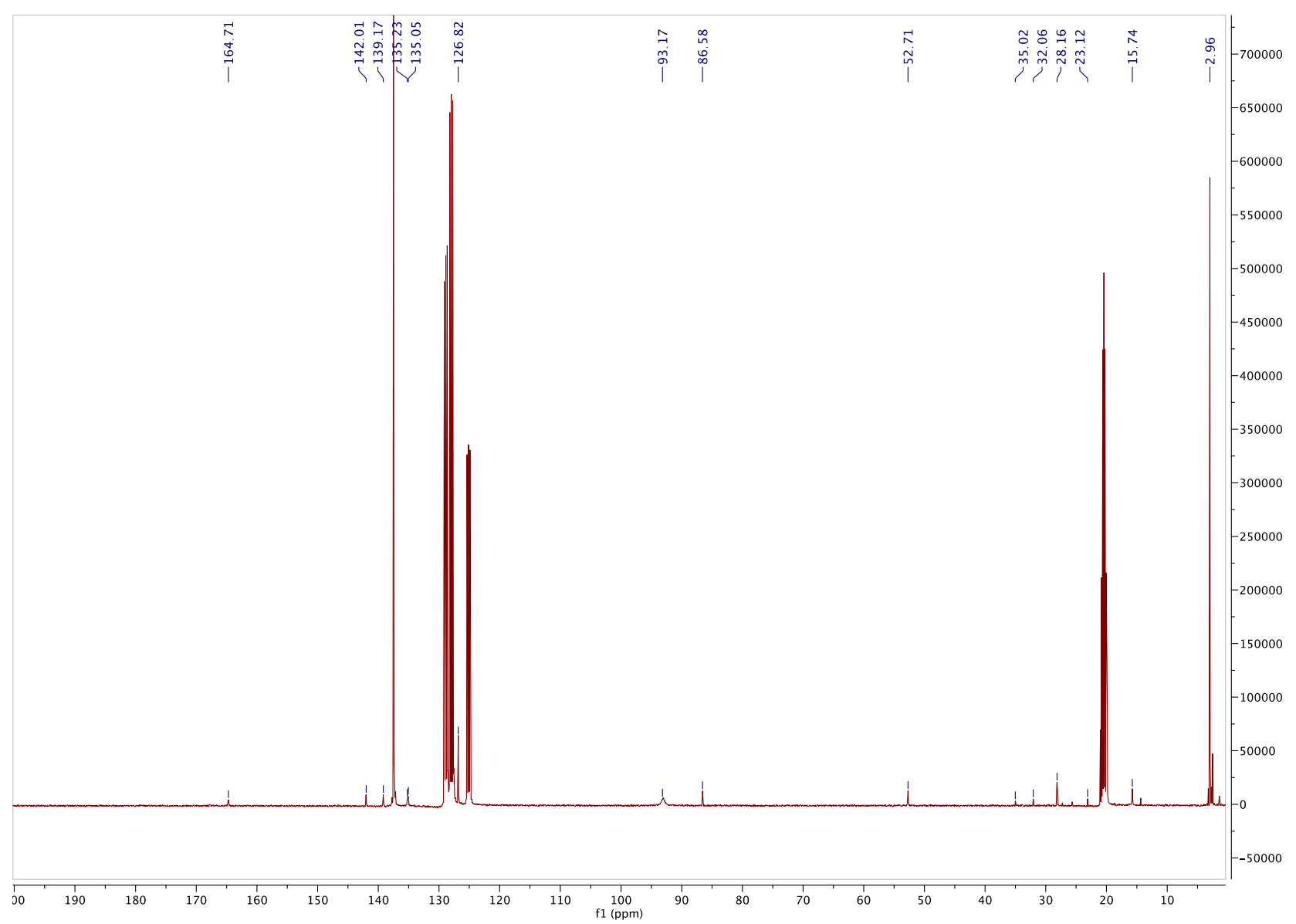

Figure S14: ${ }^{13} \mathrm{C}$ NMR spectrum $(101 \mathrm{MHz}$, Tol-d $8,298 \mathrm{~K})$ for mono( $N$-(2,6-dimethylphenyl)- $N$-methyl- $N-(1-$ phenylethyl)carbamoylamidate)-tris(methylenetrimethylsilane)chlorotantalum 


\section{S4. General Procedures for Ligand Screening Reactions}

\section{General procedure for ligand screening reactions:}

Unless otherwise stated, $\mathrm{Ta}\left(\mathrm{CH}_{2} \mathrm{SiMe}_{3}\right)_{3} \mathrm{Cl}_{2}(0.005 \mathrm{mmol}, 26.0 \mathrm{mg})$ was weighed into a vial, followed by addition of the ligand salt $(0.005 \mathrm{mmol})$. Toluene- $\mathrm{d}_{8}(300 \mathrm{mg})$ was added and the resultant mixture was left for 15 minutes. Piperidine ( $85 \mathrm{mg}, 1 \mathrm{mmol}$ ), followed by 1 -octene (112 mg, $1 \mathrm{mmol}$ ) were then added by mass with a micropipette. The reaction vial was rinsed with $300 \mathrm{mg}$ of toluene-d $\mathrm{d}_{8}$ and transferred into a J. Young NMR tube. An initial ${ }^{1} \mathrm{H}$ NMR spectrum was recorded and the sample was added to a pre-heated oil bath at $150{ }^{\circ} \mathrm{C}$ for 20 hours. All conversion values were determined by ${ }^{1} \mathrm{H}$ NMR spectroscopy by integrating the product peak at $2.96 \mathrm{ppm}(1 \mathrm{H})$ relative to one of the alkene starting material peaks. After quenching, product ratios were assessed by GC-MS

\section{S5. General Procedures for Qualitative and Quantitative Catalysis using L4}

\section{General procedure for qualitative catalytic experiments:}

Unless otherwise stated, $\mathrm{Ta}\left(\mathrm{CH}_{2} \mathrm{SiMe}_{3}\right)_{3} \mathrm{Cl}_{2}(0.005 \mathrm{mmol}, 26.0 \mathrm{mg})$ was weighed into a vial, followed by addition of $\mathbf{L} 4(0.005 \mathrm{mmol}, 15.2 \mathrm{mg})$. Toluene- $d_{8}(300 \mathrm{mg})$ was added and the resultant mixture was left for 15 minutes. Amine $(1 \mathrm{mmol})$, followed by alkene $(1 \mathrm{mmol})$ were then added by mass with a micropipette. The reaction vial was rinsed with $300 \mathrm{mg}$ of toluene- $d_{8}$ and transferred into a J. Young NMR tube. An initial ${ }^{1} \mathrm{H}$ NMR spectrum was recorded and the sample was added to a pre-heated oil bath at $150{ }^{\circ} \mathrm{C}$ for 20 hours. All conversion values were determined by ${ }^{1} \mathrm{H}$ NMR spectroscopy by integrating the product peak at $2.96 \mathrm{ppm}\left({ }^{1} \mathrm{H}\right)$ relative to one of the alkene peaks. After quenching the reaction, rinsing the NMR tube with dichloromethane, and removal of all reaction solvent, the resulting amine was purified via a silica-filtration and fractions were dried in vacuo overnight to afford the desired product. These qualitative experiments served to identify reactions that afford both branched and linear products, as was evident from both the GC-MS analysis and the corresponding complex alkyl region in crude ${ }^{1} \mathrm{H}$ NMR spectra after reaction. GC-MS would clearly show two different reaction products, and the presence of two notably different spin systems by 2D NMR would indicate regioisomers from diastereomers. In cases that generate branched product only, there would be a clear methyl product doublet in the ${ }^{1} \mathrm{H}$ NMR spectrum, as highlighted in Figure S16. If you are observing a branched reaction product and a small amount of its corresponding diastereomer, there is often a smaller, but observable second methyl group doublet from the minor diastereomer. An assumption used 
in this step is that the GS-MS response factors with a CI ionization source are similar for all isomers.

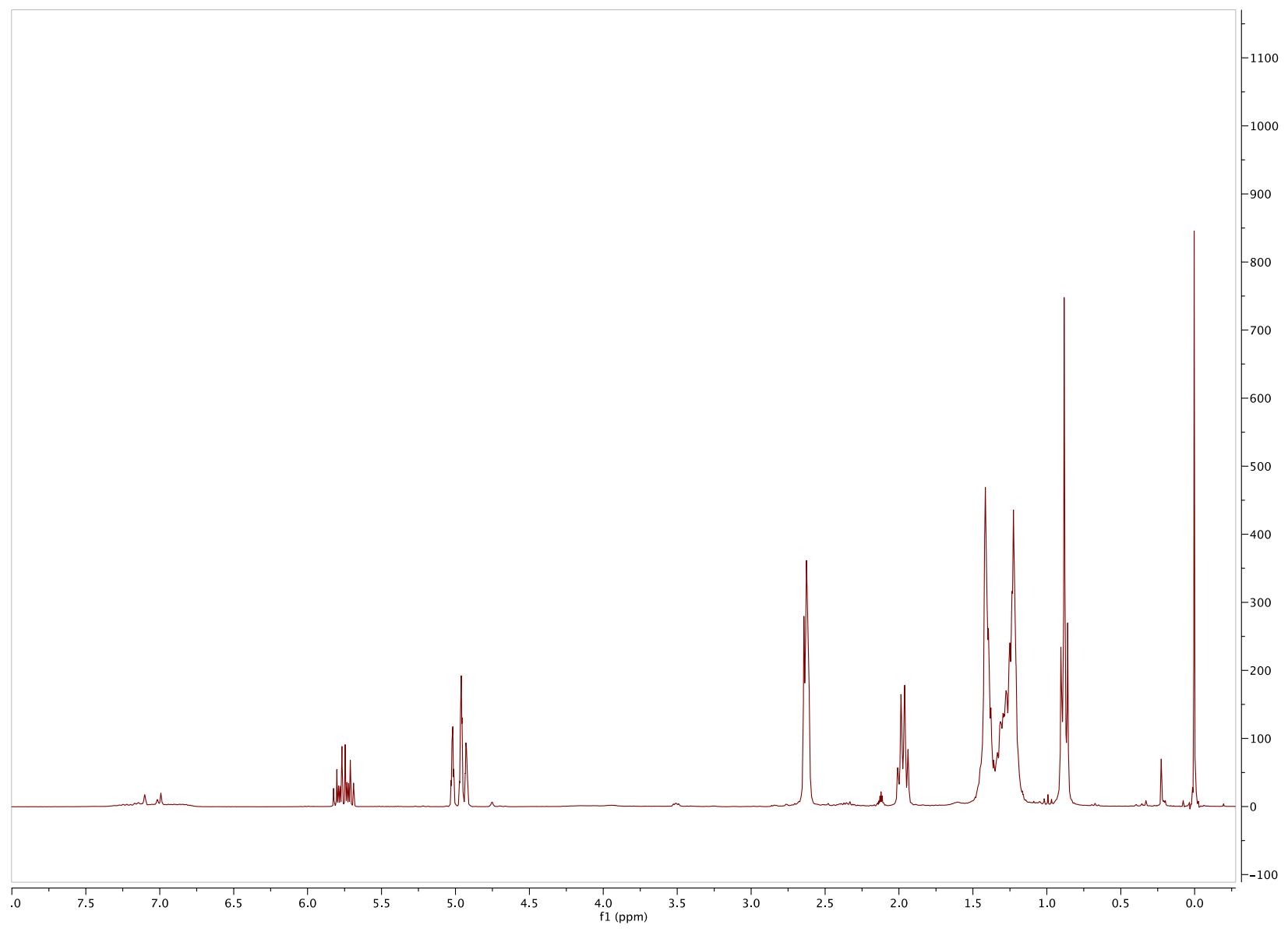

Figure S15: ${ }^{1} \mathrm{H}$ NMR spectrum $\left(400 \mathrm{MHz}\right.$, Tol- $\left.\mathrm{d}_{8}, 298 \mathrm{~K}\right)$ for the crude reaction mixture between piperidine and 1 -octene before heating. 


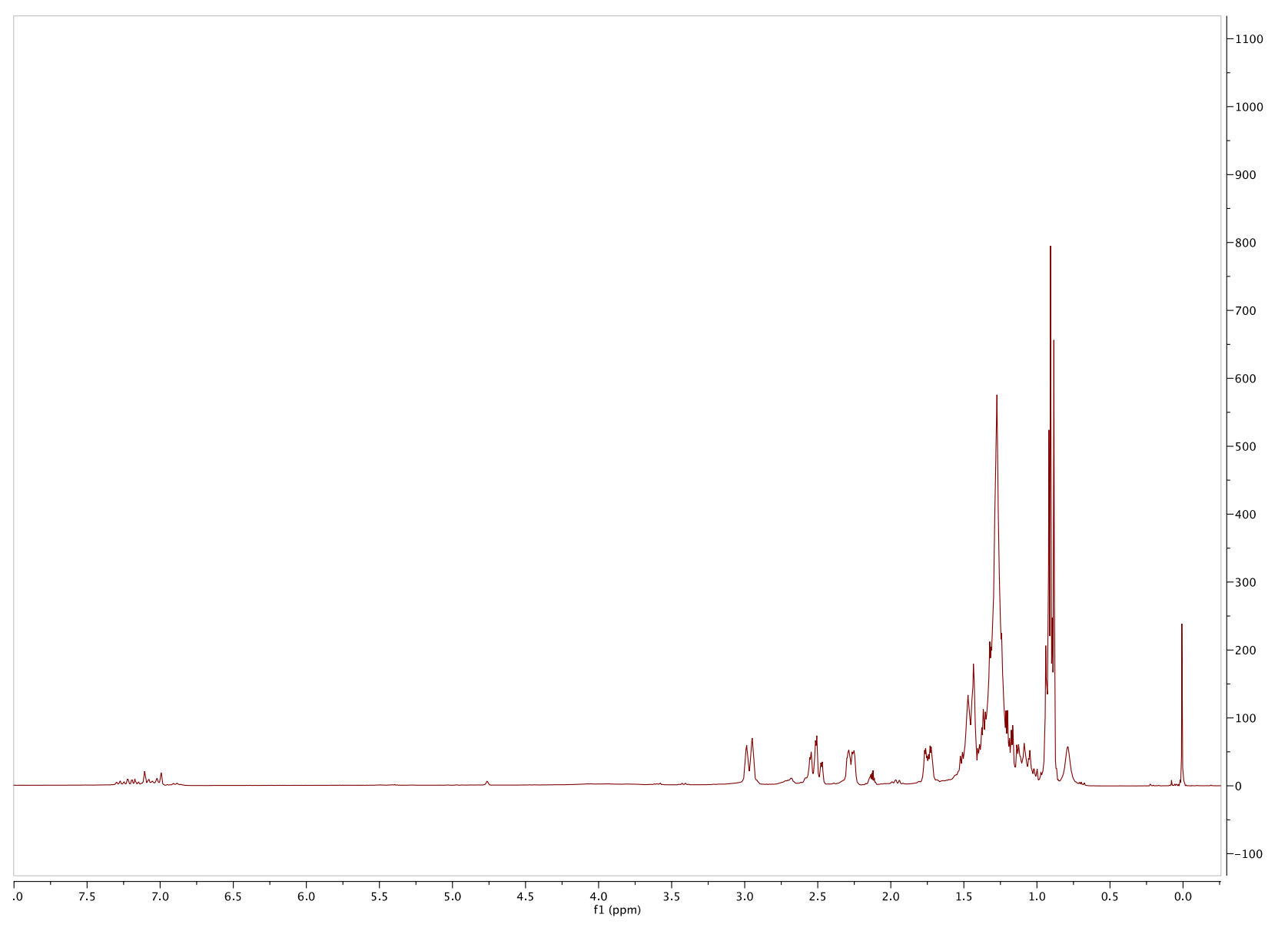

Figure S16: ${ }^{1} \mathrm{H}$ NMR spectrum $\left(400 \mathrm{MHz}\right.$, Tol- $\left.\mathrm{d}_{8}, 298 \mathrm{~K}\right)$ for the crude reaction mixture between piperidine and 1-octene after heating.

\section{General Procedures for Quantitative Catalytic Experiments:}

Quantitative Catalytic Experimental Procedure for Predominantly Branched Products (2-10)

Unless otherwise stated, $\mathrm{Ta}\left(\mathrm{CH}_{2} \mathrm{SiMe}_{3}\right)_{3} \mathrm{Cl}_{2}(0.005 \mathrm{mmol}, 26.0 \mathrm{mg})$ was weighed into a vial, followed by addition of $\mathbf{L} 4(0.005 \mathrm{mmol}, 15.2 \mathrm{mg})$. A $0.0011 \mathrm{mmol} / \mathrm{g}$ stock solution of 1,3,5-trimethoxybenzene in $\mathrm{d} 8$-toluene was prepared by weighing out $1.85 \mathrm{~g}$ solid internal standard and dissolving it in $10 \mathrm{~g} \mathrm{~d} 8$ toluene. To each reaction $300 \mathrm{mg}$ of that solution was added as an internal standard $(0.33 \mathrm{eq})$. The resultant mixture was left for 15 minutes. Piperidine $(1 \mathrm{mmol})$, followed by alkene $(1 \mathrm{mmol})$ were then added by mass with a micropipette via small drops over an analytical balance. This mixture was then transferred into a J. Young NMR tube. The reaction vial was rinsed with and additional $300 \mathrm{mg}$ of toluene- $d_{8}$ via micropipette over an analytical balance and transferred into the J. Young NMR tube. An initial ${ }^{1} \mathrm{H}$ NMR spectrum was recorded and the sample was added to a pre-heated oil bath at $150{ }^{\circ} \mathrm{C}$ for 20 hours. All NMR yield values for reactions that generate predominantly BRANCHED product were determined by ${ }^{1} \mathrm{H}$ NMR spectroscopy by integrating the product peak at $2.96 \mathrm{ppm}(1 \mathrm{H})$ relative to the internal standard peak for the three methyl groups at $3.40 \mathrm{ppm}$ (integrated to $3 \mathrm{H}$ instead of $9 \mathrm{H}$ due to 0.33 equivalents relative to amine being used). Note that for all quantitative NMR reactions, D1 values were determined to be and set as $200 \mathrm{~s}$. After quenching the reaction, the NMR tube was rinsed with dichloromethane into a $20 \mathrm{~mL}$ scintillation vial. All reaction solvent was removed, the resulting amine was purified by silica gel chromatography using 5: 4.5: 0.5 hexanes: ethylacetate: triethylamine as eluant. The resulting fractions were dried in vacuo overnight to afford the desired 
product. Regioisomer and diastereomer product ratios were determined by GC-MS of the crude reaction mixture prior to chromatographic separation.

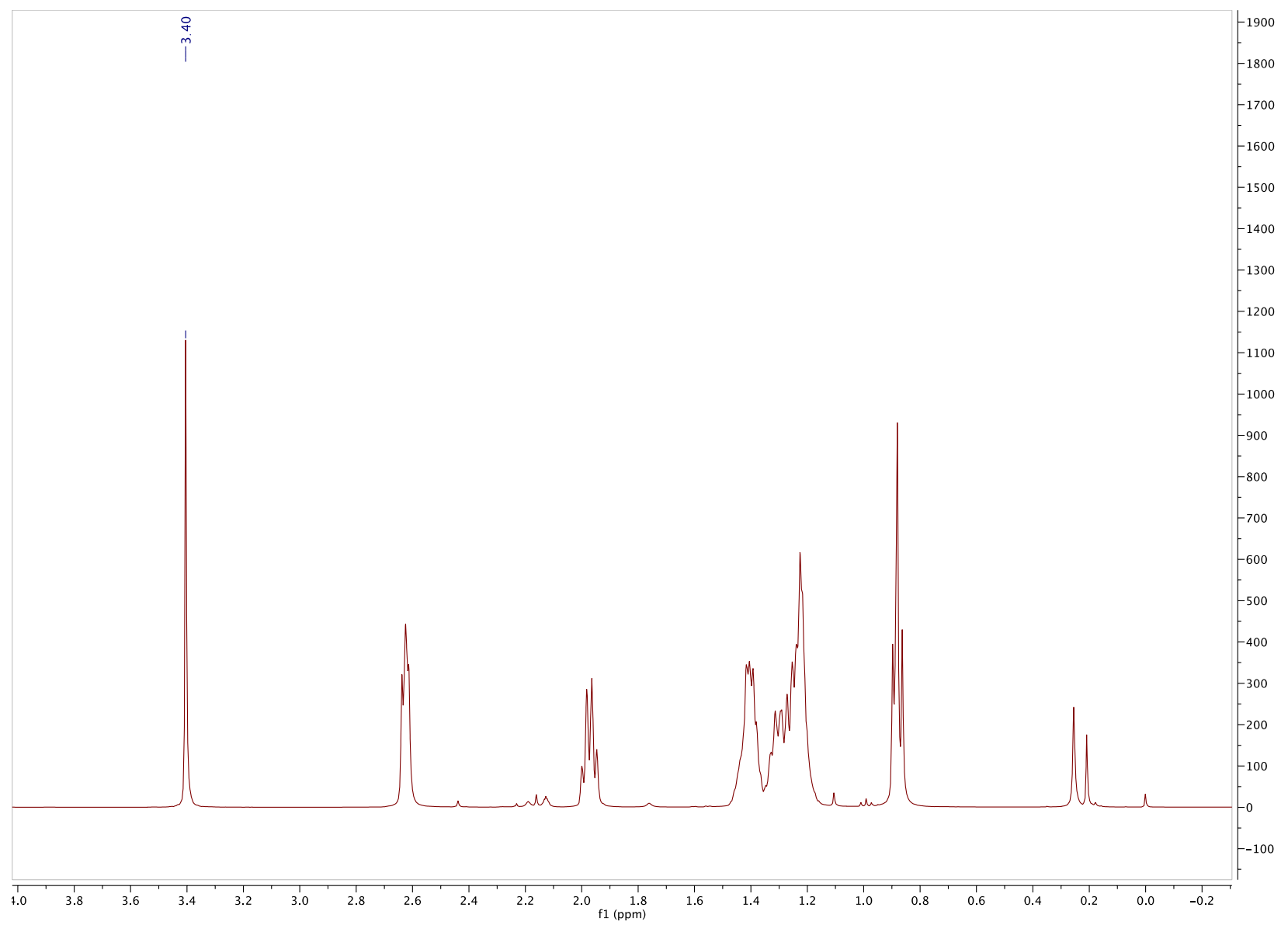

Figure S17: ${ }^{1} \mathrm{H}$ NMR spectrum $\left(400 \mathrm{MHz}\right.$, Tol- $\left.\mathrm{d}_{8}, 298 \mathrm{~K}\right)$ for the crude reaction mixture between piperidine and 1 -octene with 1,3,5-trimethoxybenzene as an internal standard ( $0.33 \mathrm{eq}$.) before heating. This image is specifically zoomed in on the product region of the NMR spectrum. 


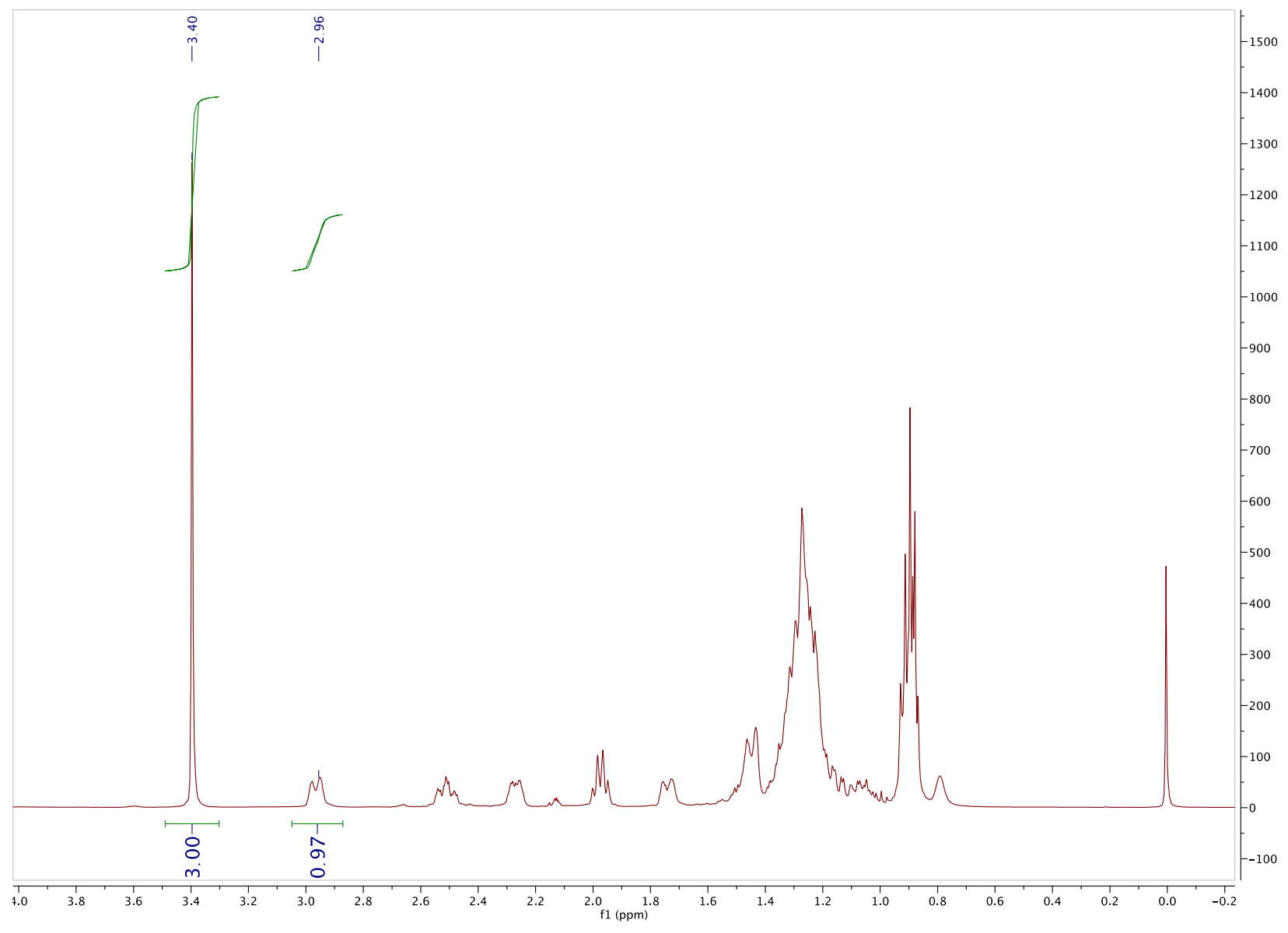

Figure S18: ${ }^{1} \mathrm{H}$ NMR spectrum $\left(400 \mathrm{MHz}\right.$, Tol- $\left.\mathrm{d}_{8}, 298 \mathrm{~K}\right)$ for the crude reaction mixture between piperidine and 1-octene with 1,3,5-trimethoxybenzene as an internal standard (0.33 eq.) after heating. This image is specifically zoomed in on the product region of the NMR spectrum. 


\section{Note: This crude reaction GC-MS spectrum is a representative example of how we determined d.r ratios for all amine products presented.}

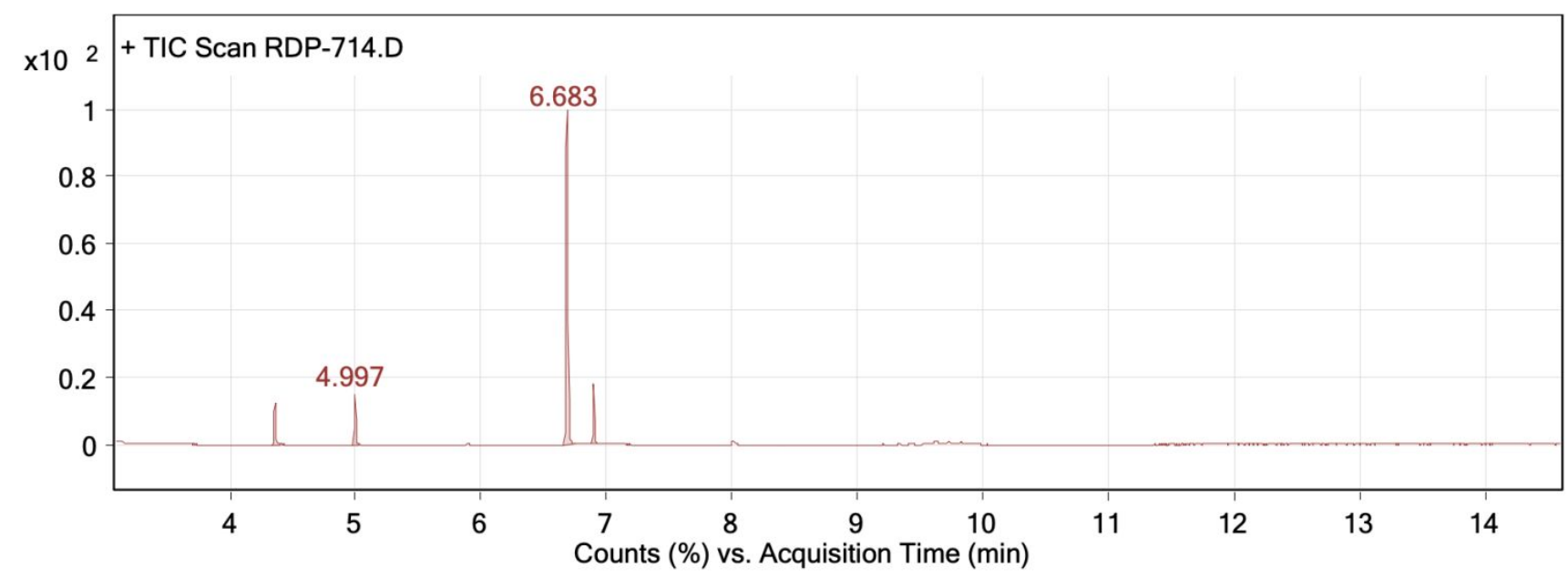

Figure S19: GC-MS for crude reaction mixture between piperidine and 1-octene.

Quantitative Catalytic Experimental Procedure for Branched and Linear Regioisomer Products (14-33)

Unless otherwise stated, $\mathrm{Ta}\left(\mathrm{CH}_{2} \mathrm{SiMe}_{3}\right)_{3} \mathrm{Cl}_{2}(0.005 \mathrm{mmol}, 26.0 \mathrm{mg})$ was weighed into a vial, followed by addition of the ligand salt $\mathbf{L} \mathbf{4}(0.005 \mathrm{mmol}, 15.2 \mathrm{mg})$. A $0.0011 \mathrm{mmol} / \mathrm{g}$ stock solution of $1,3,5-$ trimethoxybenzene in $\mathrm{d} 8$-toluene was prepared by weighing out $1.85 \mathrm{~g}$ solid internal standard and dissolving it in $10 \mathrm{~g}$ d8-toluene. To each reaction $300 \mathrm{mg}$ of that solution was added as an internal standard $(0.33 \mathrm{eq})$. The resultant mixture was left for 15 minutes. Piperidine $(1 \mathrm{mmol})$, followed by alkene $(1 \mathrm{mmol})$ were then added by mass with a micropipette via small drops over an analytical balance. This mixture was then transferred into a J. Young NMR tube. The reaction vial was rinsed with and additional $300 \mathrm{mg}$ of toluene- $d_{8}$ via micropipette over an analytical balance and transferred into the J. Young NMR tube. An initial ${ }^{1} \mathrm{H}$ NMR spectrum was recorded and the sample was added to a preheated oil bath at $150{ }^{\circ} \mathrm{C}$ for 20 hours. In determining the NMR yield values for reactions that generate mixtures of branched and linearly products the peak at $2.87 \mathrm{ppm}$ could be used to assess the combined yield of both regioisomers. Due to numerous overlapping peaks in a crude ${ }^{1} \mathrm{H}$ NMR spectrum, new $2 \mathrm{D}$ NMR data was required for crude reaction mixtures in toluene. This data was used to assess where $\mathrm{CH}$ proton peaks for each isomer were so that they could be accurately integrated. COSY, and HMBC NMR spectra were required of the NMR tube reaction to assess these complicated NMR yields in samples that contained significant mixtures of two products. The sample T20 ${ }^{1} \mathrm{H}, \mathrm{COSY}$ and HMBC NMR spectra below represent an example of how we solved this problem in the selected illustrative example below:<smiles>C=Cc1ccc(Cl)cc1</smiles>

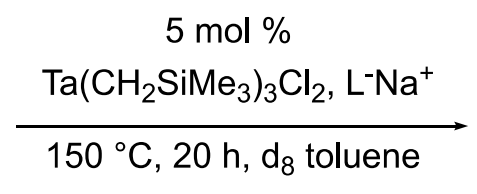<smiles>C[C@H](c1ccc(Cl)cc1)[C@H]1CCCCN1</smiles><smiles>Clc1ccc(CCC2CCCCN2)cc1</smiles>

23 


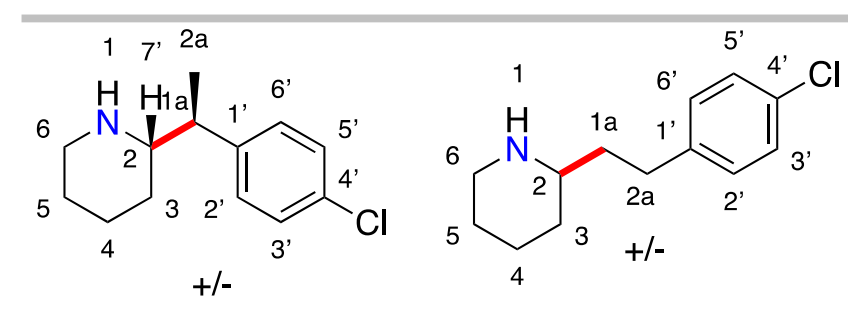

Synthesis of 2-(1-(4-chlorophenyl)ethyl)piperidine and 2-(4-chlorophenethyl)piperidine (22 and 23): Prepared following the general procedure outlined above: $26.0 \mathrm{mg}$ Ta, $15.2 \mathrm{mg}$ ligand $\mathbf{L 4}$, piperidine (85.15 mg, $1.0 \mathrm{mmol})$, 4-chlorostyrene (138.59 mg, $1.0 \mathrm{mmol})$. The reaction was subsequently concentrated and the yield was determined to be $54 \%$ for 2-(1-(4-chlorophenyl)ethyl)piperidine and $46 \%$ for 2-(4-chlorophenethyl)piperidine by NMR (1,3,5-trimethoxybenzene as a standard). The regioisomers could be separated by column chromatography (7:2.5:0.5 hexanes : ethyl acetate : triethyl amine). This reaction was scaleable up to $25 \mathrm{mmol}$. Yields from chromatography were $35 \%$ for branched (22) and 22 $\%$ for linear (23).

Branched Regioisomer: ${ }^{1} \mathrm{H} \mathrm{NMR}\left(\mathrm{CDCl}_{3}, 400 \mathrm{MHz}, 298 \mathrm{~K}\right): \delta 7.25$ (m, 2H, 3' and 5'), 7.11 (m, 2H, 2' and 6'), $3.11(\mathrm{~m}, 1 \mathrm{H}, 1 / 2$ of 6$), 2.65(\mathrm{~m}, 1 \mathrm{H}, 1 \mathrm{a}), 2.59(\mathrm{~m}, 1 \mathrm{H}, 1 / 2 \mathrm{of} 6), 2.52(\mathrm{~m}, 1 \mathrm{H}, 2), 1.85$ (broad s, $1 \mathrm{H}$, $\mathrm{NH}), 1.71(\mathrm{~m}, 1 \mathrm{H}, 1 / 2$ of 4$), 1.57(\mathrm{~m}, 1 \mathrm{H}, 1 / 2$ of 5$), 1.41(\mathrm{~m}, 1 \mathrm{H}, 1 / 2$ of 3$), 1.33(\mathrm{~m}, 1 \mathrm{H}, 1 / 2$ of 5$), 1.26(\mathrm{~d}, \mathrm{~J}=$ $1.31,3 \mathrm{H}, 2 \mathrm{a}), 1.22(\mathrm{~m}, 1 \mathrm{H}, 1 / 2$ of 4$), 1.03(\mathrm{~m}, 1 \mathrm{H}, 1 / 2$ of 3$) \mathrm{ppm} .{ }^{13} \mathrm{C} \mathrm{NMR}\left(\mathrm{CDCl}_{3}, 101 \mathrm{MHz}, 298 \mathrm{~K}\right): \delta$ $143.42,131.88,129.17,128.43,62.38,47.38,45.06,30.63,26.25,24.81,17.35 \mathrm{ppm}$. HRMS (ESI): $\mathrm{m} / z$ calcd for $\mathrm{C}_{13} \mathrm{H}_{19} \mathrm{NCl}\left[\mathrm{M}+\mathrm{H}^{+}\right]$: 224.1206 Found: 224.1201.

Linear Regioisomer: ${ }^{1} \mathrm{H}$ NMR $\left(\mathrm{CDCl}_{3}, 400 \mathrm{MHz}, 298 \mathrm{~K}\right): \delta 7.22(\mathrm{~m}, 2 \mathrm{H}, 3$ ' and 5'), $7.10(\mathrm{~m}, 2 \mathrm{H}, 2$ ' and 6'), $3.14(\mathrm{~m}, 1 \mathrm{H}, 1 / 2$ of 6$), 2.66(\mathrm{~m}, 2 \mathrm{H}, 2 \mathrm{a}), 2.64(\mathrm{~m}, 1 \mathrm{H}, 1 / 2$ of 6$), 2.53(\mathrm{~m}, 1 \mathrm{H}, 2), 2.45$, (broad s, $1 \mathrm{H}$, $\mathrm{NH}), 1.82(\mathrm{~m}, 1 \mathrm{H}, 1 / 2$ of 4$), 1.74(\mathrm{~m}, 2 \mathrm{H}, 1 \mathrm{a}), 1.69(\mathrm{~m}, 1 \mathrm{H}, 1 / 2$ of 3$), 1.61(\mathrm{~m}, 1 \mathrm{H}, 1 / 2$ of 5$), 1.48(\mathrm{~m}, 1 \mathrm{H}, 1 / 2$ of 5), $1.34\left(\mathrm{~m}, 1 \mathrm{H}, 1 / 2\right.$ of 4), 1,22 (m, 1H, 1/2 of 3) ppm. ${ }^{13} \mathrm{C} \mathrm{NMR}\left(\mathrm{CDCl}_{3}, 101 \mathrm{MHz}, 298 \mathrm{~K}\right): \delta 140.87$, $131.55,129.77,128.55,56.42,47.22,39.11,32.95,31.71,26.66,24.86 \mathrm{ppm}$. HRMS (ESI): $\mathrm{m} / z$ calcd for $\mathrm{C}_{13} \mathrm{H}_{19} \mathrm{NCl}\left[\mathrm{M}+\mathrm{H}^{+}\right]: 224.1206$ Found: 224.1207. 


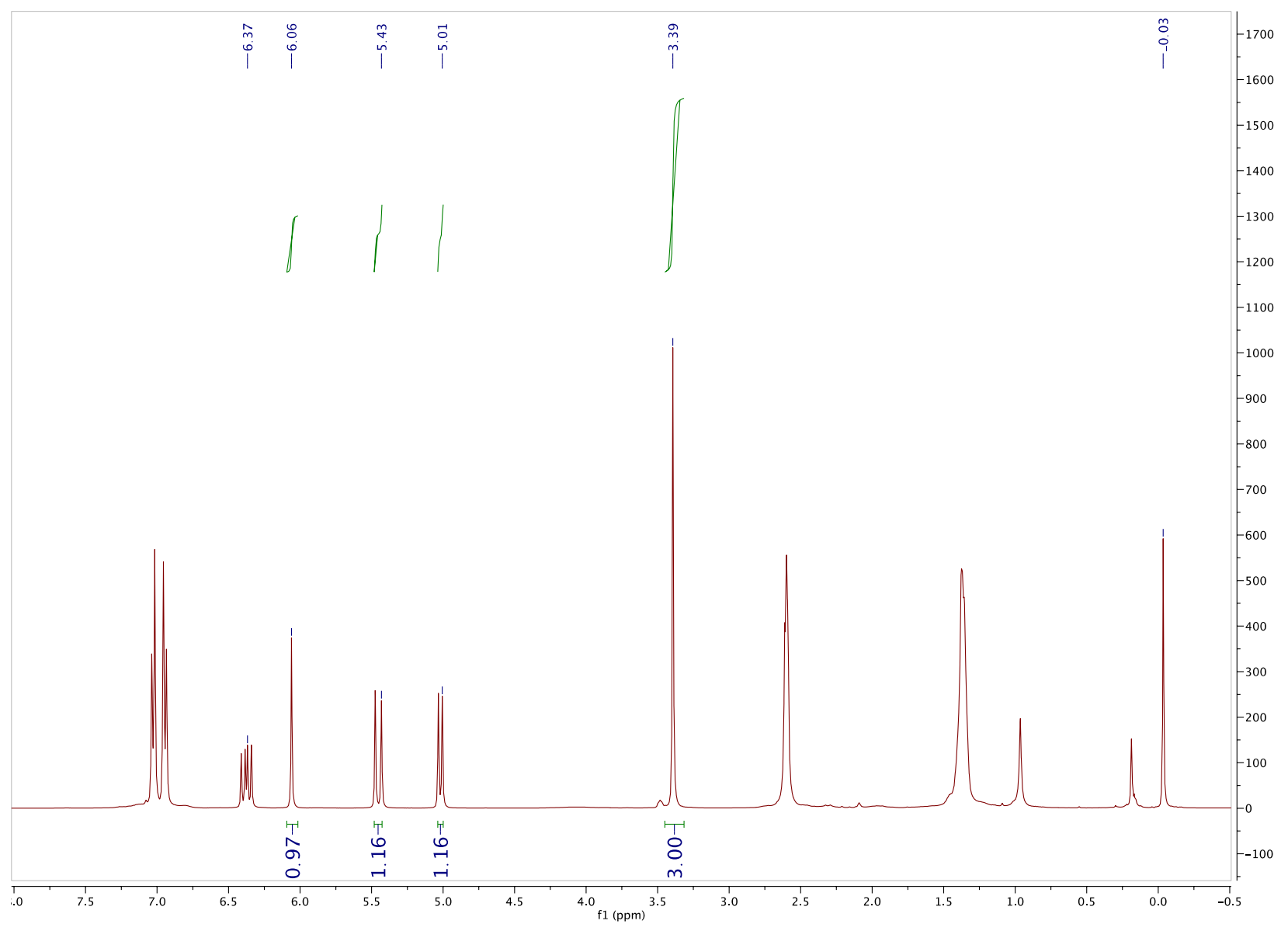

Figure S20: ${ }^{1} \mathrm{H}$ NMR spectrum $\left(400 \mathrm{MHz}, \mathrm{CDCl}_{3}, 298 \mathrm{~K}\right)$ before the reaction mixture was heated. Peaks at 6.06 and $3.39 \mathrm{ppm}$ represent the 1,3,5-trimethoxybenzene as an internal standard. The peak at $0.03 \mathrm{ppm}$ represents $\mathrm{SiMe}_{4}$ that is released upon catalyst activation. Peaks at 5.43 and 5.01 represent alkene protons. 


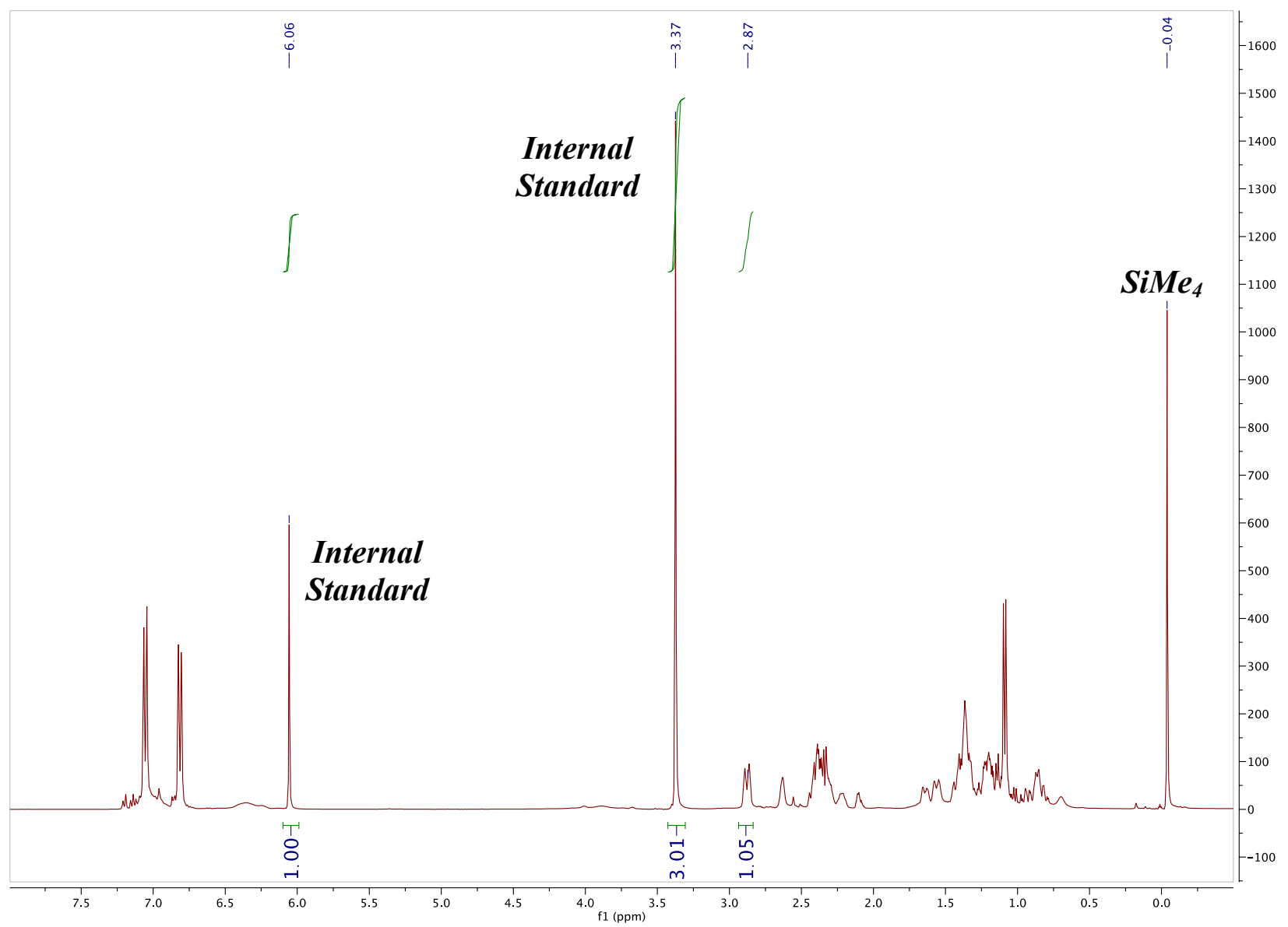

Figure S21: ${ }^{1} \mathrm{H}$ NMR spectrum $\left(400 \mathrm{MHz}, \mathrm{CDCl}_{3}, 298 \mathrm{~K}\right)$ upon completion of the reaction of piperidine with 4-chlorostyrene. Peaks at 6.06 and $3.37 \mathrm{ppm}$ represent the 1,3,5-trimethoxybenzene as an internal standard. Integration of the peak at $2.87 \mathrm{ppm}$ represents the combined yield of products. The peak at 0.04 ppm is tetramethylsilane from alkyl ligands being protonated off the Ta precatalyst during reaction.

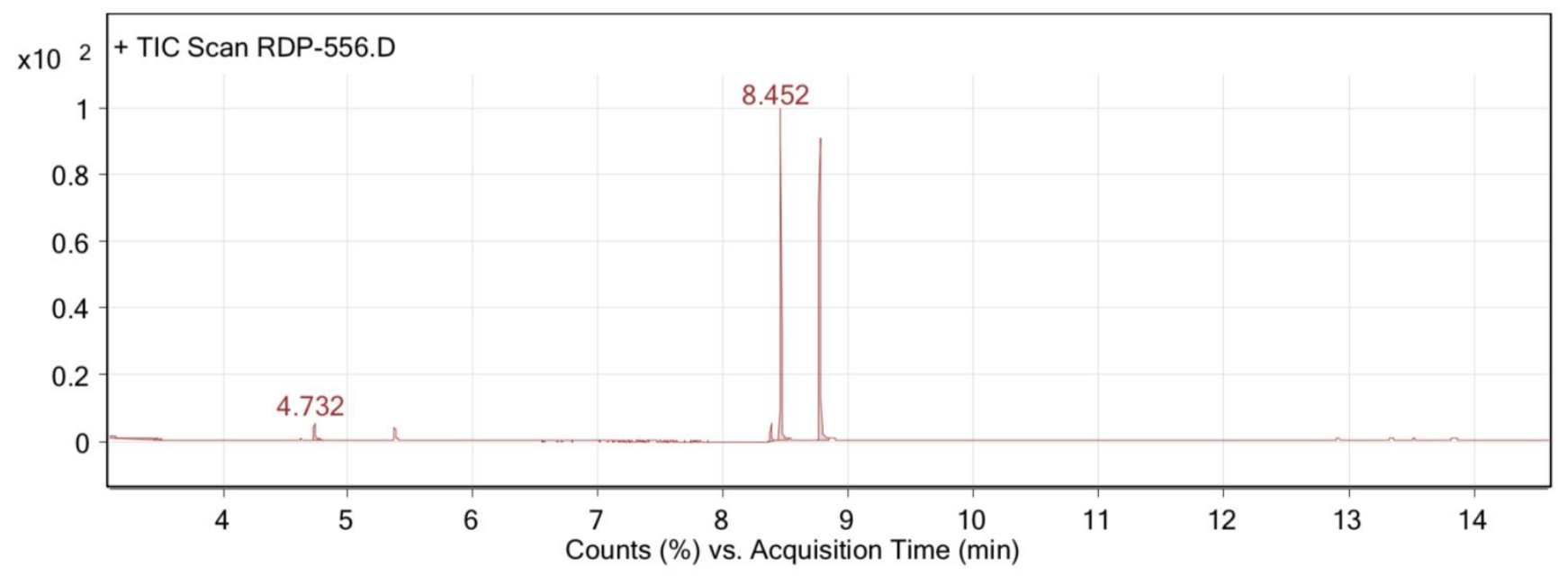

Figure S22: GC-MS for the crude reaction mixture between piperidine and 4-chlorostyrene. 


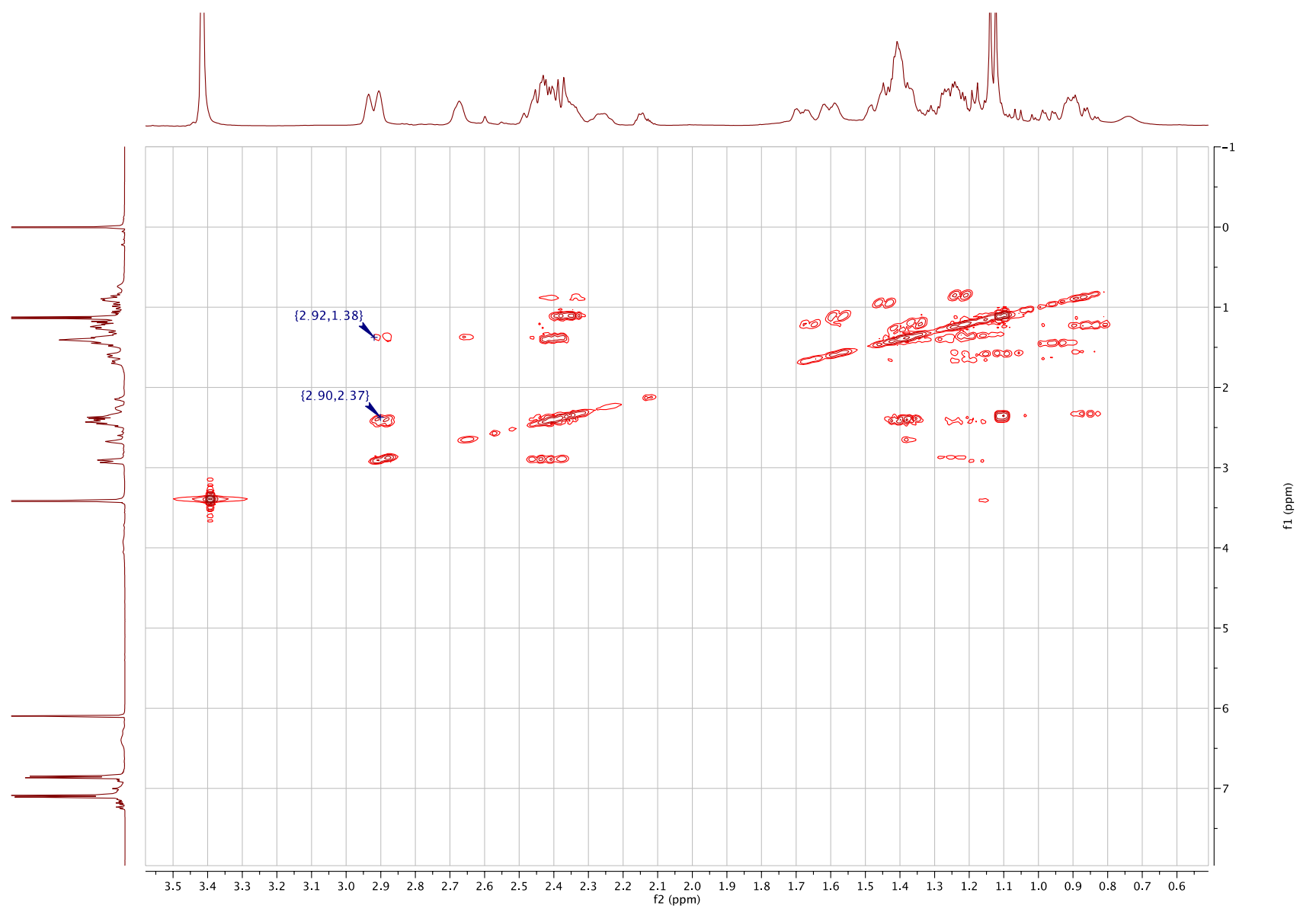

Figure S23: COSY NMR spectrum $\left(400 \mathrm{MHz}, \mathrm{CDCl}_{3}, 298 \mathrm{~K}\right)$ of the completed reaction of piperidine with 4-chlorostyrene. The linear and branched products are overlapping in the 2.87-2.90 ppm peak. 


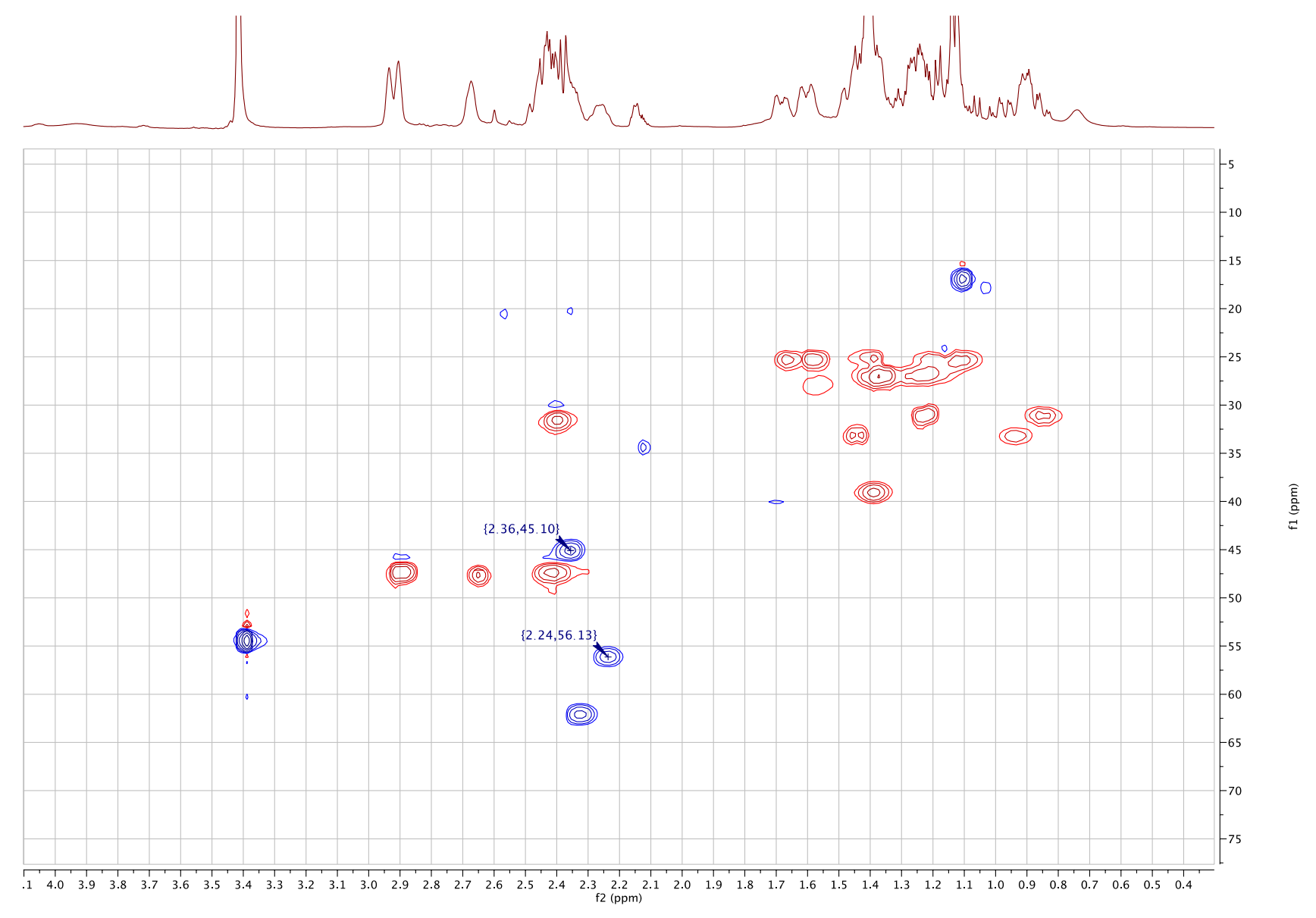

Figure S24: T20 HSQC NMR spectrum (400 MHz/ $100 \mathrm{MHz}, \mathrm{CDCl}_{3}, 298 \mathrm{~K}$ ) of the reaction of piperidine with 4-chlorostyrene that has been zoomed in on the aliphatic region of the reaction.

We were able to analyze these spectra to assess that the peak at $2.36 \mathrm{ppm}$ is the $\mathrm{CH}$ proton from the branched product and the peak at $2.24 \mathrm{ppm}$ is the $\mathrm{CH}$ peak from the linear product. These peaks could then be integrated in the original proton spectrum to give NMR yields for each of these products, respectively. These NMR yields were then verified by using relative GC-MS areas for these peaks and integrations were consistent, within error, across all styrene products. See below for an integrated proton NMR spectrum of the crude reaction mixture. 


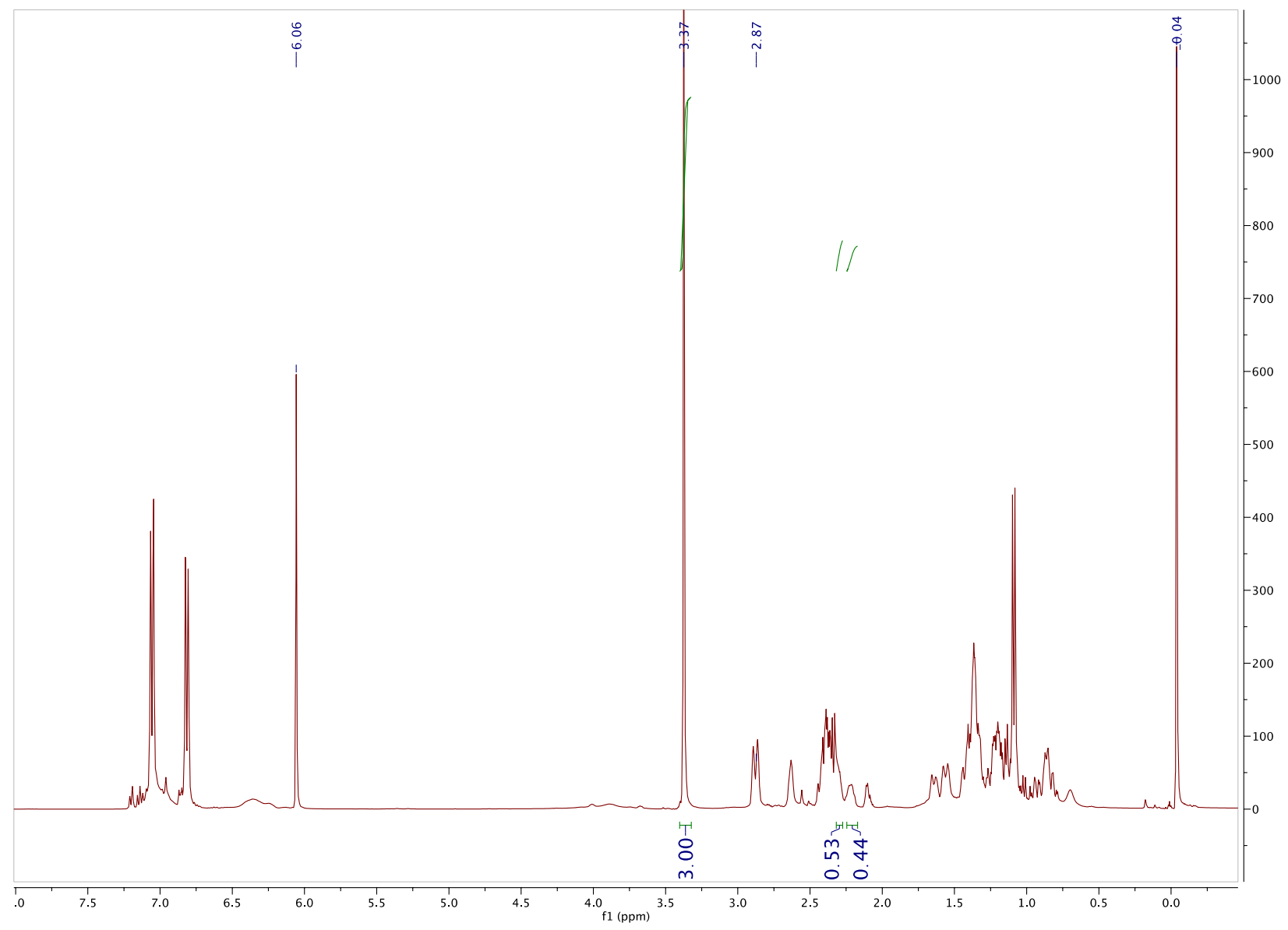

Figure S25: T20 ${ }^{1} \mathrm{H}$ NMR spectrum $\left(400 \mathrm{MHz} / 100 \mathrm{MHz}, \mathrm{CDCl}_{3}, 298 \mathrm{~K}\right)$ of the reaction of piperidine with 4-chlorostyrene. In this spectrum, diagnostic $\mathrm{CH}$ protons from branched and linear regioisomers have been integrated. 


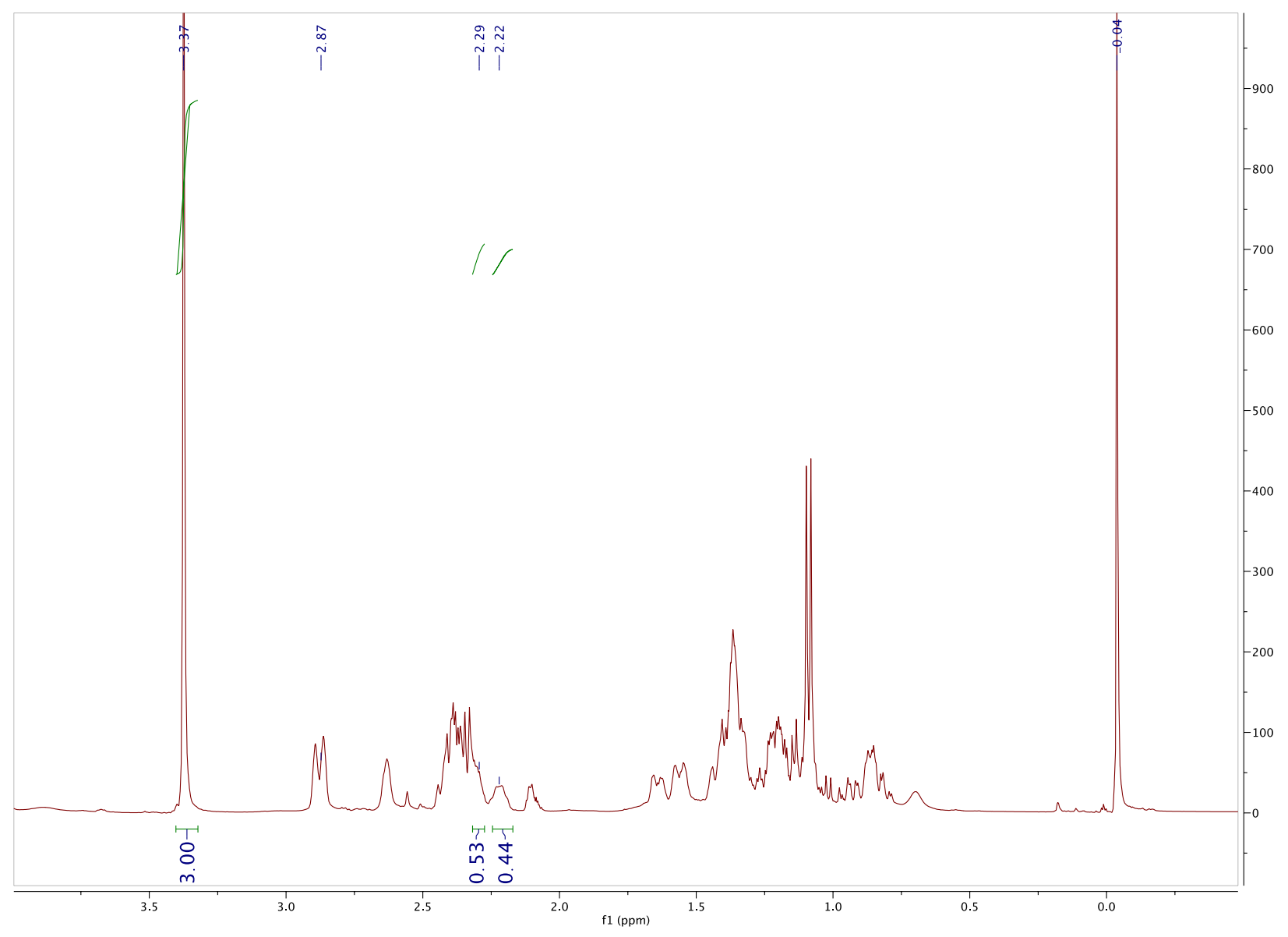

Figure S26: T20 ${ }^{1} \mathrm{H}$ NMR spectrum $\left(400 \mathrm{MHz} / 100 \mathrm{MHz}, \mathrm{CDCl}_{3}, 298 \mathrm{~K}\right)$ of the reaction of piperidine with 4-chlorostyrene. In this spectrum, data has been zoomed to the alkyl region.

The peak at $3.37 \mathrm{ppm}$ represents the methyl groups of the 1,3,5-trimethoxybenzene internal standard. This has been integrated to 3 protons instead of 9 because 0.33 equivalents of this internal standard relative to either substrate were consistently used in all reactions. The integrations of 0.53 and 0.44 protons reflect branched and linear NMR yields, respectively. 


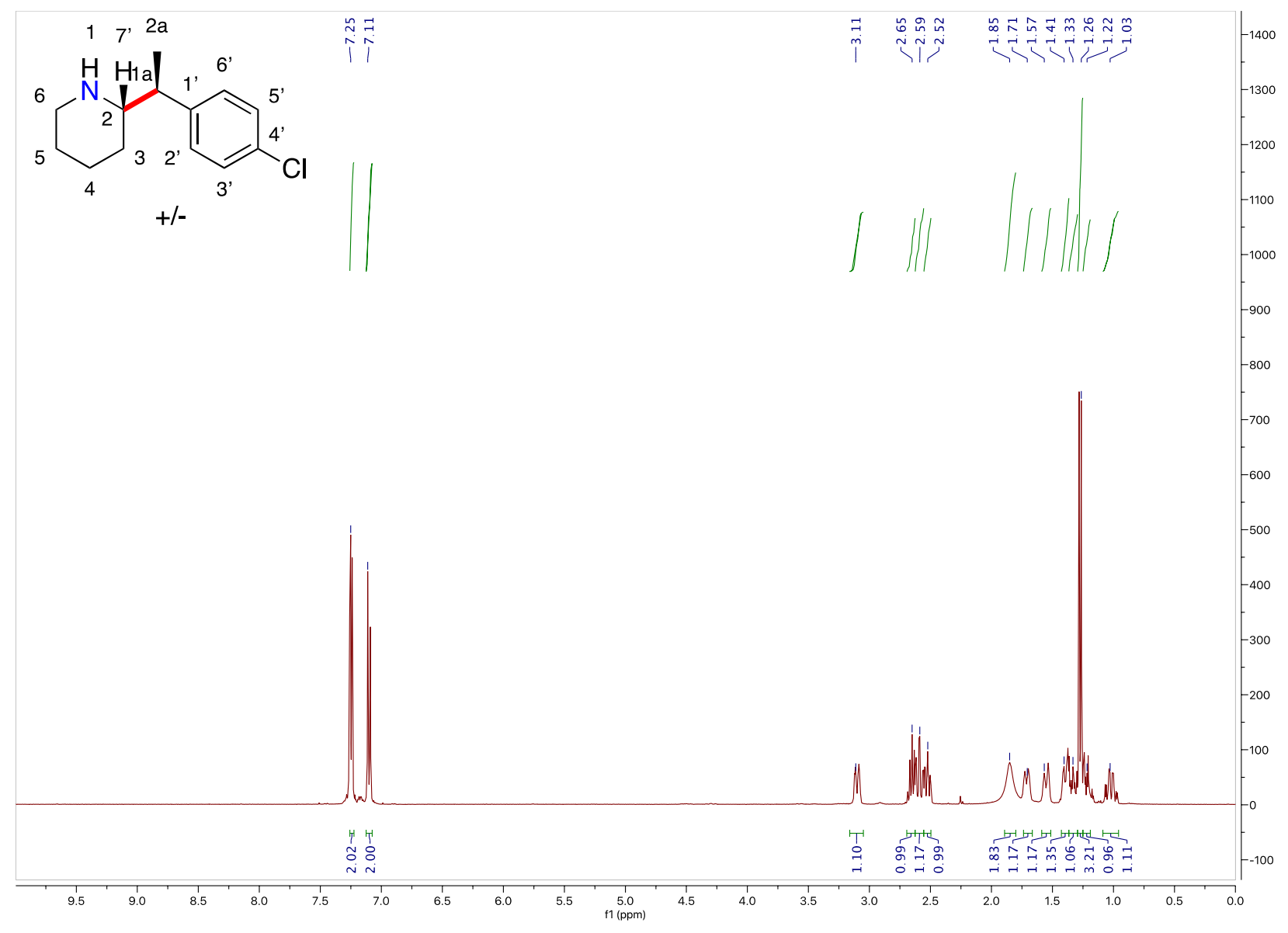

Figure S27: ${ }^{1} \mathrm{H} \quad \mathrm{NMR}$ spectrum $\quad\left(400 \mathrm{MHz}, \mathrm{CDCl}_{3}, 298 \mathrm{~K}\right)$ of purified 2-(1-(4chlorophenyl)ethyl)piperidine. 


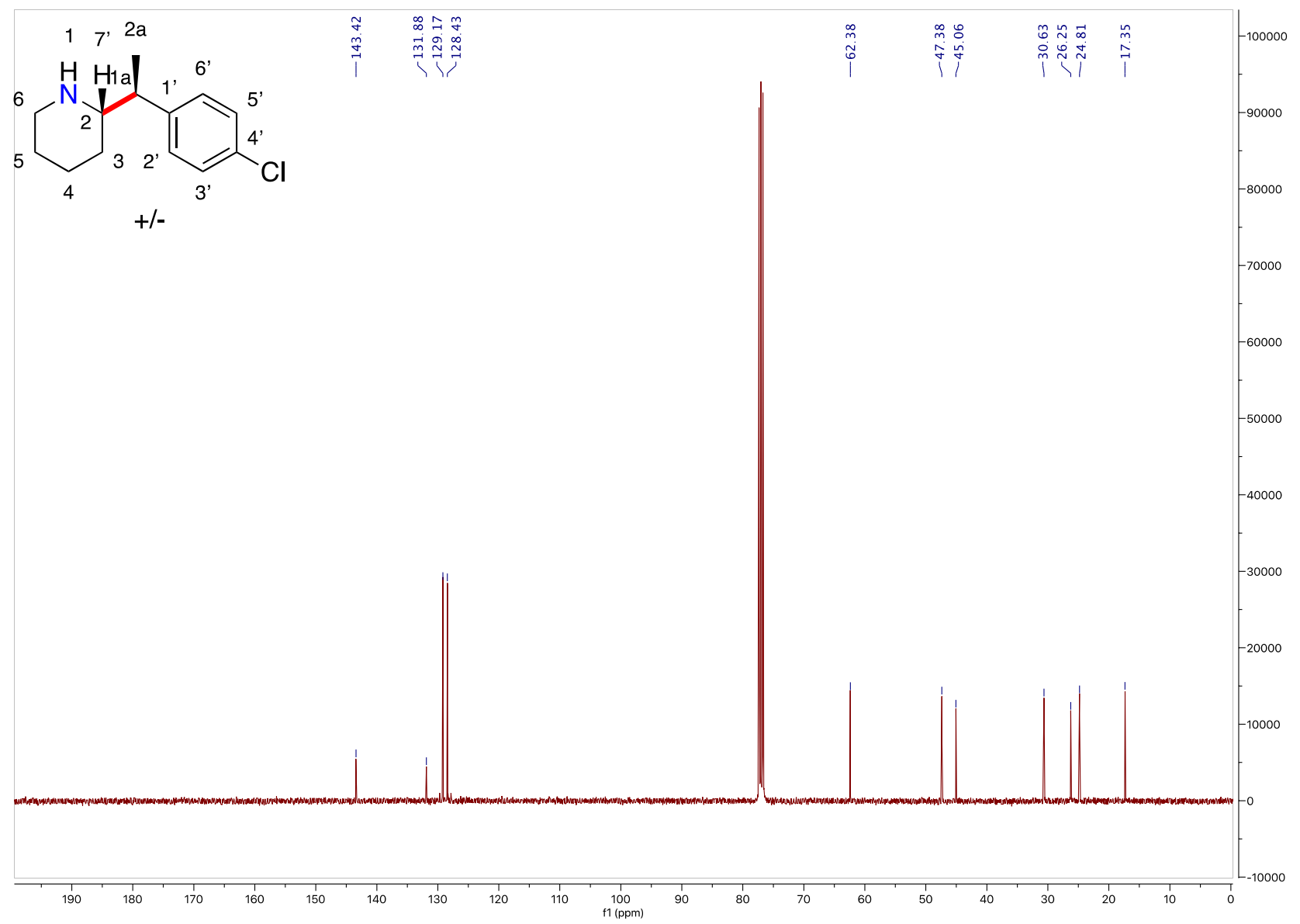

Figure S28: ${ }^{13} \mathrm{C} \quad \mathrm{NMR}$ spectrum $\left(101 \mathrm{MHz}, \mathrm{CDCl}_{3}, \quad 298 \mathrm{~K}\right)$ of purified 2-(1-(4chlorophenyl)ethyl)piperidine. 


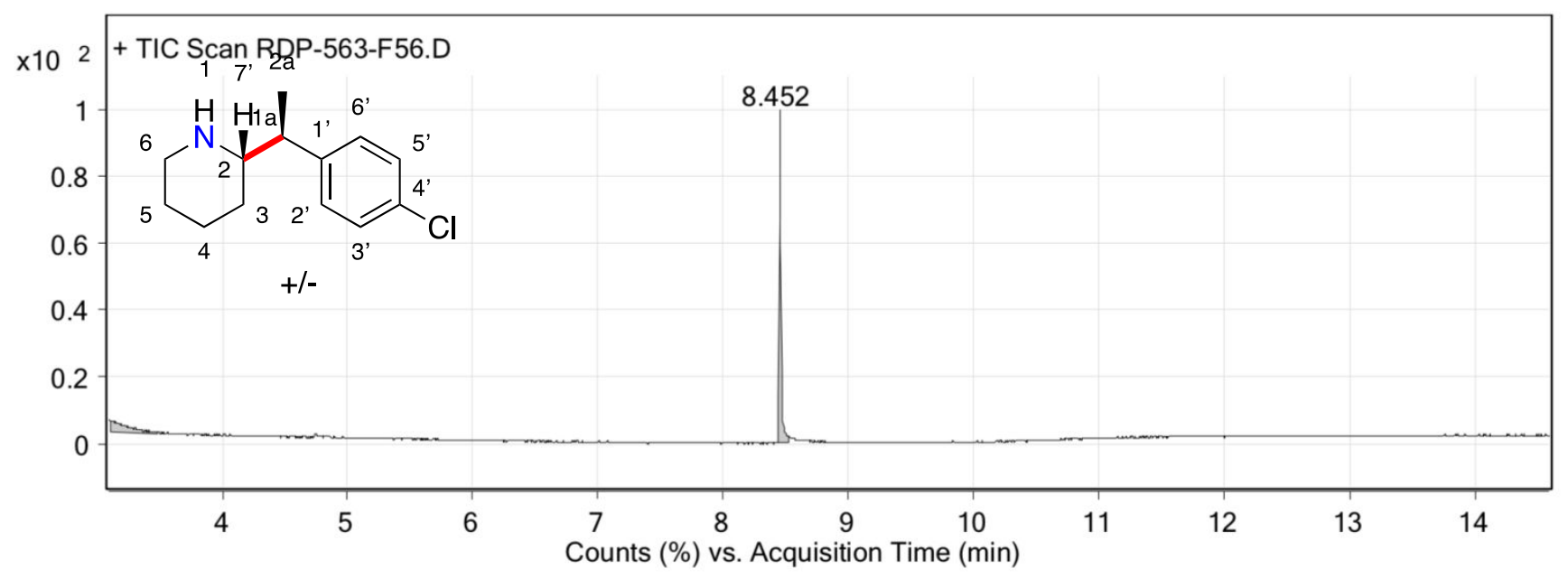

Figure S29: GC-MS report of purified 2-(1-(4-chlorophenyl)ethyl)piperidine. 


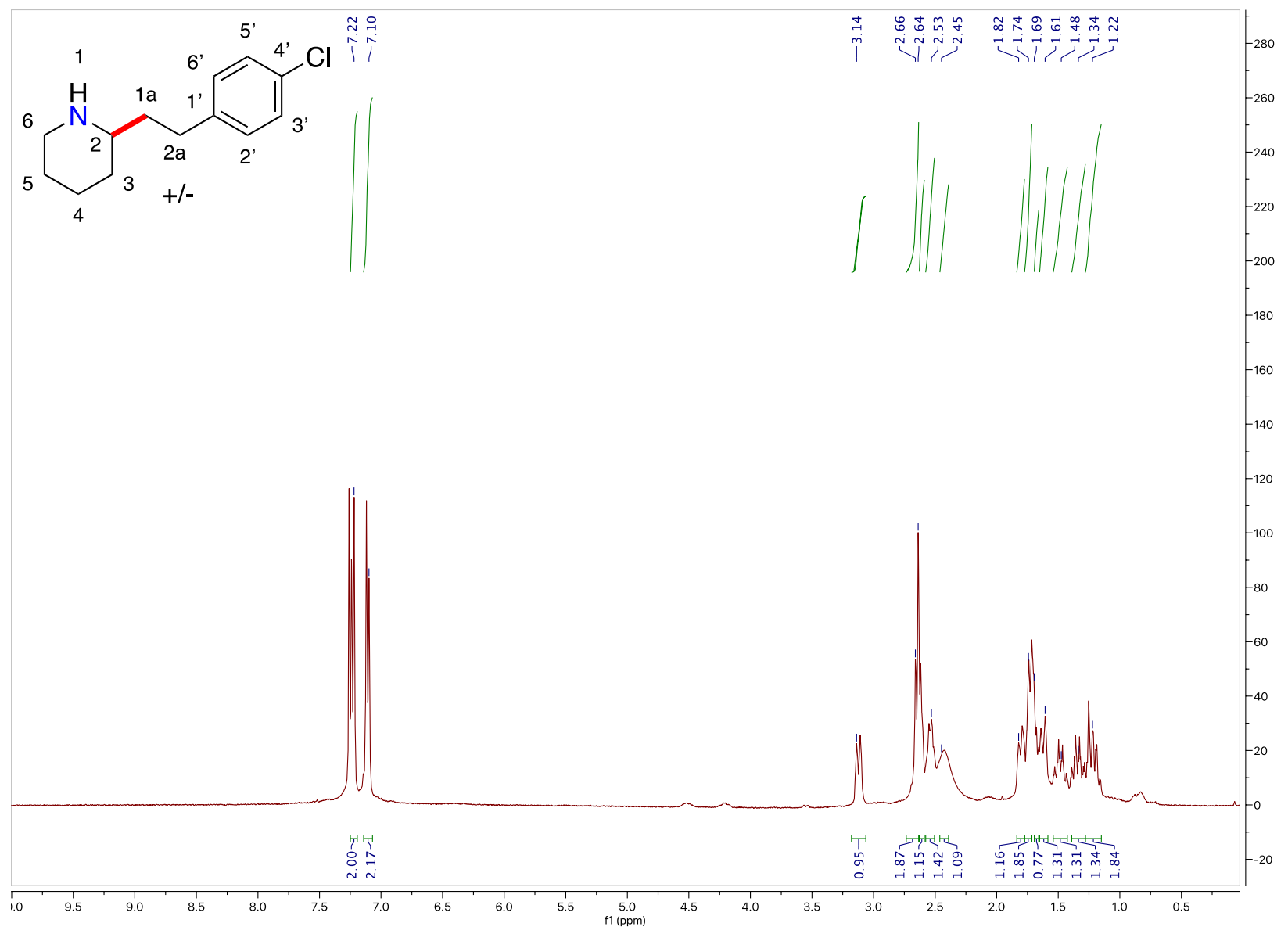

Figure S30: ${ }^{1} \mathrm{H}$ NMR spectrum (400 MHz, $\mathrm{CDCl}_{3}, 298 \mathrm{~K}$ ) of purified 2-(4-chlorophenethyl)piperidine. 


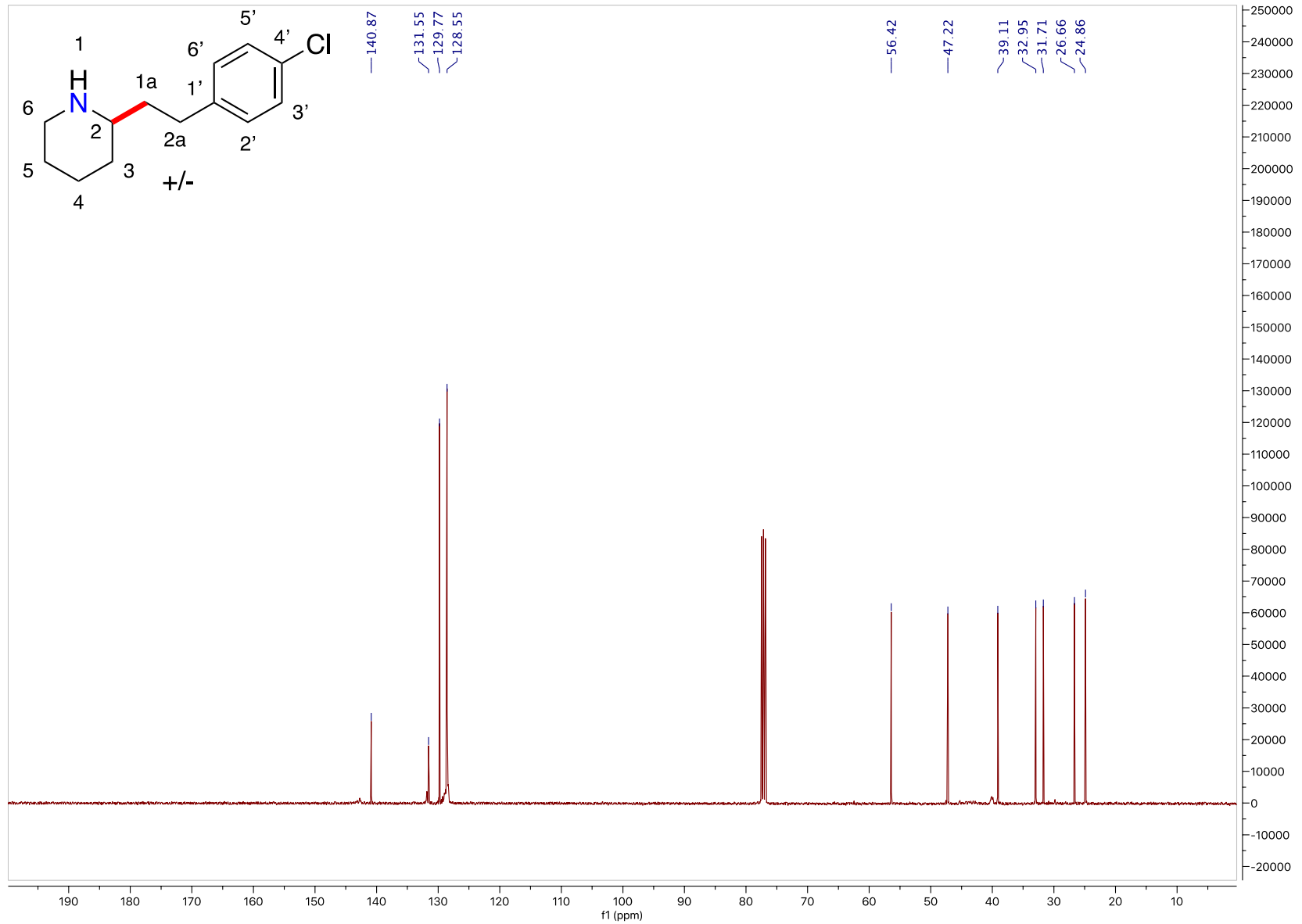

Figure S31: ${ }^{13} \mathrm{C}$ NMR spectrum $\left(101 \mathrm{MHz}, \mathrm{CDCl}_{3}, 298 \mathrm{~K}\right)$ of purified 2-(4-chlorophenethyl)piperidine.

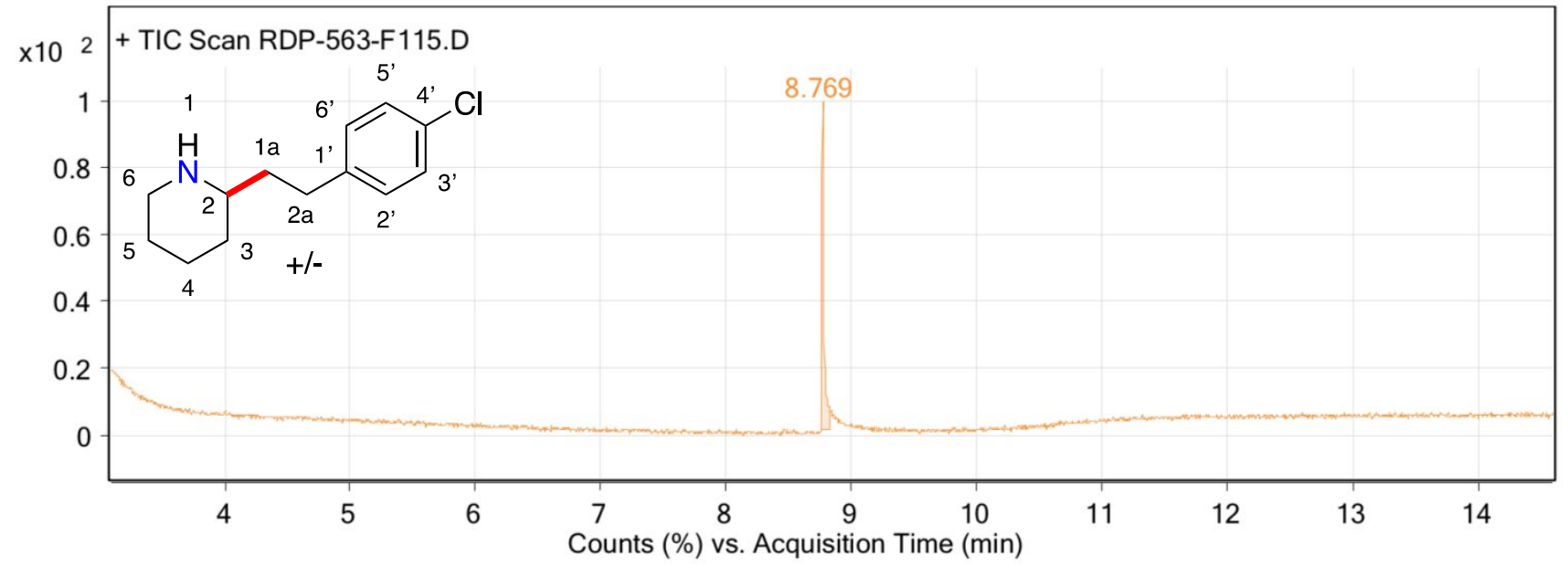

Figure S32: GC-MS report of 2-(4-chlorophenethyl)piperidine. 


\section{S6. Synthesis and Characterization of Amine Scope Products}

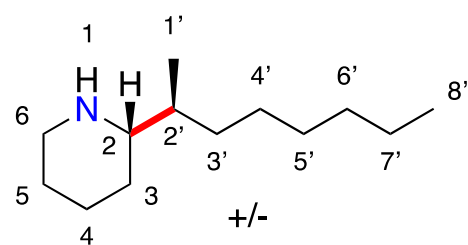

in the literature. ${ }^{8}$
Synthesis of 2-(octan-2-yl)piperidine (2): Prepared following the general procedure for predominantly branched product formation: $26.0 \mathrm{mg}$ Ta, 15.2 $\mathrm{mg}$ ligand L4, piperidine $(85.15 \mathrm{mg}, 1.0 \mathrm{mmol}), 1$-octene $(122.12 \mathrm{mg}, 1.0$ mmol). The reaction was subsequently concentrated and the yield was determined to be $99 \%$ by NMR (1,3,5-trimethoxybenzene as a standard). Purification via column chromatography $(7: 2.5: 0.5$ hexanes : ethyl acetate : triethyl amine). Chemical shifts for the title compound match those reported

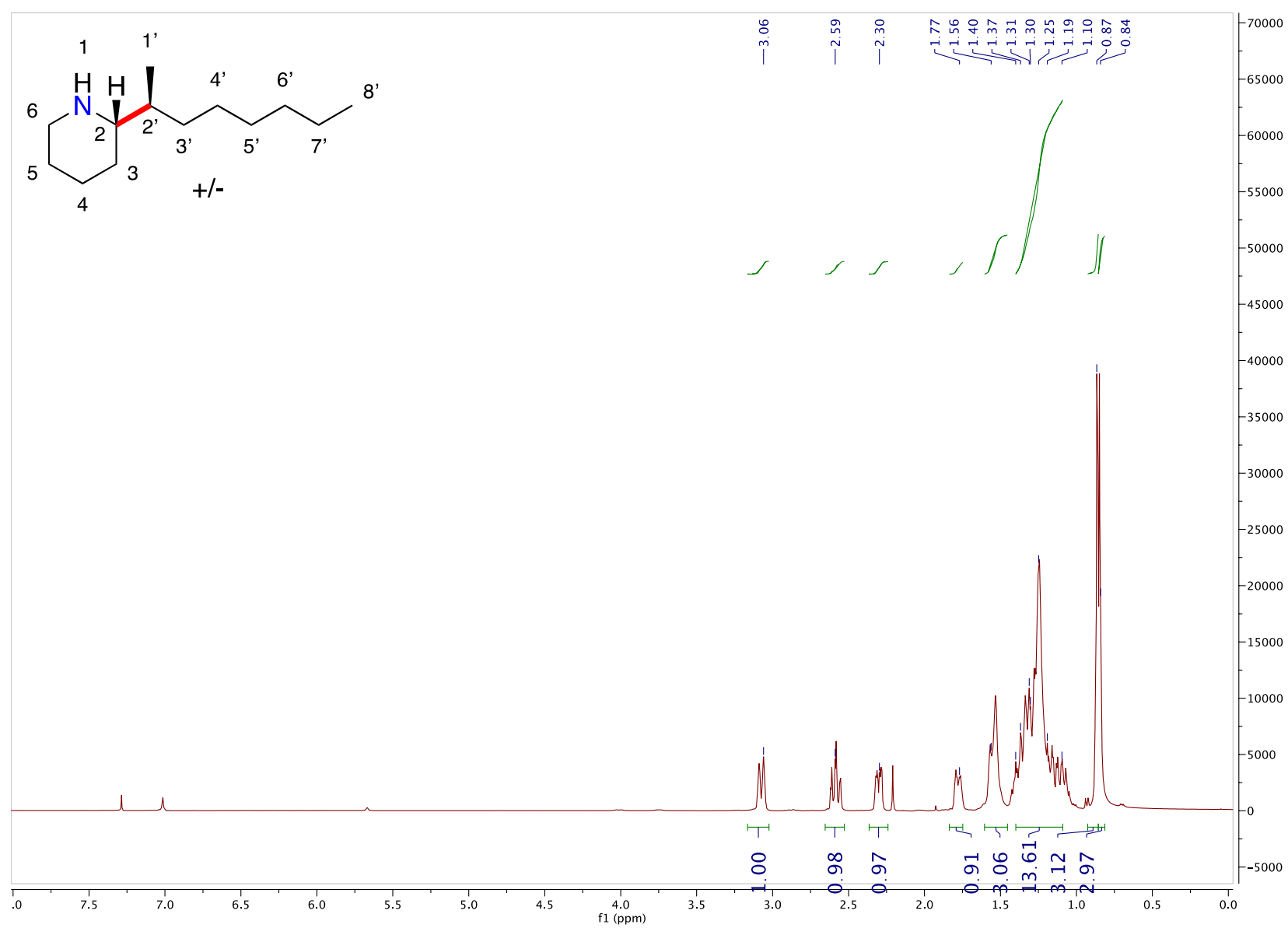

Figure S33: ${ }^{1} \mathrm{H}$ NMR spectrum $\left(400 \mathrm{MHz}, \mathrm{CDCl}_{3}, 298 \mathrm{~K}\right.$ ) of 2-(octan-2-yl)piperidine. 


\section{Note: This crude reaction GC-MS spectrum is a representative example of how we determined d.r ratios for all amine products presented.}

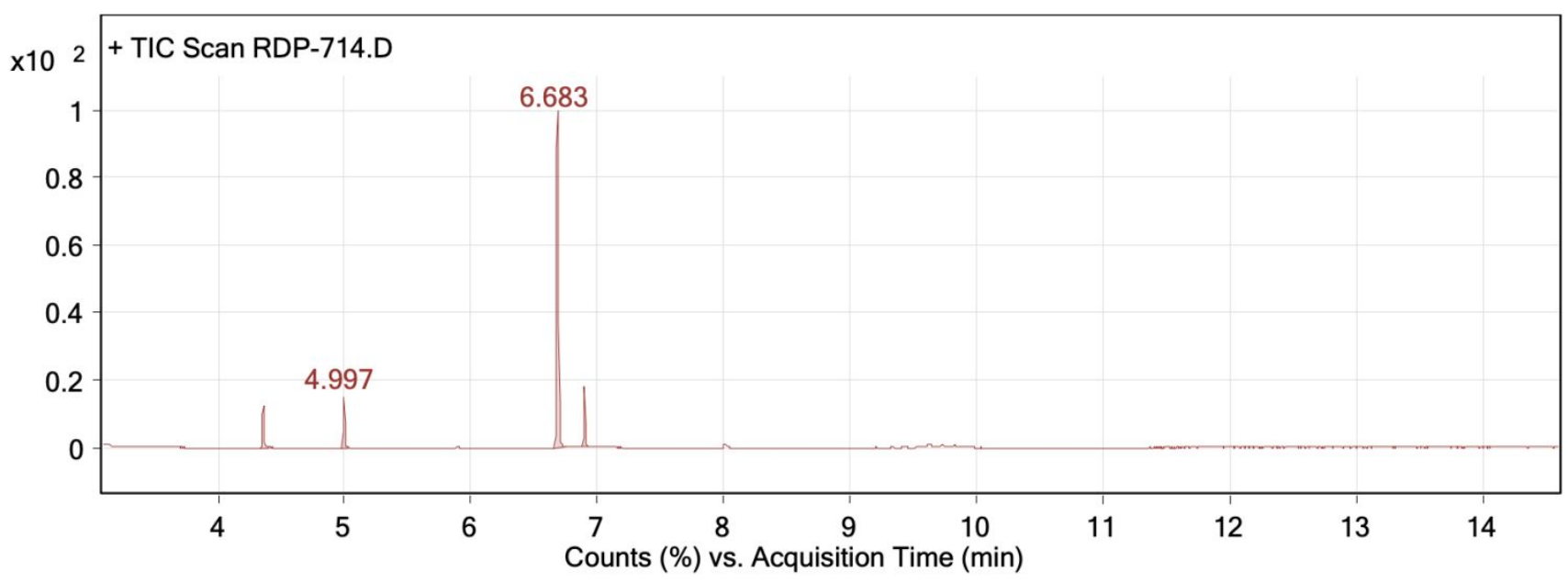

Figure S34: GC-MS for crude reaction mixture between piperidine and 1-octene.

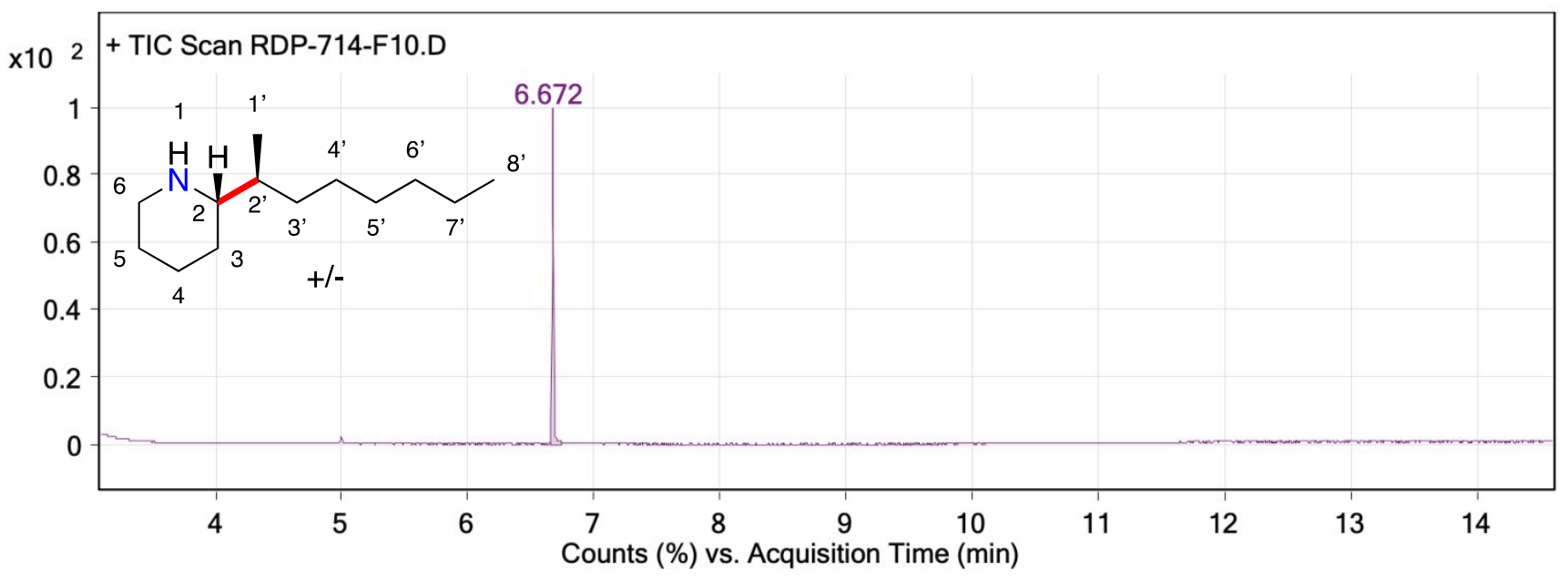

Figure S35: GC-MS report of 2-(octan-2-yl)piperidine.

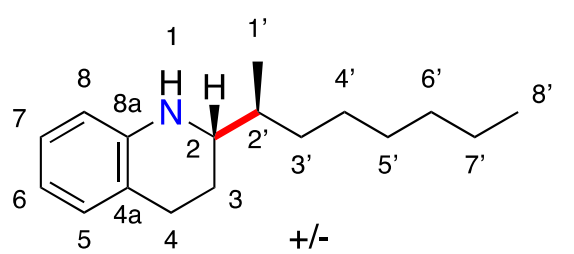

Synthesis of 2-(octan-2-yl)-1,2,3,4-tetrahydroquinoline (3):

Prepared following the general procedure for predominantly branched product formation: $26.0 \mathrm{mg}$ Ta, $15.2 \mathrm{mg}$ ligand $\mathbf{L 4}, 1,2,3,4-$ tetrahydroquinoline (133.19 mg, $1.0 \mathrm{mmol}), 1$-octene $(122.12 \mathrm{mg}, 1.0$ $\mathrm{mmol})$. The reaction was subsequently concentrated and the yield was determined to be $65 \%$ by NMR (1,3,5-trimethoxybenzene as a standard). Purification via column chromatography (7:2.5:0.5 hexanes : ethyl acetate : triethyl amine). The chemical shifts for the title compound match those reported in the literature. ${ }^{9}$ 


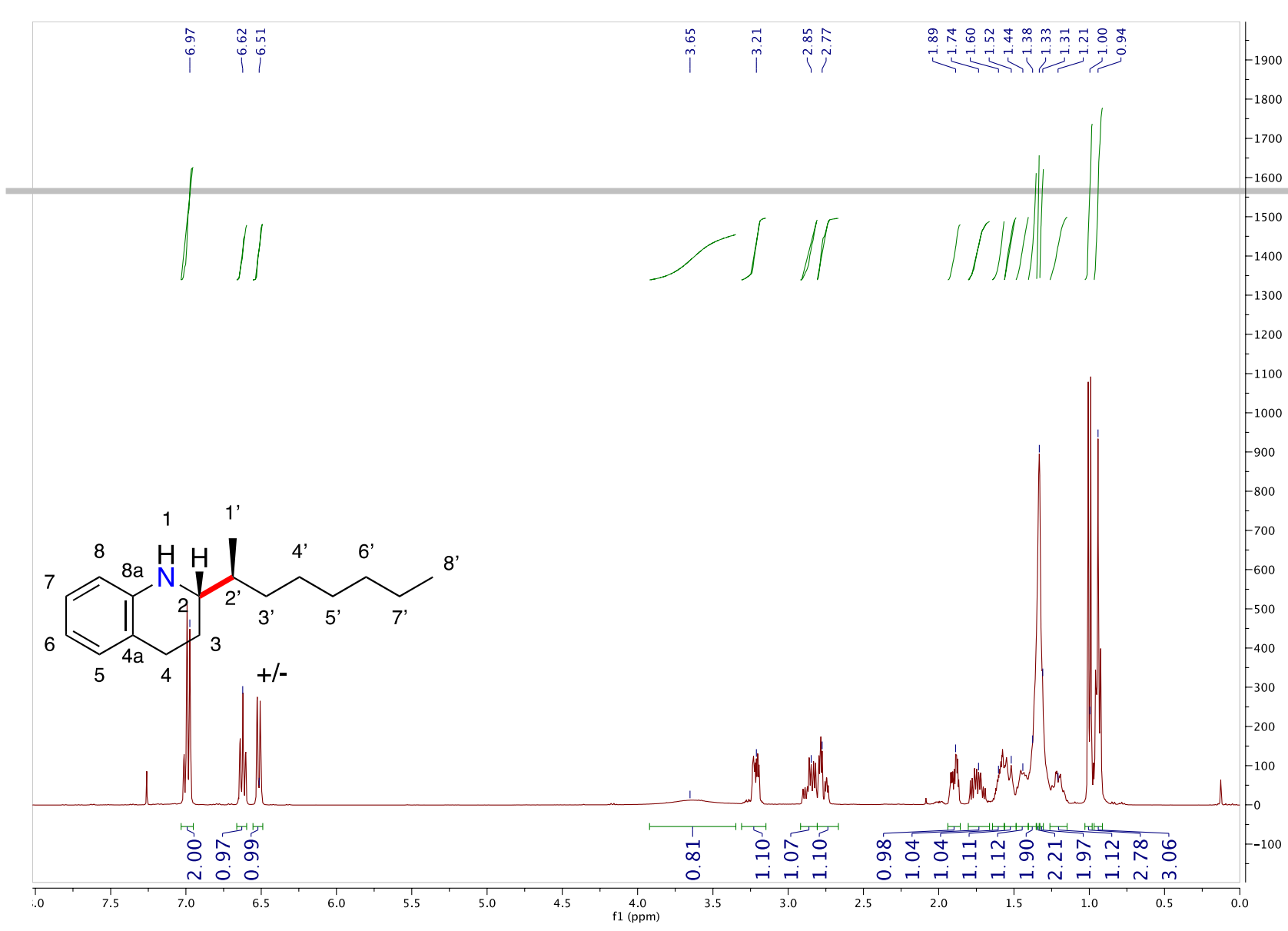

Figure S36: ${ }^{1} \mathrm{H}$ NMR spectrum (400 MHz, $\mathrm{CDCl}_{3}, 298 \mathrm{~K}$ ) of 2-(octan-2-yl)-1,2,3,4-tetrahydroquinoline.

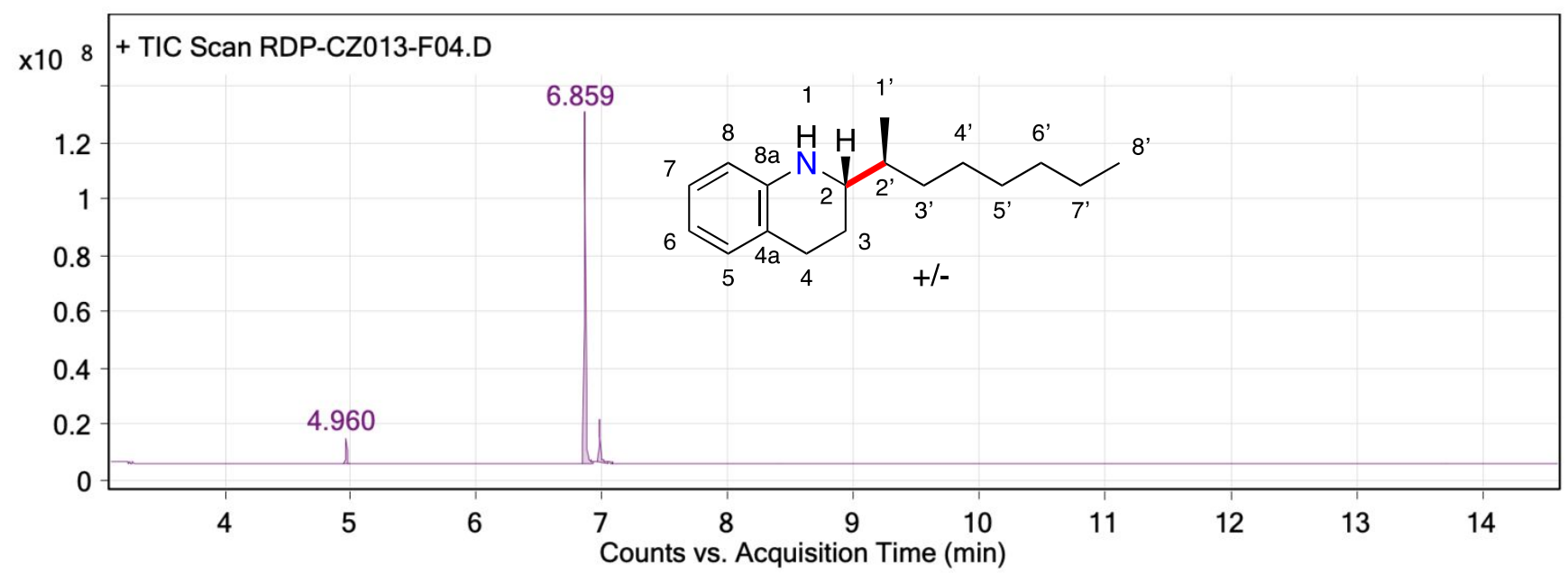

Figure S37: GC-MS report of 2-(octan-2-yl)-1,2,3,4-tetrahydroquinoline.

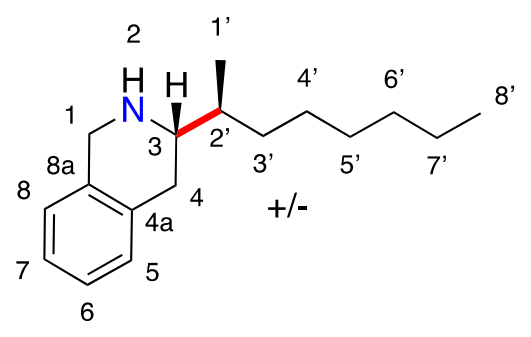

acetate $7.03(\mathrm{~m}, 2 \mathrm{H}, \mathbf{6}$

Synthesis of 3-(octan-2-yl)-1,2,3,4-tetrahydroisoquinoline (4):

Prepared following the general procedure for predominantly branched product formation: $26.0 \mathrm{mg}$ Ta, $15.2 \mathrm{mg}$ ligand $\mathbf{L 4}, 1,2,3,4-$ tetrahydroisoquinoline $(133.19 \mathrm{mg}, 1.0 \mathrm{mmol}), 1$-octene $(112.22 \mathrm{mg}, 1.0$ $\mathrm{mmol})$. The reaction was subsequently concentrated and the yield was determined to be $99 \%$ by NMR (1,3,5-trimethoxybenzene as a standard). Purification via column chromatography (7:2.5:0.5 hexanes : ethyl

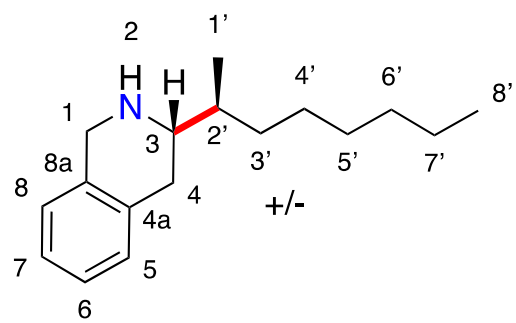
triethyl amine): ${ }^{1} \mathrm{H}$ NMR $\left(\mathrm{CDCl}_{3}, 400 \mathrm{MHz}, 298 \mathrm{~K}\right)$ : and 7), $6.99(\mathrm{~m}, 1 \mathrm{H}, \mathbf{5}), 6.92(\mathrm{~m}, 1 \mathrm{H}, \mathbf{8}), 3.97(\mathrm{~s}, 2 \mathrm{H}, \mathbf{1})$, 
2.68, (m, 1H, 3), 2.58 (m, 2H, 4), 1.78 (broad s, 1H, NH), 1.50 (m, 1H, 2'), 1.45 (m, 1H, 1/2 of 3'), 1.29 (m, 2H, 4'/5'/6'/7'), 1.24 (m, 2H, 4'/5'/6'/7'), 1.21 (m, 2H, 4'/5'/6'/7'), 1.20 (m, $2 \mathrm{H}, \mathbf{4}^{\prime} / \mathbf{5}^{\prime} / \mathbf{6}^{\prime} / \mathbf{7}^{\prime}$ ), 1.18 (m, 1H, 1/2 of 3'), $1.16(\mathrm{~m}, 1 \mathrm{H}, 1 / 2$ of 3), 0.91 (d, J = 0.91, 3H, 1'), 0.81 (t, 3H, 8'), 0.61 (d, J = 0.61, 0.42H, 1 ' of minor regiosiomer) ppm. ${ }^{13} \mathrm{C} \mathrm{NMR}\left(\mathrm{CDCl}_{3}, 101 \mathrm{MHz}, 298 \mathrm{~K}\right): \delta 133.83$ (minor), 136.49 (minor), 135.91, 135.40, 129.46, 129.16 (minor), 126.07, 126.00, 125.95 (minor), 125.69, 125.65 (minor), 125.56 (minor), 59.55 (minor), 58.28, 49.22, 43.04 (minor), 37.88, 37.71 (minor), 34.53 (minor), 32.94, 32.38, 32.00, 30.61 (minor), 29.73, 27.97 (minor), 27.43, 22.77, 15.58, 14.20, $13.46 \mathrm{ppm}$. HRMS (ESI): $\mathrm{m} / \mathrm{z}$

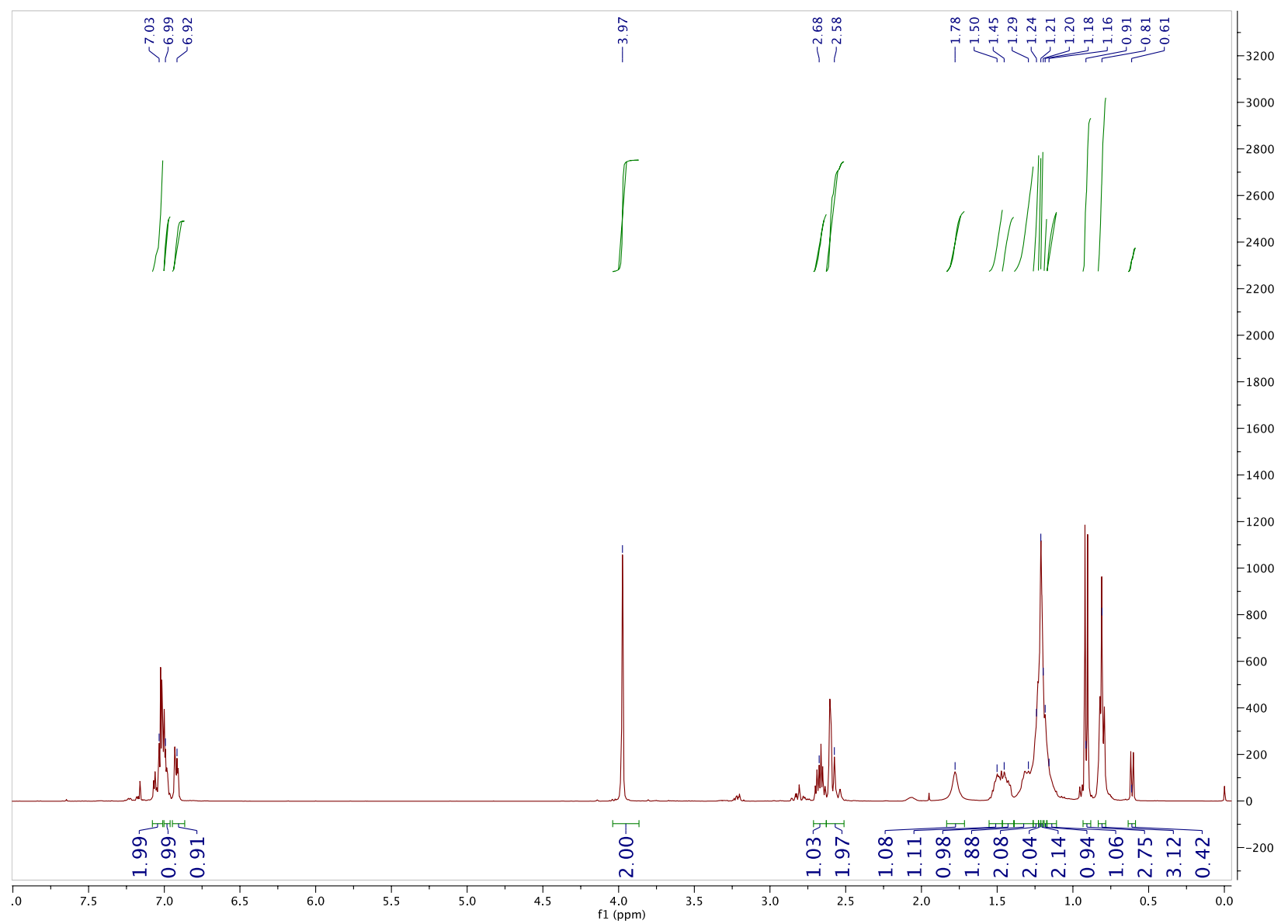

calcd for $\mathrm{C}_{17} \mathrm{H}_{27} \mathrm{~N}\left[\mathrm{M}+\mathrm{H}^{+}\right]$: 246.2221 Found: 246.2220 .

Figure S38: $\quad{ }^{1} \mathrm{H} \quad \mathrm{NMR}$ spectrum $\left(400 \mathrm{MHz}, \quad \mathrm{CDCl}_{3}, \quad 298 \quad \mathrm{~K}\right) \quad$ of 3 -(octan-2-yl)-1,2,3,4tetrahydroisoquinoline. 


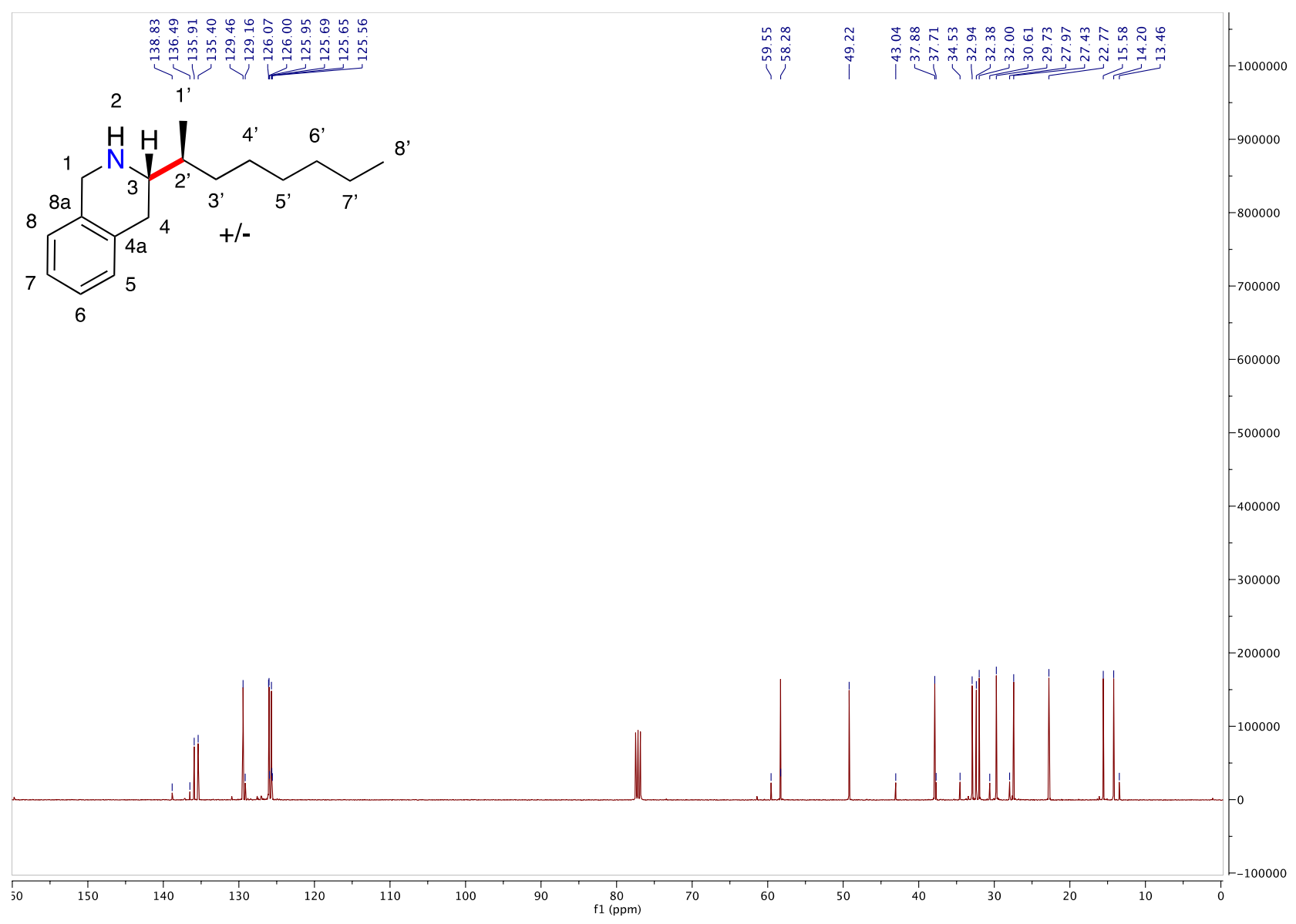

Figure S39: ${ }^{13} \mathrm{C}$ NMR spectrum (101 $\left.\mathrm{MHz}, \mathrm{CDCl}_{3}, 298 \mathrm{~K}\right)$ of 3-(octan-2-yl)-1,2,3,4tetrahydroisoquinoline.

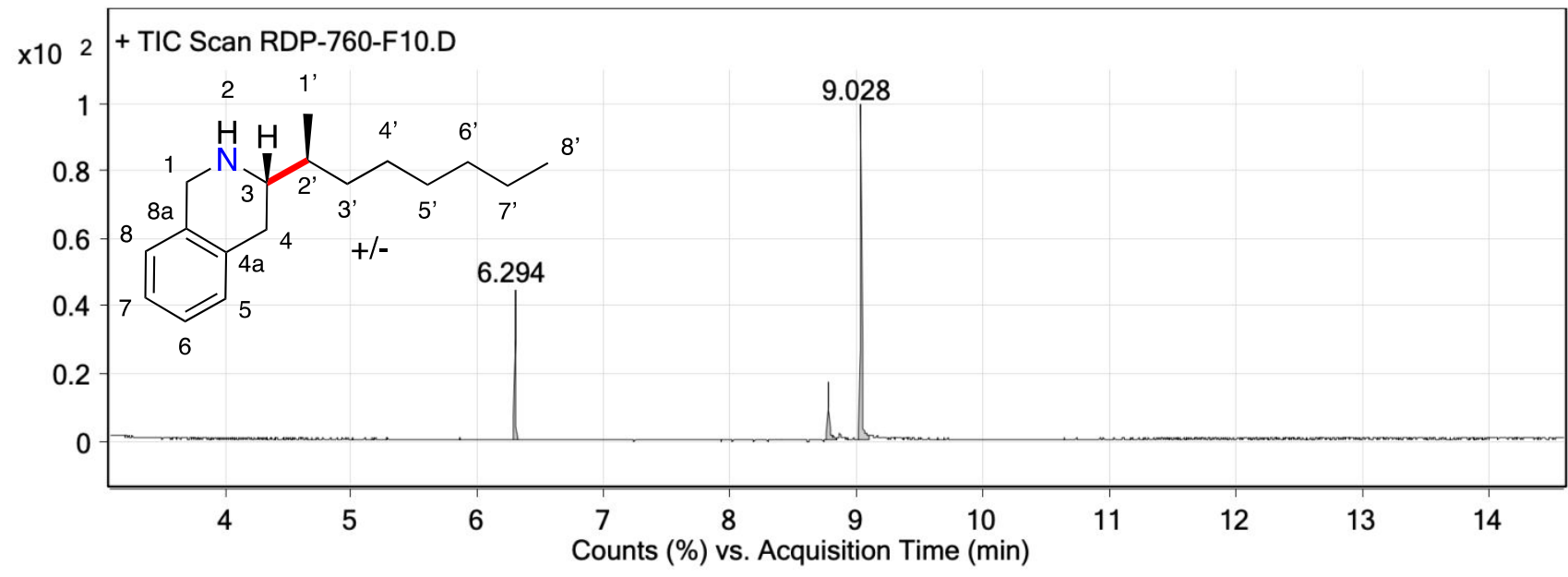

Figure S40: GC-MS report of 3-(octan-2-yl)-1,2,3,4-tetrahydroisoquinoline. Note that the peak at 6.294 represents residual internal standard. 


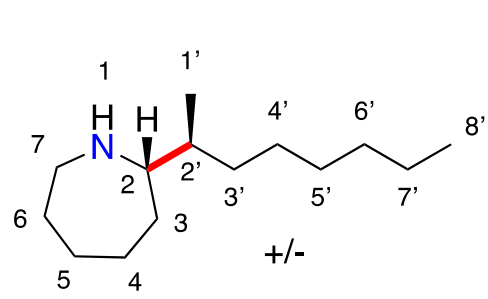

Synthesis of 2-(octan-2-yl)azepane (5): Prepared following the general procedure for predominantly branched product formation: $26.0 \mathrm{mg} \mathrm{Ta}$, ' $\quad 15.2 \mathrm{mg}$ Ligand, azepane $(99.17 \mathrm{mg}, 1.0 \mathrm{mmol}), 1$-octene $(112.22 \mathrm{mg}, 1.0$ mmol). The reaction was subsequently concentrated and the yield was determined to be $91 \%$ by NMR (1,3,5-trimethoxybenzene as a standard). Purification via column chromatography $(7: 2.5: 0.5$ hexanes : ethyl acetate : triethyl amine): ${ }^{1} \mathrm{H}$ NMR $\left(\mathrm{CDCl}_{3}, 400 \mathrm{MHz}, 298 \mathrm{~K}\right): \delta 3.00(\mathrm{~m}, 1 \mathrm{H}, 1 / 2$ of 7), $2.64(\mathrm{~m}, 1 \mathrm{H}, 1 / 2$ of 7$), 2.47(\mathrm{~m}, 1 \mathrm{H}, 2), 1.69(\mathrm{~m}, 1 \mathrm{H}, 1 / 2$ of $3 / 4), 1.63(\mathrm{~m}, 1 \mathrm{H}, 1 / 2$ of $3 / 4), 1.60(\mathrm{~m}, 2 \mathrm{H}$, $6 / 5), 1.57(\mathrm{~m}, 1 \mathrm{H}, 1 / 2$ of $3 / 4), 1.46(\mathrm{~m}, 2 \mathrm{H}, 6 / 5), 1.42\left(\mathrm{~m}, 1 \mathrm{H}, 2^{\prime}\right), 1.38\left(\mathrm{~m}, 1 \mathrm{H}, 1 / 2\right.$ of $\left.3^{\prime} / 4^{\prime}\right), 1.35(\mathrm{~m}, 1 \mathrm{H}$, $1 / 2$ of 3/4), 1.27 (m, 1H, 1/2 of 3/4), 1.26 (m, 2H, 5'/6'/7'), 1.24 (m, 2H, 5'/6'/7'), 1.20 (m, 2H, 5'/6'/7'), $1.14\left(\mathrm{~m}, 1 \mathrm{H}, 1 / 2\right.$ of $\left.3^{\prime} / 4^{\prime}\right), 1.09\left(\mathrm{~m}, 1 \mathrm{H}, 1 / 2\right.$ of $\left.3^{\prime} / 4^{\prime}\right), 0.85$ (overlapping t, $\left.3 \mathrm{H}, 8^{\prime}\right), 0.81$ (overlapping d, $3 \mathrm{H}$, 1') ppm. ${ }^{13} \mathrm{C} \mathrm{NMR}\left(\mathrm{CDCl}_{3}, 101 \mathrm{MHz}, 298 \mathrm{~K}\right): \delta 63.17,55.33,48.70,39.59,33.82,33,59,32.01,31.33$, 29.77, 27.74, 26.97, 22.76, 15.36, 14.16 ppm. HRMS (ESI): $m / z$ calcd for $\mathrm{C}_{14} \mathrm{H}_{29} \mathrm{~N}\left[\mathrm{M}+\mathrm{H}^{+}\right]: 212.2378$ Found: 212.2372 . 


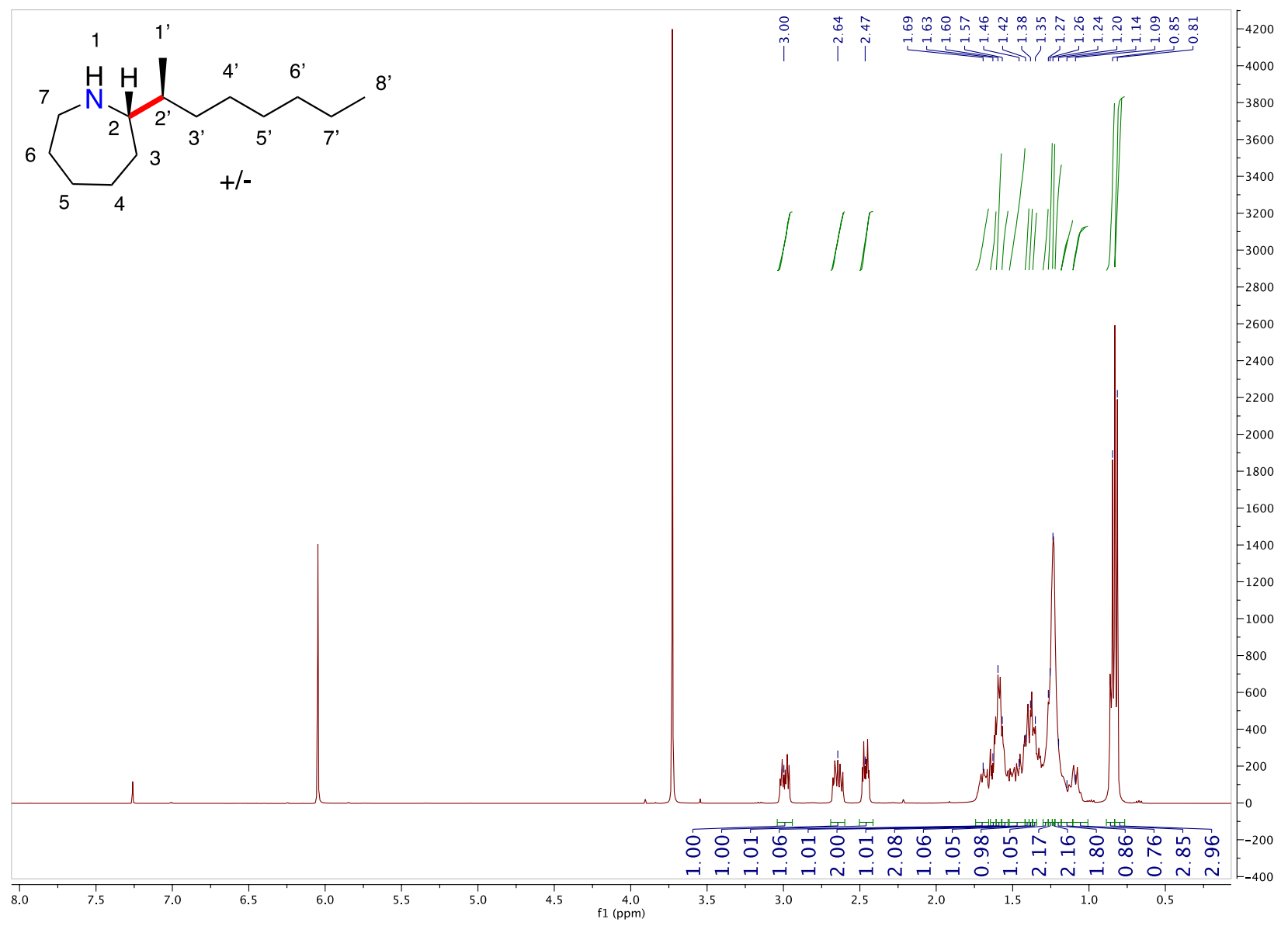

Figure S41: ${ }^{1} \mathrm{H}$ NMR spectrum (400 MHz, $\left.\mathrm{CDCl}_{3}, 298 \mathrm{~K}\right)$ of 2-(octan-2-yl)azepane. 


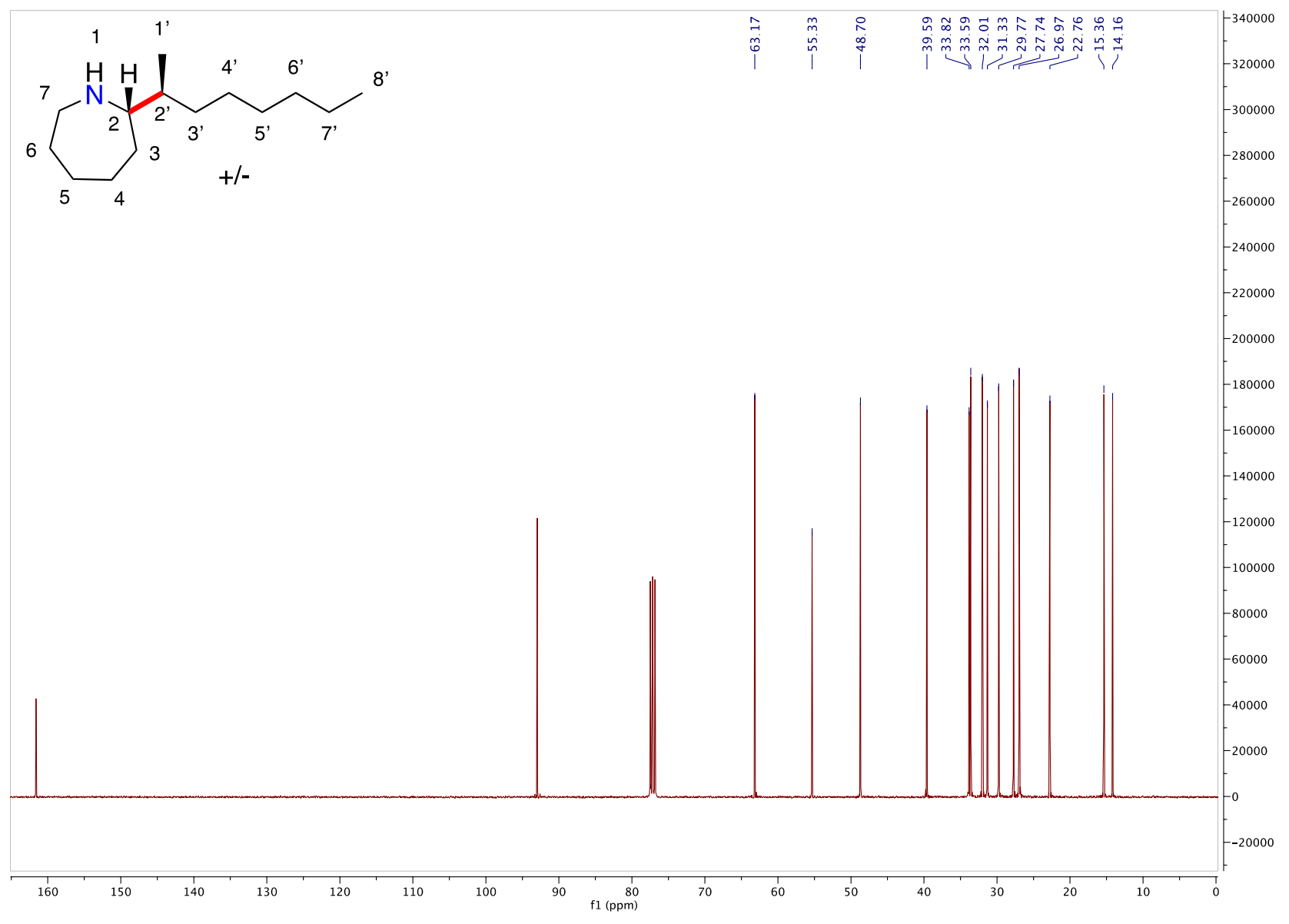

Figure S42: ${ }^{13} \mathrm{C}$ NMR spectrum $\left(101 \mathrm{MHz}, \mathrm{CDCl}_{3}, 298 \mathrm{~K}\right)$ of 2-(octan-2-yl)azepane.

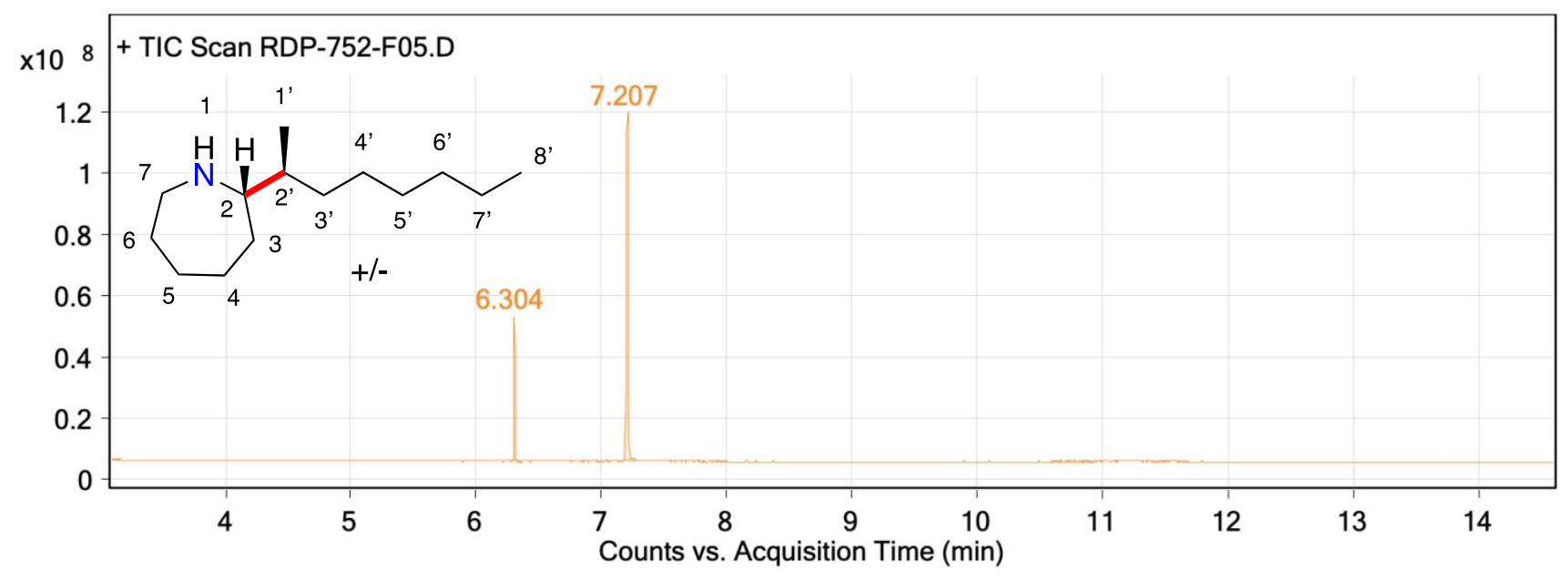

Figure S43: GC-MS report of 2-(octan-2-yl)azepane. Note that the peak at 6.304 min represents residual internal standard. 


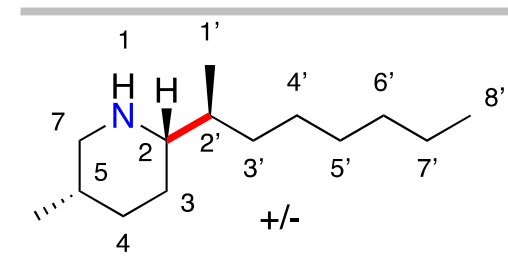

Synthesis of 4-methyl-2-(octan-2-yl)piperidine (6): Prepared following the general procedure for predominantly branched product formation: : $26.0 \mathrm{mg}$ Ta, 15.2 Ligand, 3-methylpiperidine (99.17 mg, $1.0 \mathrm{mmol}), 1$ octene (112.22 $\mathrm{mg}, \quad 1.0 \mathrm{mmol})$. The reaction was subsequently concentrated and the combined yield was determined to be $86 \%$ by NMR (1,3,5-trimethoxybenzene as a standard). Purification by column chromatography $(7: 2.5: 0.5$ hexanes : ethyl acetate : triethyl amine) yields an inseparable mixture of diastereomers (8:1) as determined by GC-MS. ${ }^{1} \mathrm{H}$ NMR $\left(\mathrm{CDCl}_{3}, 400 \mathrm{MHz}, 298\right.$ $\mathrm{K}): \delta 3.03(\mathrm{~m}, 1 \mathrm{H}, 1 / 2$ of 7), 2.33 (minor diastereomer) and $2.26(\mathrm{~m}, 1 \mathrm{H}, 2), 2.21(\mathrm{~m}, 1 \mathrm{H}, 1 / 2$ of 7$), 1.89$ (broad s, $1 \mathrm{H}, \mathrm{NH}), 1.78(\mathrm{~m}, 1 \mathrm{H}, 1 / 2$ of 4$), 1.59(\mathrm{~m}, 1 \mathrm{H}, 1 / 2$ of 3$), 1.46(\mathrm{~m}, 1 \mathrm{H}, 5), 1.41\left(\mathrm{~m}, 1 \mathrm{H}, 1 / 2\right.$ of $\left.3^{\prime} / 4^{\prime}\right)$, $1.37\left(\mathrm{~m}, 1 \mathrm{H}, 2^{\prime}\right), 1.32\left(\mathrm{~m}, 1 \mathrm{H}, 1 / 2\right.$ of $\left.4^{\prime} / 3^{\prime}\right), 1.28\left(\mathrm{~m}, 2 \mathrm{H}, 5^{\prime} / 6^{\prime} / 7^{\prime}\right), 1.26\left(\mathrm{~m}, 2 \mathrm{H}, 5^{\prime} / 6^{\prime} / 7^{\prime}\right), 1.25(\mathrm{~m}, 2 \mathrm{H}$, $\left.5^{\prime} / 6^{\prime} / 7^{\prime}\right), 1.23(\mathrm{~m}, 1 \mathrm{H}, 1 / 2$ of 3$), 1.20,\left(\mathrm{~m}, 1 \mathrm{H}, 1 / 2\right.$ of $\left.3^{\prime} / 4^{\prime}\right), 1.08\left(\mathrm{~m}, 1 \mathrm{H}, 1 / 2\right.$ of $\left.3^{\prime} / 4^{\prime}\right), 0.98(\mathrm{~m}, 1 \mathrm{H}, 1 / 2$ of 4$)$, 0.87 (overlapping $\left.\mathrm{d}, 3 \mathrm{H}, 1^{\prime}\right), 0.86$ (overlapping t, $\left.3 \mathrm{H}, 8^{\prime}\right), 0.81(\mathrm{~d}, \mathrm{~J}=0.81,3 \mathrm{H}, 6) \mathrm{ppm} .{ }^{13} \mathrm{C} \mathrm{NMR}\left(\mathrm{CDCl}_{3}\right.$, $101 \mathrm{MHz}, 298 \mathrm{~K}$ ): $\delta$ 61.41 (major) and 61.41 (minor), 54.43 (major), 54.30 (minor), 37.23 (major), 33.17 (major), 32.33 (major), 31.31 (major), 31.04 (major), 29.46 (minor), 28.76 (major), 28.73 (minor), 27.38 (minor), 26.58 (major), 26.51 (minor), 23.59 (major), 21.80 (major), 18.64 (major), 16.32 (minor), 14.75 (minor), 14.68 (major), 13.22 (major). HRMS (ESI): $m / z$ calcd for $\mathrm{C}_{14} \mathrm{H}_{29} \mathrm{~N}\left[\mathrm{M}+\mathrm{H}^{+}\right]: 212.2378$ Found: 212.2381 .

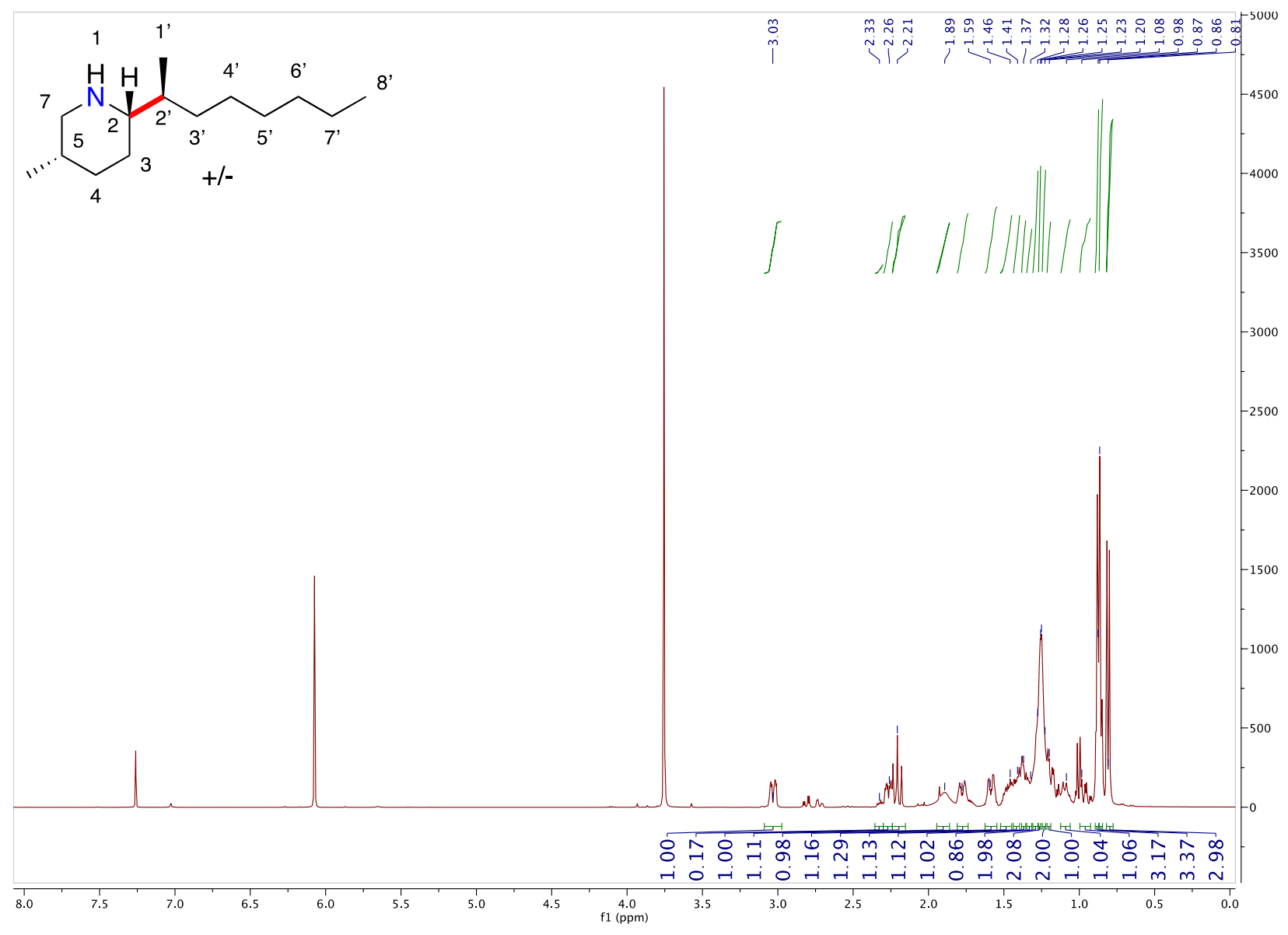

Figure S44: ${ }^{1} \mathrm{H}$ NMR spectrum $\left(400 \mathrm{MHz}, \mathrm{CDCl}_{3}, 298 \mathrm{~K}\right.$ ) of both diastereomers of 4-methyl-2-(octan-2yl)piperidine (1:10). Note that peaks at 3.7 and $6.1 \mathrm{ppm}$ represent residual 1,3,5-trimethoxybenzene internal standard. 


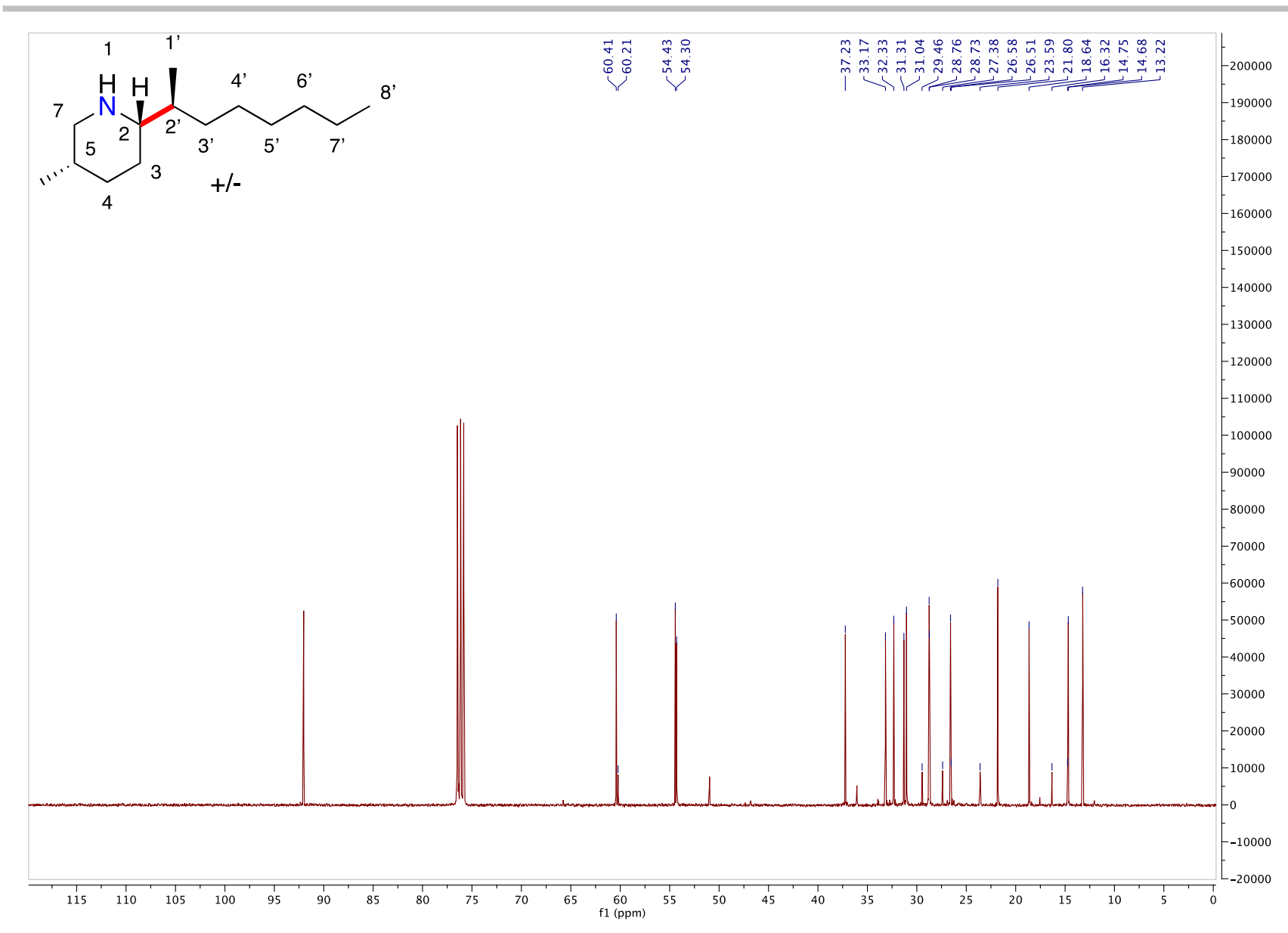

Figure S45: ${ }^{13} \mathrm{C}$ NMR spectrum $\left(101 \mathrm{MHz}, \mathrm{CDCl}_{3}, 298 \mathrm{~K}\right)$ of 4-methyl-2-(octan-2-yl)piperidine.

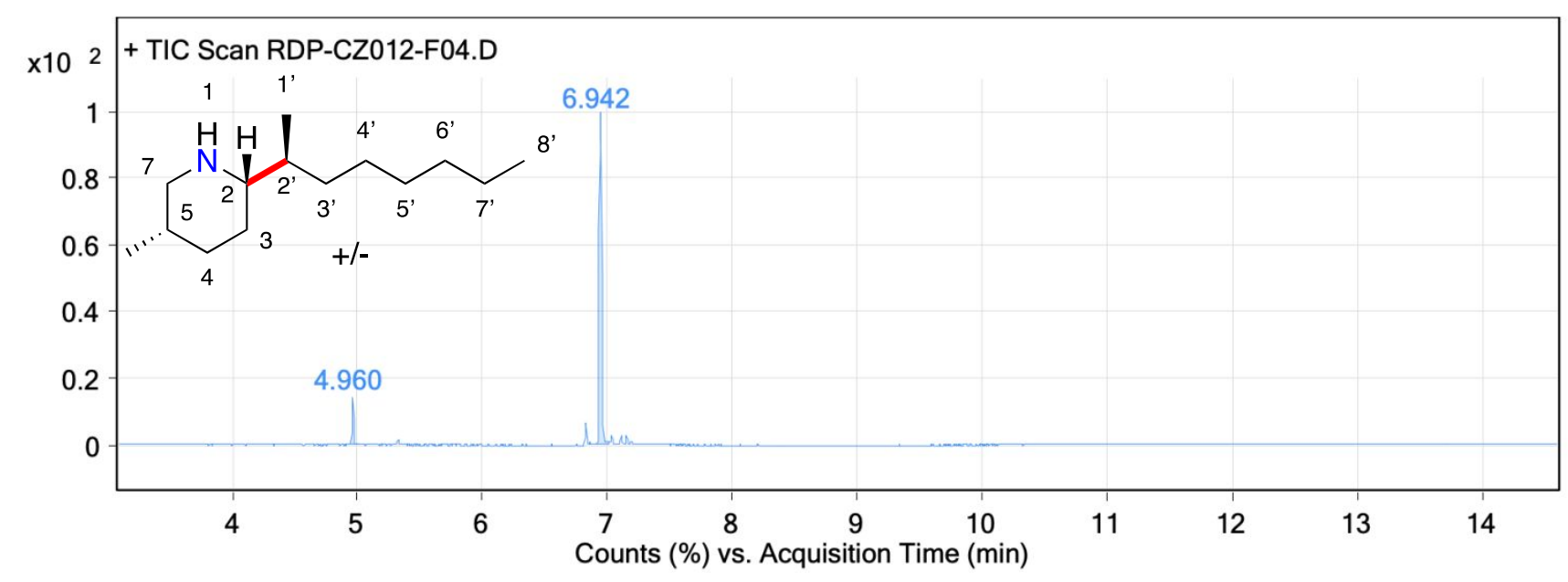

Figure S46: GC-MS report of 4-methyl-2-(octan-2-yl)piperidine.

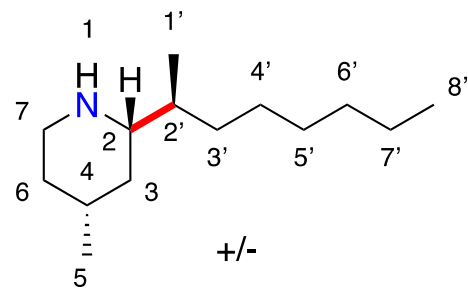

Synthesis of 4-methyl-2-(octan-2-yl)piperidine (7): Prepared following the general procedure for predominantly branched product formation: 26.0 Ta, 15.2 ligand L4, 4-methylpiperidine (99.17 mg, $1.0 \mathrm{mmol})$, 1-octene 
(250.2 $\mathrm{mg}, 1.0 \mathrm{mmol})$. The reaction was subsequently concentrated and the yield was determined to be $84 \%$ by NMR (1,3,5-trimethoxybenzene as a standard). Purification via column chromatography (7:2.5:0.5 hexanes : ethyl acetate : triethyl amine): ${ }^{1} \mathrm{H} \mathrm{NMR}\left(\mathrm{CDCl}_{3}, 400 \mathrm{MHz}, 298 \mathrm{~K}\right): \delta 3.09(\mathrm{~m}, 1 \mathrm{H}, 1 / 2$ of 7), $2.59(\mathrm{~m}, 1 \mathrm{H}, 1 / 2$ of 7$), 2.33(\mathrm{~m}, 1 \mathrm{H}, 2), 1.99$ (broad s, $1 \mathrm{H}, \mathrm{NH}), 1.59(\mathrm{~m}, 1 \mathrm{H}, 1 / 2$ of 6$), 1.55(\mathrm{~m}, 1 \mathrm{H}$, $1 / 2$ of 3$), 1.44(\mathrm{~m}, 1 \mathrm{H}, 4), 1.42\left(\mathrm{~m}, 1 \mathrm{H}, 1 / 2\right.$ of $\left.3^{\prime}\right), 1.36\left(\mathrm{~m}, 1 \mathrm{H}, 2^{\prime}\right), 1.30\left(\mathrm{~m}, 1 \mathrm{H}, 1 / 2\right.$ of $\left.4^{\prime}\right), 1.28(\mathrm{~m}, 2 \mathrm{H}$, $\left.5^{\prime} / 6^{\prime} / 7^{\prime}\right), 1.26$ (m, 2H, 5'/6'/7'), 1.25 (m, 2H, 5'/6'/7'), 1.17 (m, 1H, 1/2 of 4'), 1.08 (m, 1H, 1/2 of 3'), 1.01 $(\mathrm{m}, 1 \mathrm{H}, 1 / 2$ of 6$), 0.90(\mathrm{~d}, \mathrm{~J}=0.90,3 \mathrm{H}, 5), 0.88$ (overlapping d, 3H, 1'), 0.87 (overlapping t, 3H, 8'), 0.80 $(\mathrm{m}, 1 \mathrm{H}, 1 / 2$ of 3$)$ ppm. ${ }^{13} \mathrm{C} \mathrm{NMR}\left(\mathrm{CDCl}_{3}, 101 \mathrm{MHz}, 298 \mathrm{~K}\right): \delta 61.52,55.44,47.29,38.52,38.38,35.37$, $33.26,32.05,31.85,29.77,27.62,22.81,15.62,14.22 \mathrm{ppm}$. HRMS (ESI): $\mathrm{m} / z$ calcd for $\mathrm{C}_{14} \mathrm{H}_{29} \mathrm{~N}\left[\mathrm{M}^{+}\right]$: 212.2299 Found: 212.2310 .

Note: The 1D/2D NMR spectroscopy data for this compound is a representative example of how we were able to were able to assign all proton and carbon signals conclusively in products with 1-octene as a coupling partner as well as assign relative stereochemistry for all compounds.

For NOESY experiments: The 1D NOESY experiment illustrated irradiated the peak at $2.59 \mathrm{ppm}(1 / 2$ of 7) selectively. This data suggests that this proton interacts spatially with the other peak on the same methylene $(3.09(\mathrm{~m}, 1 \mathrm{H}, 1 / 2$ of 7$))$, as well as the $\mathrm{CH}$ at $2.33 \mathrm{ppm}(\mathrm{m}, 1 \mathrm{H}, 2)$. Other important interactions in the 1D NOESY include the coupling of the proton at $1.59 \mathrm{ppm}(\mathrm{m}, 1 \mathrm{H}, 1 / 2$ of 6$)$ with the $\mathrm{CH}$ at 1.44 $\operatorname{ppm}(\mathrm{m}, 1 \mathrm{H}, 4)$. This interaction with 4 is key, because it shows that the methyl group 5 is facing into the page as illustrated in the major diastereomer above. 2D NOESY data shown below was used to further corroborate this analysis and rule out the other possible orientation. 


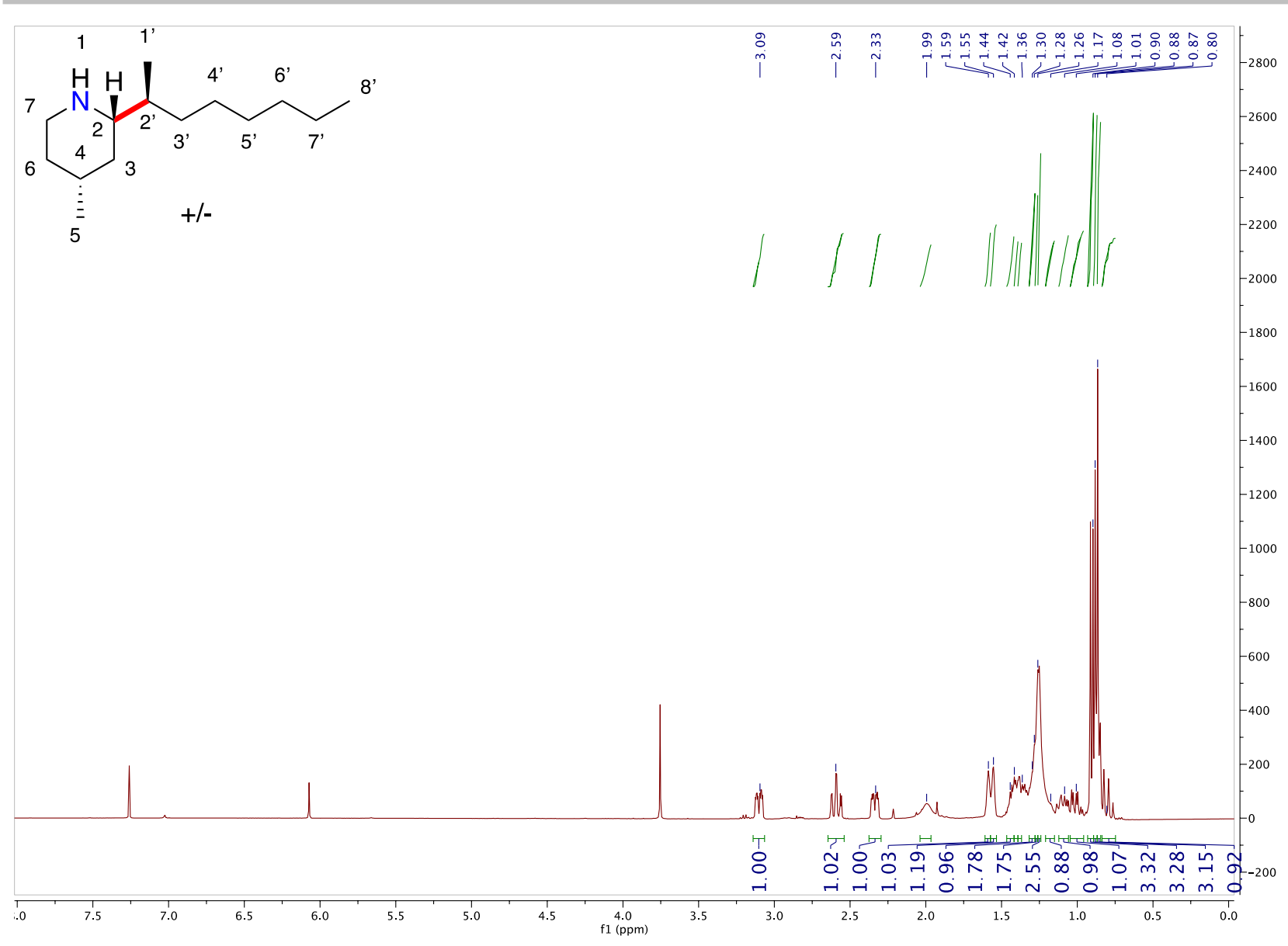

Figure S47: ${ }^{1} \mathrm{H}$ NMR spectrum $\left(400 \mathrm{MHz}, \mathrm{CDCl}_{3}, 298 \mathrm{~K}\right.$ ) of 4-methyl-2-(octan-2-yl)piperidine. 


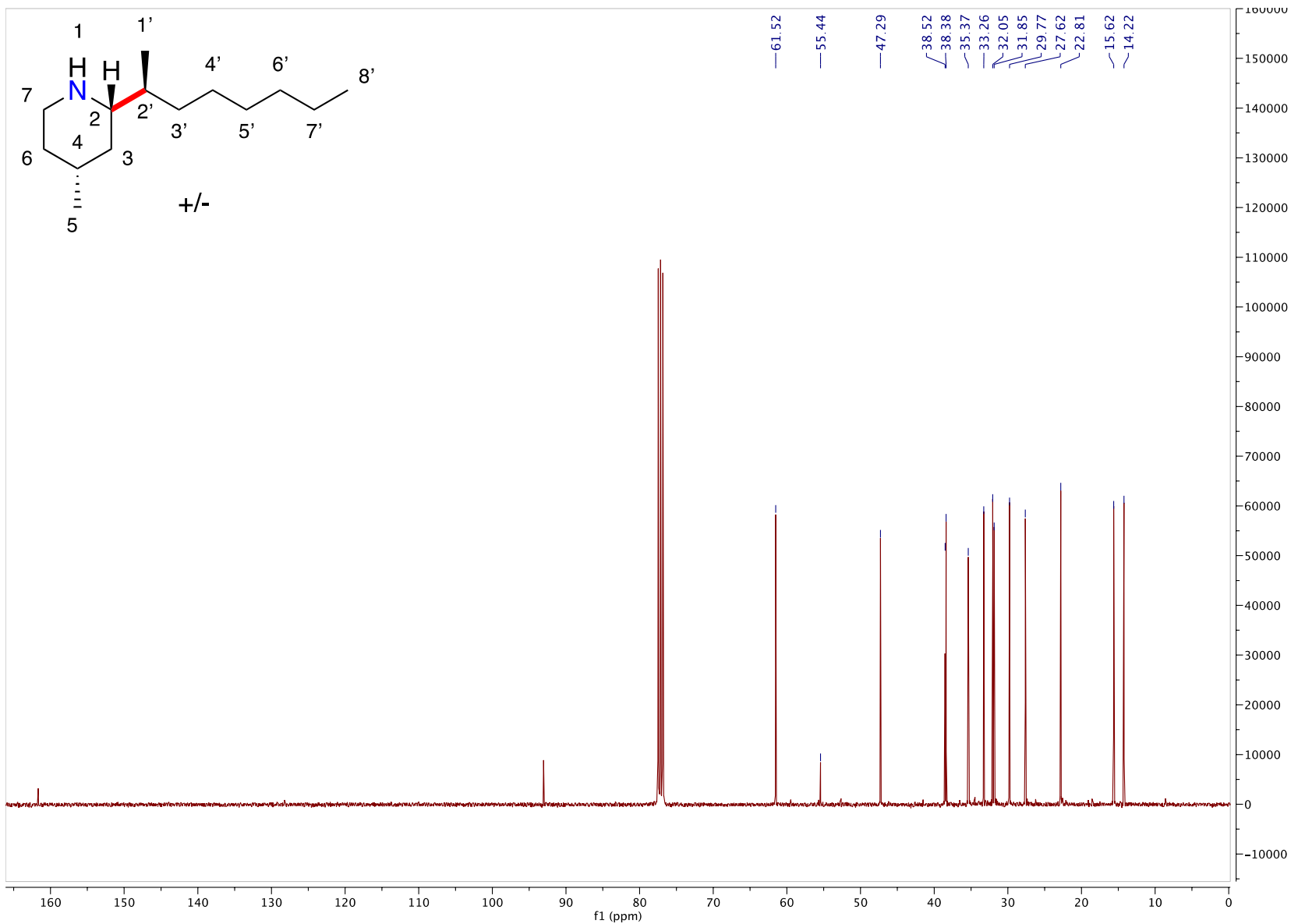

Figure S48: ${ }^{13} \mathrm{C}$ NMR spectrum $\left(101 \mathrm{MHz}, \mathrm{CDCl}_{3}, 298 \mathrm{~K}\right)$ of 4-methyl-2-(octan-2-yl)piperidine.

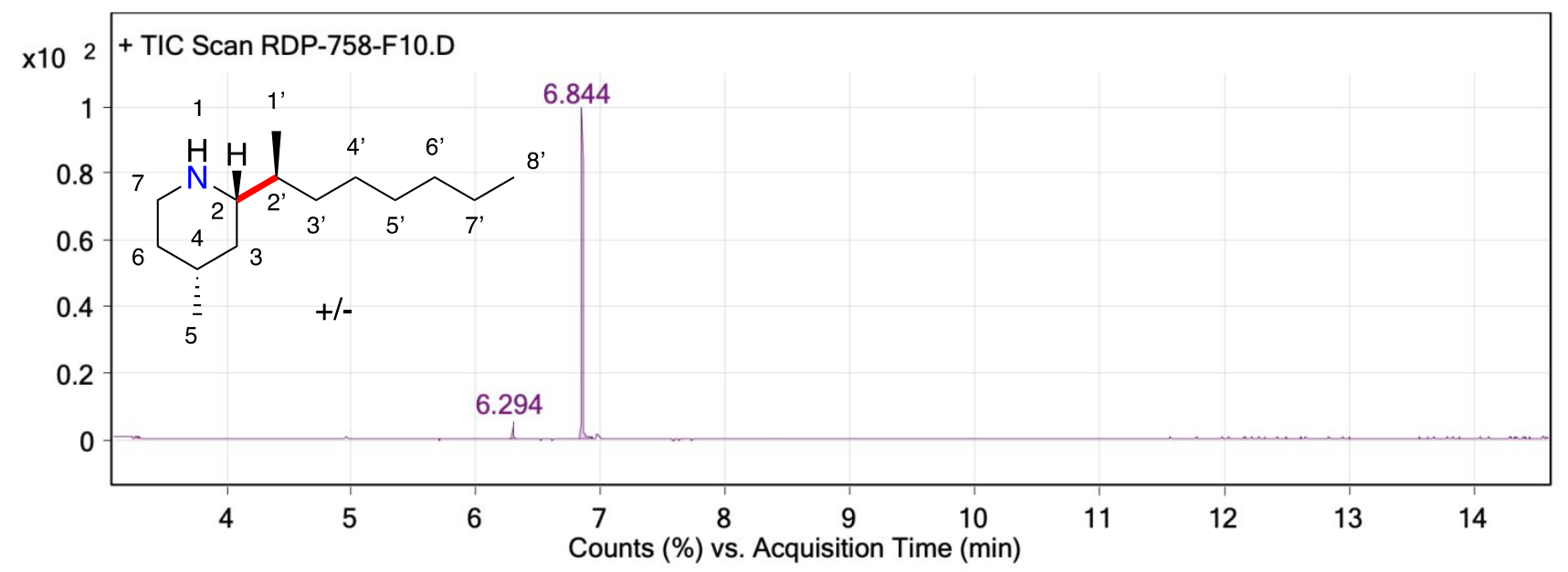

Figure S49: GC-MS report of 4-methyl-2-(octan-2-yl)piperidine. 


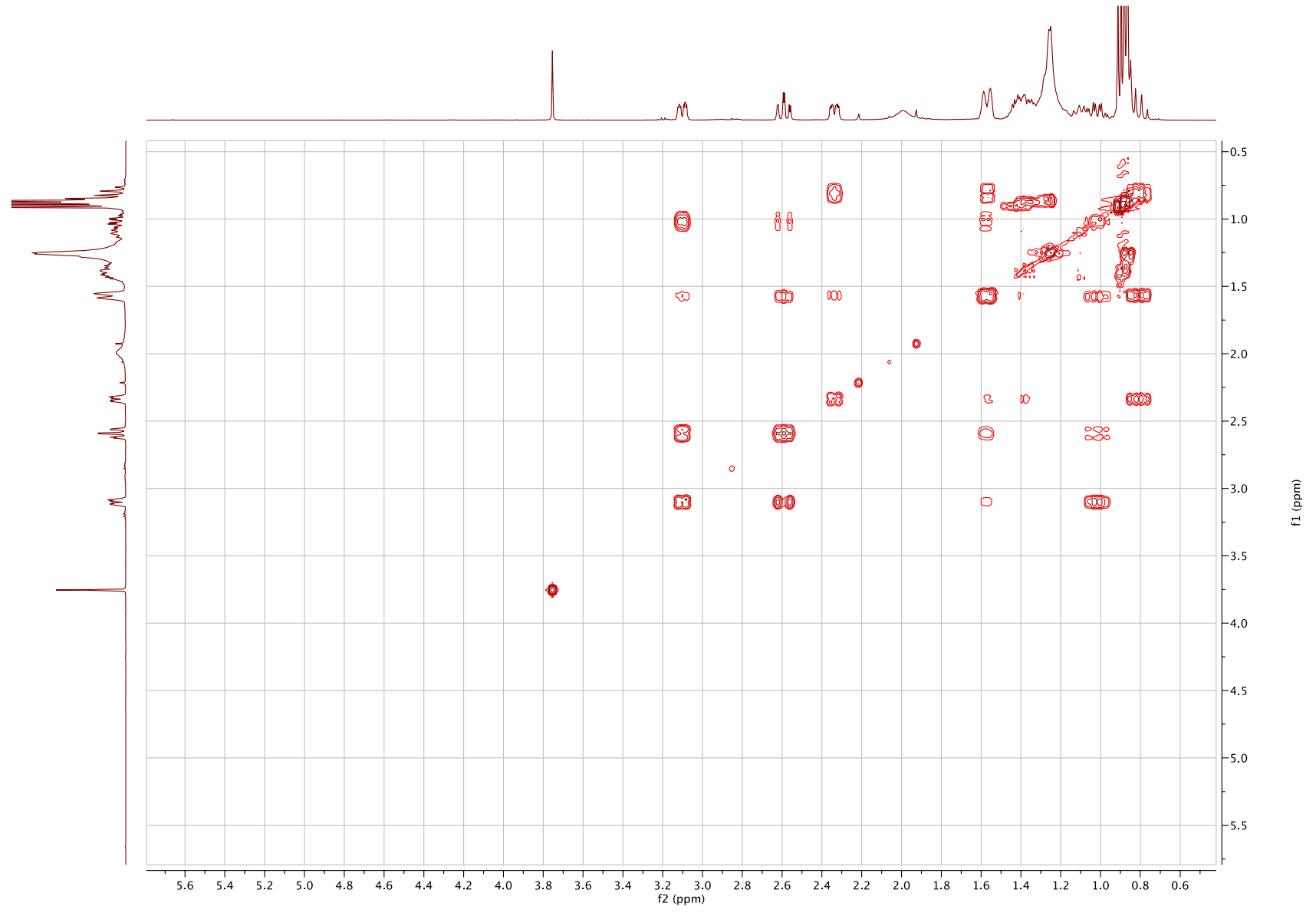

Figure S50: COSY spectrum (400 MHz, $\mathrm{CDCl}_{3}, 298 \mathrm{~K}$ ) of 4-methyl-2-(octan-2-yl)piperidine. 


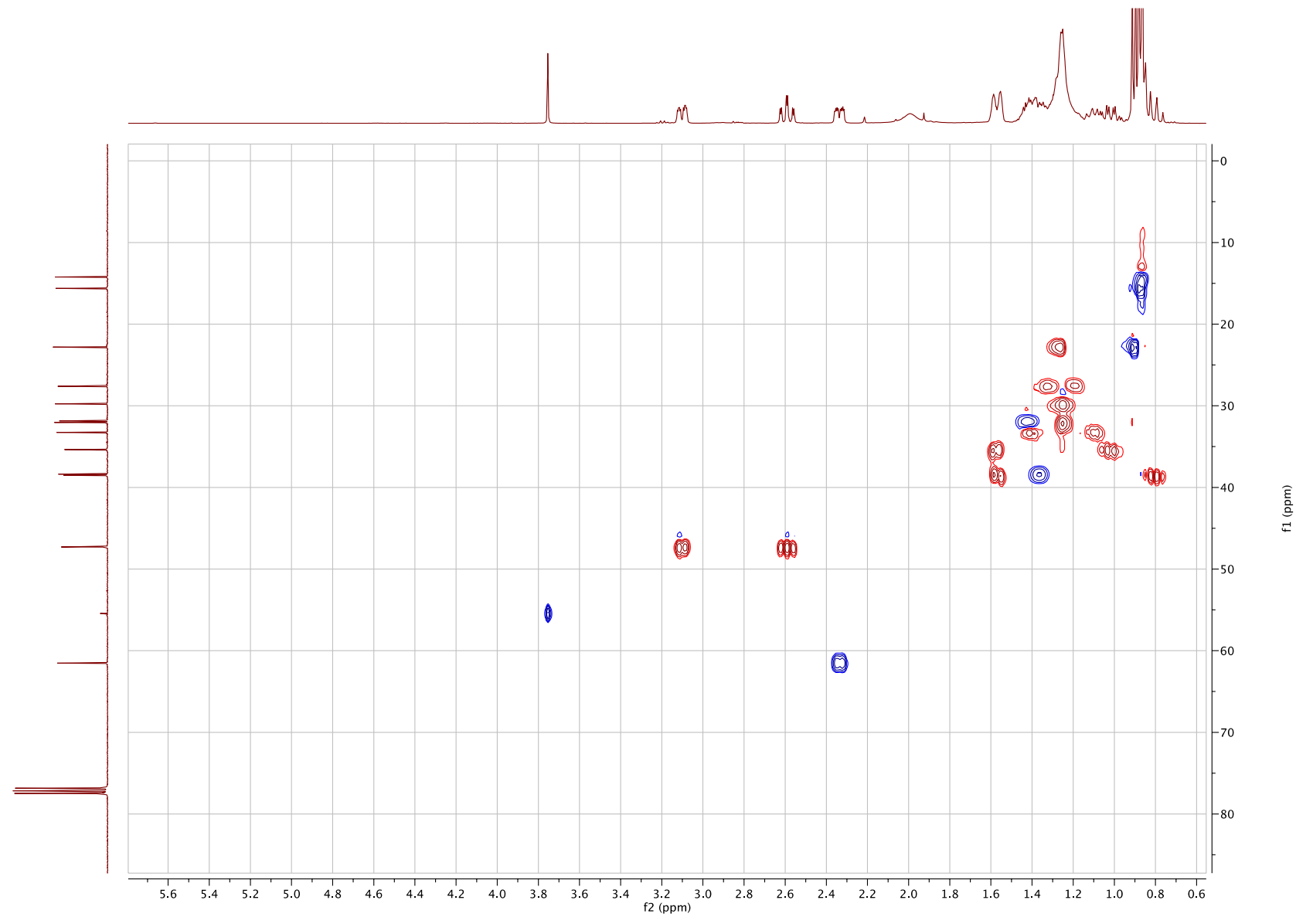

Figure S51: HSQC spectrum (400 and $101 \mathrm{MHz}, \mathrm{CDCl}_{3}, 298 \mathrm{~K}$ ) of 4-methyl-2-(octan-2-yl)piperidine. 


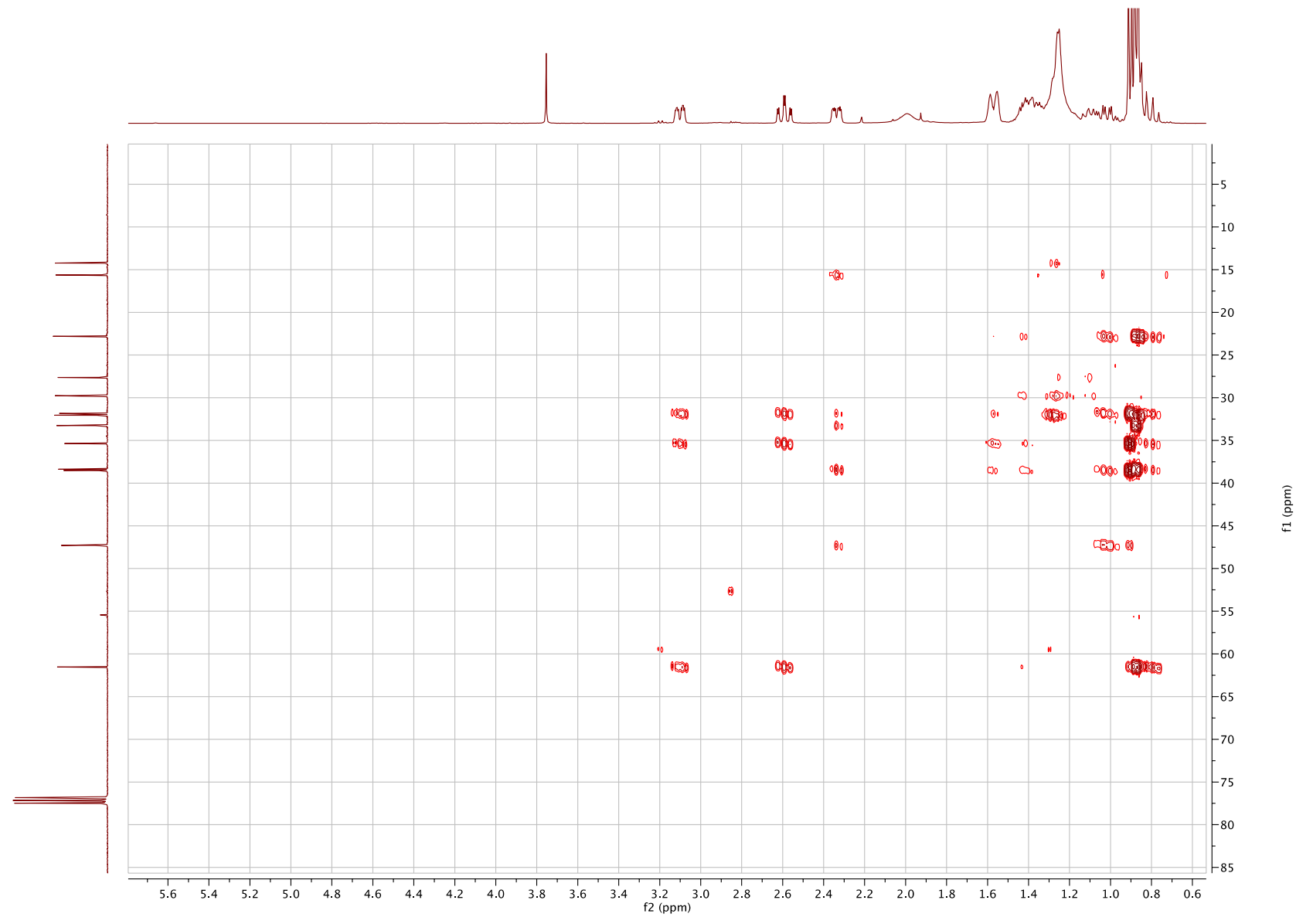

Figure S52: $\mathrm{HMBC}$ spectrum (400 and $101 \mathrm{MHz}, \mathrm{CDCl}_{3}, 298 \mathrm{~K}$ ) of 4-methyl-2-(octan-2-yl)piperidine. 


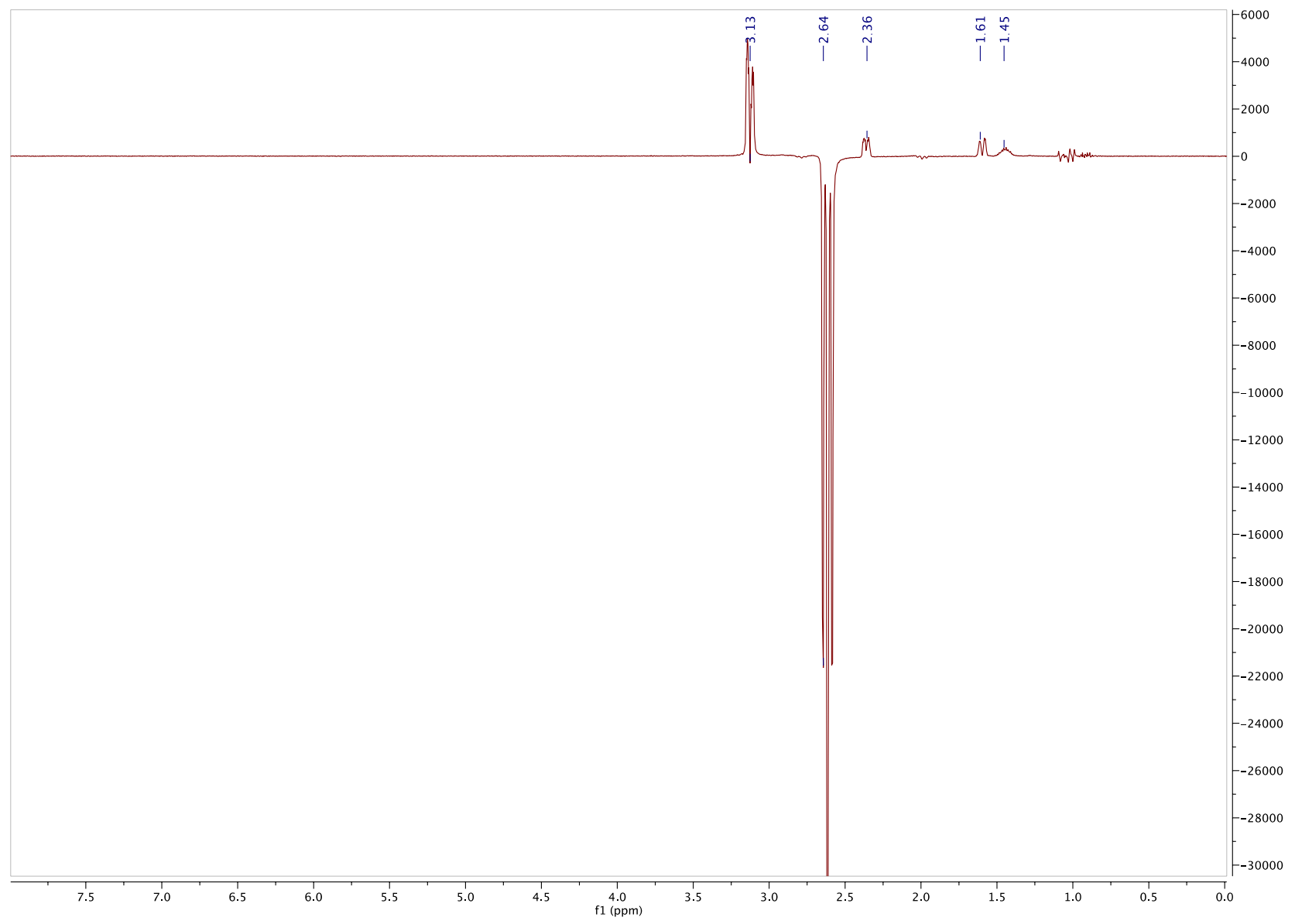

Figure S53: 1D NOE spectrum (400 MHz, $\mathrm{CDCl}_{3}, 298 \mathrm{~K}$ ) of 4-methyl-2-(octan-2-yl)piperidine. 


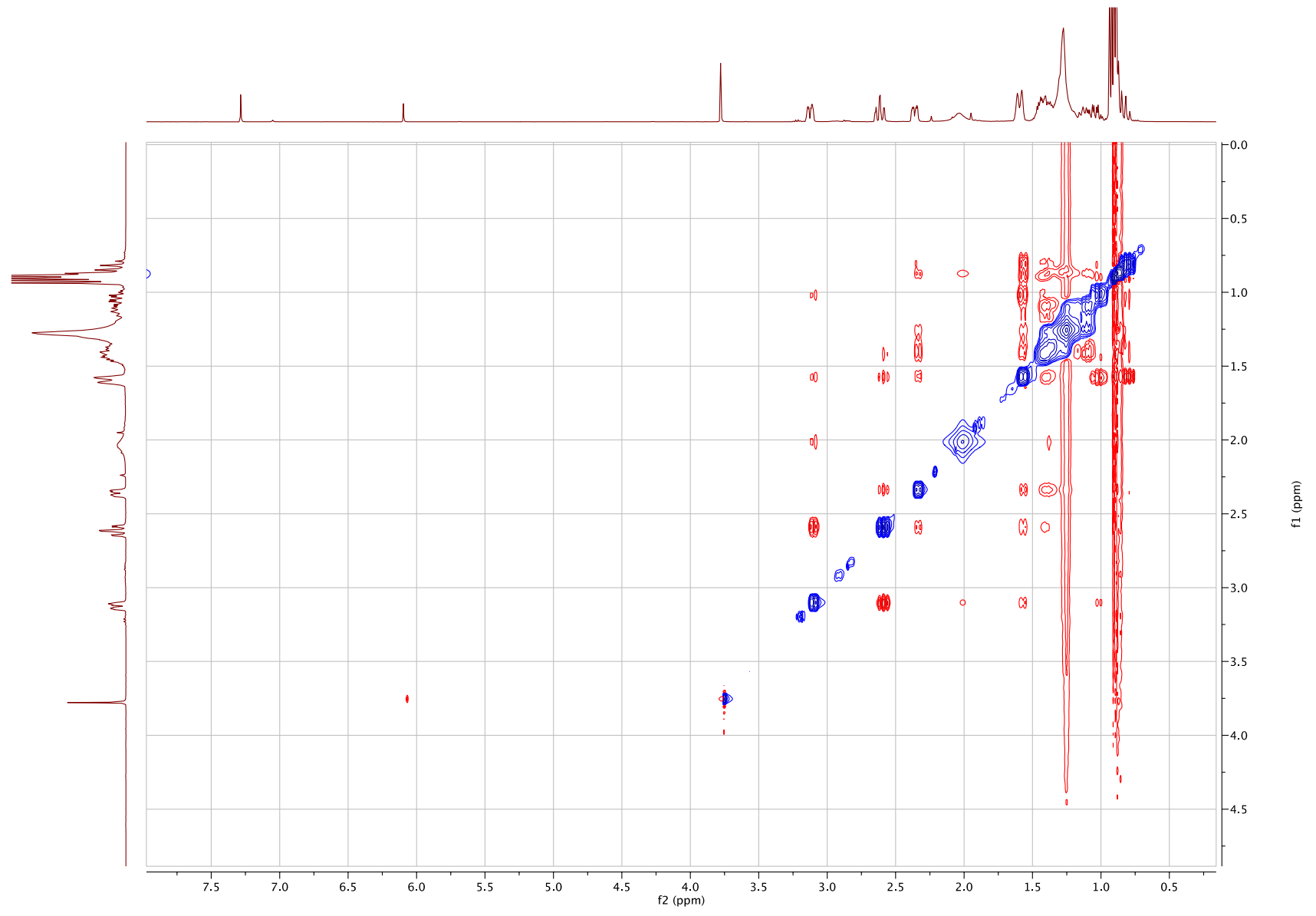

Figure S54: 2D NOESY spectrum (400 MHz, $\left.\mathrm{CDCl}_{3}, 298 \mathrm{~K}\right)$ of 4-methyl-2-(octan-2-yl)piperidine.

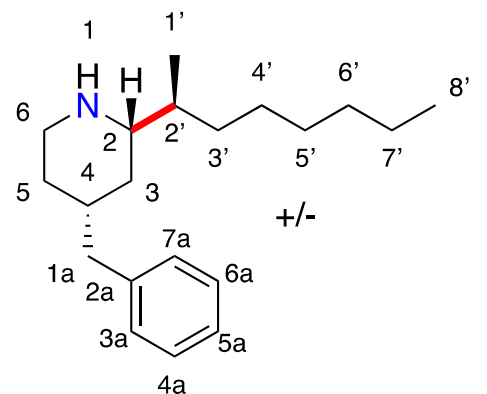
6), $2.60(\mathrm{~m}, 1 \mathrm{H}, 4), 2.55(\mathrm{~m}, 1 \mathrm{H}, 2), 1.75(\mathrm{~m}, 1 \mathrm{H}, 1 / 2$ of 3$), 1.71(\mathrm{~m}, 1 \mathrm{H}, 1 / 2$ of $5 / 3$ '), $1.67(\mathrm{~m}, 1 \mathrm{H}, 1 / 2$ of 5/3'), $1.61\left(\mathrm{~m}, 1 \mathrm{H}, 1 / 25 / 3^{\prime}\right), 1.51\left(\mathrm{~m}, 1 \mathrm{H}, 2^{\prime}\right), 1.37\left(\mathrm{~m}, 1 \mathrm{H}, 1 / 25 / 3^{\prime}\right) 1.33(\mathrm{~m}, 2 \mathrm{H}, 1 \mathrm{a}), 1.30$ (m, 2H, 4'/5'/6'/7'), 1.29 (m, 2H, 4'/5'/6'/7'), 1.26 (m, 2H, 4'/5'/6'/7'), 1.23 (m, 2H, 4'/5'/6'/7'), 1.17 (m, 1H, 1/2 of 3), 0.98 (d, J = 0.98, 3H, 1'), 0.91 (t, 3H, 8') ppm. ${ }^{13} \mathrm{C}$ NMR $\left(\mathrm{CDCl}_{3}, 101 \mathrm{MHz}, 298 \mathrm{~K}\right): \delta \mathrm{ppm}$. HRMS

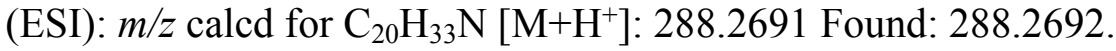

Synthesis of 4-benzyl-2-(octan-2-yl)piperidine (8): Prepared following the general procedure for predominantly branched product formation: 26.0 $\mathrm{mg}$ Ta, $15.2 \mathrm{mg}$ ligand L4, 4-benzylpiperazine (175.3 mg, $1.0 \mathrm{mmol}$ ), 1octene $(112.22 \mathrm{mg}, 1.0 \mathrm{mmol})$. The reaction was subsequently concentrated and the yield was determined to be $84 \%$ by NMR $(1,3,5-$ trimethoxybenzene as a standard). Purification via column chromatography (7:2.5:0.5 hexanes : ethyl acetate : triethyl amine): ${ }^{1} \mathrm{H}$ NMR $\left(\mathrm{CDCl}_{3}, 400\right.$ $\mathrm{MHz}, 298 \mathrm{~K}): \delta 7.31(\mathrm{~m}, 2 \mathrm{H}, 4 \mathrm{a}$ and $6 \mathrm{a}), 7.23(\mathrm{~m}, 1 \mathrm{H}, 5 \mathrm{a}), 7.18(\mathrm{~m}, 2 \mathrm{H}, 3 \mathrm{a}$ and $7 \mathrm{a}), 3.58$ (broad s, 1H, NH), $3.30(\mathrm{~m}, 1 \mathrm{H}, 1 / 2$ of 6$), 2.68(\mathrm{~m}, 1 \mathrm{H}, 1 / 2$ of 


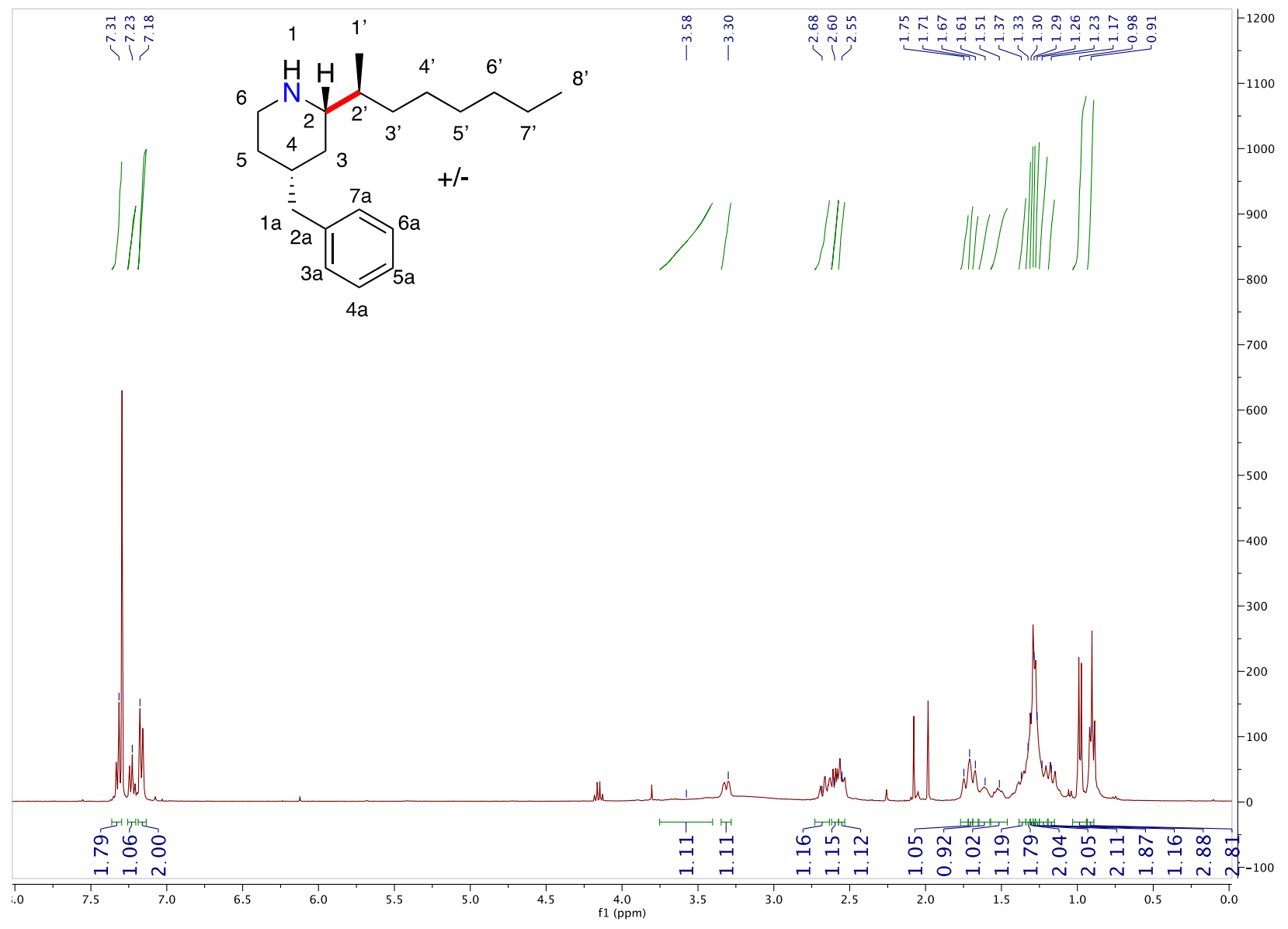

Figure S55: ${ }^{1} \mathrm{H}$ NMR spectrum (400 MHz, $\mathrm{CDCl}_{3}, 298 \mathrm{~K}$ ) of 4-benzyl-2-(octan-2-yl)piperidine. 


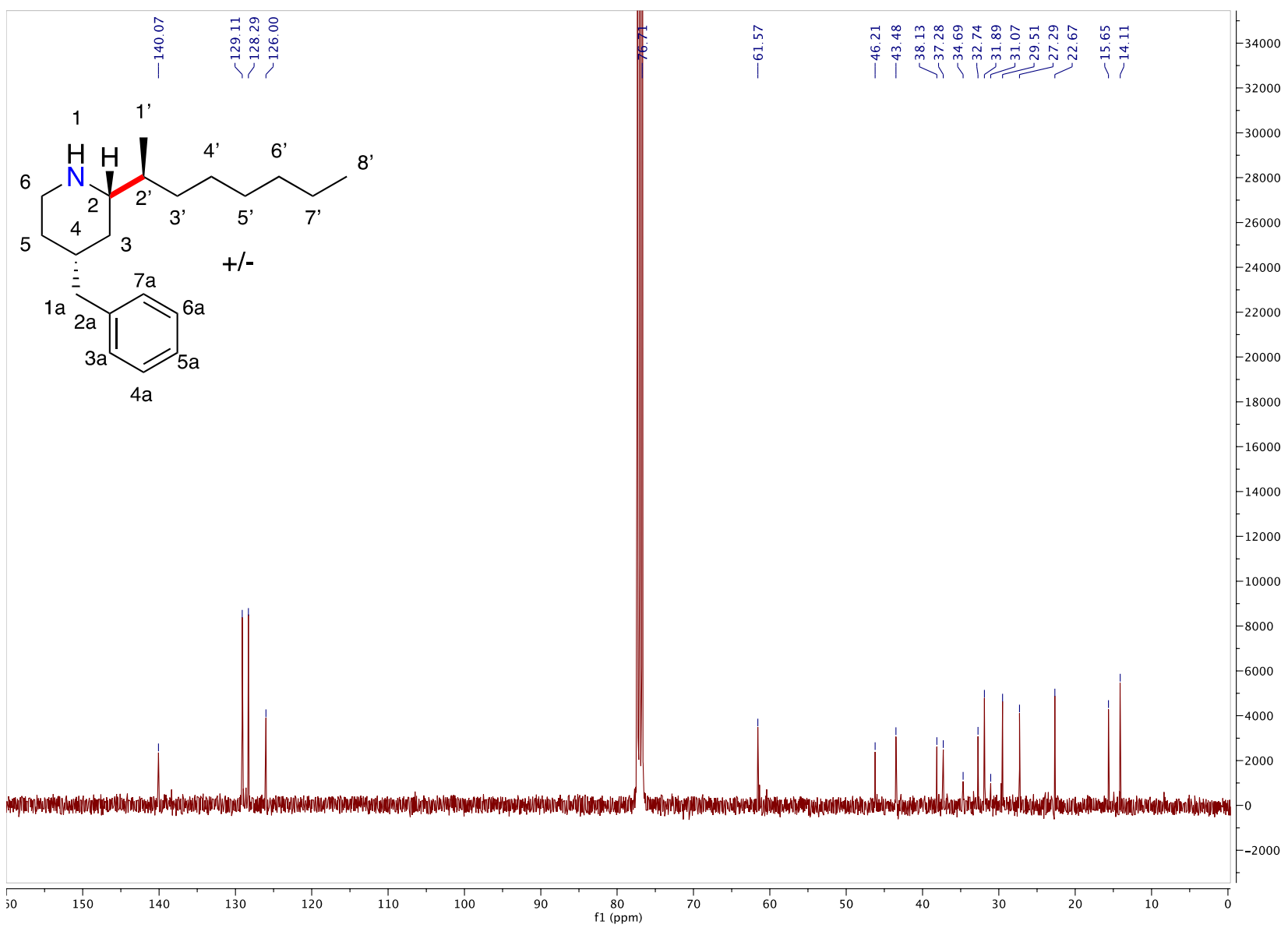

Figure S56: ${ }^{13} \mathrm{C}$ NMR spectrum $\left(101 \mathrm{MHz}, \mathrm{CDCl}_{3}, 298 \mathrm{~K}\right)$ of 4-benzyl-2-(octan-2-yl)piperidine.

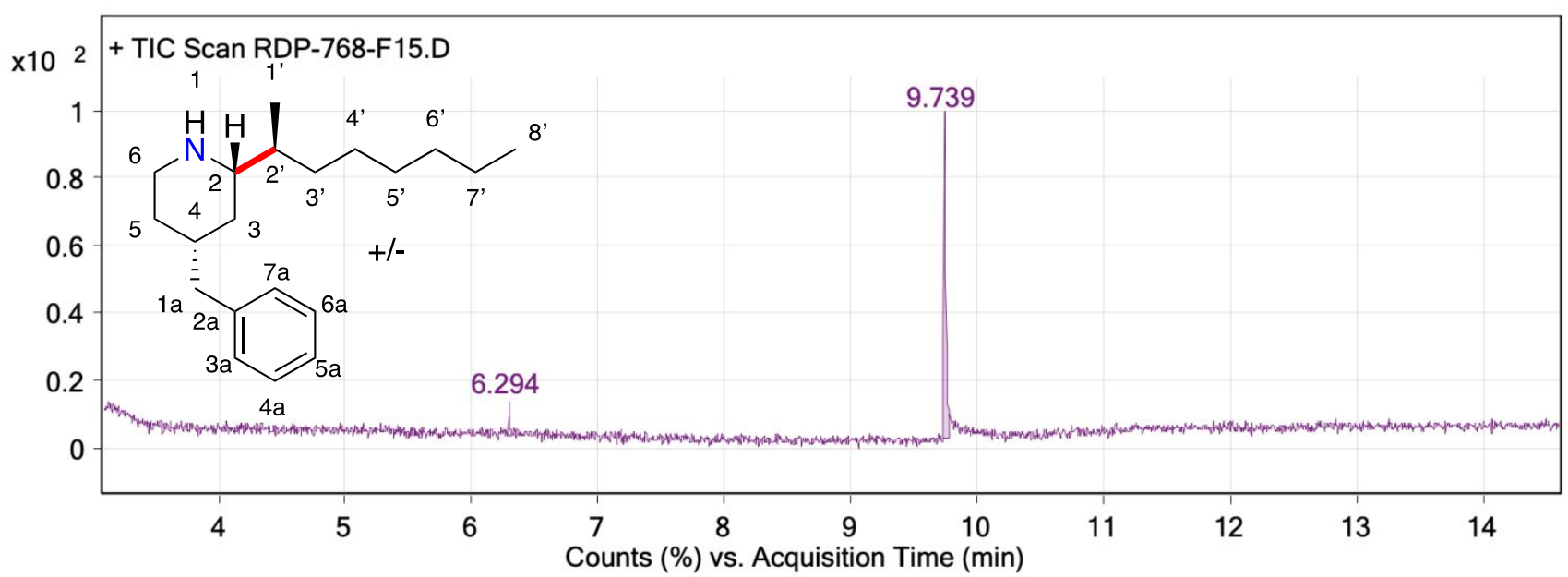

Figure S57: GC-MS report of 4-benzyl-2-(octan-2-yl)piperidine.

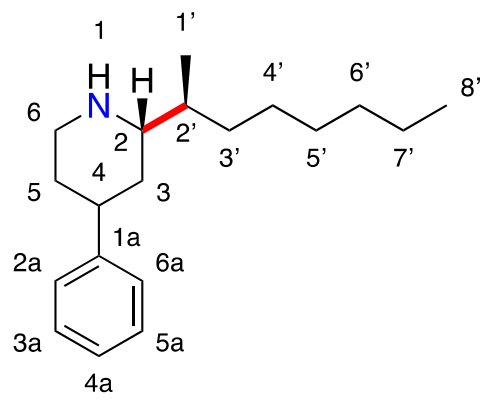

Synthesis of 2-(octan-2-yl)-4-phenylpiperidine (9): Prepared following the general procedure for predominantly branched product formation: 26.0 $\mathrm{mg}$ Ta, $15.2 \mathrm{mg}$ ligand L4, 4-phenylpiperidine (307 mg, $1.0 \mathrm{mmol}$ ), 1- 
octene $(250.2 \mathrm{mg}, 1.0 \mathrm{mmol})$. The reaction was subsequently concentrated and the yield was determined to be $99 \%$ by NMR (1,3,5-trimethoxybenzene as a standard). Purification via column chromatography (7:2.5:0.5 hexanes : ethyl acetate : triethyl amine): ${ }^{1} \mathrm{H}$ NMR $\left(\mathrm{CDCl}_{3}, 400 \mathrm{MHz}, 298 \mathrm{~K}\right): \delta 7.31(\mathrm{~m}, 2 \mathrm{H}$, 3a and 5a), $7.24(\mathrm{~m} \mathrm{2H}, 2 \mathrm{a}$ and $6 \mathrm{a}), 7.20(\mathrm{~m}, 1 \mathrm{H}, 4 \mathrm{a}), 3.26(\mathrm{~m} \mathrm{1H}, 1 / 2$ of 6$), 2.79(\mathrm{~m}, 1 \mathrm{H}, 1 / 2$ of 6$), 2.61(\mathrm{~m}$, $1 \mathrm{H}, 4), 2.53(\mathrm{~m}, 1 \mathrm{H}, 2), 1.90$ (broad s, $1 \mathrm{H}, \mathrm{NH}), 1.83(\mathrm{~m}, 1 \mathrm{H}, 1 / 2 \mathrm{of} 3), 1.80(\mathrm{~m}, 1 \mathrm{H}, 1 / 2$ of 5$), 1.64(\mathrm{~m}, 1 \mathrm{H}$, $1 / 2$ of 5$), 1.49$ (m, $1 \mathrm{H}, 1 / 2$ of $\left.4^{\prime}\right), 1.44\left(\mathrm{~m} 1 \mathrm{H}, 2^{\prime}\right), 1.39$ (m, $1 \mathrm{H}, 1 / 2$ of 3$), 1.32\left(\mathrm{~m}, 1 \mathrm{H}, 1 / 2\right.$ of $\left.3^{\prime}\right), 1.28(\mathrm{~m}, 2 \mathrm{H}$, 5'/6'/7'), 1.26 (m, 2H, 5'/6'/7'), 1.24 (m, 2H, 5'/6'/7'), 1.21 (m, 1H, 1/2 of 3'), 1.14 (m, 1H, 1/2 of 4'), 0.92 (d, J = 0.93, 3H, 1'), 0.88 (overlapping t, 3H, 8') ppm. ${ }^{13} \mathrm{C} \mathrm{NMR}\left(\mathrm{CDCl}_{3}, 101 \mathrm{MHz}, 298 \mathrm{~K}\right): \delta 146.99$, $128.56,127.00,126.23,61.89,47.51,43.56,38.46,37.68,34.12$, 33.23, 32.03, 29.76, 27.62, 22.80, 15.67, 14.23 ppm. HRMS (ESI): $m / z$ calcd for $\mathrm{C}_{19} \mathrm{H}_{31} \mathrm{~N}\left[\mathrm{M}^{+}\right]$: 273.2456 Found: 273.2464 .

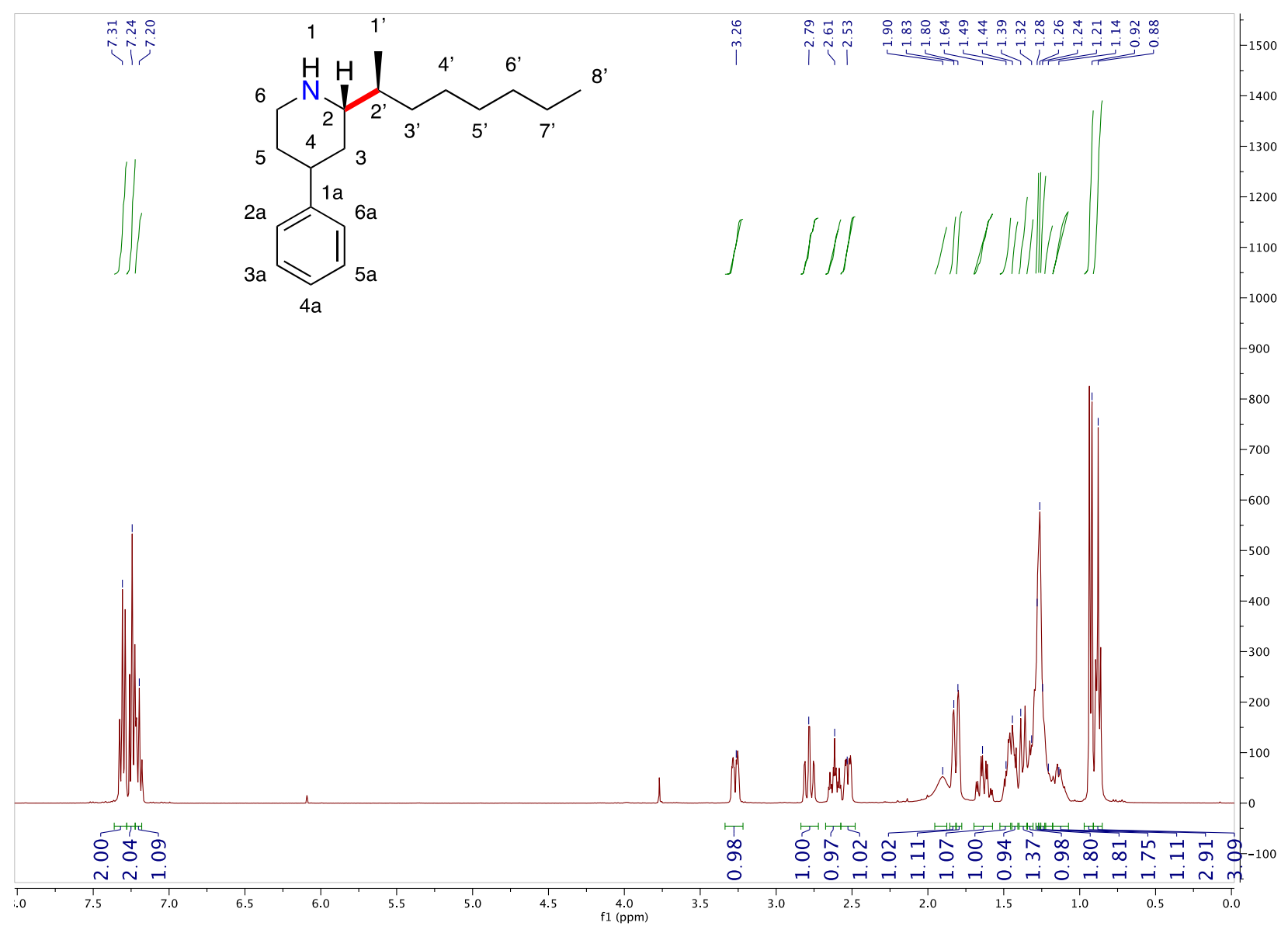

Figure S58: ${ }^{1} \mathrm{H}$ NMR spectrum (400 MHz, $\mathrm{CDCl}_{3}, 298 \mathrm{~K}$ ) of 2-(octan-2-yl)-4-phenylpiperidine. 


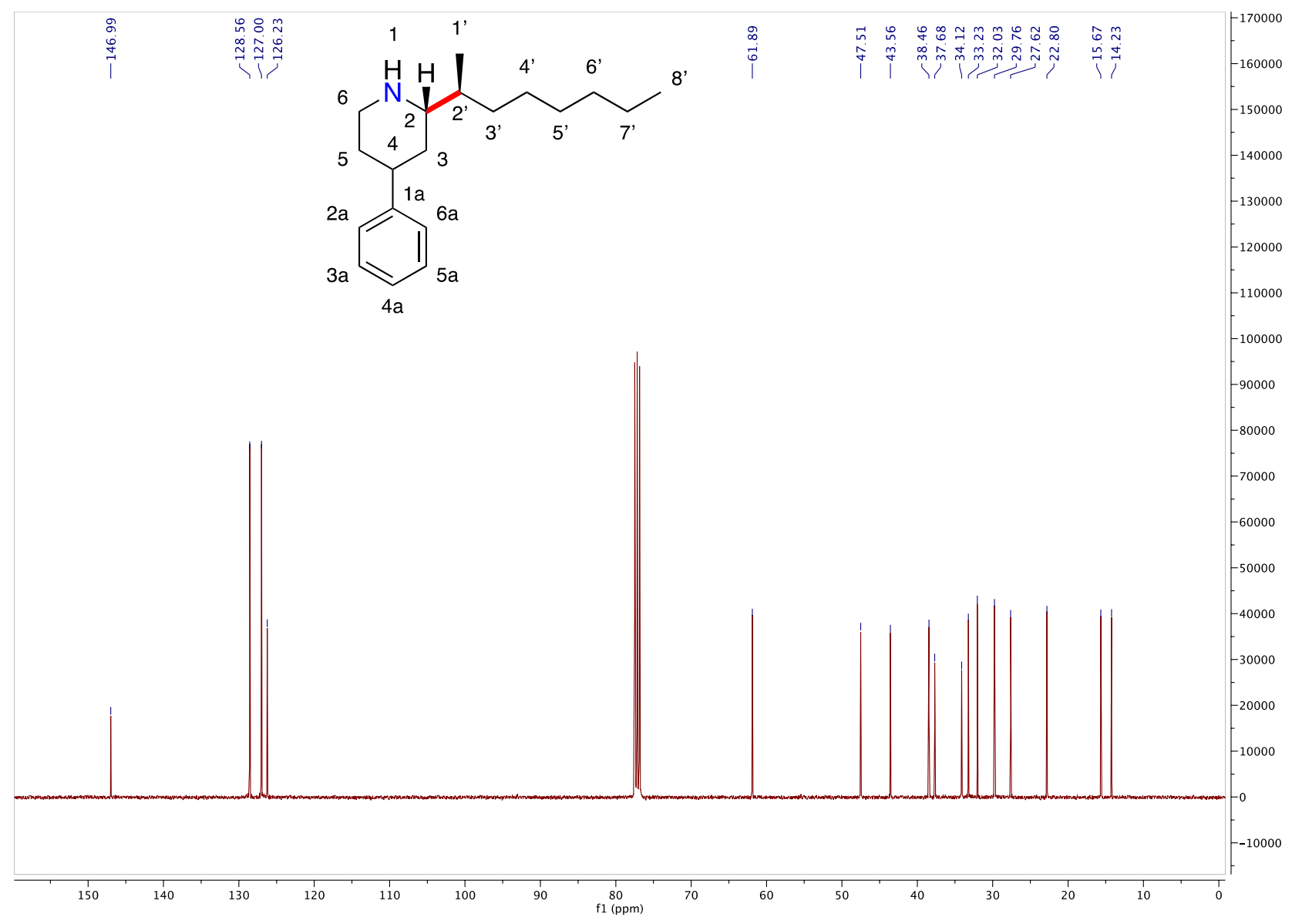

Figure S59: ${ }^{13} \mathrm{C}$ NMR spectrum $\left(101 \mathrm{MHz}, \mathrm{CDCl}_{3}, 298 \mathrm{~K}\right)$ of 2-(octan-2-yl)-4-phenylpiperidine.

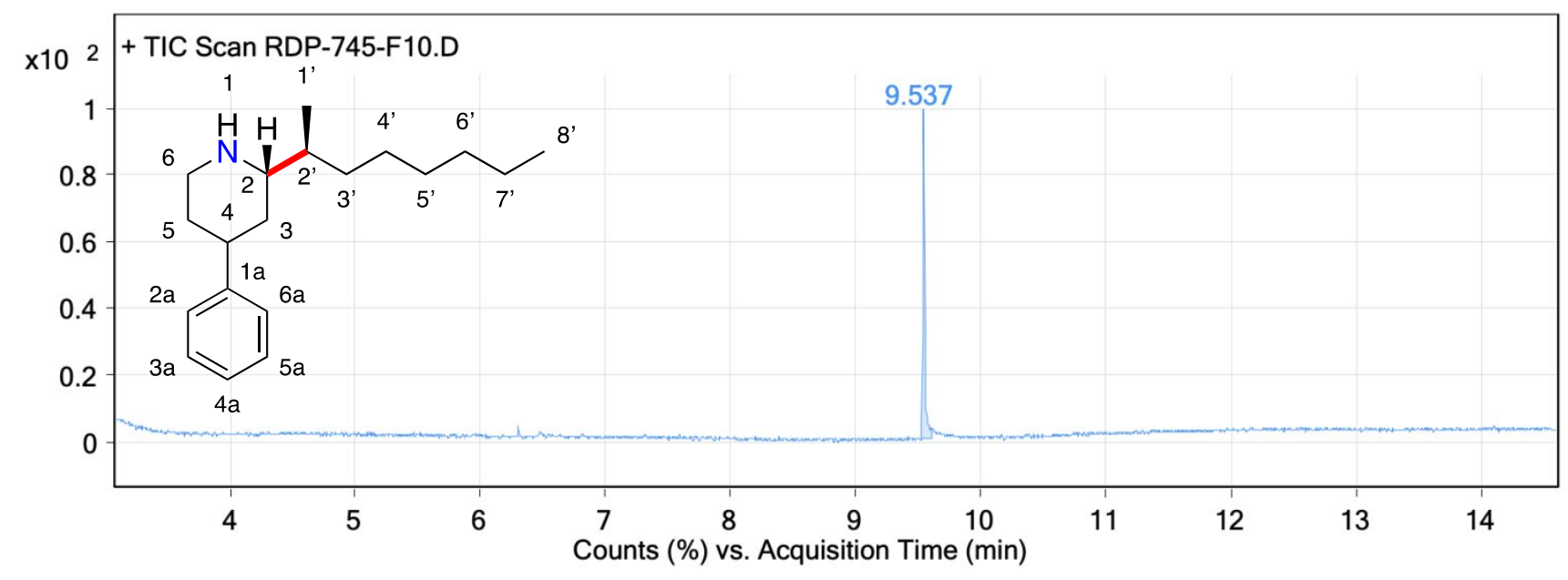

Figure S60: GC-MS report of 2-(octan-2-yl)-4-phenylpiperidine. 


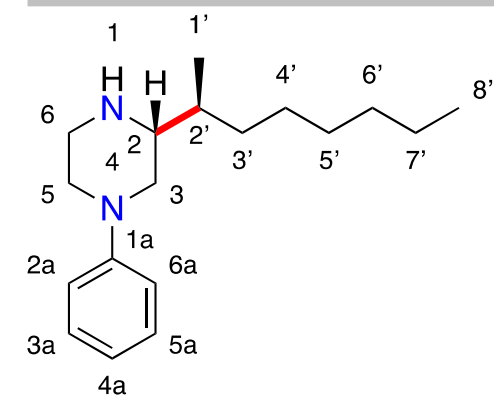

Synthesis of 3-(octan-2-yl)-1-phenylpiperazine (10): Prepared following

8 the general procedure for predominantly branched product formation: 26.0 mg Ta, 15.2 ligand L4, 4-phenylpiperazine (162.24 mg, $1.0 \mathrm{mmol}$ ), 1octene $(112.22 \mathrm{mg}, 1.0 \mathrm{mmol})$. The reaction was subsequently concentrated and the yield was determined to be $48 \%$ by NMR $(1,3,5-$ trimethoxybenzene as a standard). Purification via column chromatography (7:2.5:0.5 hexanes : ethyl acetate : triethyl amine). The chemical shifts for the title compound match those reported in the literature. ${ }^{8}$

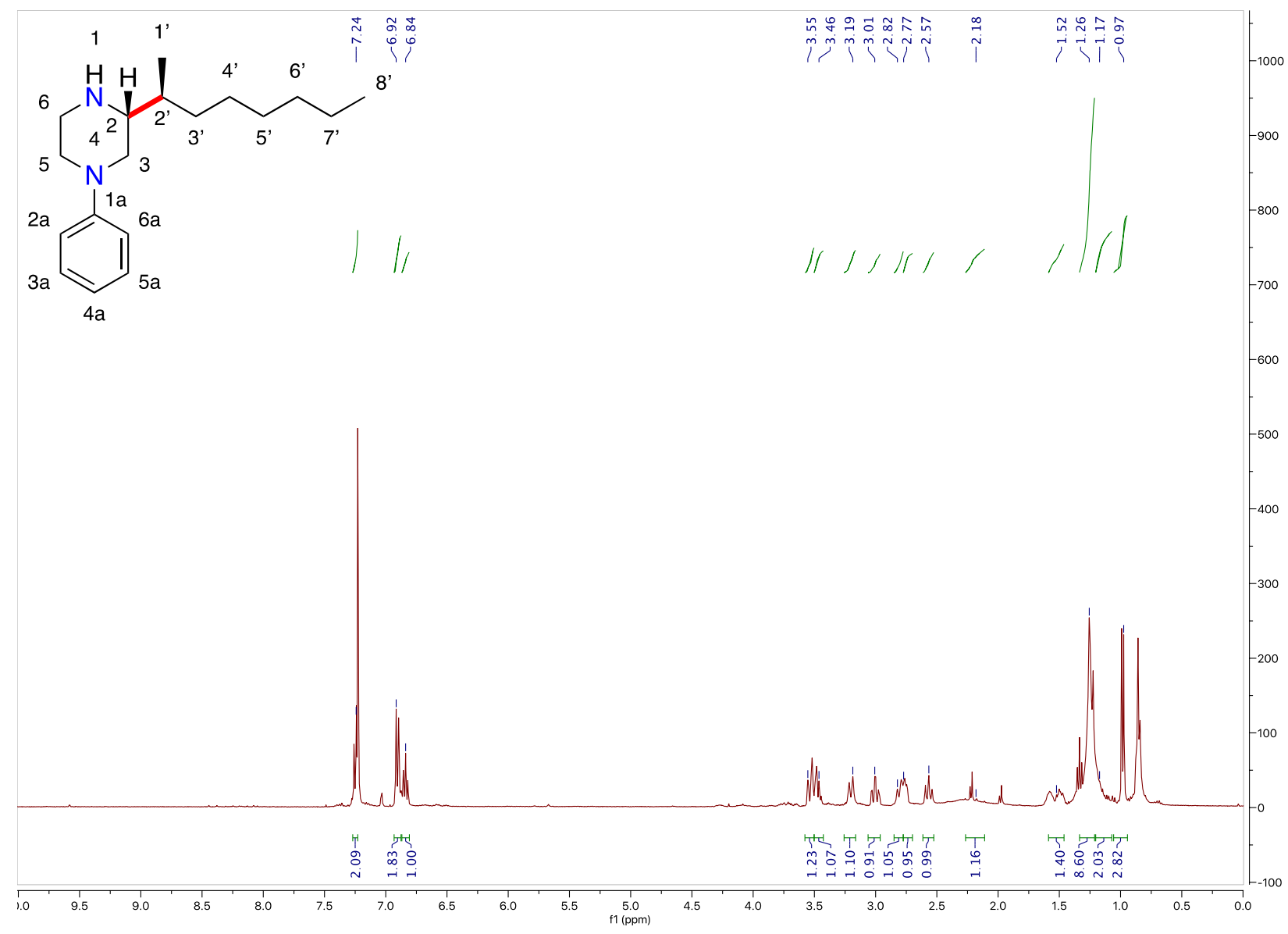

Figure S61: ${ }^{1} \mathrm{H}$ NMR spectrum $\left(400 \mathrm{MHz}, \mathrm{CDCl}_{3}, 298 \mathrm{~K}\right)$ of 3-(octan-2-yl)-1-phenylpiperazine.

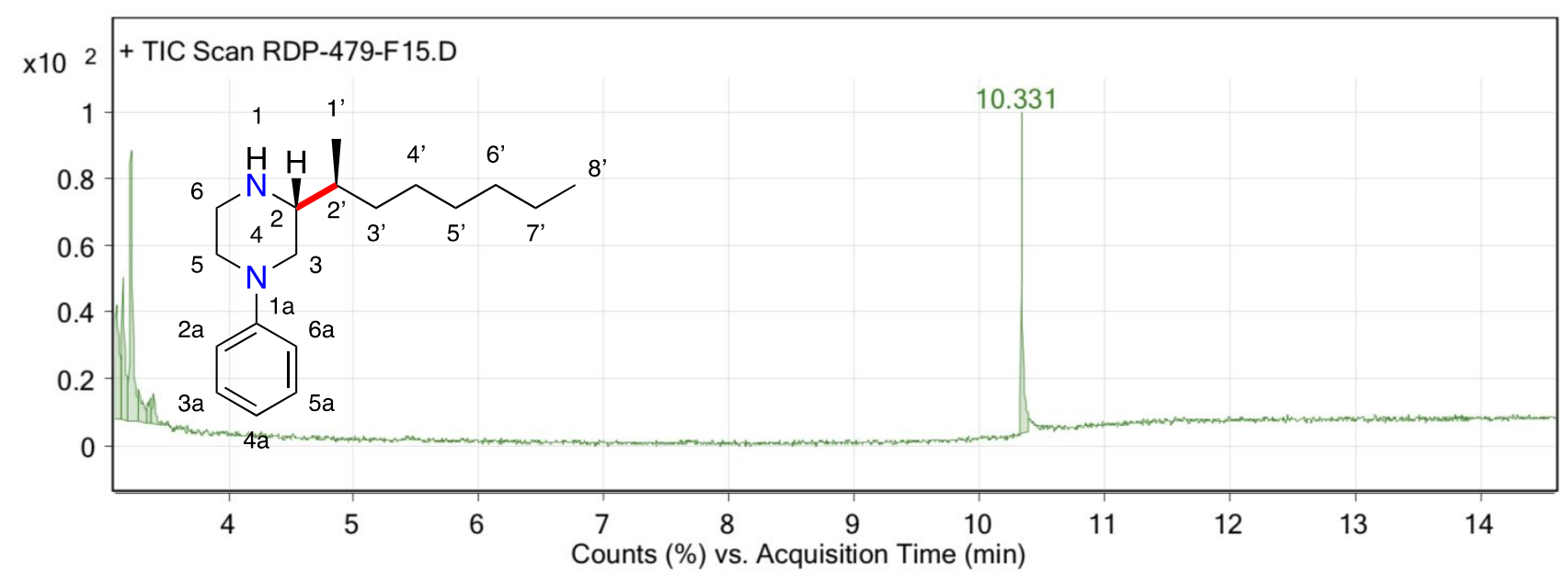


Figure S62: GC-MS report of 3-(octan-2-yl)-1-phenylpiperazine.

\section{S7. Synthesis and Characterization of Alkene Scope Products}

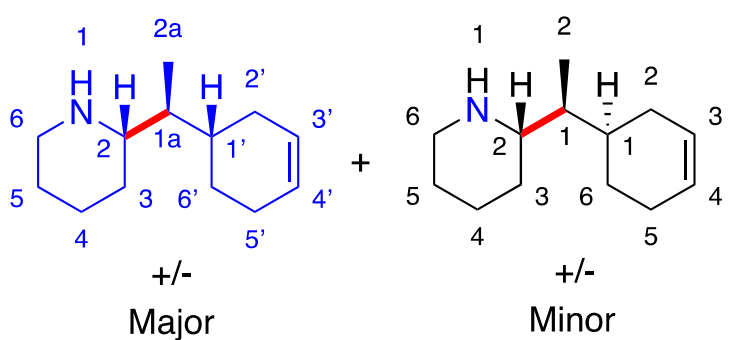

Synthesis of 2-(1-(cyclohex-3-en-1-yl)ethyl)piperidine (11): Prepared following the general procedure for predominantly branched product formation: $26.0 \mathrm{mg} \mathrm{Ta}$, $15.2 \mathrm{mg}$ ligand $\mathbf{L 4}$, piperidine $(85.15 \mathrm{mg}, 1.0 \mathrm{mmol})$, vinylcyclohexene $(108.18 \mathrm{mg}, 1.0 \mathrm{mmol})$. The reaction was subsequently concentrated and the yield was determined to be $99 \% \quad(2.7: 1$ major-minor $)$ by NMR (1,3,5trimethoxybenzene as a standard). Purification via column chromatography $(7: 2.5: 0.5$ hexanes : ethyl acetate : triethyl amine) yields a mixture of diastereomers $(2.7: 1)$ that could only be separated in small amounts, see below.: ${ }^{1} \mathrm{H} \mathrm{NMR}\left(\mathrm{CDCl}_{3}, 400 \mathrm{MHz}, 298 \mathrm{~K}\right): \delta 5.63\left(\mathrm{~m}, 2 \mathrm{H}, 3\right.$ ' and 4' and $3^{\prime}$ ' and $\left.4^{\prime}\right), 3.09\left(\mathrm{~m}, 1 \mathrm{H},{ }^{1 / 2}\right.$ of 6 and 6$), 2.57(\mathrm{~m}, 1 \mathrm{H}, 1 / 2$ of 6 and 6$), 2.47(\mathrm{~m}, 1 \mathrm{H}, 2$ and 2$), 2.03\left(\mathrm{~m}, 1.08 \mathrm{H}, 5^{\prime}\right), 1.96\left(\mathrm{~m}, 1 \mathrm{H}, 1 / 2\right.$ of $\left.5^{\prime}\right)$, $1.89\left(\mathrm{~m}, 1 \mathrm{H}, 1 / 2\right.$ of $2^{\prime}$ and $\left.2^{\prime}\right), 1.81\left(\mathrm{~m}, 0.95 \mathrm{H}, 1 / 2\right.$ of $\left.5^{\prime}\right), 1.75(\mathrm{~m}, 1 \mathrm{H}, 1 / 2$ of 4 and 4$), 1.69\left(\mathrm{~m}, 1 \mathrm{H}, 1 / 2\right.$ of $2^{\prime}$ and $\left.2^{\prime}\right), 1.63\left(\mathrm{~m}, 1 \mathrm{H}, 1 / 2\right.$ of $1^{\prime}$ and $\left.1^{\prime}\right), 1.60\left(\mathrm{~m}, 1 \mathrm{H}, 1 / 2\right.$ of $6^{\prime}$ and $\left.6^{\prime}\right), 1.57(\mathrm{~m}, 1 \mathrm{H}, 1 / 2$ of 3 and 3$), 1.54(\mathrm{~m}$, $1 \mathrm{H}, 1 / 2$ of 5 and 5$), 1.39(\mathrm{~m}, 1 \mathrm{H}, 1 / 2$ of 4 and 4$), 1.34\left(\mathrm{~m}, 1 \mathrm{H}, 1 / 2\right.$ of $6^{\prime}$ and $\left.6^{\prime}\right), 1.28(\mathrm{~m}, 1 \mathrm{H}, 1 / 2$ of 5 and 5$)$, 
$1.23(\mathrm{~m}, 1 \mathrm{H}, 1 \mathrm{a}$ and $1 \mathrm{a}), 1.17(\mathrm{~m}, 1 \mathrm{H}, 1 / 2$ of 3 and 3$), 0.86(\mathrm{~d}, \mathrm{~J}=0.95,3 \mathrm{H}, 2 \mathrm{a}), 0.84(\mathrm{~d}, 0.57 \mathrm{H}, 2 \mathrm{a}), \mathrm{ppm}$. ${ }^{13} \mathrm{C} \mathrm{NMR}\left(\mathrm{CDCl}_{3}, 101 \mathrm{MHz}, 298 \mathrm{~K}\right): \delta 127.15$ (major and minor), 127.05 (major and minor), 126. 91 (major and minor), 58.98 (major and minor), 47.70 (major), 47.67 (minor), 43.17 (major), 42.71 (minor), 35.26 (minor), 35.11 (minor), 31.19 (minor), 31.12 (major), 30.73 (major and minor), 27.81 (major), 27.69 (minor), 26.80 (minor), 26.76 (major), 26.11 (major), 25.96 (minor), 25.46 (minor), 25.39 (major), 11.61 (minor), 11.19 (major) ppm. HRMS (ESI): $m / z$ calcd for major: $\mathrm{C}_{13} \mathrm{H}_{23} \mathrm{~N}\left[\mathrm{M}^{+}\right]$: 193.1830 Found: 193.1834 and minor: $\mathrm{C}_{13} \mathrm{H}_{23} \mathrm{~N}\left[\mathrm{M}+\mathrm{H}^{+}\right]$: 193.1830 Found:193.1832.

Note: With these diastereomers, we obtained enough sample for each pure diastereomer to get a clean GC-MS sample for each. However, NMR peaks are reported for the mixture. 


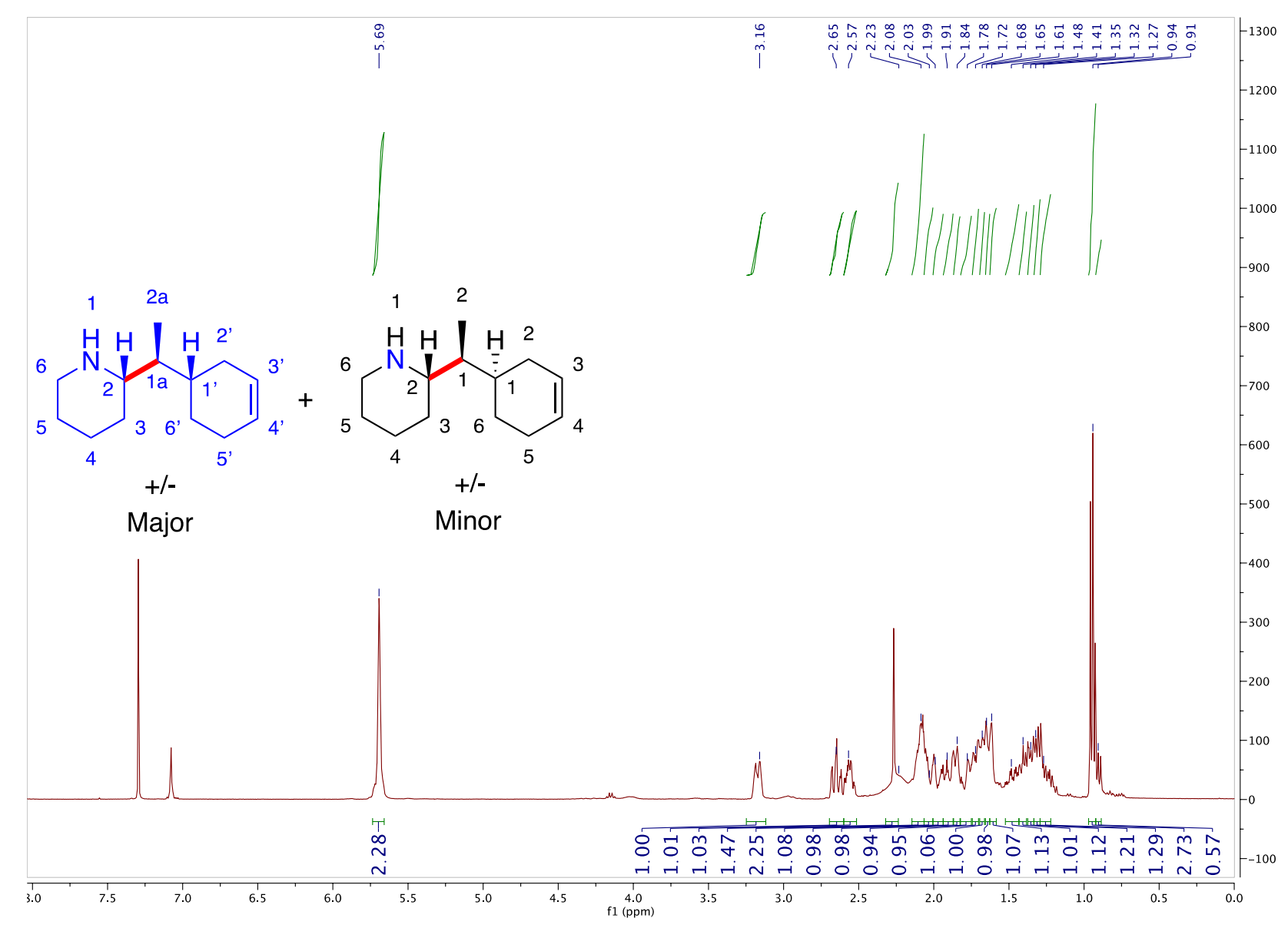

Figure S63: ${ }^{1} \mathrm{H}$ NMR spectrum $\left(400 \mathrm{MHz}, \mathrm{CDCl}_{3}, 298 \mathrm{~K}\right)$ of 2-(1-(cyclohex-3-en-1-yl)ethyl)piperidine. 


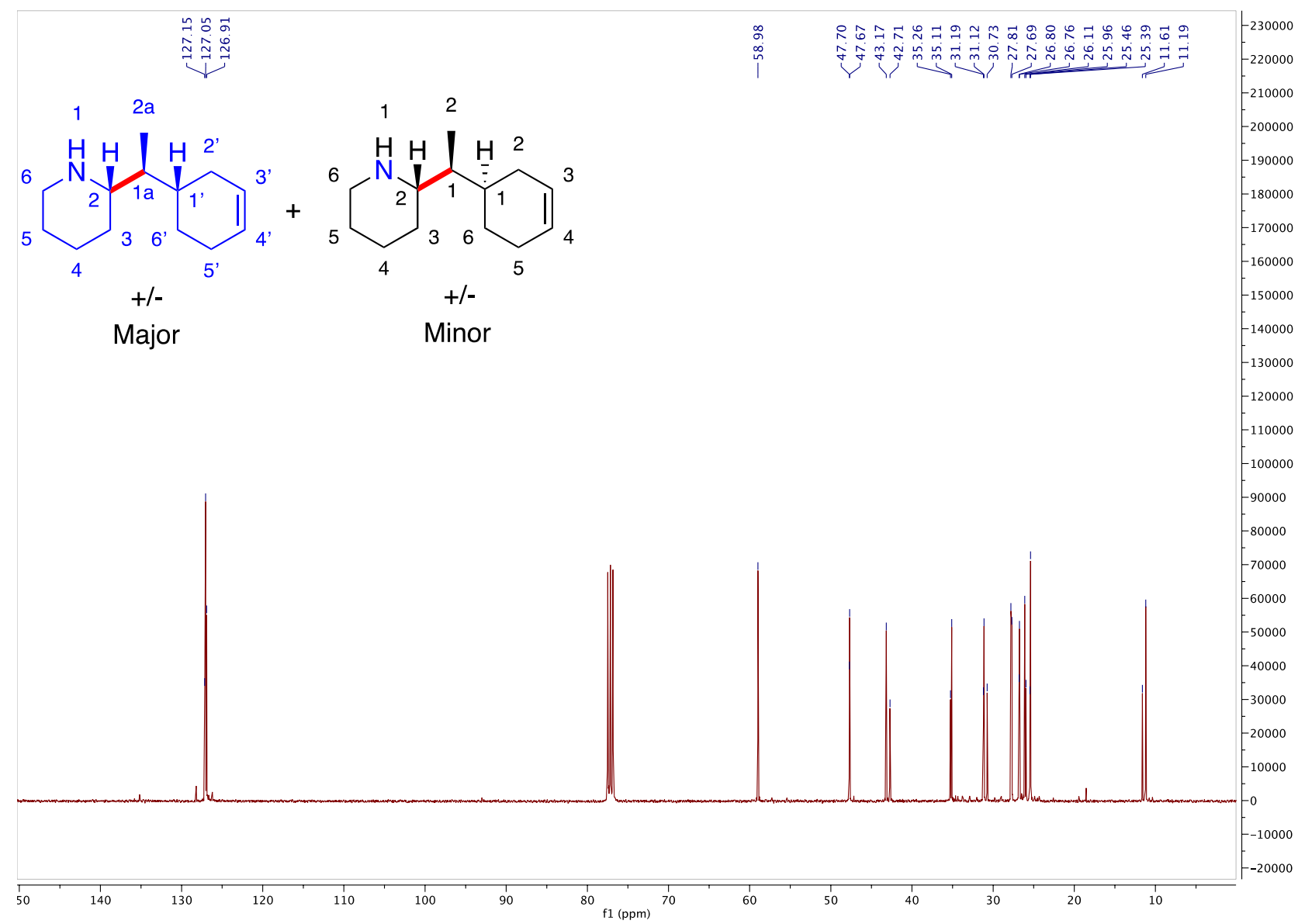

Figure S64: ${ }^{13} \mathrm{C}$ NMR spectrum $\left(101 \mathrm{MHz}, \mathrm{CDCl}_{3}, 298 \mathrm{~K}\right)$ of both diastereomers of 2-(1-(cyclohex-3-en1-yl)ethyl)piperidine.

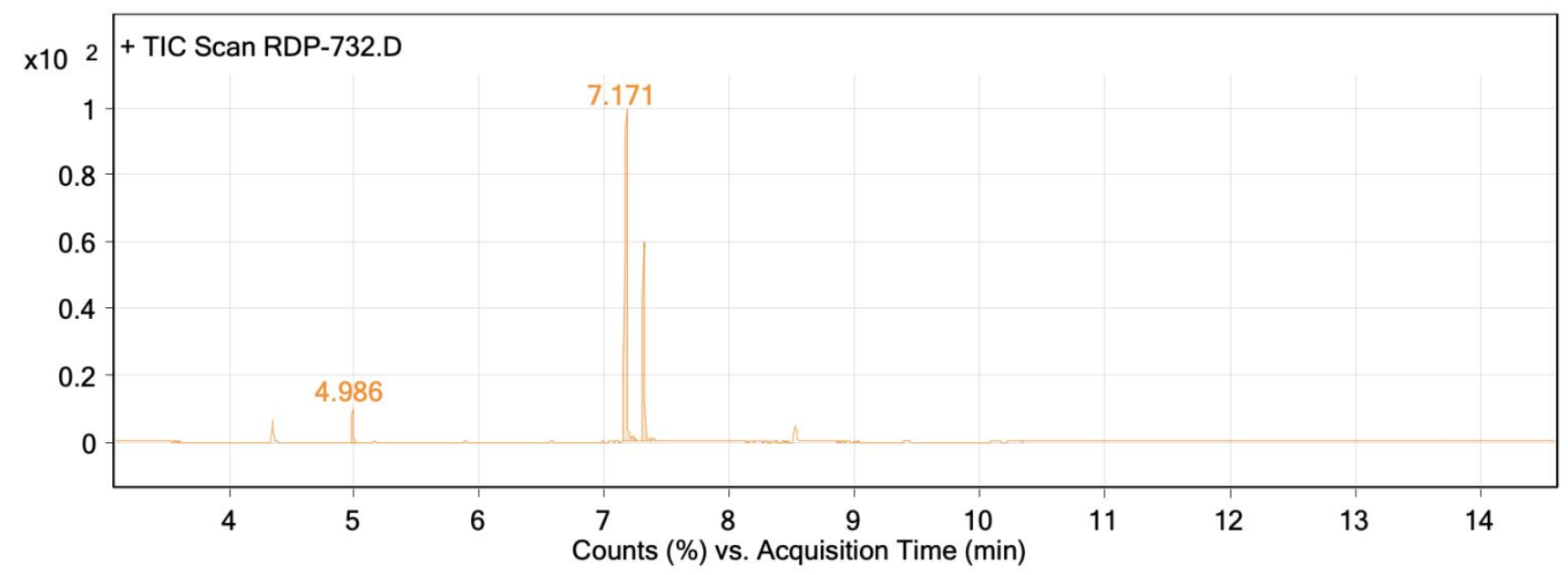

Figure S65: GC-MS for crude reaction mixture between piperidine and vinylcyclohexene. 

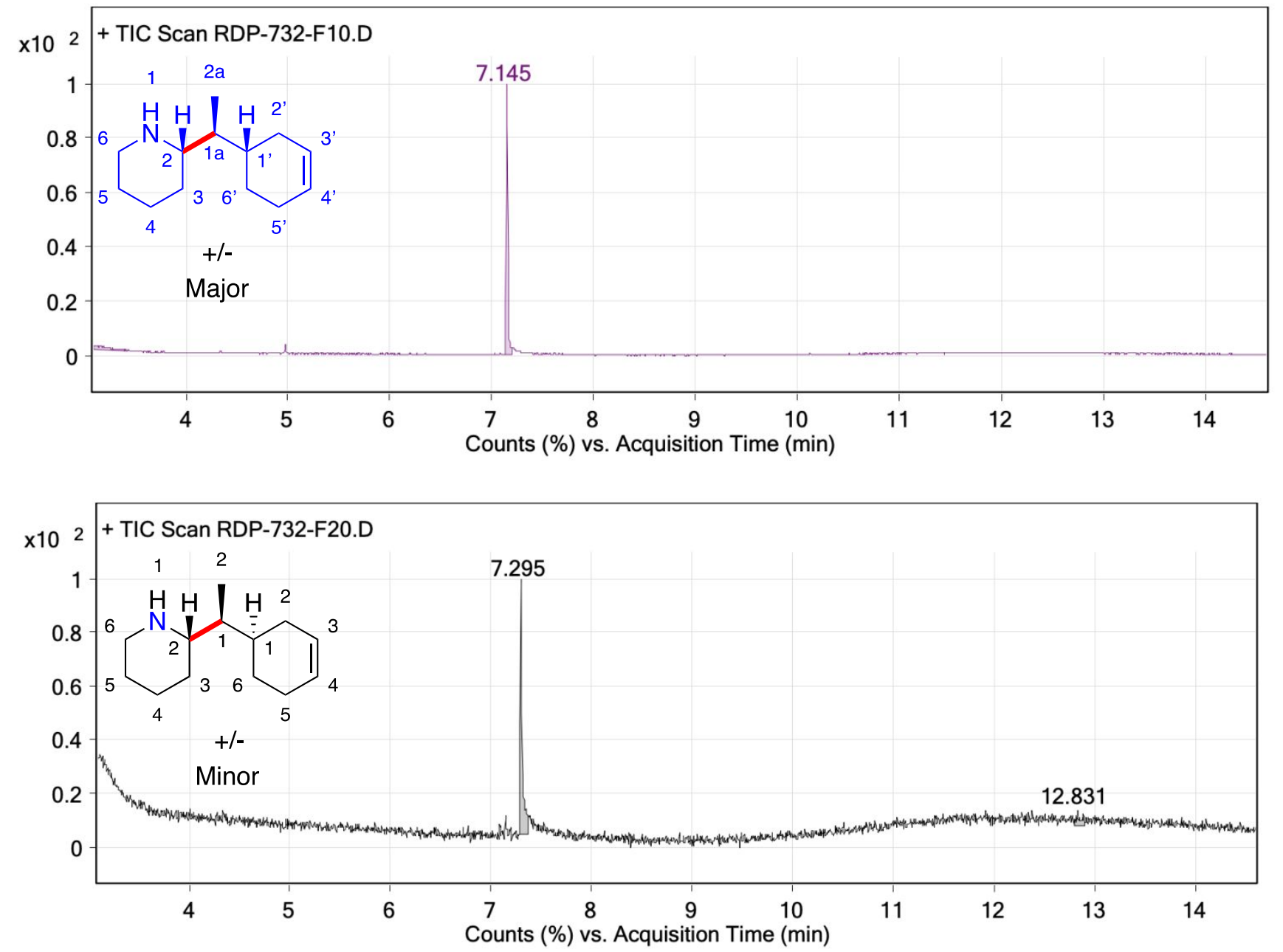

Figure S66: GC-MS reports for the two diastereomers of 2-(1-(cyclohex-3-en-1-yl)ethyl)piperidine.

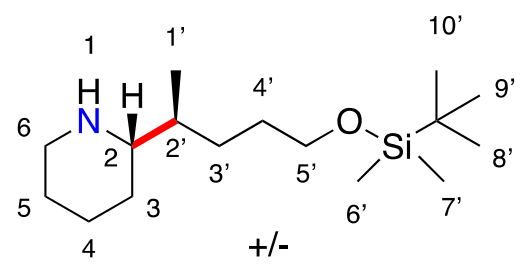

Synthesis of 2-(5-((tert-butyldimethylsilyl)oxy)pentan-2yl)piperidine (12): Prepared following the general procedure for predominantly branched product formation: $26.0 \mathrm{mg}$ Ta, $15.2 \mathrm{mg}$ ligand L4, piperidine $(85.15 \mathrm{mg}, 1.0 \mathrm{mmol})$, tert-butyldimethyl(pent-4-en-1yloxy)silane $(200.4 \mathrm{mg}, 1.0 \mathrm{mmol})$. The reaction was subsequently concentrated and the yield was determined to be $93 \%$ by NMR $(1,3,5-$ trimethoxybenzene as a standard). Purification via column chromatography $(7: 2.5: 0.5$ hexanes : ethyl acetate : triethyl amine): ${ }^{1} \mathrm{H}$ NMR $\left(\mathrm{CDCl}_{3}, 400 \mathrm{MHz}, 298 \mathrm{~K}\right): \delta 3.57(\mathrm{~m}, 2 \mathrm{H}, 5), 3.09(\mathrm{~m}, 1 \mathrm{H}, 1 / 2$ of 6$)$, $2.59(\mathrm{~m}, 1 \mathrm{H}, 1 / 2$ of 6$), 2.33(\mathrm{~m}, 1 \mathrm{H}, 2), 2.17$ (broad s, $1 \mathrm{H}, \mathrm{NH}), 1.78(\mathrm{~m}, 1 \mathrm{H}, 1 / 2$ of 4$), 1.60(\mathrm{~m}, 1 \mathrm{H}, 1 / 2$ of $\left.3^{\prime}\right), 1.57\left(\mathrm{~m}, 1 \mathrm{H}, 1 / 2\right.$ of $\left.4^{\prime}\right), 1.55(\mathrm{~m}, 1 \mathrm{H}, 1 / 2$ of 5$), 1.47\left(\mathrm{~m}, 1 \mathrm{H}, 1 / 2\right.$ of $\left.4^{\prime}\right), 1.42(\mathrm{~m}, 1 \mathrm{H}, 1 / 2$ of 3$), 1.38(\mathrm{~m}$, $\left.1 \mathrm{H}, 2^{\prime}\right), 1.34$ (m 1H, 1/2 of 5), 1.29 (m, 1H, 1/2 of 4), 1.17 (m, 1H, 1/2 of 3'), 1.12 (m, 1H, 1/2 of 3 ), 0.89 (overlapping d, 3H, 1'), 0.87 (s, 9H, 8' and 9' and 10'), 0.03 (s, 6H, 6' and 7') ppm. ${ }^{13} \mathrm{C} \mathrm{NMR}^{\prime}\left(\mathrm{CDCl}_{3}\right.$, $101 \mathrm{MHz}, 298 \mathrm{~K}): \delta 63.65,61.64,47.68,38.21,30.83,29.77,29.24,26.70,26.10,25.27,18.47,15.62$, 5.13 ppm. HRMS (ESI): $m / z$ calcd for $\mathrm{C}_{16} \mathrm{H}_{35} \mathrm{NOSi}\left[\mathrm{M}+\mathrm{H}^{+}\right]: 285.2488$ Found: 285.2492. 


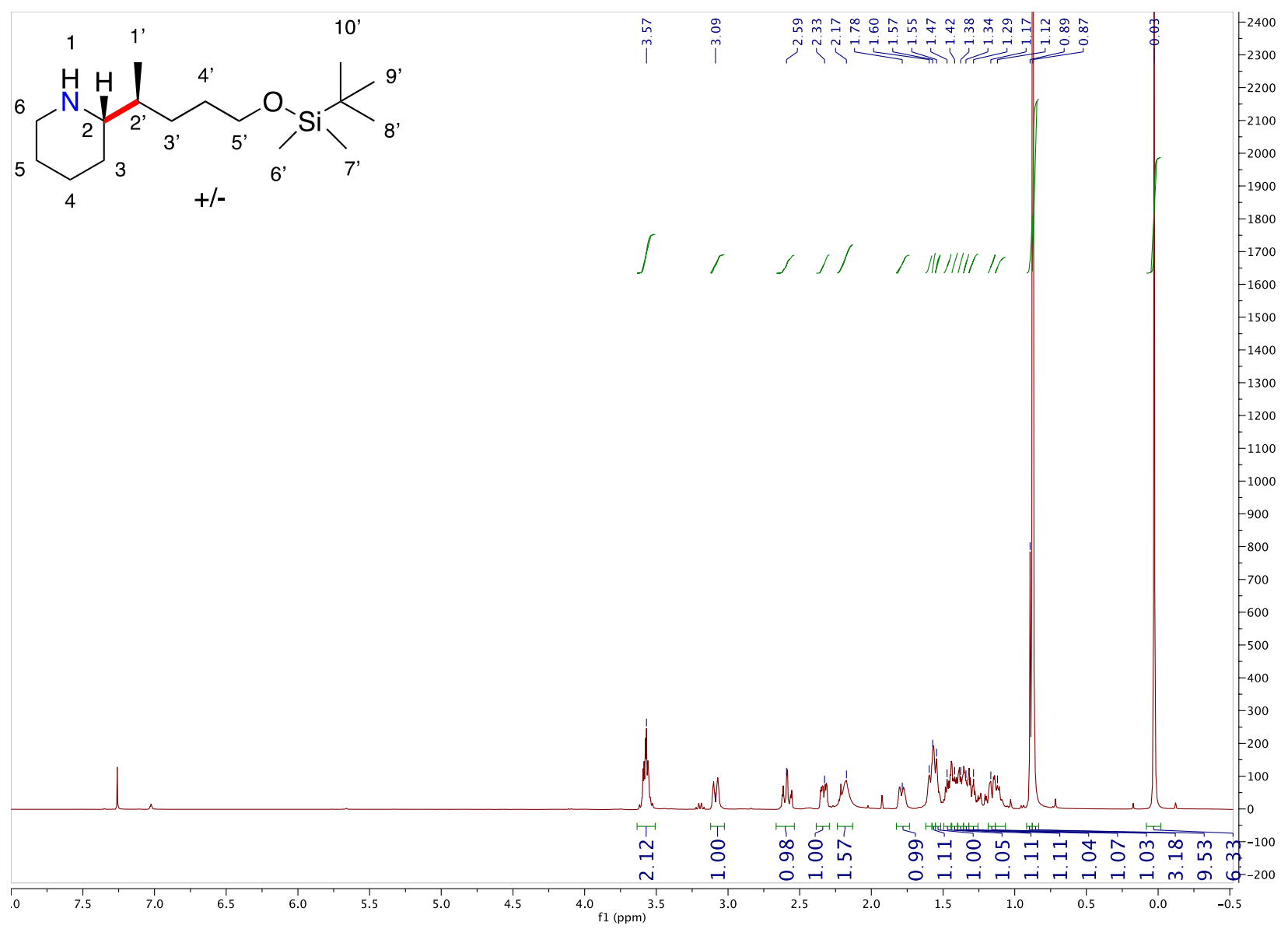

Figure S67: ${ }^{1} \mathrm{H}$ NMR spectrum $\left(400 \mathrm{MHz}, \mathrm{CDCl}_{3}, 298 \mathrm{~K}\right)$ of 2-(5-((tert-butyldimethylsilyl)oxy)pentan2-yl)piperidine. 


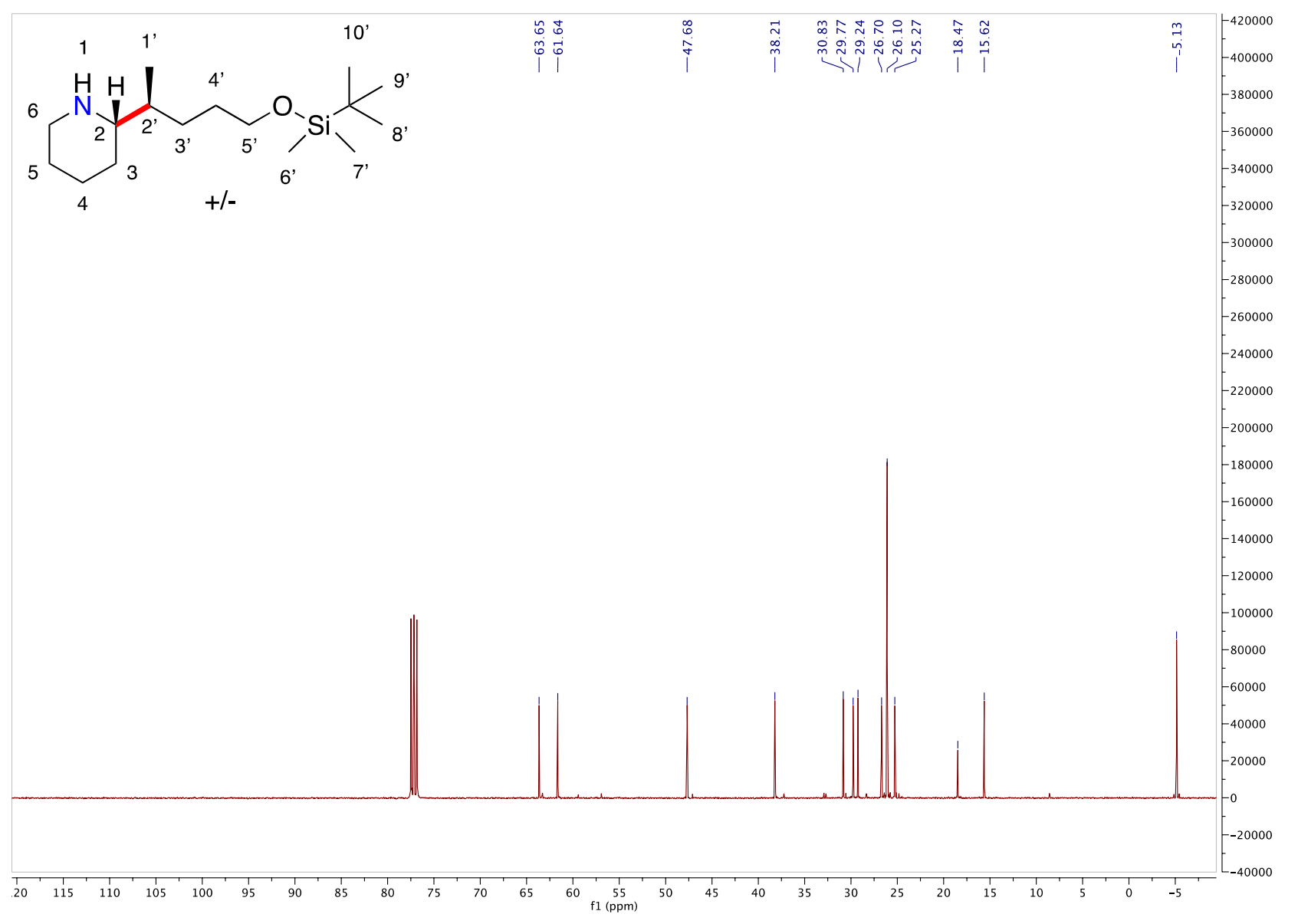

Figure S68: ${ }^{13} \mathrm{C}$ NMR spectrum $\left(101 \mathrm{MHz}, \mathrm{CDCl}_{3}, 298 \mathrm{~K}\right)$ of 2-(5-((tert-butyldimethylsilyl)oxy)pentan2-yl)piperidine.

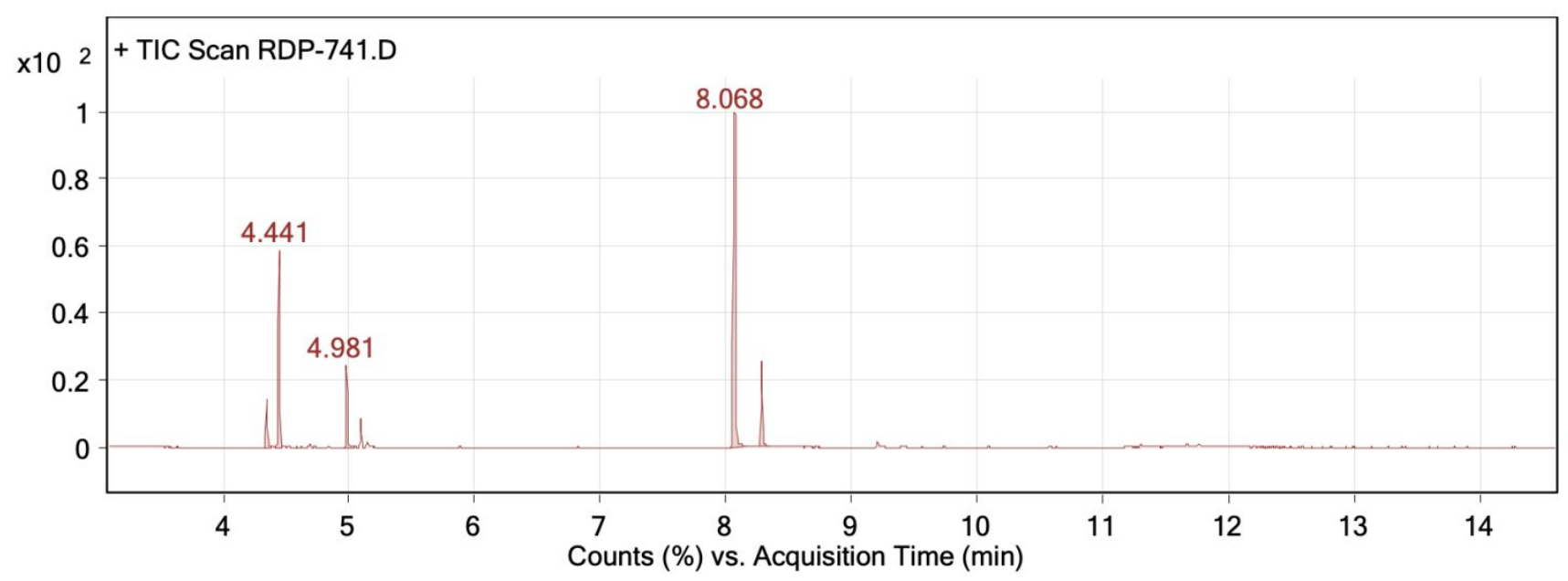

Figure S69: GC-MS for crude reaction mixture between piperidine and tert-butyldimethyl(pent-4-en-1yloxy)silane. 


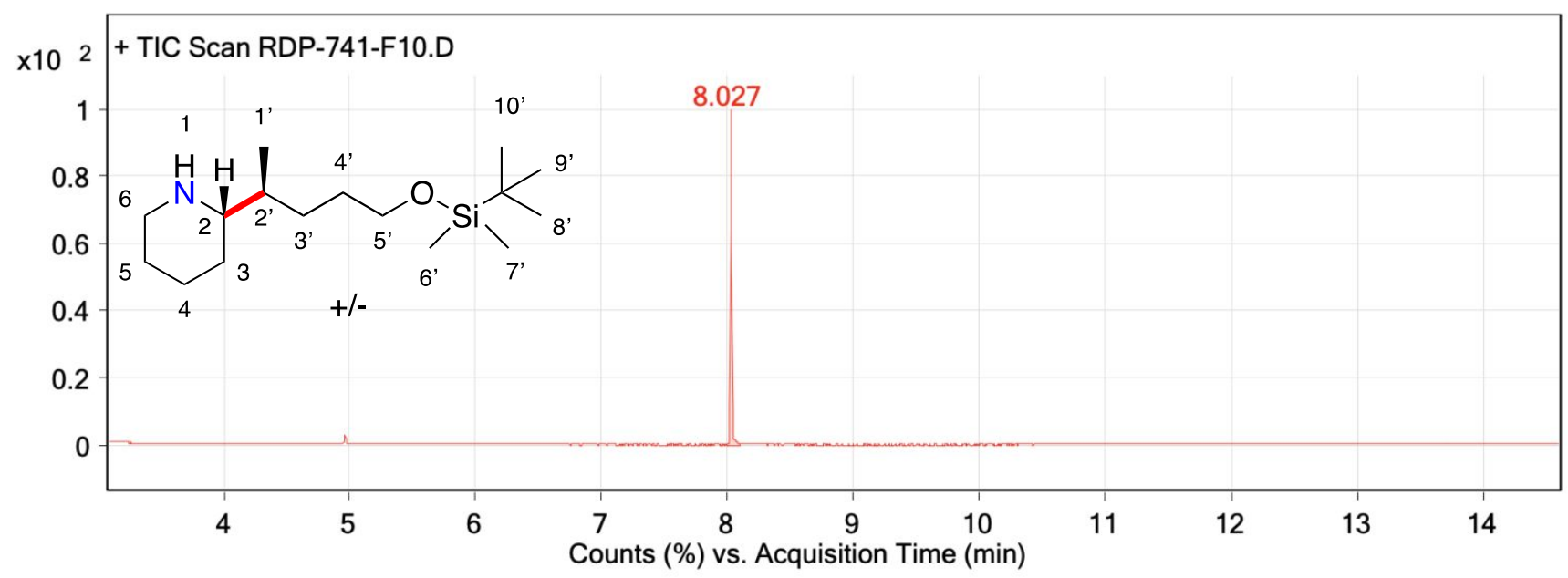

Figure S70: GC-MS report of 2-(5-((tert-butyldimethylsilyl)oxy)pentan-2-yl)piperidine.

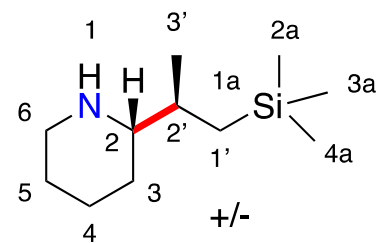

Synthesis of 2-(1-(trimethylsilyl)propan-2-yl)piperidine (13): Prepared following the general procedure for predominantly branched product formation: $26.0 \mathrm{mg} \mathrm{Ta}, 15.2 \mathrm{mg}$ ligand $\mathbf{L 4}$, piperidine $(85.15 \mathrm{mg}, 1.0 \mathrm{mmol})$, allyltrimethylsilane $(114.26 \mathrm{mg}, 1.0 \mathrm{mmol})$. The reaction was subsequently concentrated and the yield was determined to be $99 \%$ by NMR $(1,3,5-$ trimethoxybenzene as a standard). Purification via column chromatography (7:2.5:0.5 hexanes : ethyl acetate : triethyl amine): ${ }^{1} \mathrm{H}$ NMR $\left(\mathrm{CDCl}_{3}, 400 \mathrm{MHz}, 298 \mathrm{~K}\right): \delta 3.12(\mathrm{~m} 1 \mathrm{H}, 1 / 2$ of 6), $2.60(\mathrm{~m}, 1 \mathrm{H}, 1 / 2$ of 6$), 2.25(\mathrm{~m}, 1 \mathrm{H}, 2), 1.95$ (broad s, $1 \mathrm{H}, \mathrm{NH}), 1.81(\mathrm{~m}, 1 \mathrm{H}, 1 / 2$ of 4$), 1.60(\mathrm{~m}, 1 \mathrm{H}$, $1 / 2$ of 3$), 1.57(\mathrm{~m}, 1 \mathrm{H}, 1 / 2$ of 2$), 1.54\left(\mathrm{~m}, 1 \mathrm{H}, 2^{\prime}\right), 1.40(\mathrm{~m}, 1 \mathrm{H}, 1 / 2$ of 5$), 1.29(\mathrm{~m}, 1 \mathrm{H}, 1 / 2$ of 4$), 1.15(\mathrm{~m}, 1 \mathrm{H}$, $1 / 2$ of 3$), 0.90\left(\mathrm{~d}, \mathrm{~J}=0.90,3 \mathrm{H}, 3^{\prime}\right), 0.71\left(\mathrm{~m}, 1 \mathrm{H}, 1 / 2\right.$ of $\left.1^{\prime}\right), 0.36\left(\mathrm{~m}, 1 \mathrm{H}, 1 / 2\right.$ of $\left.1^{\prime}\right), 0.00,(\mathrm{~s}, 9 \mathrm{H}, 2 \mathrm{a}$ and $3 \mathrm{a}$ and 4a) ppm. ${ }^{13} \mathrm{C} \mathrm{NMR}\left(\mathrm{CDCl}_{3}, 101 \mathrm{MHz}, 298 \mathrm{~K}\right): \delta$ 64.74, 48.32, 35.46, 29.65, 27.25, 25.84, 21.22, 19.10, 0.00 ppm. HRMS (ESI): $m / z$ calcd for $\mathrm{C}_{11} \mathrm{H}_{26} \mathrm{~N}_{1} \mathrm{Si}_{1}\left[\mathrm{M}+\mathrm{H}^{+}\right]$: 200.1835 Found: 200.1835 . 


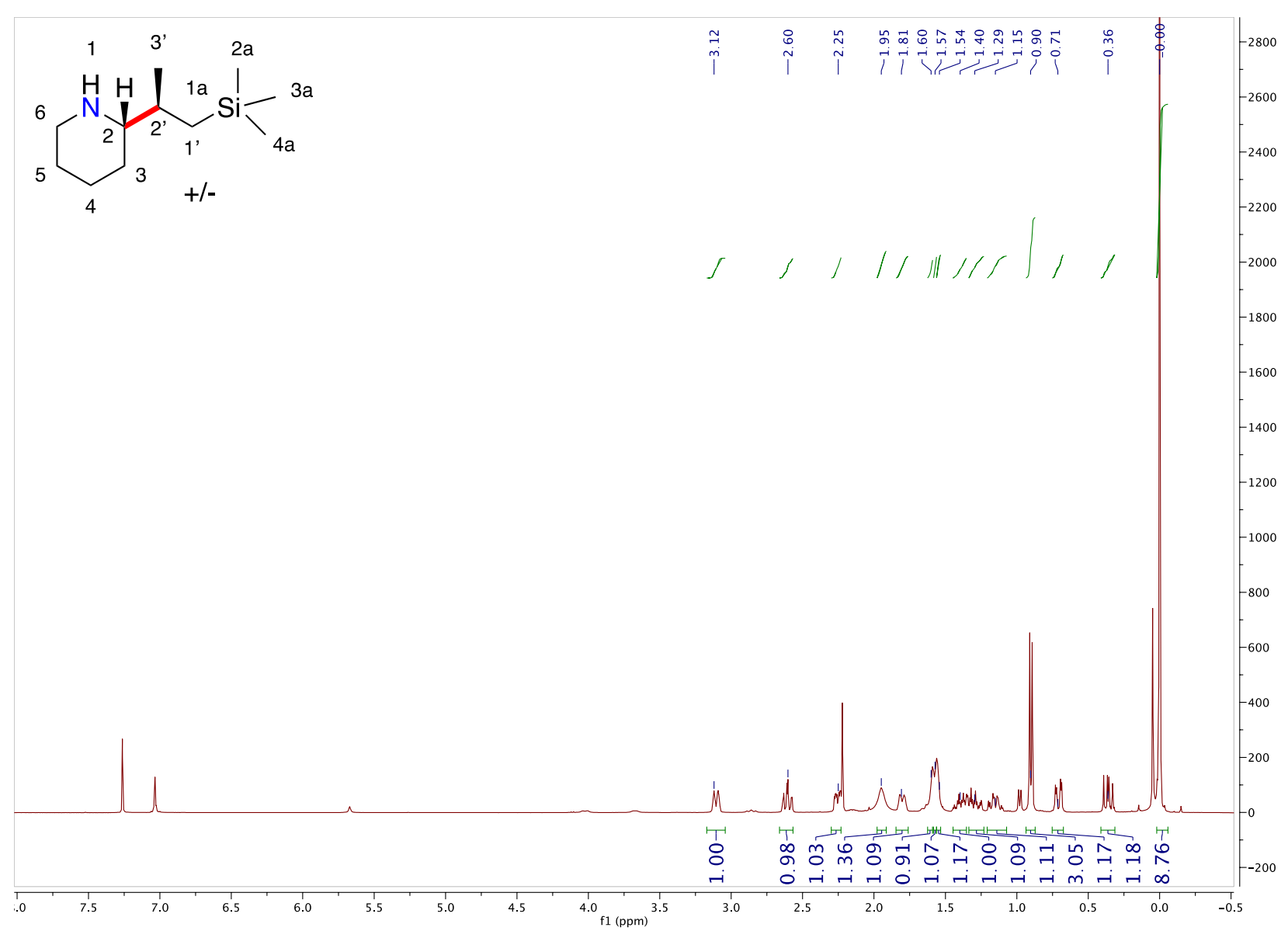

Figure S71: ${ }^{1} \mathrm{H}$ NMR spectrum (400 MHz, $\mathrm{CDCl}_{3}, 298 \mathrm{~K}$ ) of 2-(1-(trimethylsilyl)propan-2-yl)piperidine. 

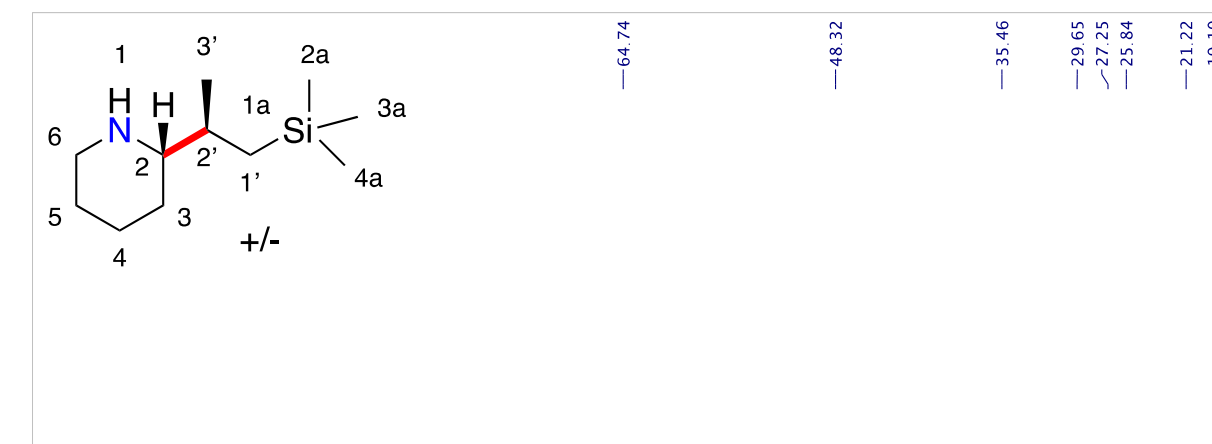


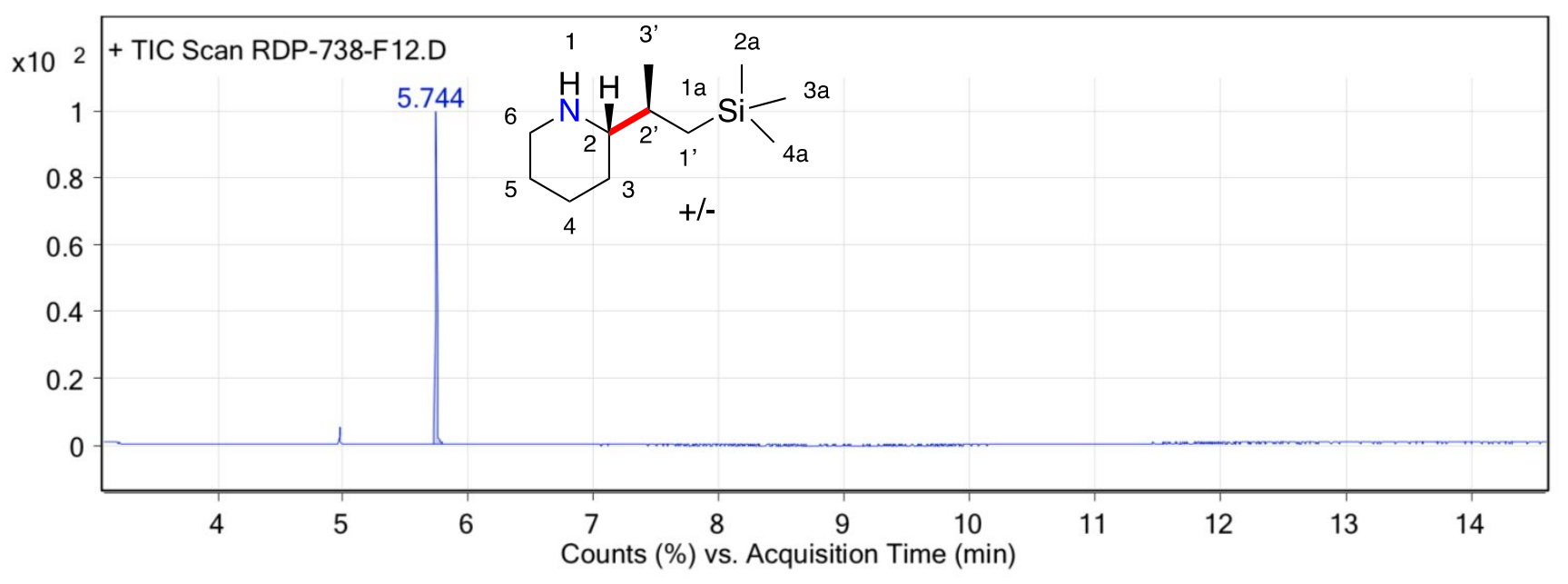

Figure S74: GC-MS report of 2-(1-(trimethylsilyl)propan-2-yl)piperidine.

NOTE: For all reactions that generate significant amounts of both regioisomers, both products could be isolated from a single reaction as indicated in main text. Yields indicated represents yields by quantitative NMR studies and are yields for a single regioisomer.

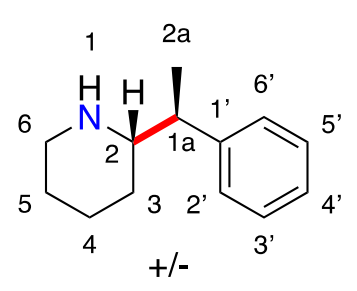

Synthesis of 2-(1-phenylethyl)piperidine (14 and 15): Prepared following the general procedure for branched and linear product mixtures outlined above: 26.0 mg Ta, $15.2 \mathrm{mg}$ ligand L4, piperidine ( $85.15 \mathrm{mg}, 1.0 \mathrm{mmol}$ ), styrene (104.15 mg, $1.0 \mathrm{mmol})$. The reaction was subsequently concentrated and the yield was determined to be $60 \%$ for 2-(1-phenylethyl)piperidine and $40 \%$ for 2phenethylpiperidine by NMR (1,3,5-trimethoxybenzene as a standard). Purification via column chromatography (7:2.5:0.5 hexanes : ethyl acetate : triethyl amine):

Branched Regiosiomer: ${ }^{1} \mathrm{H} \mathrm{NMR}\left(\mathrm{CDCl}_{3}, 400 \mathrm{MHz}, 298 \mathrm{~K}\right): \delta 7.22$ (m, 2H, 3' and 5'), 7.16 (m, 2H, 2' and 6'), $7.12\left(\mathrm{~m}, 1 \mathrm{H}, 4^{\prime}\right), 3.07(\mathrm{~m}, 1 \mathrm{H}, 1 / 2$ of 6$), 2.63(\mathrm{~m}, 1 \mathrm{H}, 1 \mathrm{a}), 2.52(\mathrm{~m}, 1 \mathrm{H}, 1 / 2 \mathrm{of} 6), 2.52(\mathrm{~m}, 1 \mathrm{H}, 2)$, 1.92 (broad s, $1 \mathrm{H}, \mathrm{NH}), 1.68(\mathrm{~m}, 1 \mathrm{H}, 1 / 2$ of 4$), 1.52(\mathrm{~m}, 1 \mathrm{H}, 1 / 2$ of 5$), 1.39(\mathrm{~m}, 1 \mathrm{H}, 1 / 2$ of 3$), 1.30(\mathrm{~m}, 1 \mathrm{H}, 1 / 2$ of 5), $1.25(\mathrm{~d}, \mathrm{~J}=1.26,3 \mathrm{H}, 2 \mathrm{a}), 1.19(\mathrm{~m}, 1 \mathrm{H}, 1 / 2$ of 4$), 1.00(\mathrm{~m}, 1 \mathrm{H}, 1 / 2$ of 3$) \mathrm{ppm} .{ }^{13} \mathrm{C} \mathrm{NMR}\left(\mathrm{CDCl}_{3}, 101\right.$ MHz, $298 \mathrm{~K}): \delta$ 145.12, 128.43, 127.98, 126.34, 62.61, 47.53, 45.72, 30.85, 26.43, 25.01, 17.42 ppm. HRMS (ESI): $m / z$ calcd for $\mathrm{C}_{13} \mathrm{H}_{20} \mathrm{~N}\left[\mathrm{M}+\mathrm{H}^{+}\right]: 190.1596$ Found: 190.1594.

Linear Regioisomer: ${ }^{1} \mathrm{H}$ NMR $\left(\mathrm{CDCl}_{3}, 400 \mathrm{MHz}, 298 \mathrm{~K}\right): \delta 7.23$ (m, 2H, 3' and 5'), 7.16 (m, 2H, 2' and 6'), $7.14\left(\mathrm{~m}, 1 \mathrm{H}, 4^{\prime}\right), 3.07$ (m, 1H, 1/2 of 6), $2.66(\mathrm{~m}, 2 \mathrm{H}, 2 \mathrm{a}), 2.59$ (m, 1H, 1/2 of 6), 2.50 (m, 1H, 2), 2.19 (broad s, 1H, NH), $1.76(\mathrm{~m}, 1 \mathrm{H}, 1 / 2$ of 4$), 1.70(\mathrm{~m}, 2 \mathrm{H}, 1 \mathrm{a}), 1.64(\mathrm{~m}, 1 / 2$ of 3), $1.55(\mathrm{~m}, 1 \mathrm{H}, 1 / 2$ of 5), 1.41 (m, $1 \mathrm{H}, 1 / 2$ of 5), $1.31(\mathrm{~m}, 1 \mathrm{H}, 1 / 2$ of 4$), 1.14(\mathrm{~m}, 1 \mathrm{H}, 1 / 2$ of 3$) \mathrm{ppm} .{ }^{13} \mathrm{C} \mathrm{NMR}\left(\mathrm{CDCl}_{3}, 101 \mathrm{MHz}, 298 \mathrm{~K}\right): \delta$ $142.37,128.51,128.47,125.90,56.61,47.14,39.04,32.77,32.38,26.48,24.81 \mathrm{ppm}$. HRMS (ESI): $\mathrm{m} / z$ calcd for $\mathrm{C}_{13} \mathrm{H}_{20} \mathrm{~N}\left[\mathrm{M}+\mathrm{H}^{+}\right]$: 190.1596 Found: 190.1592 . 


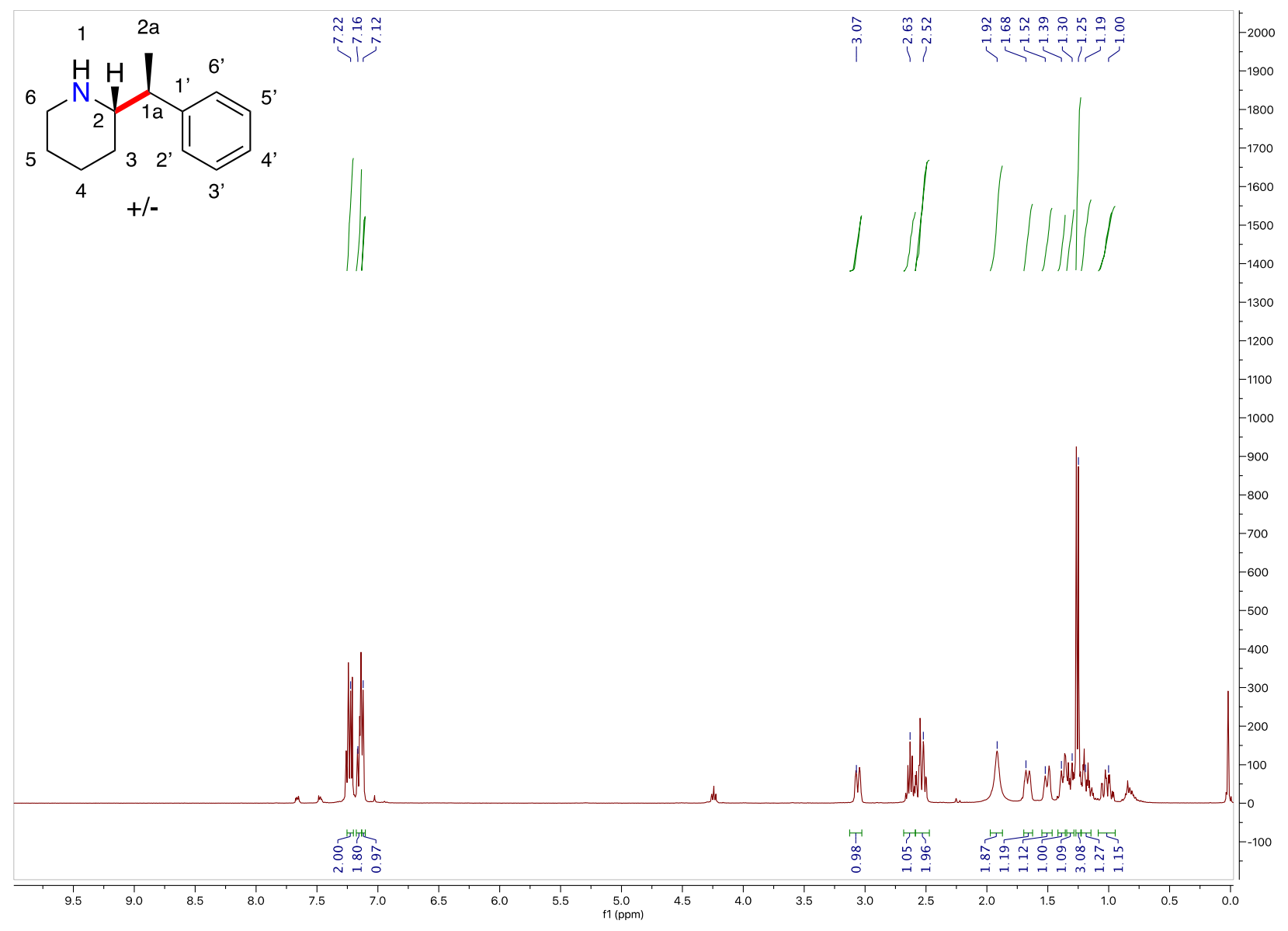

Figure S75: ${ }^{1} \mathrm{H}$ NMR spectrum of 2-(1-phenylethyl)piperidine. 


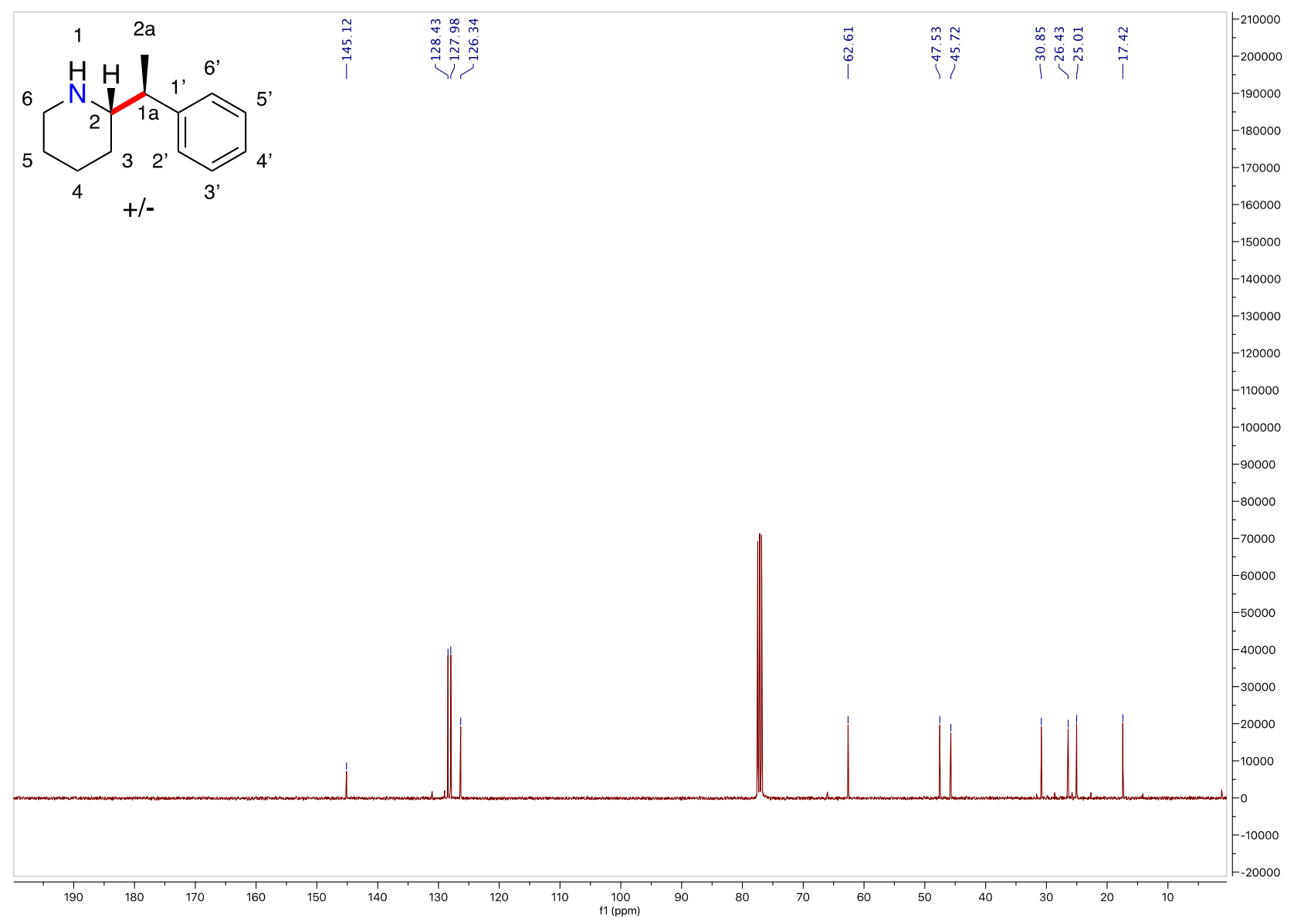

Figure S76: ${ }^{13} \mathrm{C}$ NMR spectrum (101 MHz, $\left.\mathrm{CDCl}_{3}, 298 \mathrm{~K}\right)$ of 2-(1-phenylethyl)piperidine. 


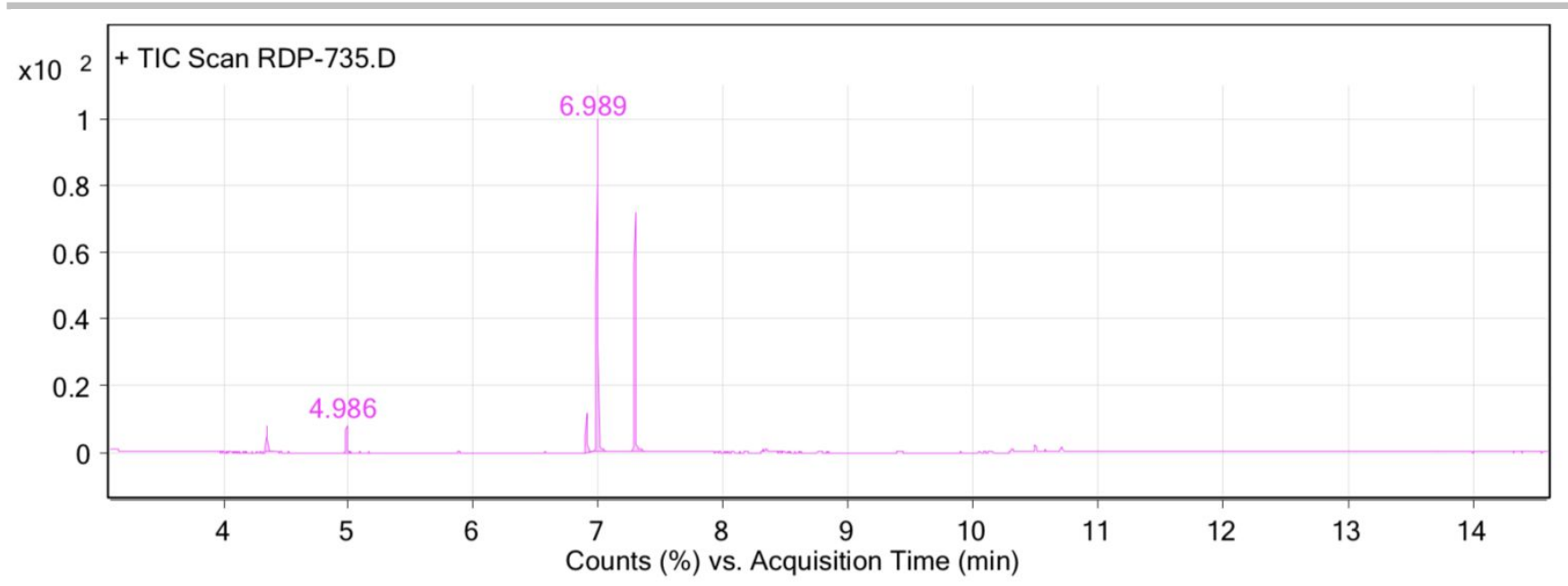

Figure S77: GC-MS for the crude reaction mixture between piperidine and styrene.

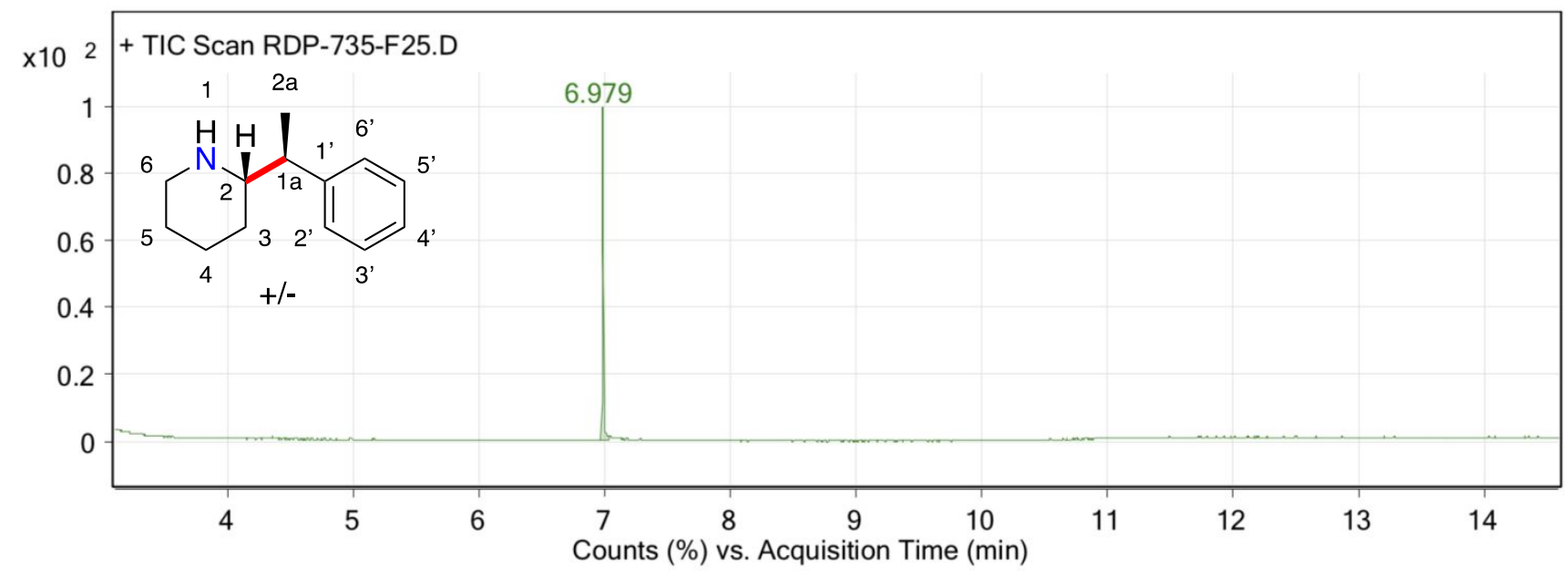

Figure S78: GC-MS report of 2-(1-phenylethyl)piperidine. 


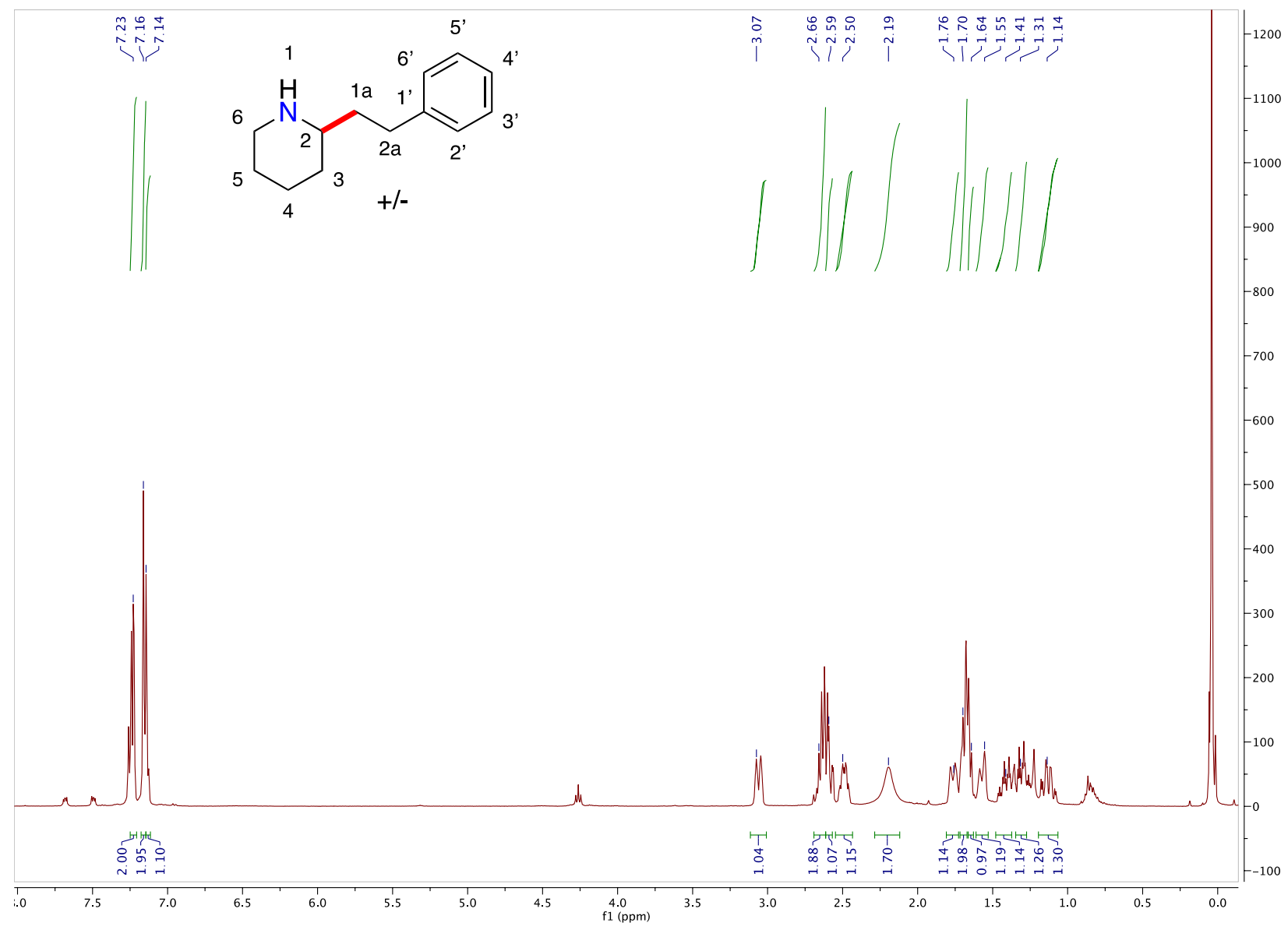

Figure S79: ${ }^{1} \mathrm{H}$ NMR spectrum (400 MHz, $\mathrm{CDCl}_{3}, 298 \mathrm{~K}$ ) of 2-phenethylpiperidine. 


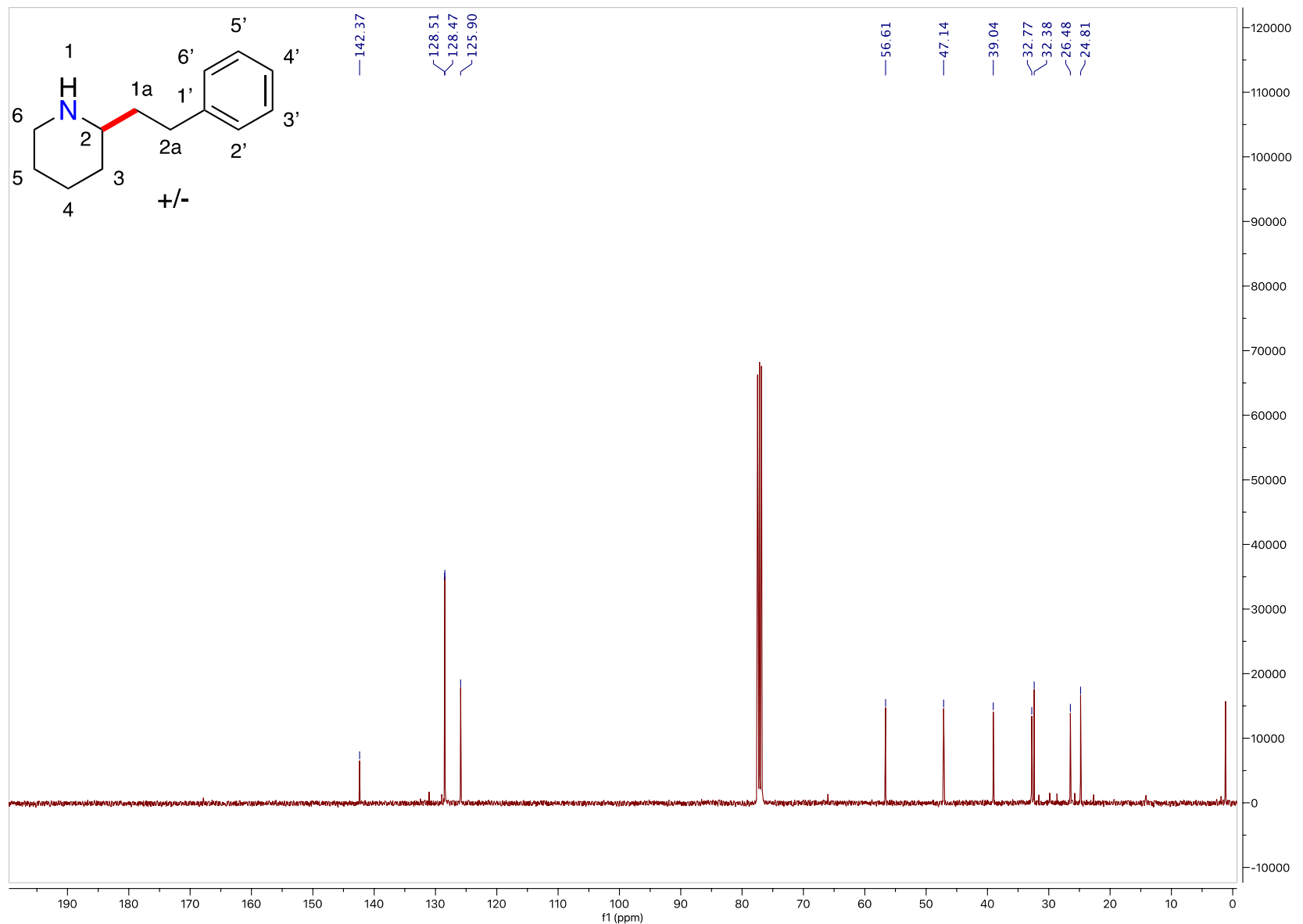

Figure S80: ${ }^{13} \mathrm{C}$ NMR spectrum $\left(101 \mathrm{MHz}, \mathrm{CDCl}_{3}, 298 \mathrm{~K}\right)$ of 2-phenethylpiperidine.

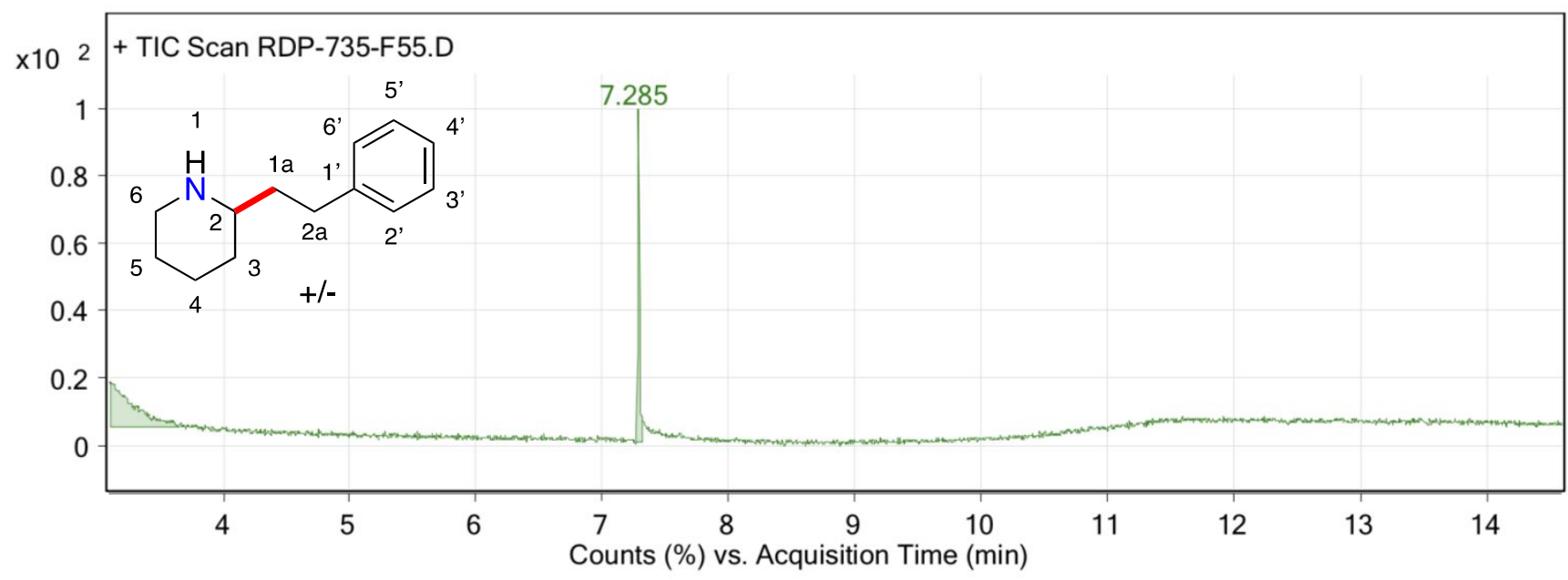

Figure S81: GC-MS report (101 MHz, $\mathrm{CDCl}_{3}, 298 \mathrm{~K}$ ) of 2-phenethylpiperidine. 


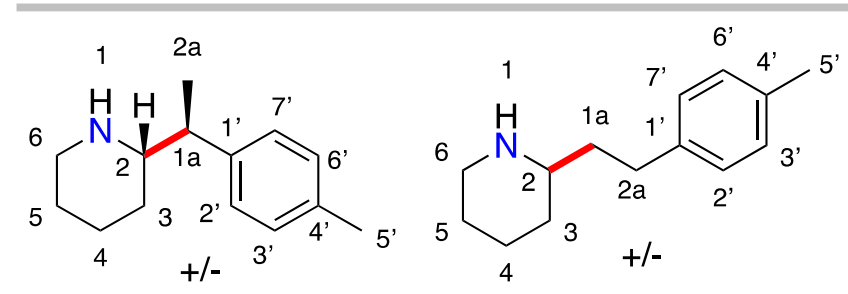

Synthesis of 2-(1-(p-tolyl)ethyl)piperidine and 2(4-methylphenethyl)piperidine (16 and 17): Prepared following the general procedure for branched and linear product mixtures outlined above: 26.0 Ta, 15.2 Ligand, piperidine $(85.15 \mathrm{mg}, 1.0$ mmol), 4-methylstyrene (118.18 mg, $1.0 \mathrm{mmol})$. The reaction was subsequently concentrated and the yield was determined to be $67 \%$ for 2-(1-(ptolyl)ethyl)piperidine and $29 \%$ for 2-(4-methylphenethyl)piperidine by NMR (1,3,5-trimethoxybenzene as a standard). Purification via column chromatography (7:2.5:0.5 hexanes : ethyl acetate : triethyl amine):

Branched Regioisomer: ${ }^{1} \mathrm{H}$ NMR $\left(\mathrm{CDCl}_{3}, 400 \mathrm{MHz}, 298 \mathrm{~K}\right): \delta 7.10(\mathrm{~m}, 2 \mathrm{H}, 3$ ' and 6'), 7.08 (m, 2H, 2' and $\left.7^{\prime}\right), 3.12(\mathrm{~m}, 1 \mathrm{H}, 1 / 2$ of 6$), 2.65(\mathrm{~m}, 1 \mathrm{H}, 1 \mathrm{a}), 2.62(\mathrm{~m}, 1 \mathrm{H}, 1 / 2$ of 6$), 2.54(\mathrm{~m}, 1 \mathrm{H}, 2), 2.32\left(\mathrm{~s}, 3 \mathrm{H}, 5^{\prime}\right)$, $1.95($ broad s, $1 \mathrm{H}, \mathrm{NH}), 1.72(\mathrm{~m}, 1 \mathrm{H}, 1 / 2$ of 4$), 1.56(\mathrm{~m}, 1 \mathrm{H}, 1 / 2$ of 5$), 1.45(\mathrm{~m}, 1 \mathrm{H}, 1 / 2$ of 3$), 1.36(\mathrm{~m}, 1 \mathrm{H}, 1 / 2$ of 5), $1.29(\mathrm{~d}, \mathrm{~J}=1.28,3 \mathrm{H}, 2 \mathrm{a}), 1.24(\mathrm{~m}, 1 \mathrm{H}, 1 / 2$ of 4$), 1.06(\mathrm{~m}, 1 \mathrm{H}, 1 / 2$ of 3$) \mathrm{ppm} .{ }^{13} \mathrm{C} \mathrm{NMR}\left(\mathrm{CDCl}_{3}, 101\right.$ MHz, $298 \mathrm{~K}): \delta$ 142.07, 135. 79, 129.11, 127.84, 62.64, 47.54, 45.26, 30.83, 26.46, 25.04, 21.13, 17.43 ppm. HRMS (ESI): $m / z$ calcd for $\mathrm{C}_{14} \mathrm{H}_{22} \mathrm{~N}\left[\mathrm{M}+\mathrm{H}^{+}\right]$: 204.1752 Found: 204.1748 .

Linear Regioisomer: ${ }^{1} \mathrm{H}$ NMR $\left(\mathrm{CDCl}_{3}, 400 \mathrm{MHz}, 298 \mathrm{~K}\right): \delta 7.08(\mathrm{~m}, 4 \mathrm{H}, 2$ ' and 3' and 6' and 7'), 3.09 (m, 1H, 1/2 of 6), 2.65 (m, 1H, 1/2 of 6), 2.59 (m, 2H, 2a), $2.52(\mathrm{~m}, 1 \mathrm{H}, 2), 2.31$ (s, 3H, 5), 1.96 (broad s, $1 \mathrm{H}, \mathrm{NH}), 1.81(\mathrm{~m}, 1 \mathrm{H}, 1 / 2$ of 4$), 1.73(\mathrm{~m}, 1 \mathrm{H}, 1 / 2$ of 3$), 1.68(\mathrm{~m}, 2 \mathrm{H}, 1 \mathrm{a}), 1.58(\mathrm{~m}, 1 \mathrm{H}, 1 / 2$ of 5$), 1.45(\mathrm{~m}$, $1 \mathrm{H}, 1 / 2$ of 5$), 1.35(\mathrm{~m}, 1 \mathrm{H}, 1 / 2$ of 4$), 1.14(\mathrm{~m}, 1 \mathrm{H}, 1 / 2$ of 3$) \mathrm{ppm} .{ }^{13} \mathrm{C} \mathrm{NMR}\left(\mathrm{CDCl}_{3}, 101 \mathrm{MHz}, 298 \mathrm{~K}\right): \delta$ $139.29,135.33,129.19,128.34,56.60,47.17,39.22$, 32.82, 31.92, 26.53, 24.84, 21.12 ppm. HRMS (ESI): $m / z$ calcd for $\mathrm{C}_{14} \mathrm{H}_{22} \mathrm{~N}\left[\mathrm{M}+\mathrm{H}^{+}\right]: 204.1752$ Found: 204.1755 .

Note: The 1D/2D NMR spectroscopy data for the branched regioisomer below is a representative example of how we were able to were able to assign all proton and carbon signals conclusively in products with styrenes as coupling partners. 


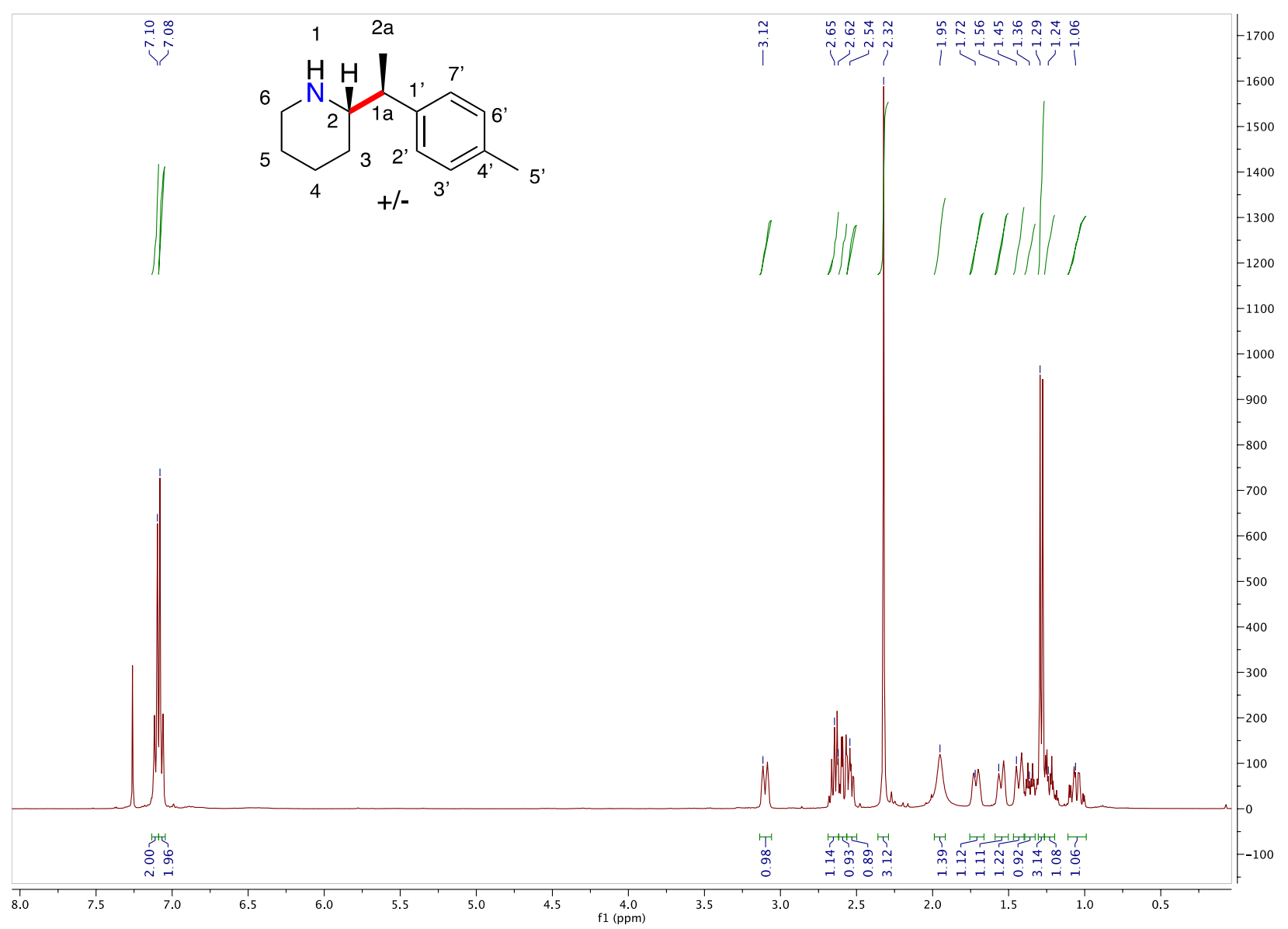

Figure S82: ${ }^{1} \mathrm{H}$ NMR spectrum $\left(400 \mathrm{MHz}, \mathrm{CDCl}_{3}, 298 \mathrm{~K}\right)$ of 2-(1-(p-tolyl)ethyl)piperidine. 


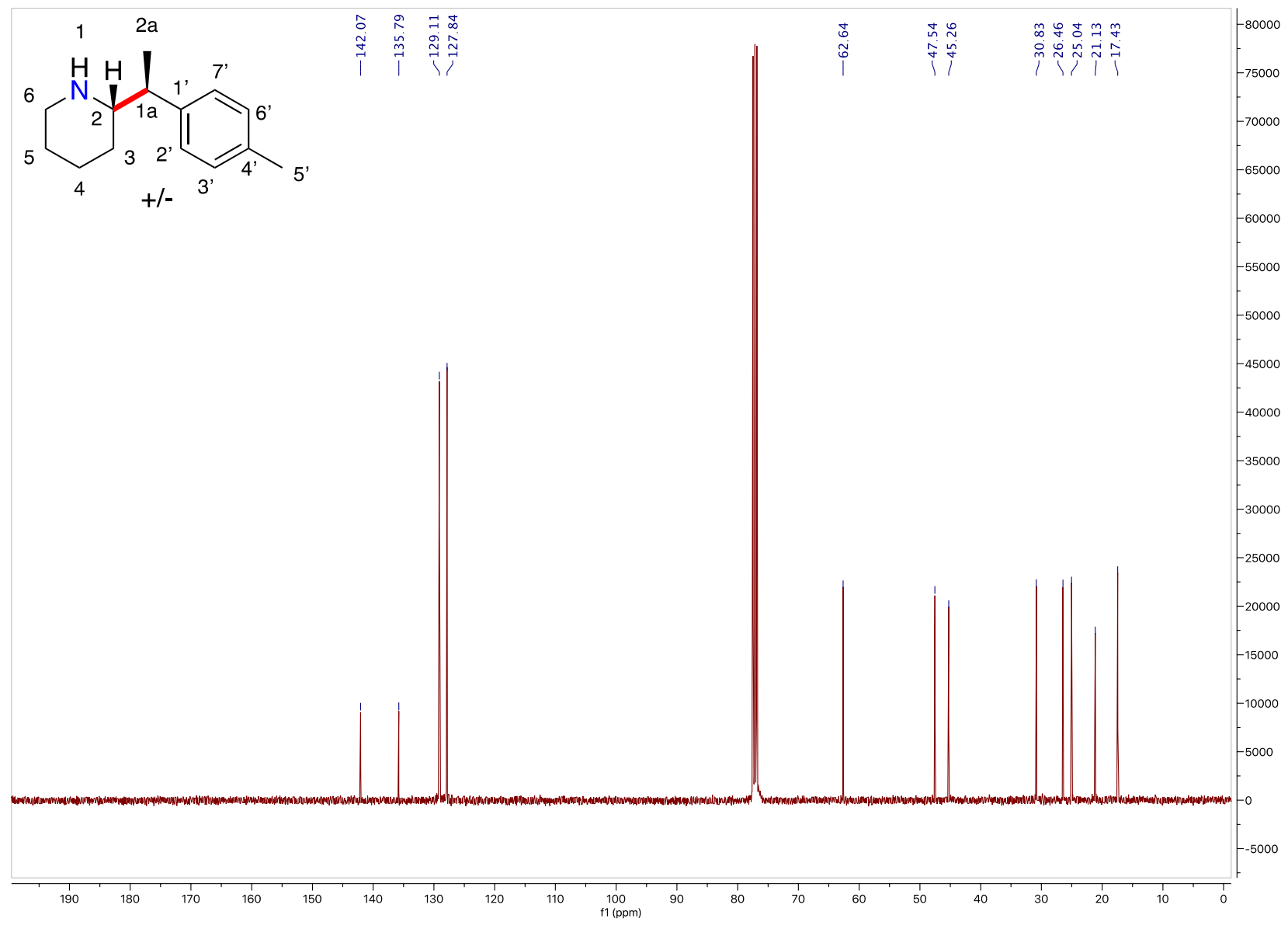

Figure S83: ${ }^{13} \mathrm{C}$ NMR spectrum $\left(101 \mathrm{MHz}, \mathrm{CDCl}_{3}, 298 \mathrm{~K}\right)$ of 2-(1-(p-tolyl)ethyl)piperidine. 


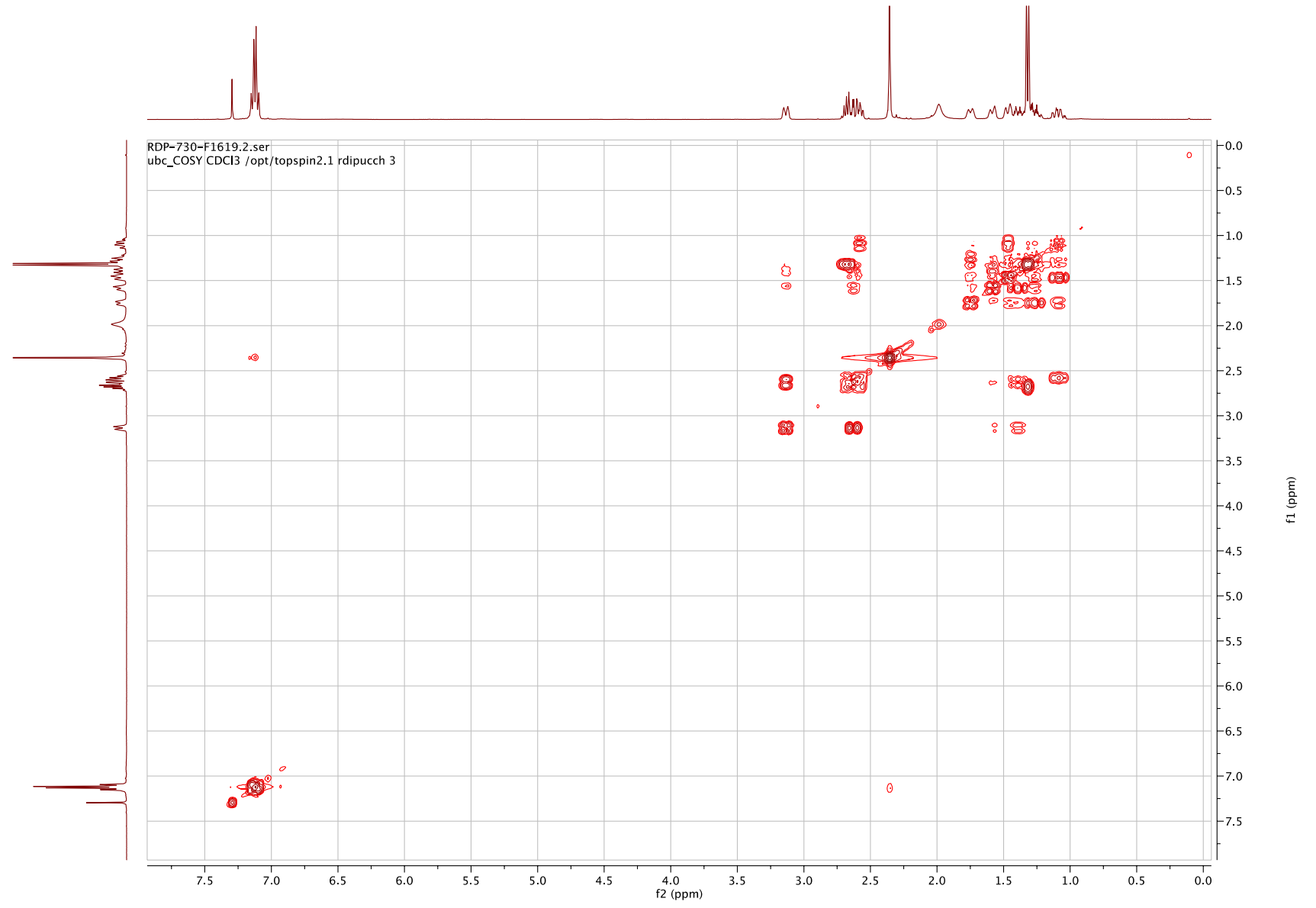

Figure S84: COSY spectrum (400 MHz, $\left.\mathrm{CDCl}_{3}, 298 \mathrm{~K}\right)$ of 2-(1-(p-tolyl)ethyl)piperidine. 


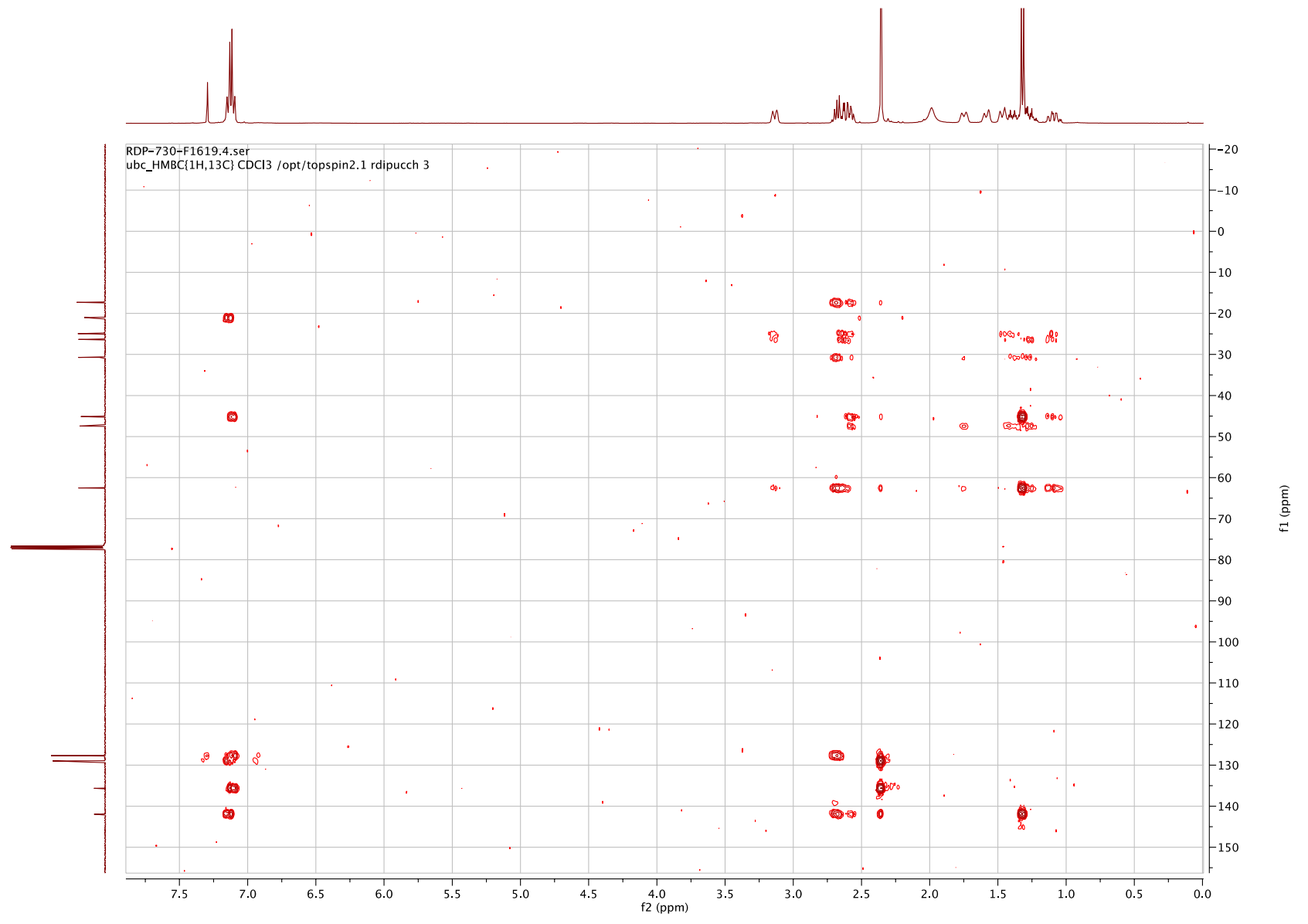

Figure S85: HMBC spectrum (101 MHz, $\left.\mathrm{CDCl}_{3}, 298 \mathrm{~K}\right)$ 2-(1-(p-tolyl)ethyl)piperidine. 


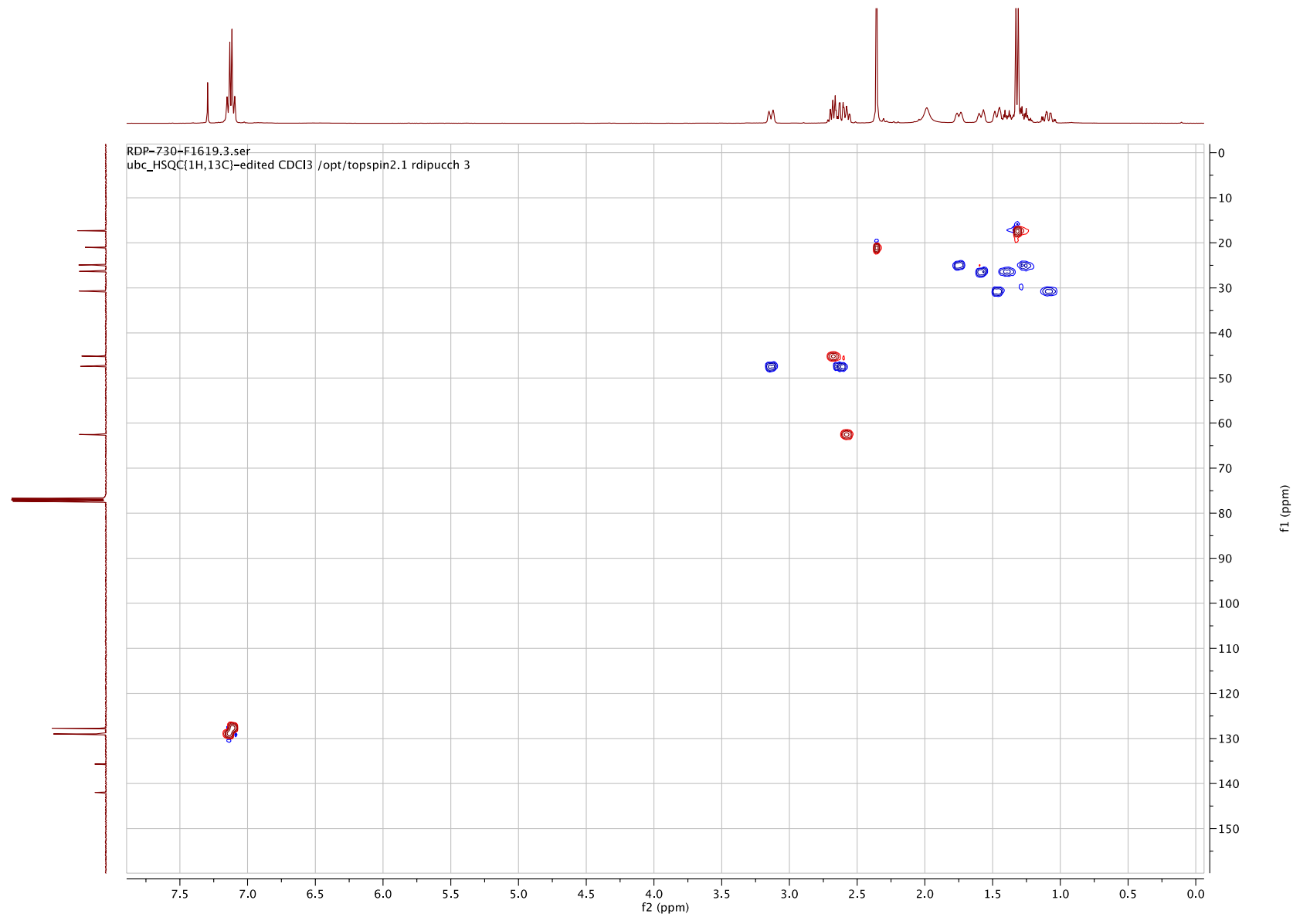

Figure S86: HSQC spectrum (101 MHz, $\left.\mathrm{CDCl}_{3}, 298 \mathrm{~K}\right)$ 2-(1-(p-tolyl)ethyl)piperidine.

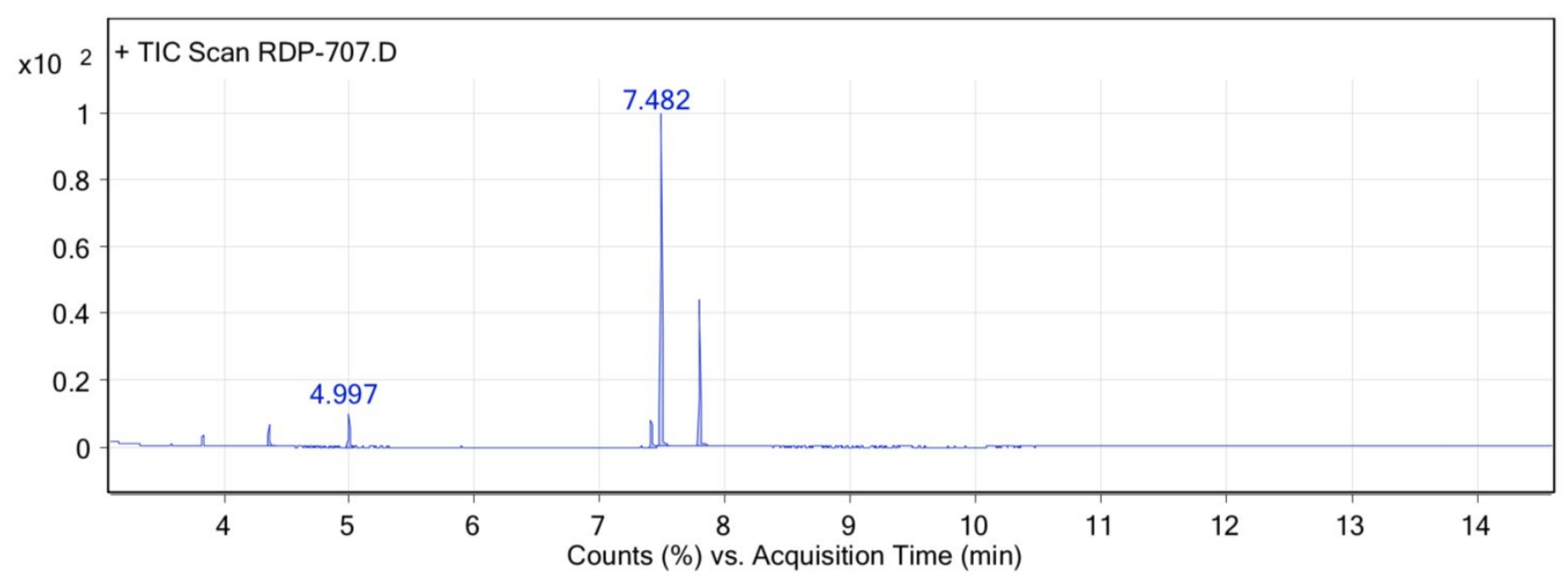

Figure S87: GC-MS for crude reaction mixture between piperidine and 4-methylstyrene. 


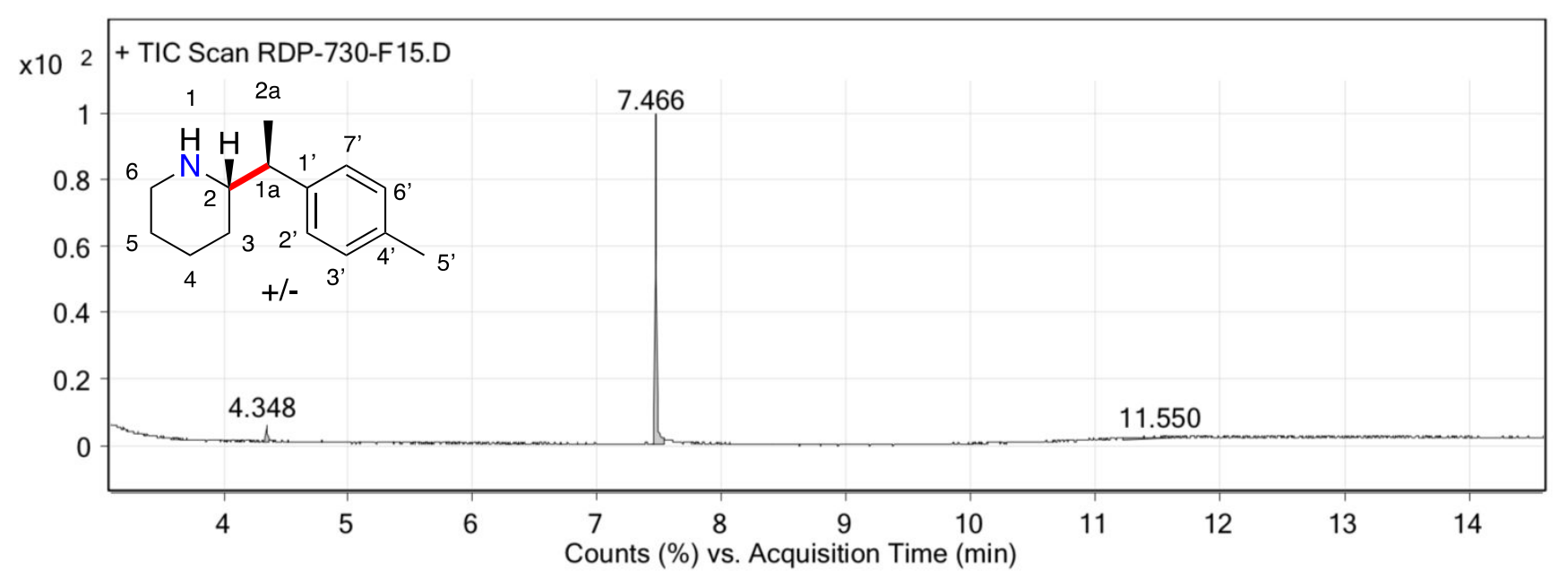

Figure S88: GC-MS report of 2-(1-(p-tolyl)ethyl)piperidine. 


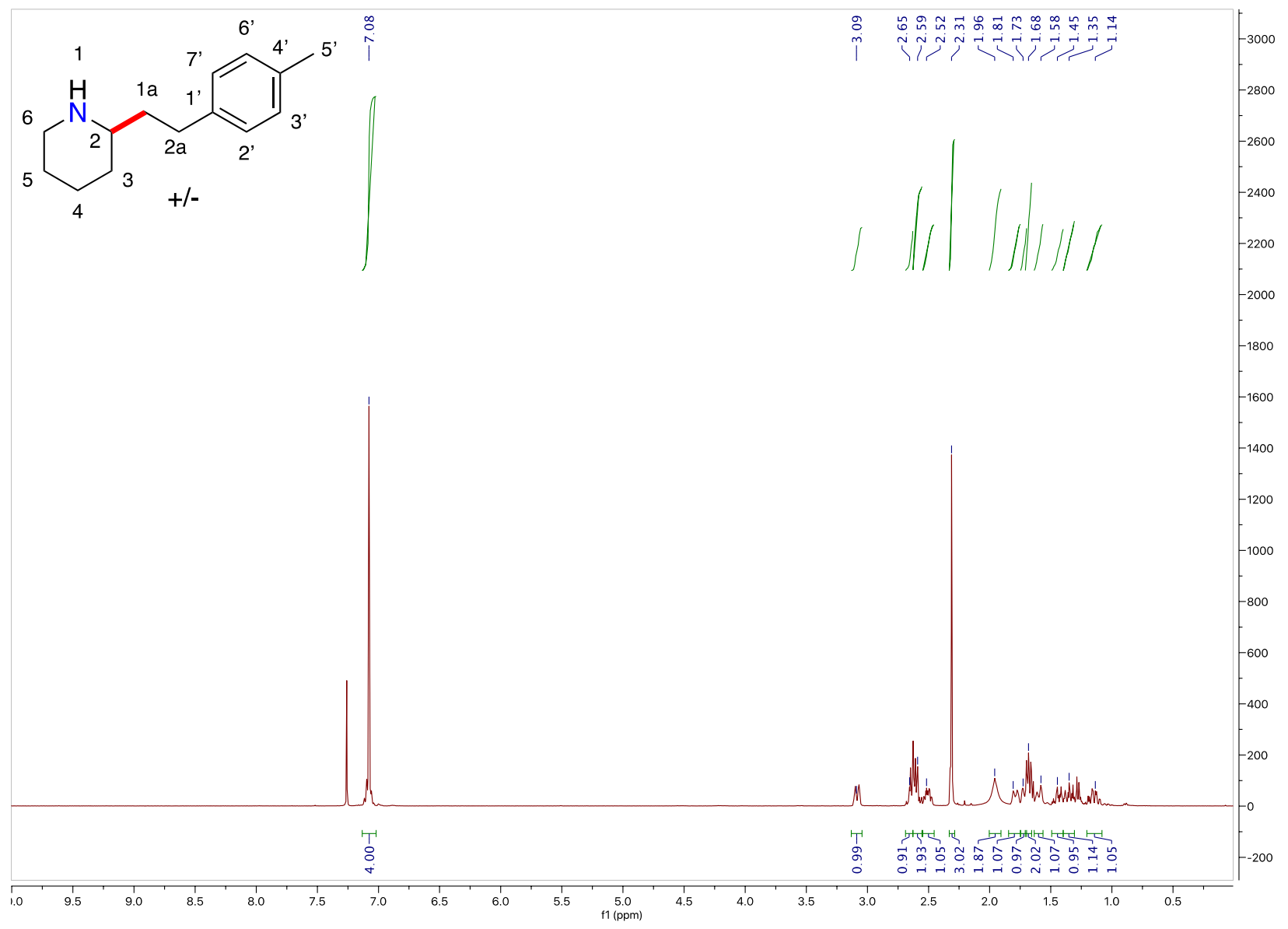

Figure S89: ${ }^{1} \mathrm{H}$ NMR spectrum (400 MHz, $\mathrm{CDCl}_{3}, 298 \mathrm{~K}$ ) of 2-(4-methylphenethyl)piperidine. 


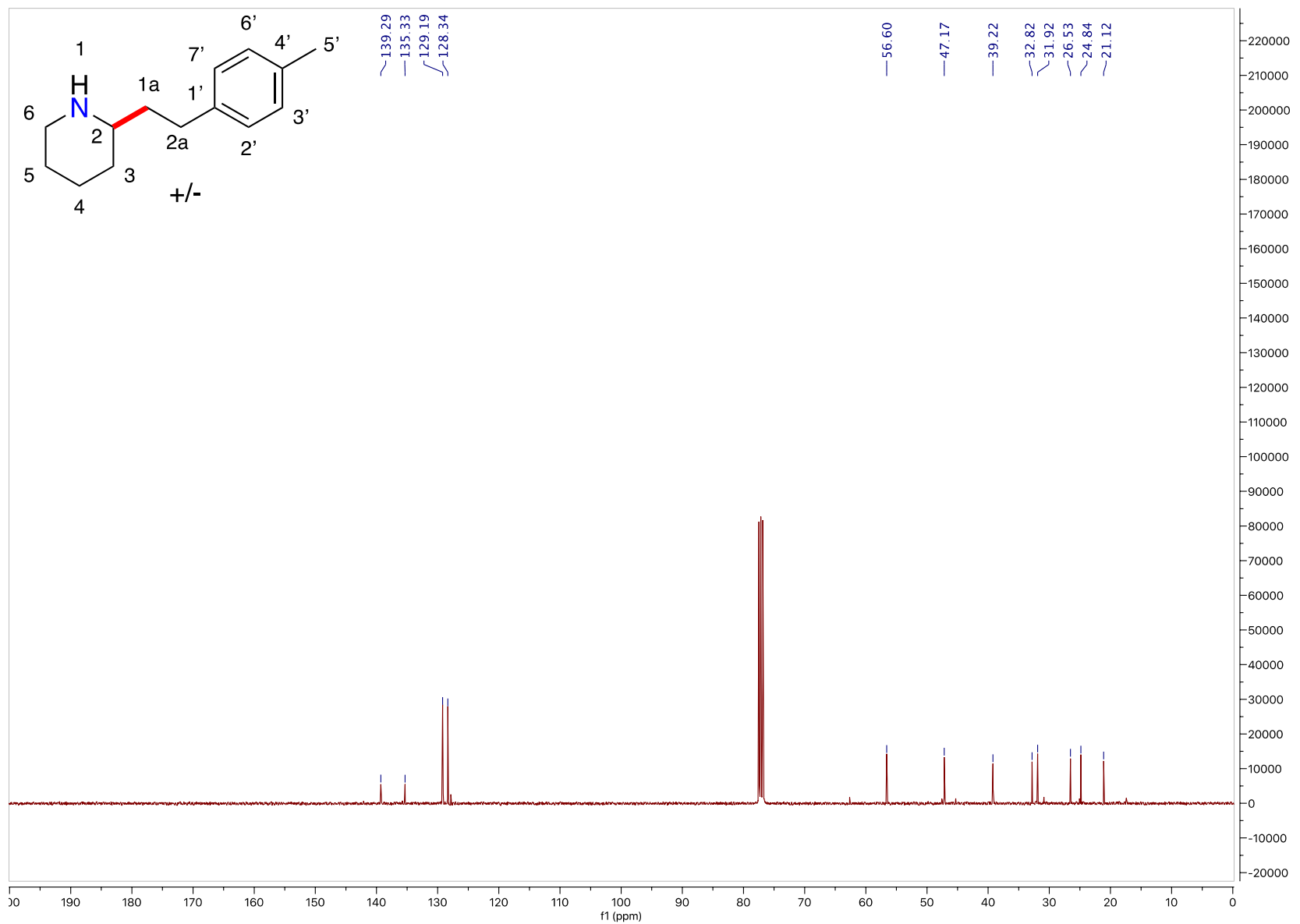

Figure S90: ${ }^{13} \mathrm{C}$ NMR spectrum $\left(101 \mathrm{MHz}, \mathrm{CDCl}_{3}, 298 \mathrm{~K}\right)$ of 2-(4-methylphenethyl)piperidine.

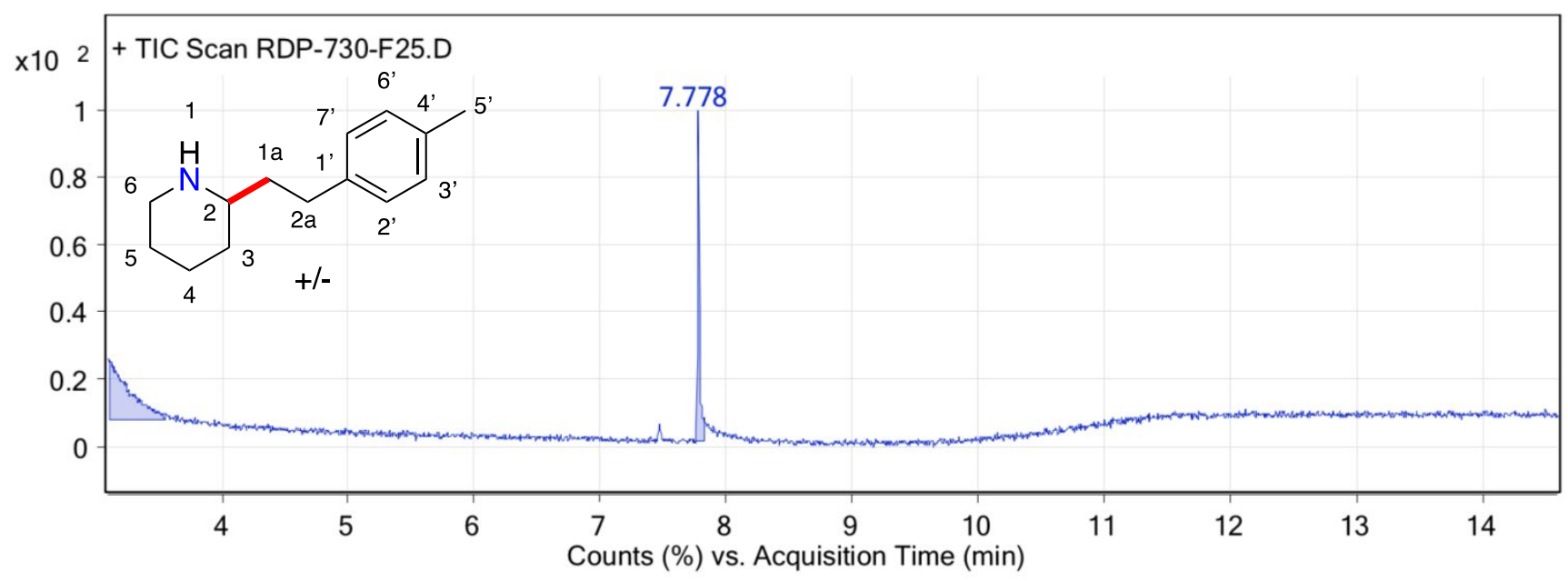

Figure S91: GC-MS report (101 MHz, $\mathrm{CDCl}_{3}, 298 \mathrm{~K}$ ) of 2-(4-methylphenethyl)piperidine.
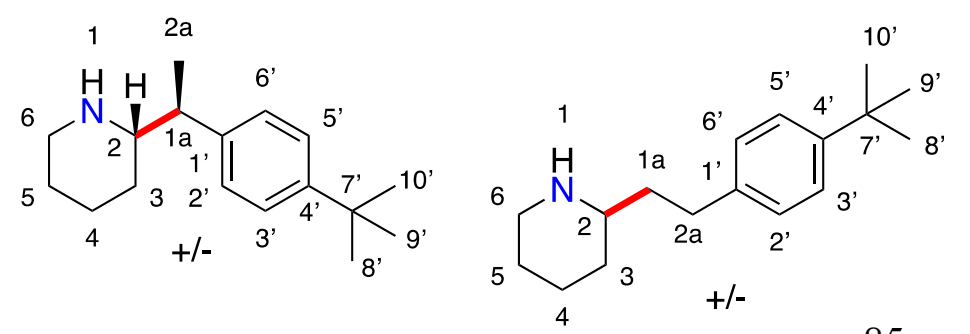

Synthesis of 2-(1-(4-(tertbutyl)phenyl)ethyl)piperidine and 2-(4(tert-butyl)phenethyl)piperidine (18 and 19): Prepared following the general procedure 


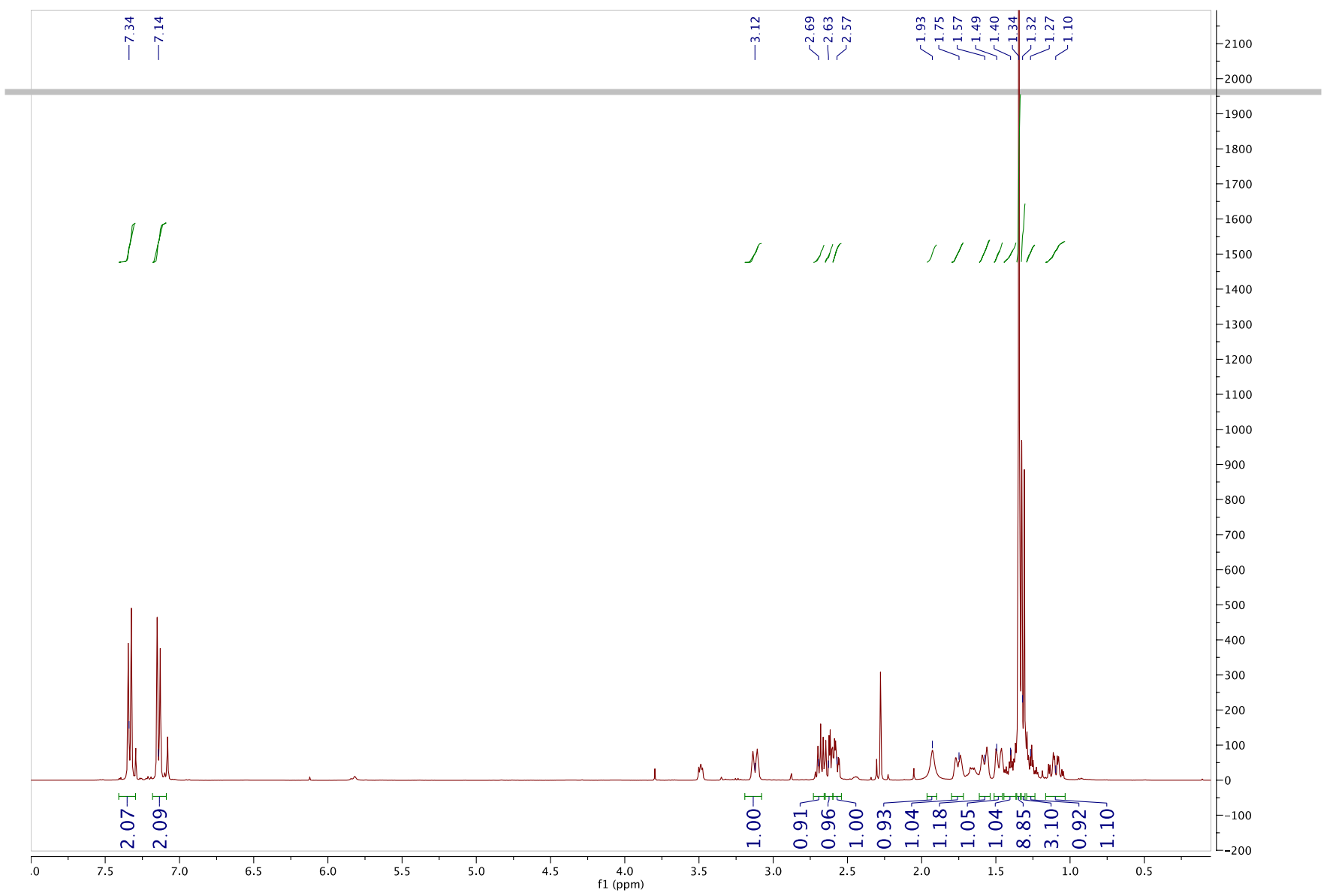

for branched and linear product mixtures outlined above: $26.0 \mathrm{mg}$ Ta, $15.2 \mathrm{mg}$ ligand $\mathbf{L} 4$, piperidine $(85.15 \mathrm{mg}, 1.0 \mathrm{mmol})$, para-t-butylstyrene $(160.13 \mathrm{mg}, 1.0 \mathrm{mmol})$. The reaction was subsequently concentrated and the

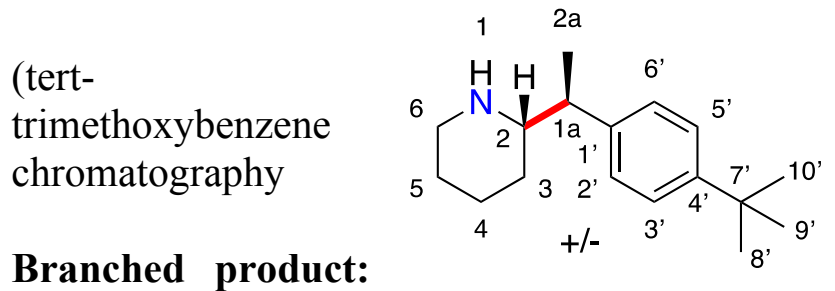
yield was determined to be $65 \%$ for 2-(1-(4-(tertbutyl)phenyl)ethyl)piperidine and $34 \%$ for $2-(4-$ butyl)phenethyl)piperidine by NMR $(1,3,5-$ as a standard). Purification via column (7:2.5:0.5 hexanes : ethyl acetate : triethyl amine):

${ }^{1} \mathrm{H}$ NMR $\left(\mathrm{CDCl}_{3}, 400 \mathrm{MHz}, 298 \mathrm{~K}\right): \delta 7.34(\mathrm{~m}, 2 \mathrm{H}$, 3' and 5'), $7.14\left(\mathrm{~m}, 2 \mathrm{H}, 2^{\prime}\right.$ and 6'), $3.12(\mathrm{~m}, 1 \mathrm{H}, 1 / 2$ of 6), $2.69(\mathrm{~m}, 1 \mathrm{H}, 1 \mathrm{a}), 2.63(\mathrm{~m}, 1 \mathrm{H}, 1 / 2$ of 6$), 2.57(\mathrm{~m}$, $1 \mathrm{H}, 2), 1.93$ (broad s, 1H, NH), $1.75(\mathrm{~m}, 1 \mathrm{H}, 1 / 2$ of 4), 1.57 (m, 1H, 1/2 of 5), $1.49(\mathrm{~m}, 1 \mathrm{H}, 1 / 2$ of 3$), 1.40$ (m, 1H, 1/2 of 5), $1.34\left(\mathrm{~s}, 9 \mathrm{H}, 8^{\prime}\right.$ and 9' and 10'), $1.32(\mathrm{~d}, \mathrm{~J}=1.32,3 \mathrm{H}, 2 \mathrm{a}), 1.27(\mathrm{~m}, 1 \mathrm{H}, 1 / 2$ of 4$), 1.10(\mathrm{~m}$, $1 \mathrm{H}, 1 / 2$ of 3) ppm. ${ }^{13} \mathrm{C} \mathrm{NMR}\left(\mathrm{CDCl}_{3}, 101 \mathrm{MHz}, 298 \mathrm{~K}\right): \delta 148.86,141.88,127.44,125.11,47.47,45.03$, $34.37,31.44,30.79,26.46,25.02,17.00 \mathrm{ppm}$. HRMS (ESI): $\mathrm{m} / z$ calcd for $\mathrm{C}_{17} \mathrm{H}_{27} \mathrm{~N}\left[\mathrm{M}+\mathrm{H}^{+}\right]: 245.2143$ Found: 245.2147.

Linear Product: ${ }^{1} \mathrm{H}$ NMR ( $\left.\mathrm{CDCl}_{3}, 400 \mathrm{MHz}, 298 \mathrm{~K}\right): \delta 7.33(\mathrm{~m}, 2 \mathrm{H}, 3$ ' and 5'), 7.15 (m, 2H, 2' and 6'), $3.12(\mathrm{~m}, 1 \mathrm{H}, 1 / 2$ of 6$), 2.70(\mathrm{~m}, 1 \mathrm{H}, 1 / 2$ of 6$), 2.64(\mathrm{~m}, 2 \mathrm{H}, 2 \mathrm{a}), 2.56(\mathrm{~m}, 1 \mathrm{H}, 2), 2.26$ (broad s, 1H, NH), $1.82(\mathrm{~m}, 1 \mathrm{H}, 1 / 2$ of 4$), 1.77(\mathrm{~m}, 1 \mathrm{H}, 1 / 2$ of 3$), 1.70(\mathrm{~m}, 2 \mathrm{H}, 1 \mathrm{a}), 1.63(\mathrm{~m}, 1 \mathrm{H}, 1 / 2$ of 5$), 1.48(\mathrm{~m}, 1 \mathrm{H}, 1 / 2$ of 5$)$, $1.41(\mathrm{~m}, 1 \mathrm{H}, 1 / 2$ of 4$), 1.34\left(\mathrm{~s}, 9 \mathrm{H}, 8^{\prime}\right.$ and $9^{\prime}$ and $\left.10^{\prime}\right), 1.18(\mathrm{~m}, 1 \mathrm{H}, 1 / 2$ of 3$) \mathrm{ppm} .{ }^{13} \mathrm{C} \mathrm{NMR}\left(\mathrm{CDCl}_{3}, 101\right.$ $\mathrm{MHz}, 298 \mathrm{~K}): \delta 148.55,139.22,127.97,125.26,56.56,47.05,39.01,34.36,32.75,31.72,31.42,26.46$, 24.76 ppm. HRMS (ESI): $m / z$ calcd for $\mathrm{C}_{17} \mathrm{H}_{27} \mathrm{~N}\left[\mathrm{M}+\mathrm{H}^{+}\right]$: 245.2143 Found: 245.2148 .

Figure S92: ${ }^{1} \mathrm{H}$ NMR spectrum (400 MHz, $\mathrm{CDCl}_{3}, 298 \mathrm{~K}$ ) of 2-(1-(4-(tert-butyl)phenyl)ethyl)piperidine. 


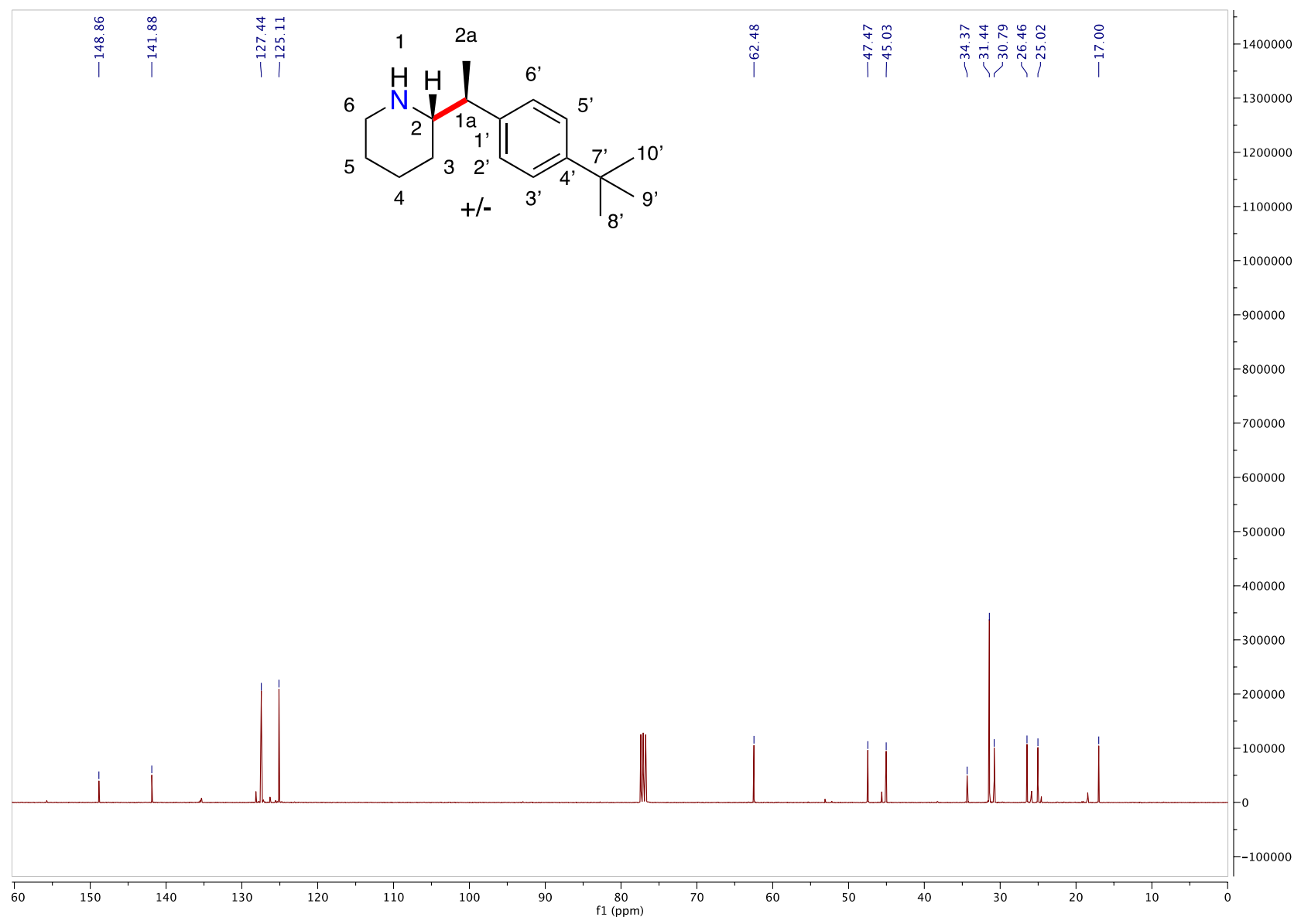

Figure S93: ${ }^{13} \mathrm{C}$ NMR spectrum $\left(101 \mathrm{MHz}, \mathrm{CDCl}_{3}, 298 \mathrm{~K}\right)$ 2-(1-(4-(tert-butyl)phenyl)ethyl)piperidine.

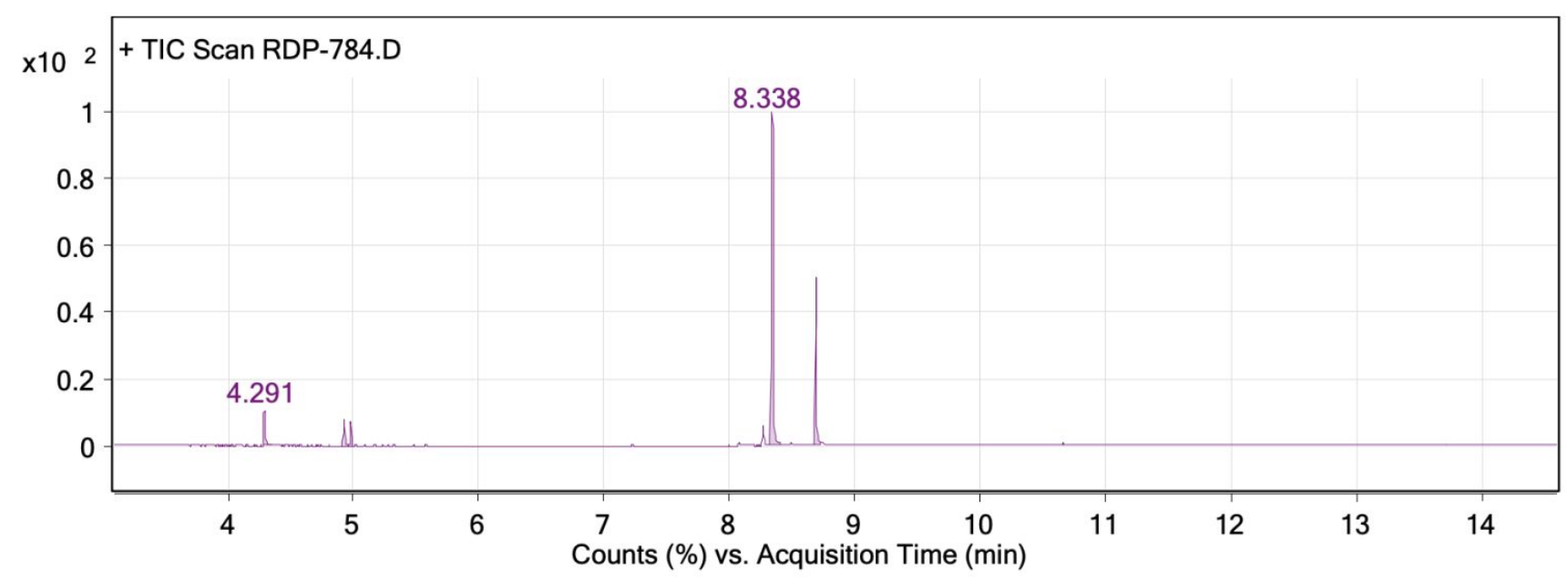

Figure S94: GC-MS report for the crude reaction mixture between piperidine and para-t-butylstyrene. 


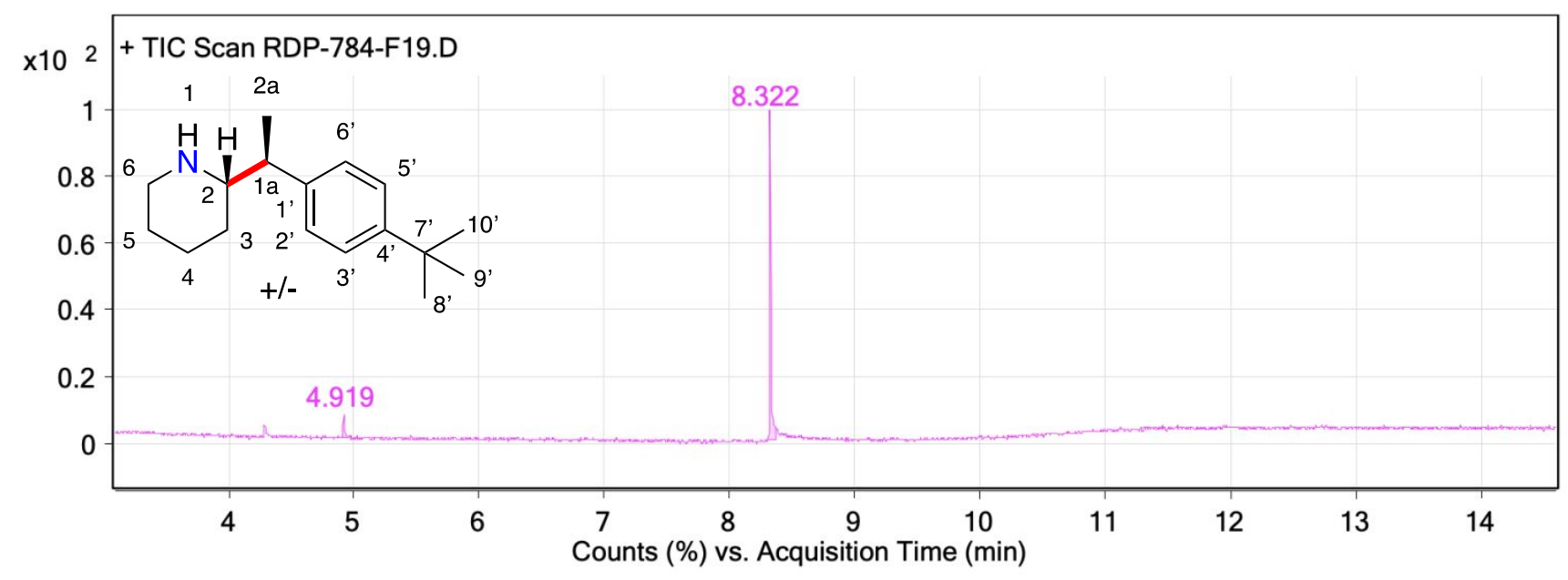

Figure S95: GC-MS report for 2-(1-(4-(tert-butyl)phenyl)ethyl)piperidine.

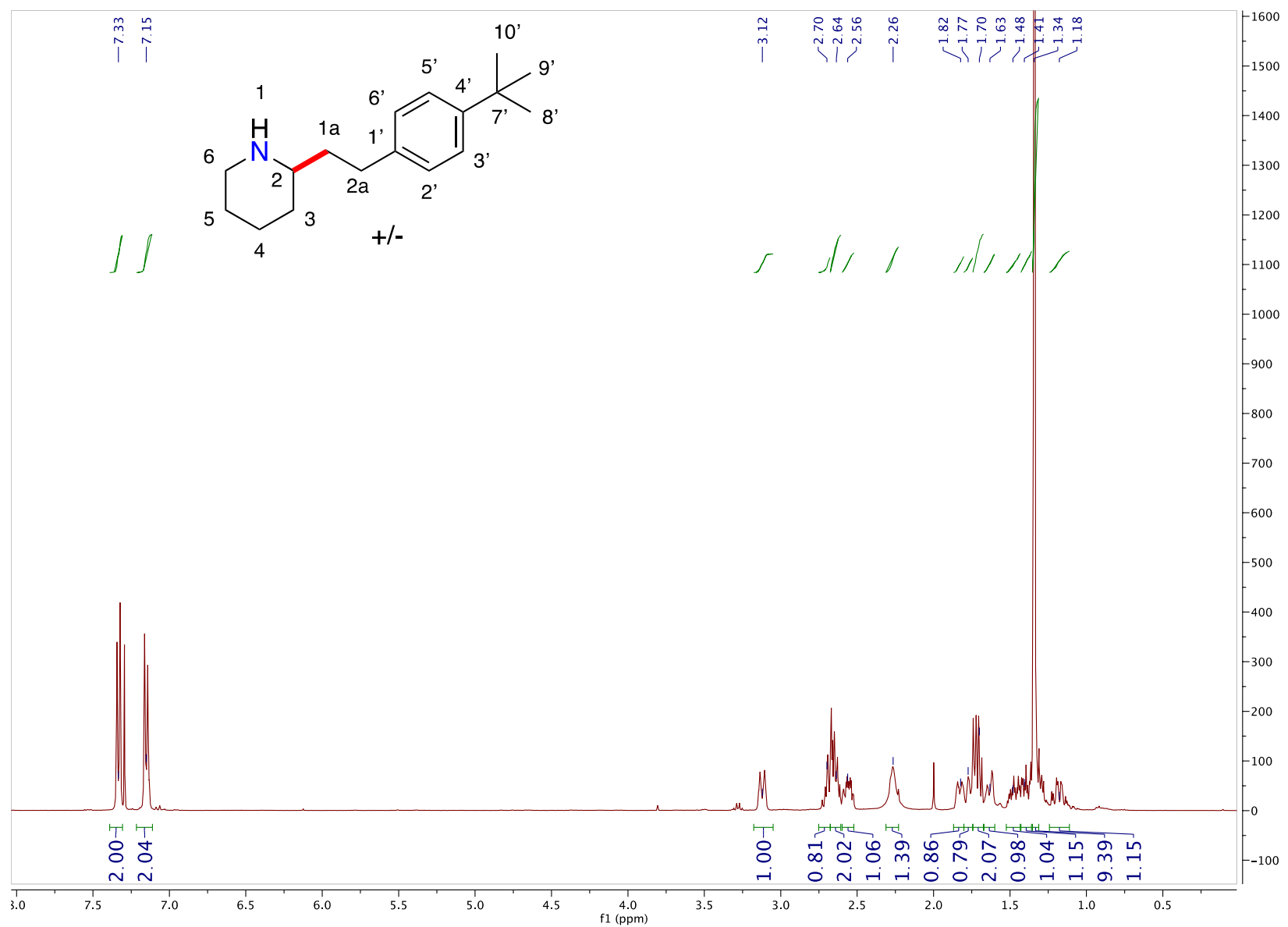

Figure S96: ${ }^{1} \mathrm{H}$ NMR spectrum (400 MHz, $\left.\mathrm{CDCl}_{3}, 298 \mathrm{~K}\right)$ of 2-(4-(tert-butyl)phenethyl)piperidine. 


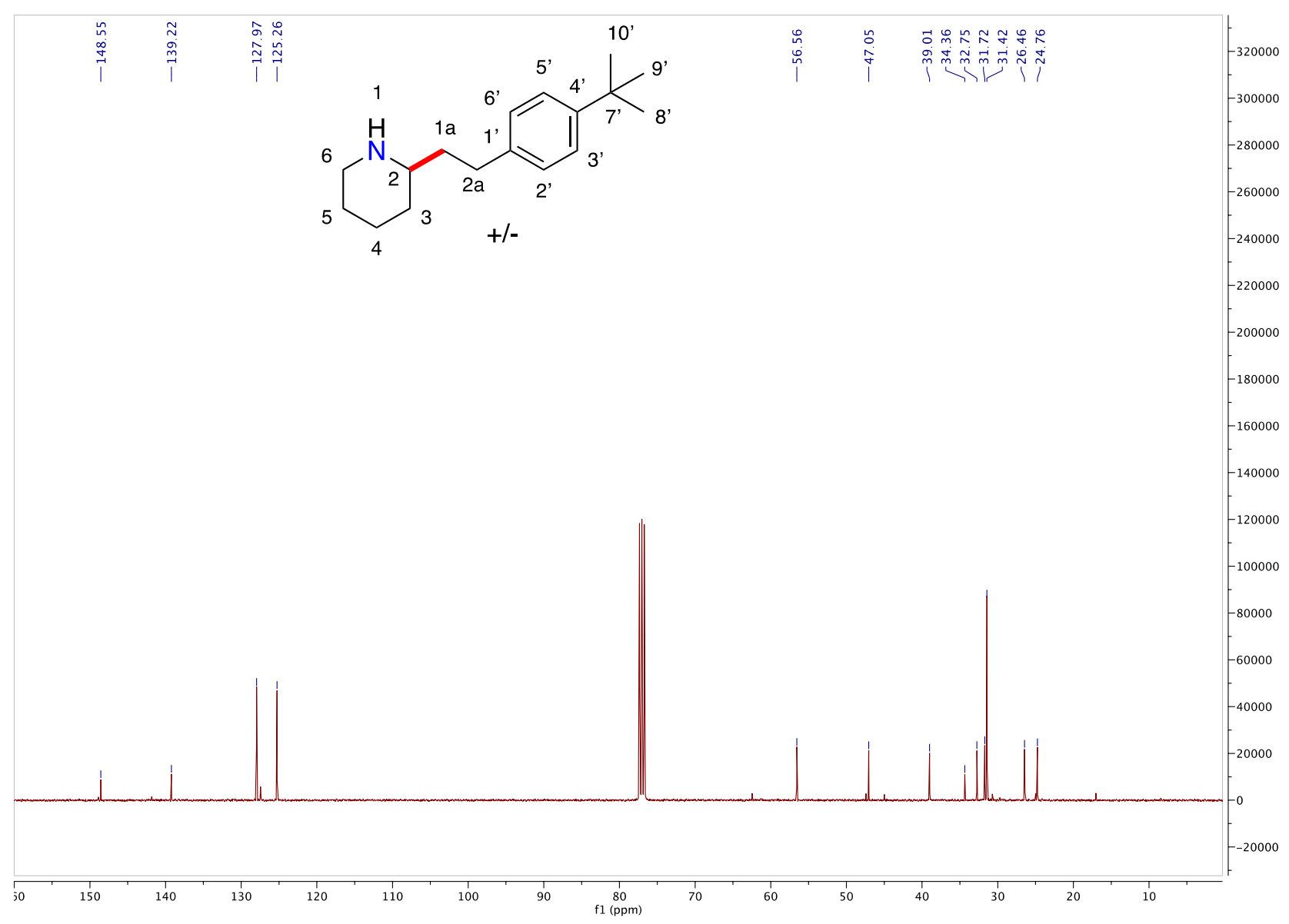

Figure S97: ${ }^{13} \mathrm{C}$ NMR spectrum $\left(101 \mathrm{MHz}, \mathrm{CDCl}_{3}, 298 \mathrm{~K}\right)$ 2-(4-(tert-butyl)phenethyl)piperidine.

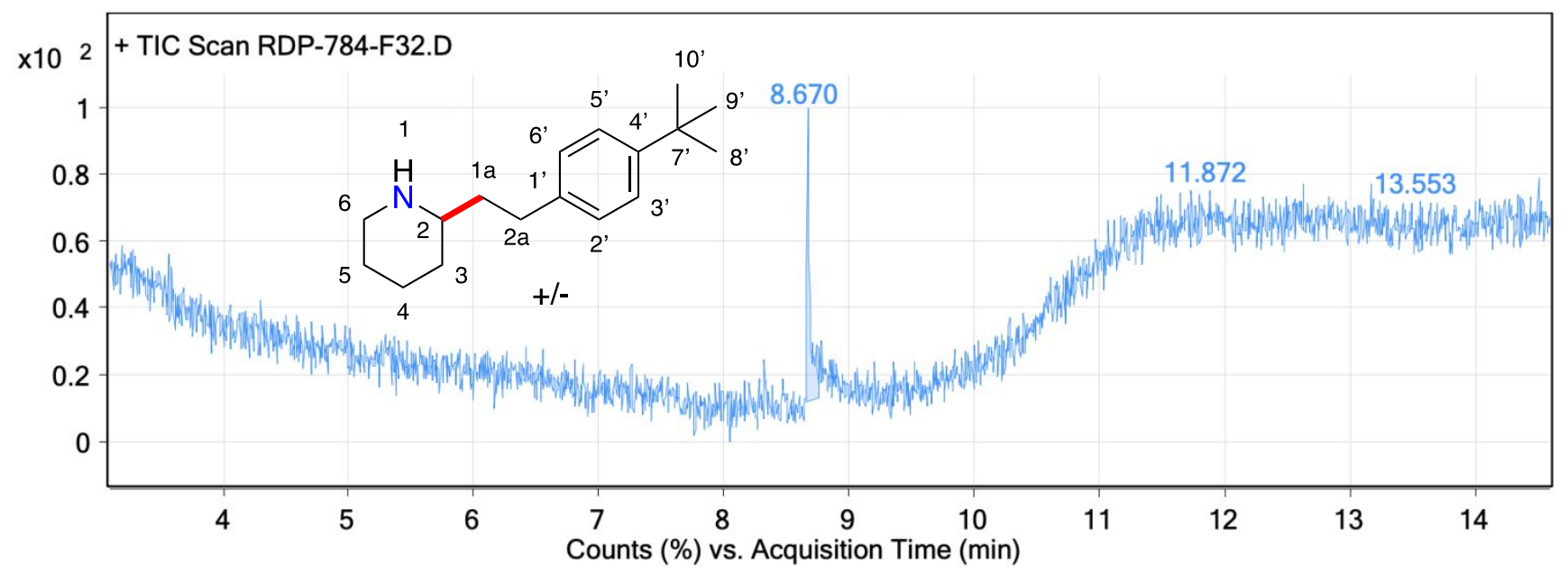

Figure S98: GC-MS report for 2-(4-(tert-butyl)phenethyl)piperidine. 

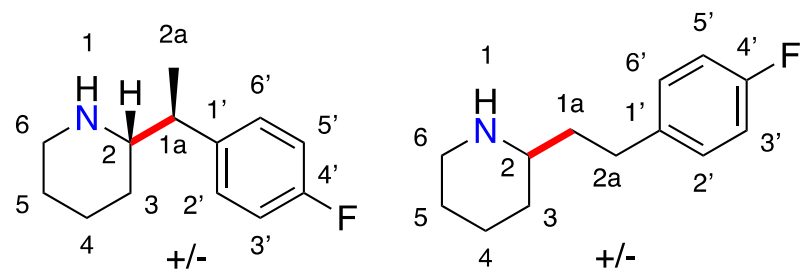

Synthesis of 2-(1-(4-fluorophenyl)ethyl)piperidine and 2-(4-fluorophenethyl)piperidine) (20 and 21): Prepared following the general procedure for branched and linear product mixtures outlined above: $26.0 \mathrm{mg} \mathrm{Ta}$, $15.2 \mathrm{mg}$ ligand $\mathbf{L} 4$, piperidine $(85.15 \mathrm{mg}, 1.0 \mathrm{mmol}$ ), para-fluorostyrene $(122.05 \mathrm{mg}, 1.0 \mathrm{mmol})$. The reaction was subsequently concentrated and the yield was determined to be $60 \%$ for 2-(1-(4fluorophenyl)ethyl)piperidine and $39 \%$ for 2-(4-fluorophenethyl)piperidine by NMR (1,3,5trimethoxybenzene as a standard). Purification via column chromatography (7:2.5:0.5 hexanes : ethyl acetate : triethyl amine):

Branched Regioisomer: ${ }^{1} \mathrm{H}$ NMR $\left(\mathrm{CDCl}_{3}, 400 \mathrm{MHz}, 298 \mathrm{~K}\right): \delta 7.12(\mathrm{~m}, 2 \mathrm{H}, 3$ ' and 5'), $6.96(\mathrm{~m}, 2 \mathrm{H}, 2$ ' and 6'), $3.09(\mathrm{~m}, 1 \mathrm{H}, 1 / 2$ of 6$), 2.64(\mathrm{~m}, 1 \mathrm{H}, 1 \mathrm{a}), 2.58(\mathrm{~m}, 1 \mathrm{H}, 1 / 2 \mathrm{of} 6), 2.50(\mathrm{~m}, 1 \mathrm{H}, 2), 1.74($ broad s, $1 \mathrm{H}$, $\mathrm{NH}), 1.70(\mathrm{~m}, 1 \mathrm{H}, 1 / 2$ of 4$), 1.55(\mathrm{~m}, 1 \mathrm{H}, 1 / 2$ of 5$), 1.37(\mathrm{~m}, 1 \mathrm{H}, 1 / 2$ of 4$), 1.32(\mathrm{~m}, 1 \mathrm{H}, 1 / 2$ of 5$), 1.25(\mathrm{~d}, \mathrm{~J}=$ 1.26, 3H, 2a), $1.21(\mathrm{~m}, 1 \mathrm{H}, 1 / 2$ of 4$), 1.02(\mathrm{~m}, 1 \mathrm{H}, 1 / 2$ of 3$) \mathrm{ppm} .{ }^{13} \mathrm{C} \mathrm{NMR}\left(\mathrm{CDCl}_{3}, 101 \mathrm{MHz}, 298 \mathrm{~K}\right): \delta$ 162.70-160-27 (d, J = 242.97), 140.79, 129.24-129.17 (d, J = 7.546), 115.20-114.99 (J = 20.8689), 62.60, 47.54, 45.06, 30.83, 26.54, 25.03, $17.51 \mathrm{ppm}$. HRMS (ESI): $\mathrm{m} / z$ calcd for $\mathrm{C}_{13} \mathrm{H}_{18} \mathrm{FN}\left[\mathrm{M}+\mathrm{H}^{+}\right]: 207.1423$ Found: 207.1427.

Linear Regioisomer: ${ }^{~} \mathrm{H}$ NMR $\left(\mathrm{CDCl}_{3}, 400 \mathrm{MHz}, 298 \mathrm{~K}\right): \delta 7.13(\mathrm{~m}, 2 \mathrm{H}, 3$ ' and 5'), $6.95(\mathrm{~m}, 2 \mathrm{H}, 2$ ' and 6'), $3.07(\mathrm{~m}, 1 \mathrm{H}, 1 / 2$ of 6$), 2.66(\mathrm{~m}, 2 \mathrm{H}, 1 \mathrm{a}), 2.58(\mathrm{~m}, 1 \mathrm{H}, 1 / 2$ of 6$), 2.49(\mathrm{~m}, 1 \mathrm{H}, 2), 2.08$ (broad s, $1 \mathrm{H}, \mathrm{NH})$, $1.79(\mathrm{~m}, 1 \mathrm{H}, 1 / 2$ of 4$), 1,71(\mathrm{~m}, 2 \mathrm{H}, 2 \mathrm{a}), 1.64(\mathrm{~m}, 1 \mathrm{H}, 1 / 2$ of 3$), 1.58(\mathrm{~m}, 1 \mathrm{H}, 1 / 2$ of 5$), 1.42(\mathrm{~m}, 1 \mathrm{H}, 1 / 2$ of 5$)$, $1.34(\mathrm{~m}, 1 \mathrm{H}, 1 / 2$ of 4$), 1.12(\mathrm{~m}, 1 \mathrm{H}, 1 / 2$ of 3$) \mathrm{ppm} .{ }^{13} \mathrm{C} \mathrm{NMR}\left(\mathrm{CDCl}_{3}, 101 \mathrm{MHz}, 298 \mathrm{~K}\right): \delta 161.56-160.14$ $(\mathrm{d}, \mathrm{J}=243.074), 138.03-138.00(\mathrm{~d}, \mathrm{~J}=3.382), 129.77-129.69(\mathrm{q}, \mathrm{J}=7.762), 115.32-115.11(\mathrm{q}, \mathrm{J}=21.148)$, 56.46, 47.19, 39.31, 32.92, 31.58, 26.62, $24.87 \mathrm{ppm}$. HRMS (ESI): $\mathrm{m} / z$ calcd for $\mathrm{C}_{13} \mathrm{H}_{18} \mathrm{FN}\left[\mathrm{M}+\mathrm{H}^{+}\right]$: 207.1423 Found: 207.1427.

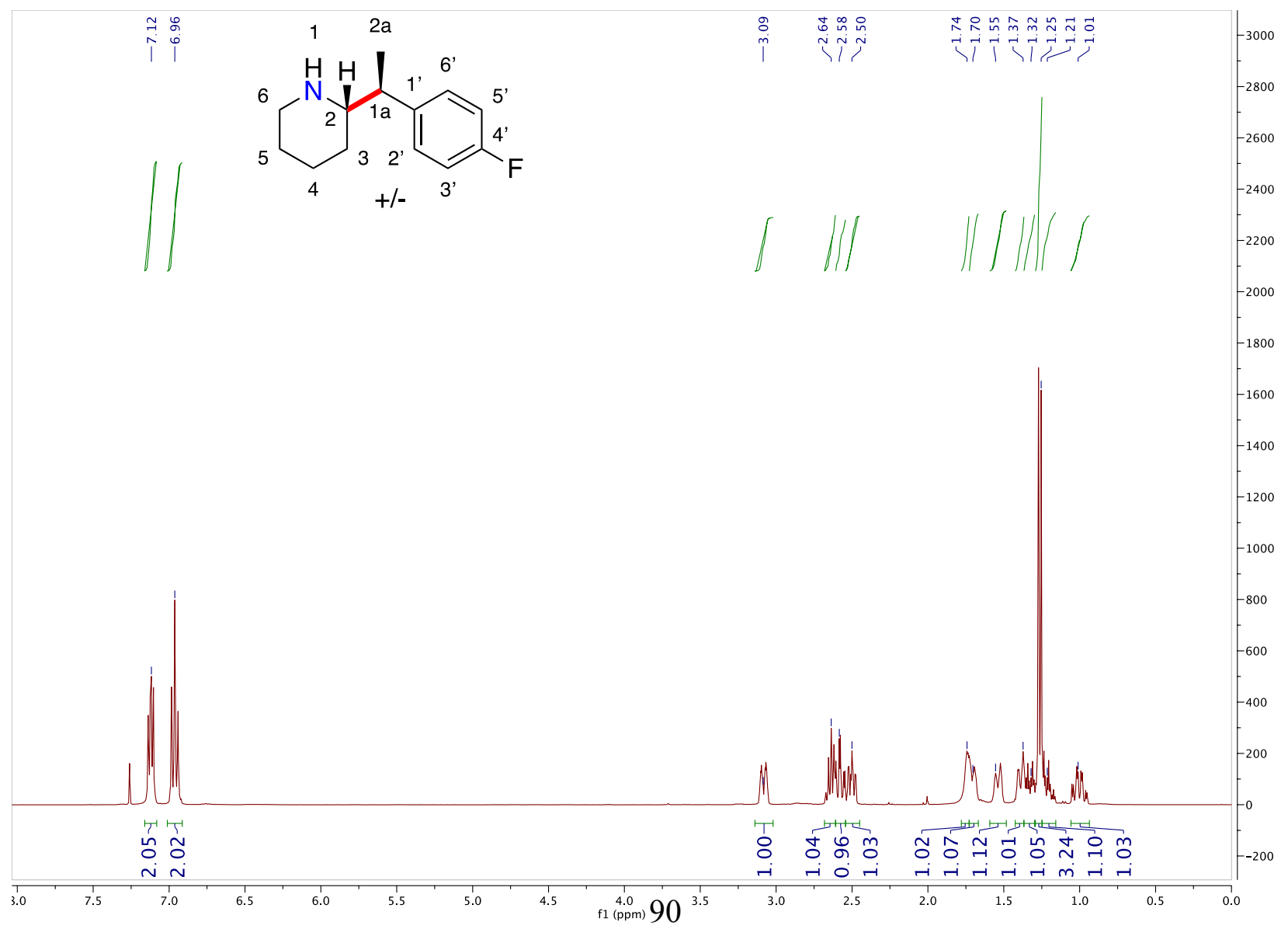


Figure S99: ${ }^{1} \mathrm{H}$ NMR spectrum $\left(400 \mathrm{MHz}, \mathrm{CDCl}_{3}, 298 \mathrm{~K}\right)$ of 2-(1-(4-fluorophenyl)ethyl)piperidine.

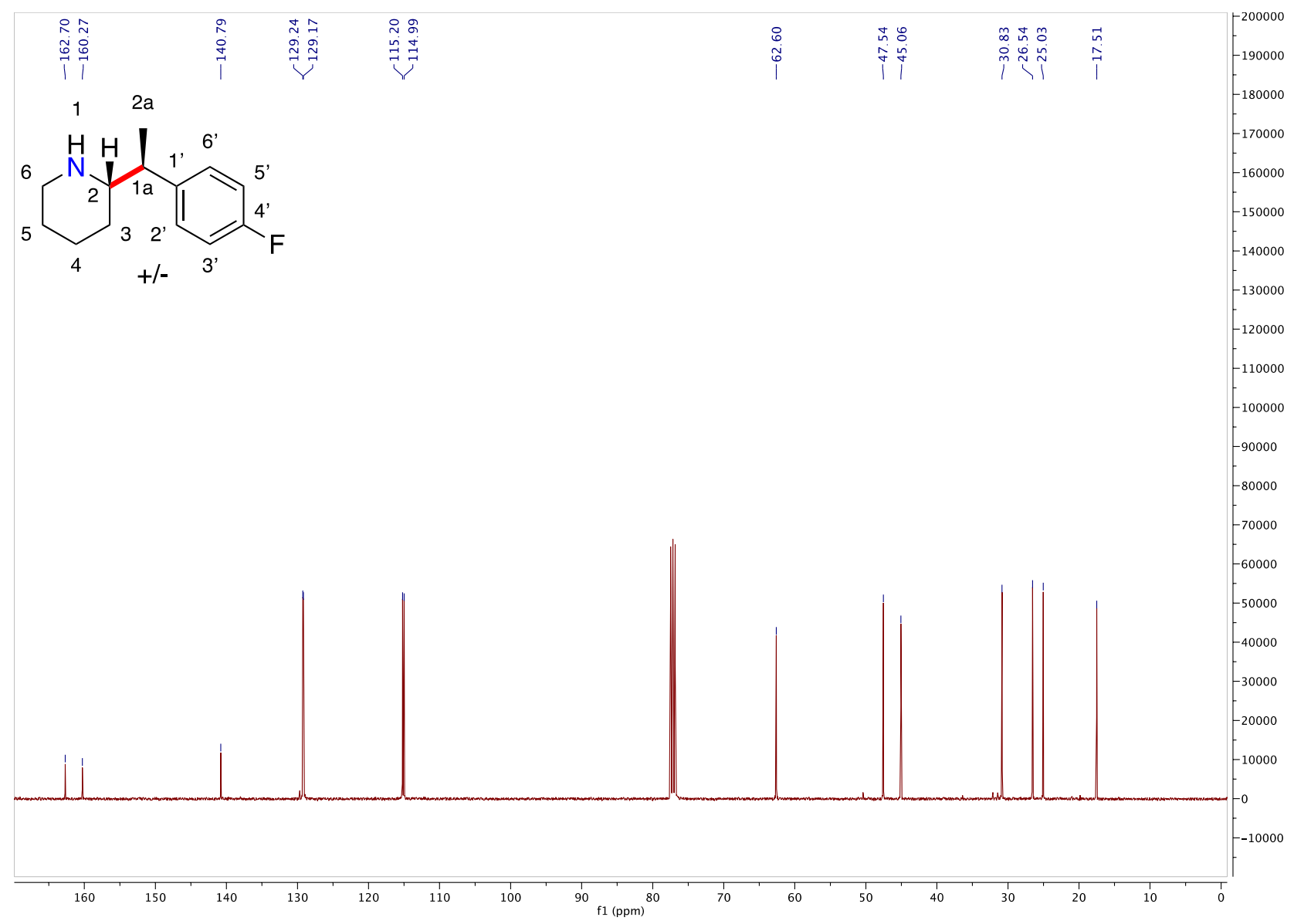

Figure S100: ${ }^{13} \mathrm{C}$ NMR spectrum $\left(101 \mathrm{MHz}, \mathrm{CDCl}_{3}, 298 \mathrm{~K}\right)$ 2-(1-(4-fluorophenyl)ethyl)piperidine. 


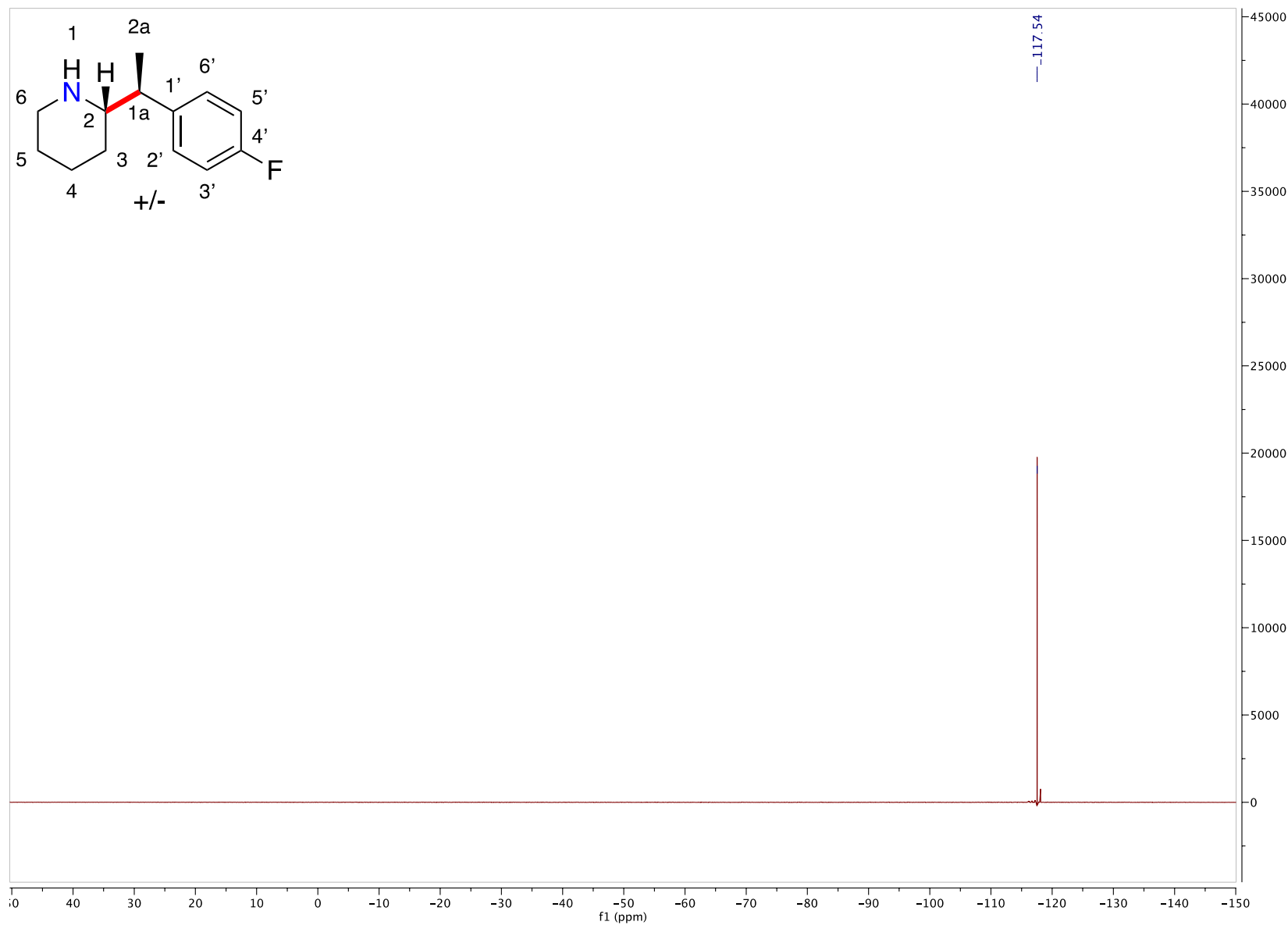

Figure S101: ${ }^{19} \mathrm{~F}$ NMR spectrum (101 MHz, $\left.\mathrm{CDCl}_{3}, 298 \mathrm{~K}\right)$ 2-(1-(4-fluorophenyl)ethyl)piperidine

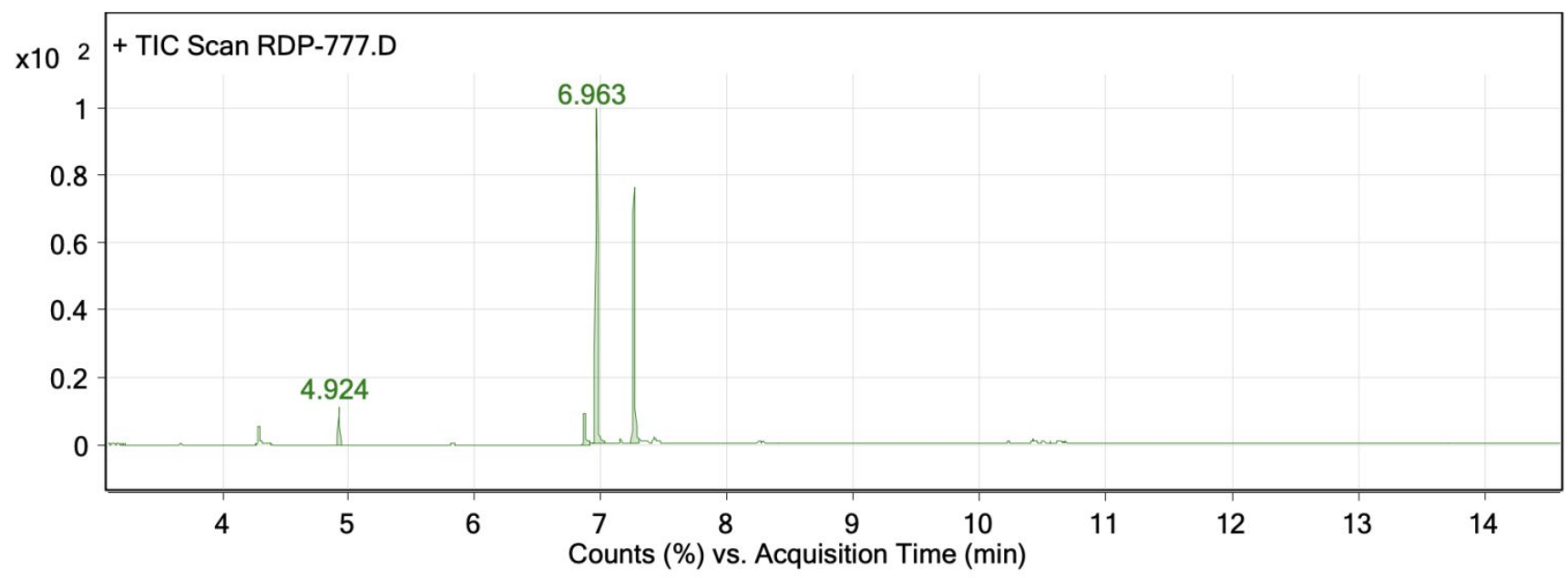

Figure S102: GC-MS for crude reaction mixture between piperidine and para-fluorostyrene. 


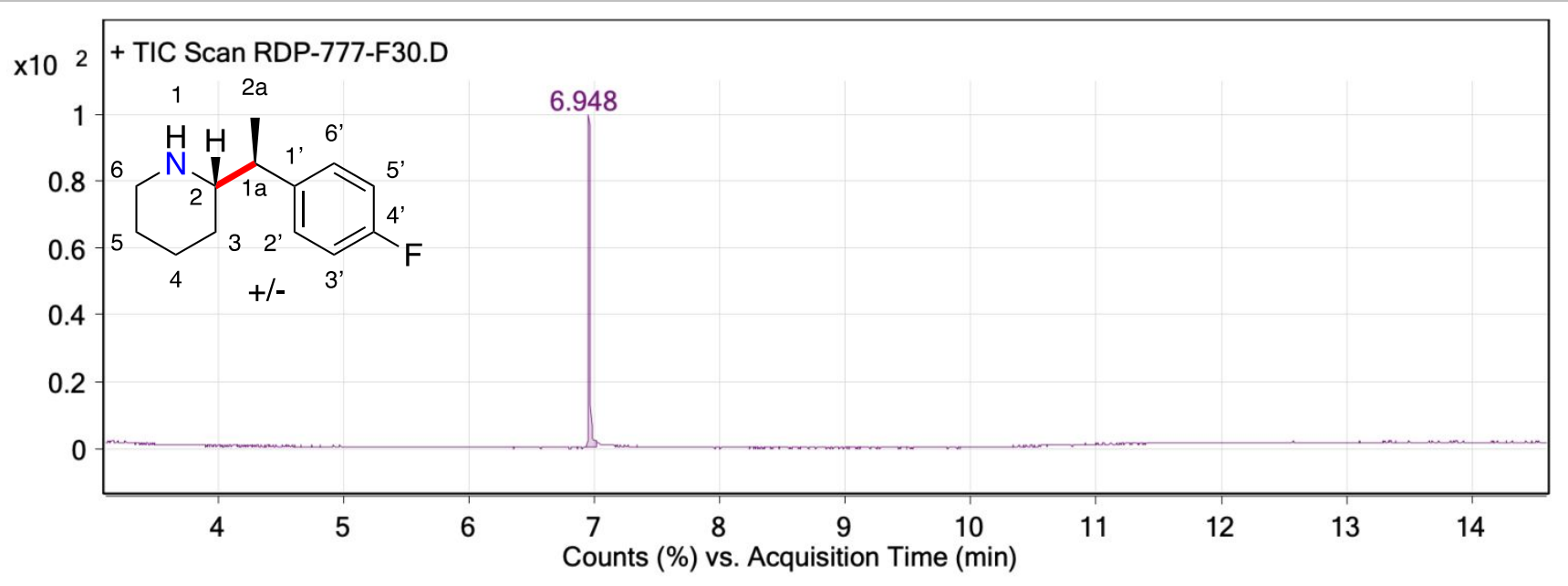

Figure S103: GC-MS report for 2-(1-(4-fluorophenyl)ethyl)piperidine.

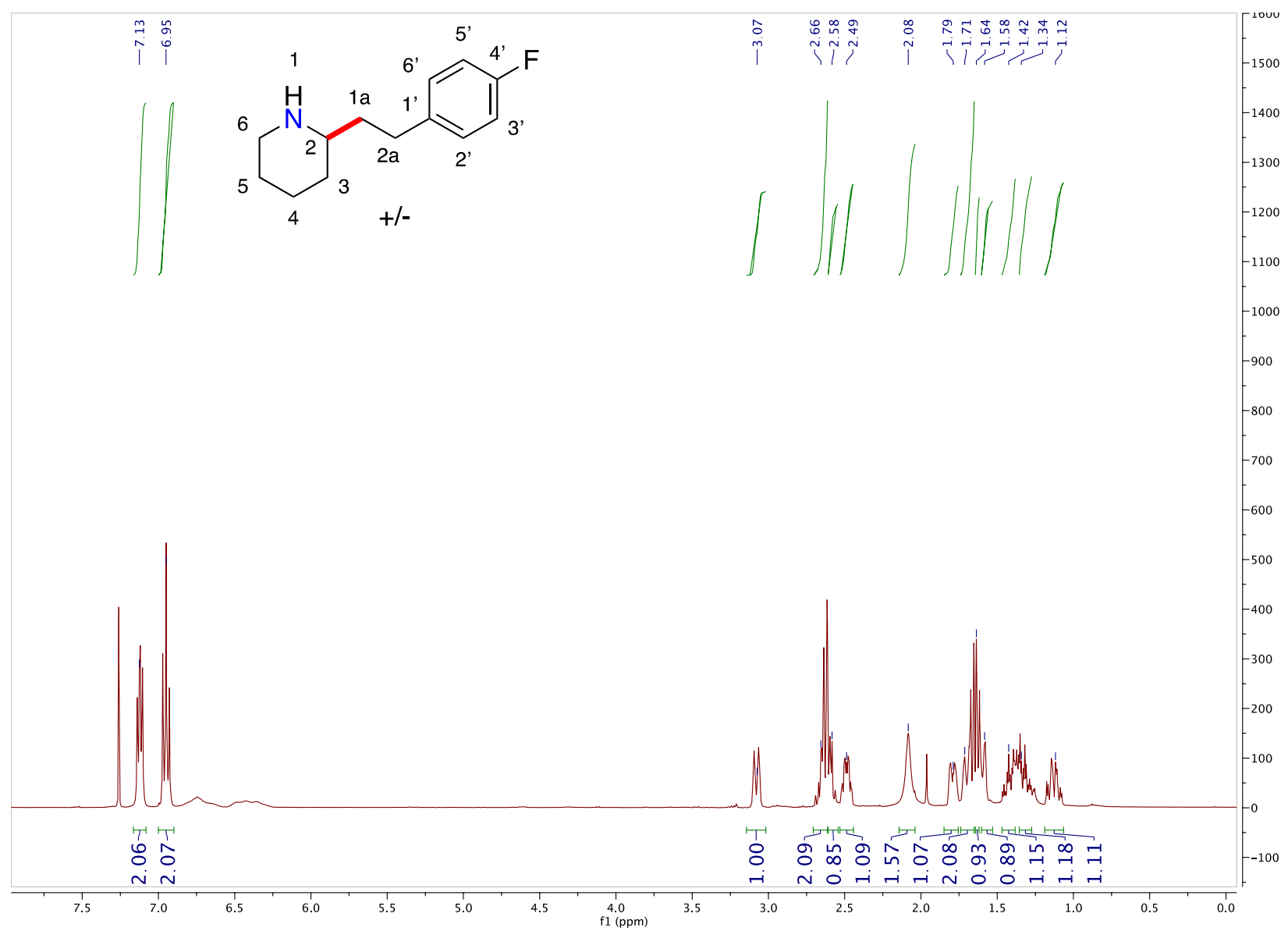

Figure S104: ${ }^{1} \mathrm{H}$ NMR spectrum (400 MHz, $\mathrm{CDCl}_{3}, 298 \mathrm{~K}$ ) of 2-(4-fluorophenethyl)piperidine. 


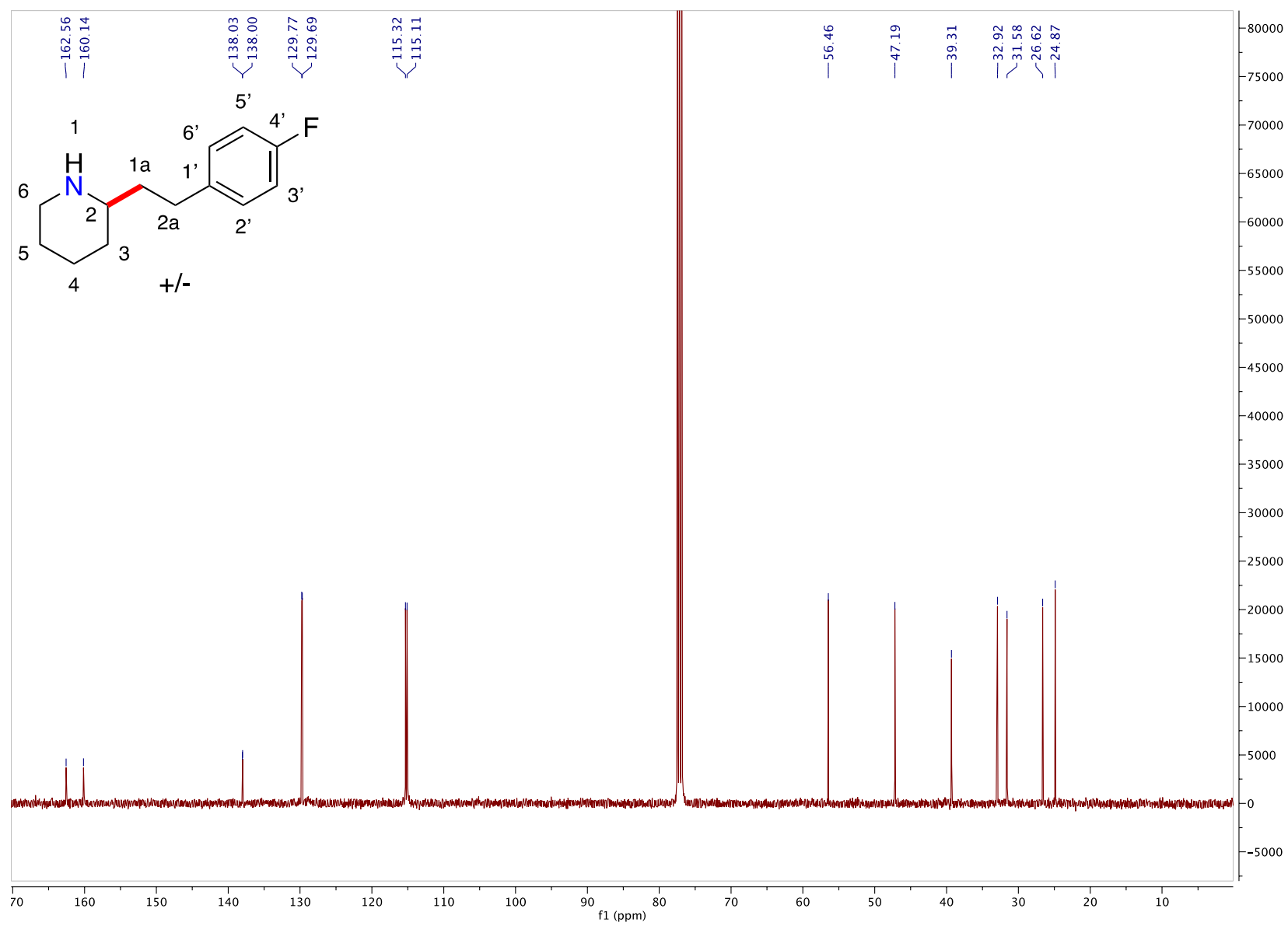

Figure S105: ${ }^{13} \mathrm{C}$ NMR spectrum $\left(101 \mathrm{MHz}, \mathrm{CDCl}_{3}, 298 \mathrm{~K}\right)$ 2-(4-fluorophenethyl)piperidine. 

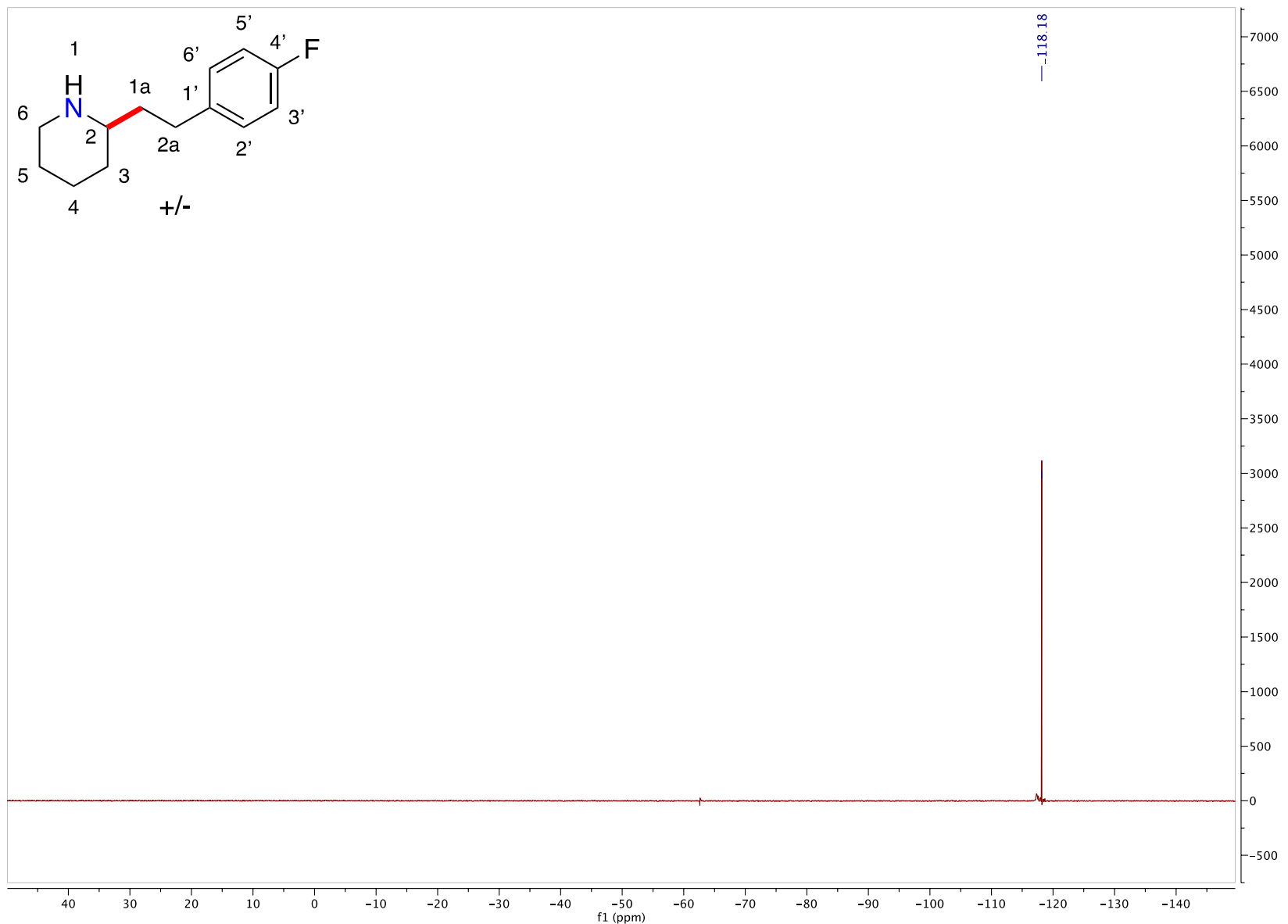

Figure S106: ${ }^{19} \mathrm{~F}$ NMR spectrum $\left(101 \mathrm{MHz}, \mathrm{CDCl}_{3}, 298 \mathrm{~K}\right)$ 2-(4-fluorophenethyl)piperidine.

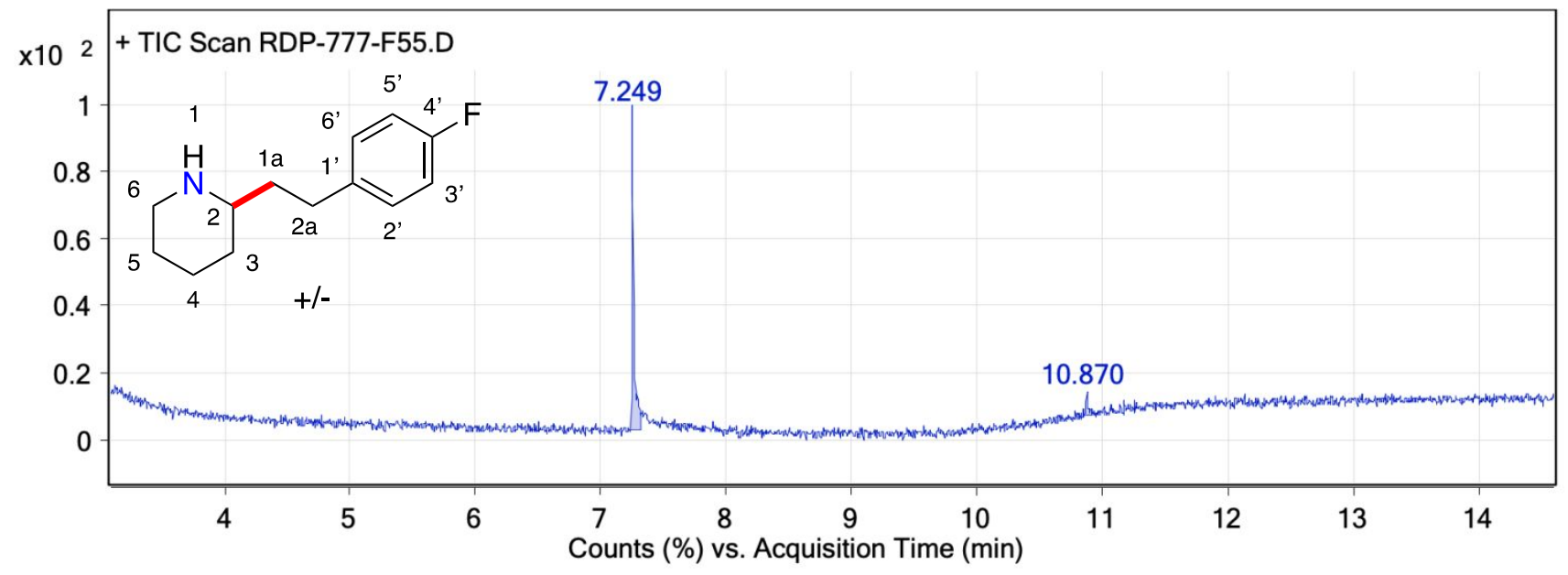

Figure S107: GC-MS report for 2-(4-fluorophenethyl)piperidine. 


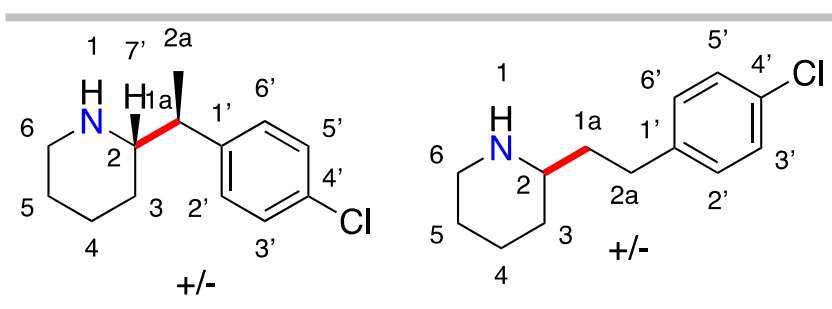

Synthesis of 2-(1-(4-chlorophenyl)ethyl)piperidine and 2-(4-chlorophenethyl)piperidine (22 and 23): Prepared following the general procedure for branched and linear product mixtures outlined above: $26.0 \mathrm{mg}$ Ta, $15.2 \mathrm{mg}$ ligand $\mathbf{L} 4$, piperidine $(85.15 \mathrm{mg}$, $1.0 \mathrm{mmol})$, 4-chlorostyrene (138.59 $\mathrm{mg}, 1.0 \mathrm{mmol})$.

The reaction was subsequently concentrated and the yield was determined to be $54 \%$ for 2-(1-(4chlorophenyl)ethyl)piperidine and $46 \%$ for 2-(4-chlorophenethyl)piperidine by NMR $(1,3,5$ trimethoxybenzene as a standard). Purification via column chromatography (7:2.5:0.5 hexanes : ethyl acetate : triethyl amine):

Branched Regioisomer: ${ }^{1} \mathrm{H}$ NMR $\left(\mathrm{CDCl}_{3}, 400 \mathrm{MHz}, 298 \mathrm{~K}\right): \delta 7.25(\mathrm{~m}, 2 \mathrm{H}, 3$ ' and 5'), 7.11 (m, 2H, 2' and $\left.6^{\prime}\right), 3.11(\mathrm{~m}, 1 \mathrm{H}, 1 / 2$ of 6$), 2.65(\mathrm{~m}, 1 \mathrm{H}, 1 \mathrm{a}), 2.59(\mathrm{~m}, 1 \mathrm{H}, 1 / 2 \mathrm{of} 6), 2.52(\mathrm{~m}, 1 \mathrm{H}, 2), 1.85$ (broad s, $1 \mathrm{H}$, $\mathrm{NH}), 1.71(\mathrm{~m}, 1 \mathrm{H}, 1 / 2$ of 4$), 1.57(\mathrm{~m}, 1 \mathrm{H}, 1 / 2$ of 5$), 1.41(\mathrm{~m}, 1 \mathrm{H}, 1 / 2$ of 3$), 1.33(\mathrm{~m}, 1 \mathrm{H}, 1 / 2$ of 5$), 1.26(\mathrm{~d}, \mathrm{~J}=$ $1.31,3 \mathrm{H}, 2 \mathrm{a}), 1.22(\mathrm{~m}, 1 \mathrm{H}, 1 / 2$ of 4$), 1.03(\mathrm{~m}, 1 \mathrm{H}, 1 / 2$ of 3$)$ ppm. ${ }^{13} \mathrm{C} \mathrm{NMR}\left(\mathrm{CDCl}_{3}, 101 \mathrm{MHz}, 298 \mathrm{~K}\right): \delta$ $143.42,131.88,129.17,128.43,62.38,47.38,45.06,30.63,26.25,24.81,17.35 \mathrm{ppm}$. HRMS (ESI): $\mathrm{m} / z$ calcd for $\mathrm{C}_{13} \mathrm{H}_{19} \mathrm{NCl}\left[\mathrm{M}+\mathrm{H}^{+}\right]$: 224.1206 Found: 224.1201 .

Linear Regioisomer: ${ }^{1} \mathrm{H}$ NMR $\left(\mathrm{CDCl}_{3}, 400 \mathrm{MHz}, 298 \mathrm{~K}\right): \delta 7.22(\mathrm{~m}, 2 \mathrm{H}, 3$ ' and 5'), 7.10 (m, 2H, 2' and 6'), $3.14(\mathrm{~m}, 1 \mathrm{H}, 1 / 2$ of 6$), 2.66(\mathrm{~m}, 2 \mathrm{H}, 2 \mathrm{a}), 2.64(\mathrm{~m}, 1 \mathrm{H}, 1 / 2 \mathrm{of} 6), 2.53(\mathrm{~m}, 1 \mathrm{H}, 2), 2.45$, (broad s, 1H, $\mathrm{NH}), 1.82(\mathrm{~m}, 1 \mathrm{H}, 1 / 2$ of 4$), 1.74(\mathrm{~m}, 2 \mathrm{H}, 1 \mathrm{a}), 1.69(\mathrm{~m}, 1 \mathrm{H}, 1 / 2$ of 3$), 1.61(\mathrm{~m}, 1 \mathrm{H}, 1 / 2$ of 5$), 1.48(\mathrm{~m}, 1 \mathrm{H}, 1 / 2$ of 5), $1.34(\mathrm{~m}, 1 \mathrm{H}, 1 / 2$ of 4$), 1,22(\mathrm{~m}, 1 \mathrm{H}, 1 / 2$ of 3$) \mathrm{ppm} .{ }^{13} \mathrm{C} \mathrm{NMR}\left(\mathrm{CDCl}_{3}, 101 \mathrm{MHz}, 298 \mathrm{~K}\right): \delta 140.87$, $131.55,129.77,128.55,56.42,47.22,39.11,32.95,31.71,26.66,24.86 \mathrm{ppm}$. HRMS (ESI): $\mathrm{m} / z$ calcd for $\mathrm{C}_{13} \mathrm{H}_{19} \mathrm{NCl}\left[\mathrm{M}+\mathrm{H}^{+}\right]: 224.1206$ Found: 224.1207.

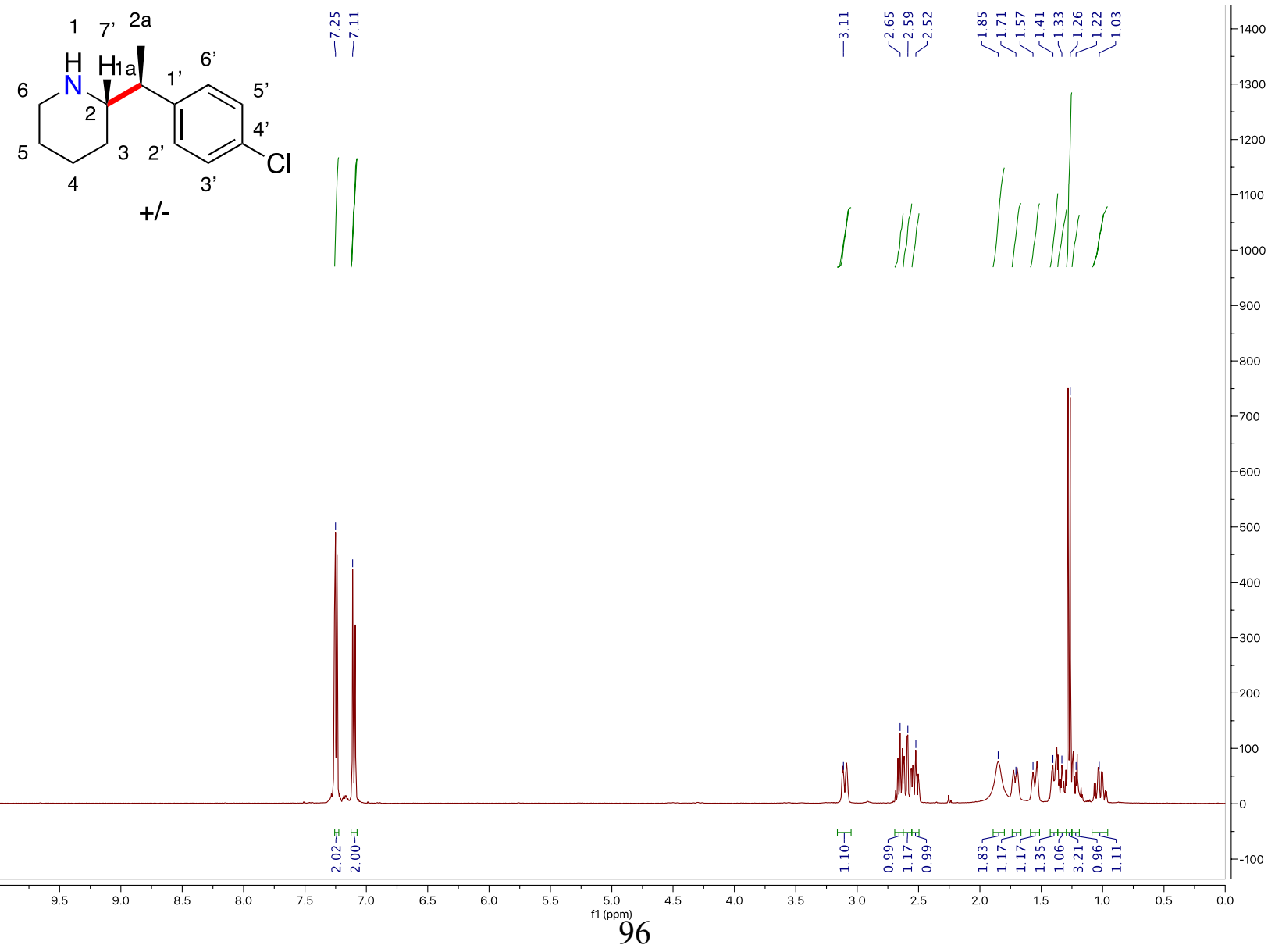


Figure S108: ${ }^{1} \mathrm{H}$ NMR spectrum $\left(400 \mathrm{MHz}, \mathrm{CDCl}_{3}, 298 \mathrm{~K}\right)$ of 2-(1-(4-chlorophenyl)ethyl)piperidine.

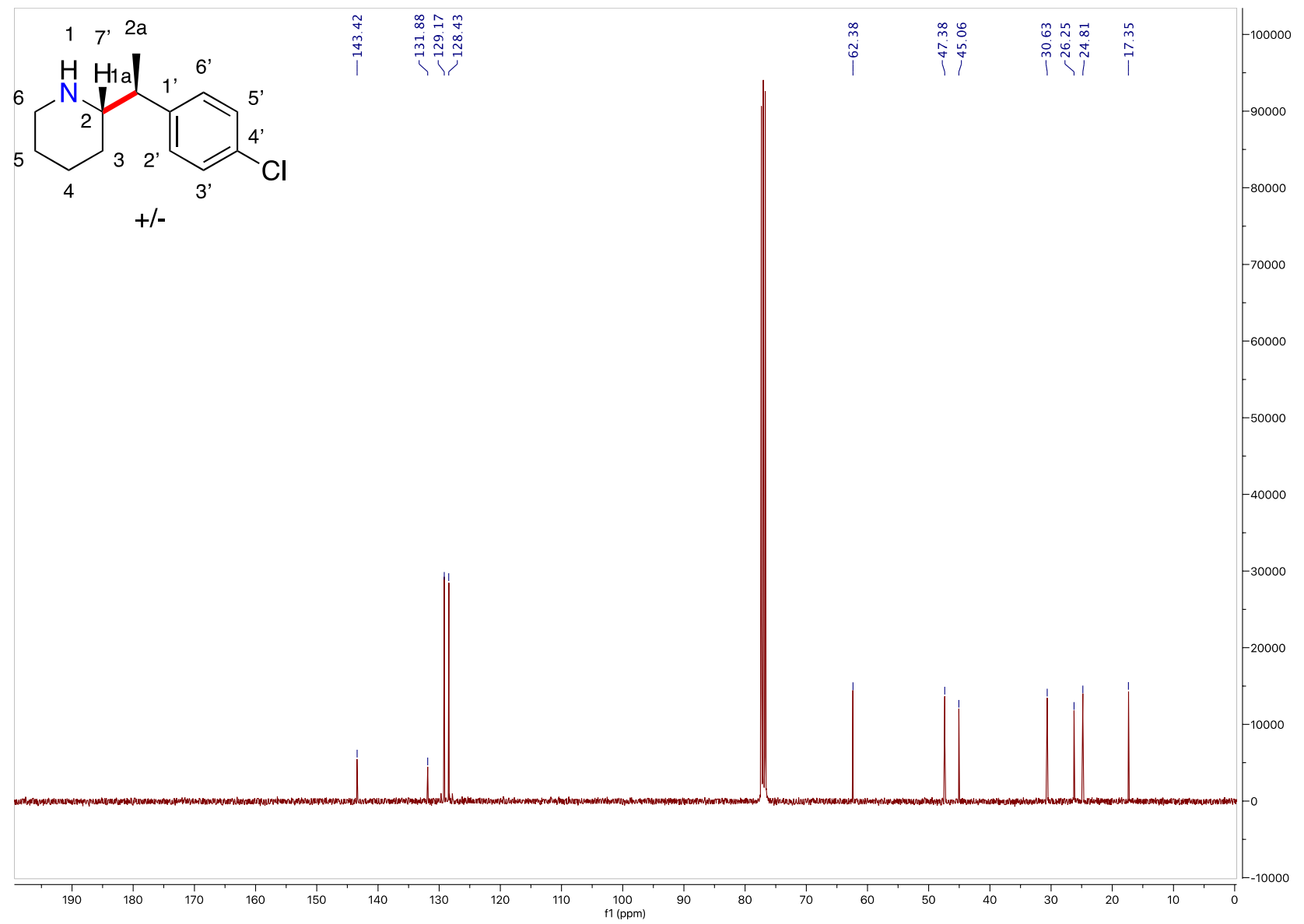

Figure S109: ${ }^{13} \mathrm{C}$ NMR spectrum (101 MHz, $\left.\mathrm{CDCl}_{3}, 298 \mathrm{~K}\right)$ of 2-(1-(4-chlorophenyl)ethyl)piperidine. 


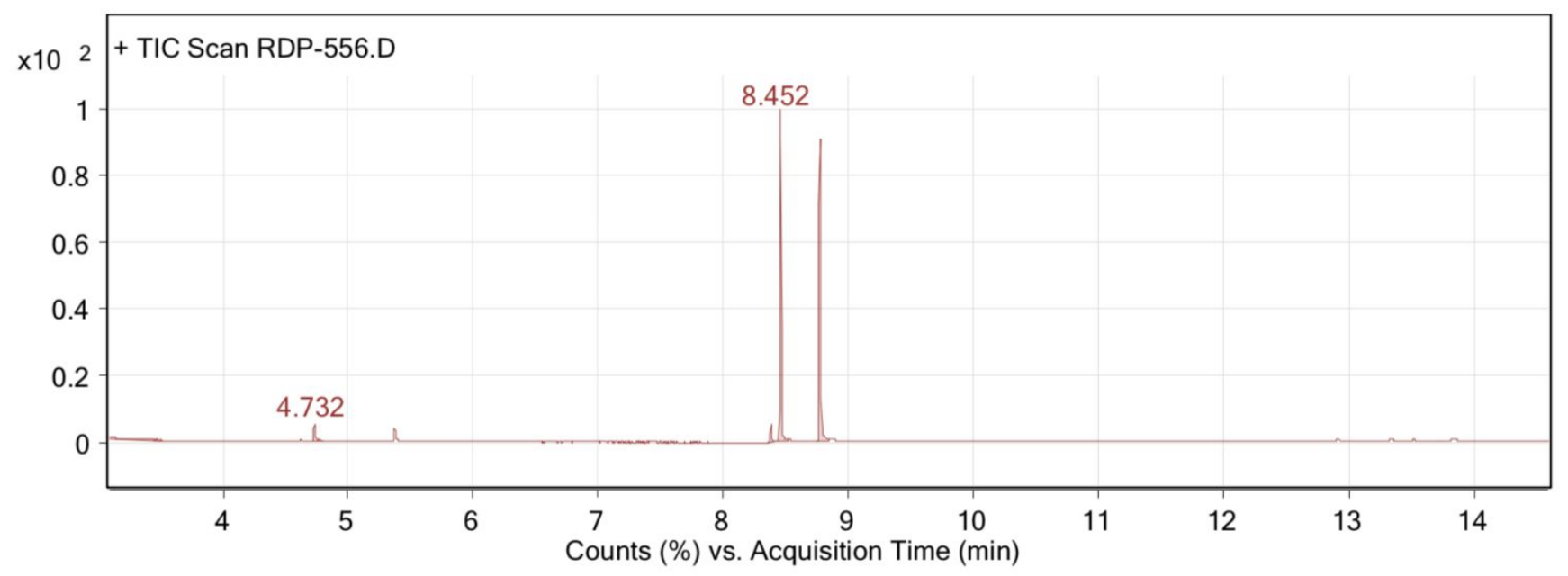

Figure S110: GC-MS for the crude reaction mixture between piperidine and 4-chlorostyrene.

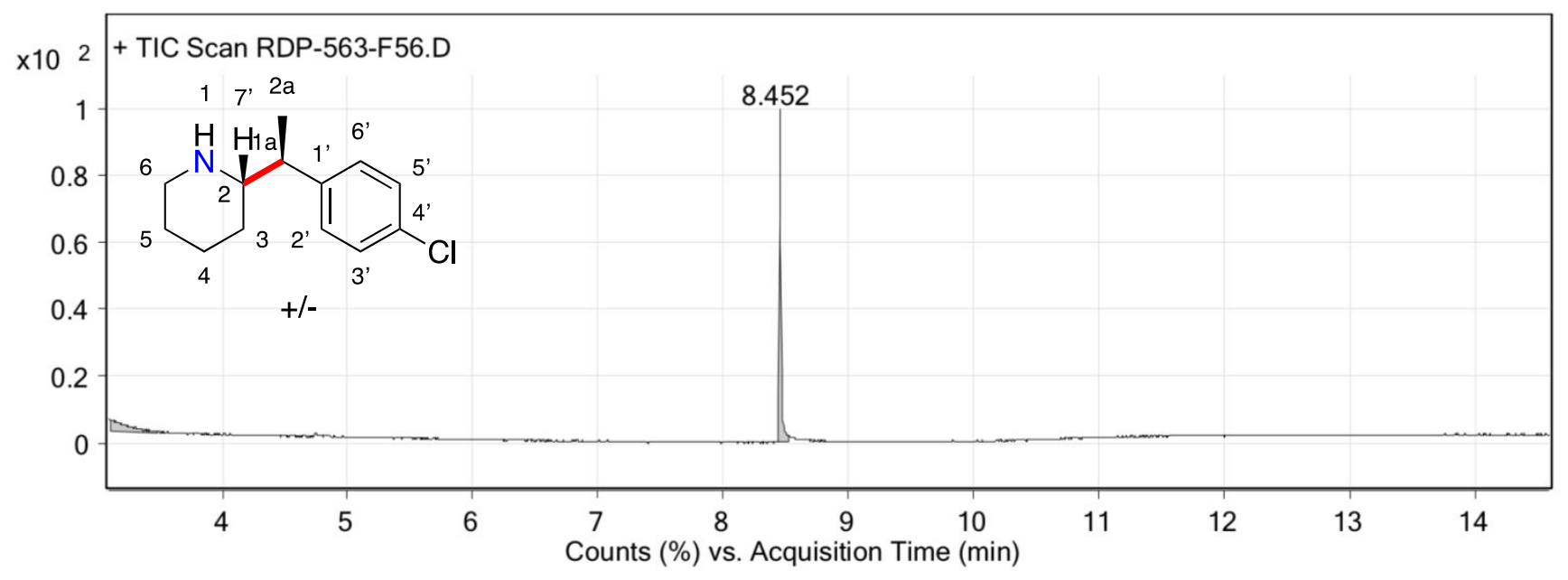

Figure S111: GC-MS report of 2-(1-(4-chlorophenyl)ethyl)piperidine. 


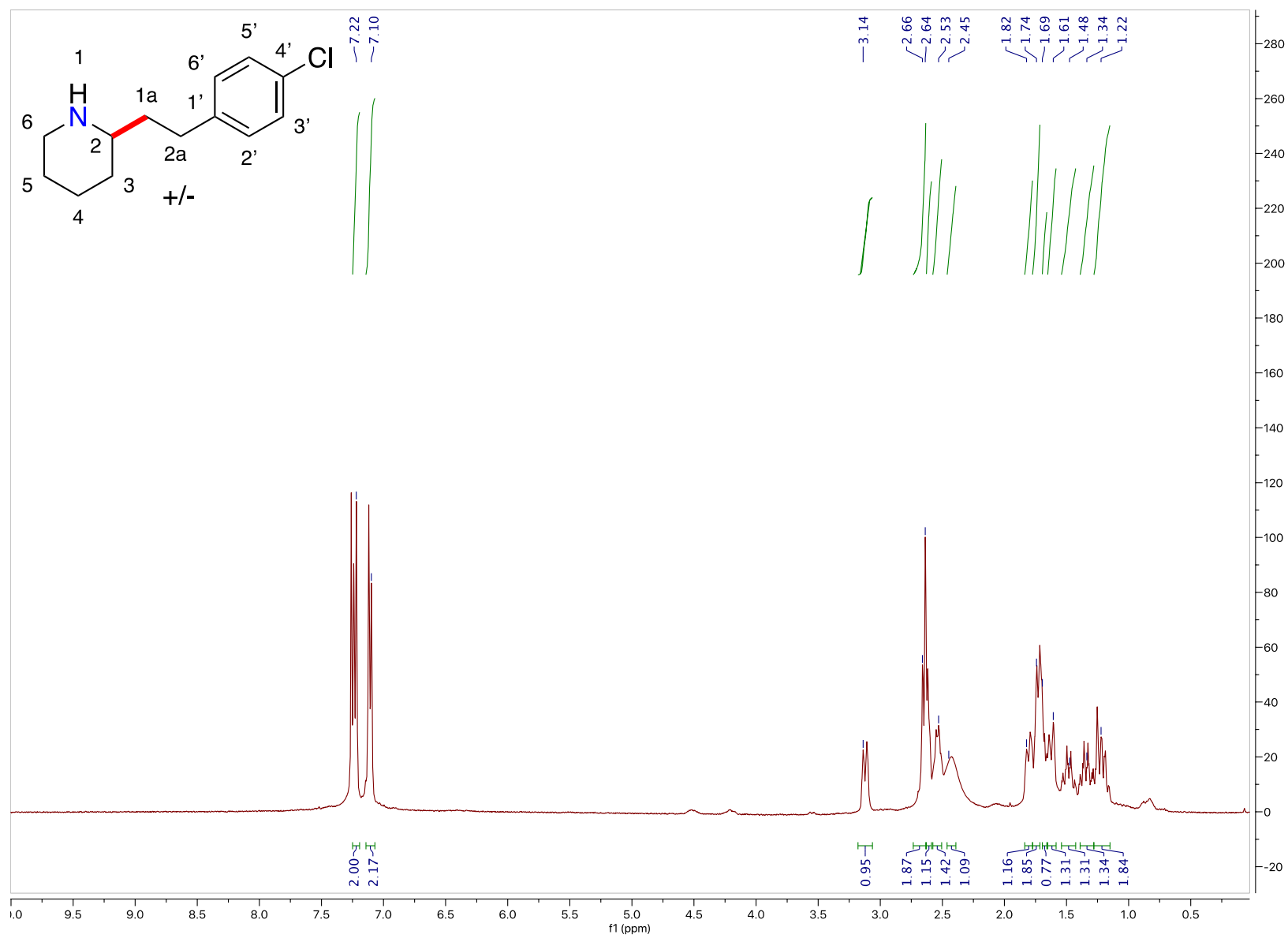

Figure S112: ${ }^{1} \mathrm{H}$ NMR spectrum $\left(400 \mathrm{MHz}, \mathrm{CDCl}_{3}, 298 \mathrm{~K}\right)$ of 2-(4-chlorophenethyl)piperidine. 


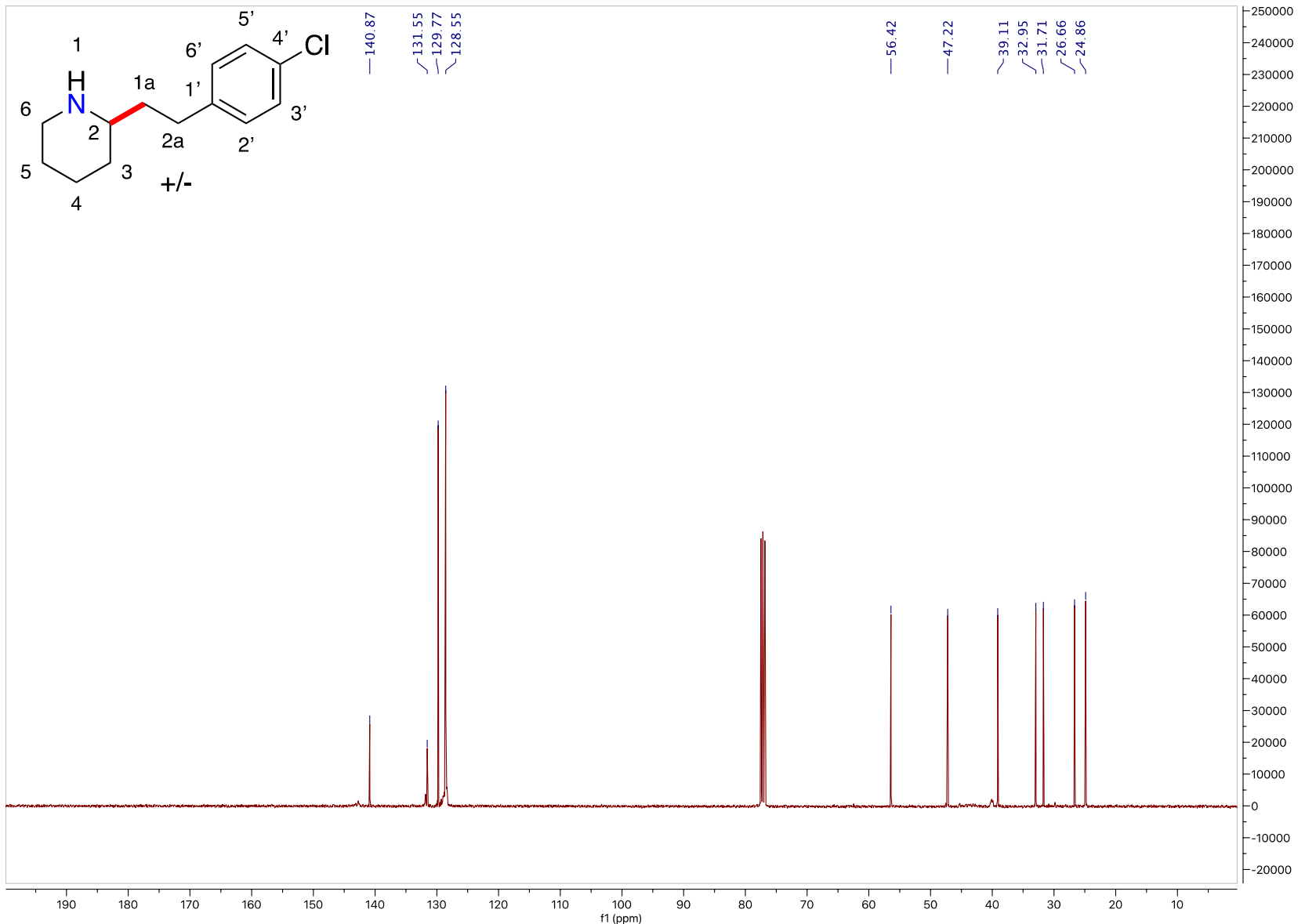

Figure S113: ${ }^{13} \mathrm{C}$ NMR spectrum $\left(101 \mathrm{MHz}, \mathrm{CDCl}_{3}, 298 \mathrm{~K}\right)$ of 2-(4-chlorophenethyl)piperidine.

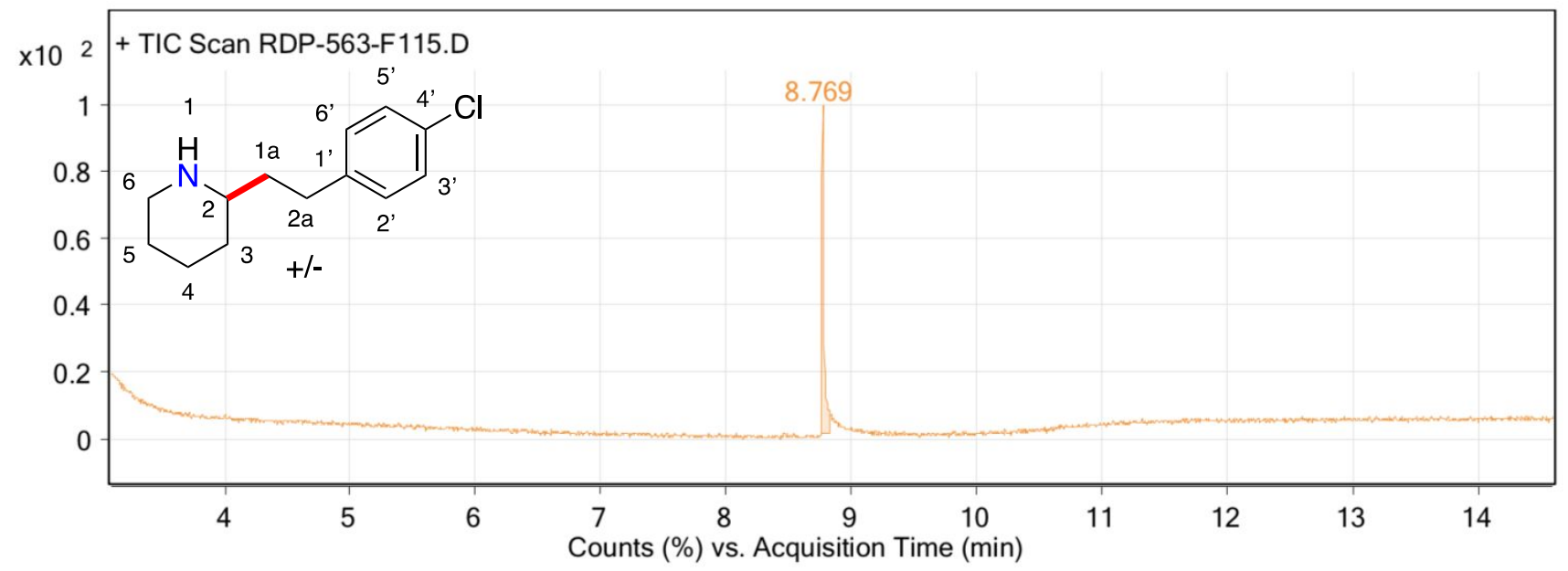

Figure S114: GC-MS report of 2-(4-chlorophenethyl)piperidine. 


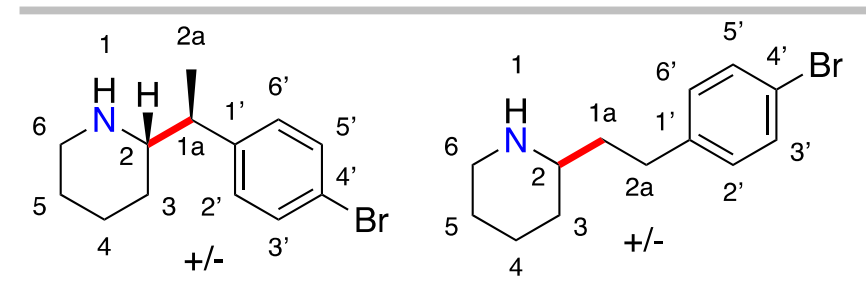

Eyouthopisenyl)ethyl)piperidine and 2-(2-(4bromophenethyl)piperidine (24 and 25): Prepared following the general procedure for branched and linear product mixtures outlined above: $26.0 \mathrm{mg}$ Ta, $15.2 \mathrm{mg}$ ligand $\mathbf{L} 4$, piperidine ( $85.15 \mathrm{mg}, 1.0 \mathrm{mmol}$ ), para-bromostyrene $(181.9 \mathrm{mg}, 1.0 \mathrm{mmol})$. The reaction was subsequently concentrated and the yield was determined to be $58 \%$ for 2-(1-(4bromophenyl)ethyl)piperidine and $42 \%$ for 2-(4-bromophenethyl)piperidine by NMR (1,3,5trimethoxybenzene as a standard). Purification via column chromatography (7:2.5:0.5 hexanes : ethyl acetate : triethyl amine):

Branched Regioisomer: ${ }^{1} \mathrm{H}$ NMR $\left(\mathrm{CDCl}_{3}, 400 \mathrm{MHz}, 298 \mathrm{~K}\right): \delta 7.40$ (m, 2H, 3' and 5'), 7.07 (m, 2H, 2' and 6'), $3.11(\mathrm{~m}, 1 \mathrm{H}, 1 / 2$ of 6$), 2.65(\mathrm{~m}, 1 \mathrm{H}, 1 \mathrm{a}), 2.59(\mathrm{~m}, 1 \mathrm{H}, 1 / 2 \mathrm{of} 6), 2.52(\mathrm{~m}, 1 \mathrm{H}, 2), 1.81$ (broad s, $1 \mathrm{H}$, $\mathrm{NH}), 1.71(\mathrm{~m}, 1 \mathrm{H}, 1 / 2$ of 4$), 1.54(\mathrm{~m}, 1 \mathrm{H}, 1 / 2$ of 5$), 1.39(\mathrm{~m}, 1 \mathrm{H}, 1 / 2$ of 3$), 1.34(\mathrm{~m}, 1 \mathrm{H}, 1 / 2$ of 5$), 1.26(\mathrm{~d}, \mathrm{~J}=$ $1.27,3 \mathrm{H}, 2 \mathrm{a}), 1.22(\mathrm{~m}, 1 \mathrm{H}, 1 / 2$ of 4$), 1.02(\mathrm{~m}, 1 \mathrm{H}, 1 / 2$ of 3$) \mathrm{ppm} .{ }^{13} \mathrm{C} \mathrm{NMR}\left(\mathrm{CDCl}_{3}, 101 \mathrm{MHz}, 298 \mathrm{~K}\right): \delta$ $144.17,131.47,129.71,120.00,62.41,47.53,45.32,30.84,26.51,25.00,17.32 \mathrm{ppm}$. HRMS (ESI): $\mathrm{m} / z$ calcd for $\mathrm{C}_{13} \mathrm{H}_{18} \mathrm{BrN}\left[\mathrm{M}+\mathrm{H}^{+}\right]$: 267.0623 Found: 267.0626 .

Linear Regioisomer: ${ }^{1} \mathrm{H}$ NMR $\left(\mathrm{CDCl}_{3}, 400 \mathrm{MHz}, 298 \mathrm{~K}\right): \delta 7.39(\mathrm{~m}, 2 \mathrm{H}, 3$ ' and 5'), $7.04(\mathrm{~m}, 2 \mathrm{H}, 2$ ' and 6'), $3.11(\mathrm{~m}, 1 \mathrm{H}, 1 / 2$ of 6$) 2.82$ (broad s 1H, NH), $2.65(\mathrm{~m}, 1 \mathrm{H}, 1 / 2$ of 6$), 2.60(\mathrm{~m}, 2 \mathrm{H}, 2 \mathrm{a}), 2.52(\mathrm{~m}, 1 \mathrm{H}, 2)$, $1.79(\mathrm{~m}, 1 \mathrm{H}, 1 / 2$ of 4$), 1.73(\mathrm{~m}, 1 \mathrm{H}, 1 / 2$ of 3$), 1.67(\mathrm{~m}, 2 \mathrm{H}, 1 \mathrm{a}), 1.61(\mathrm{~m}, 1 \mathrm{H}, 1 / 2$ of 5$), 1.45(\mathrm{~m}, 1 \mathrm{H}, 1 / 2$ of 5$)$, $1.36(\mathrm{~m}, 1 \mathrm{H}, 1 / 2$ of 4$), 1.18(\mathrm{~m}, 1 \mathrm{H}, 1 / 2$ of 3$) \mathrm{ppm} .{ }^{13} \mathrm{C} \mathrm{NMR}\left(\mathrm{CDCl}_{3}, 101 \mathrm{MHz}, 298 \mathrm{~K}\right): \delta 141.22,131.56$, $130.23,119.65,56.34,46.88,38.58,32.46,31.70,26.30,24.64 \mathrm{ppm}$. HRMS (ESI): $\mathrm{m} / z$ calcd for $\mathrm{C}_{13} \mathrm{H}_{18} \mathrm{BrN}\left[\mathrm{M}+\mathrm{H}^{+}\right]: 267.0623$ Found: 267.0625 . 


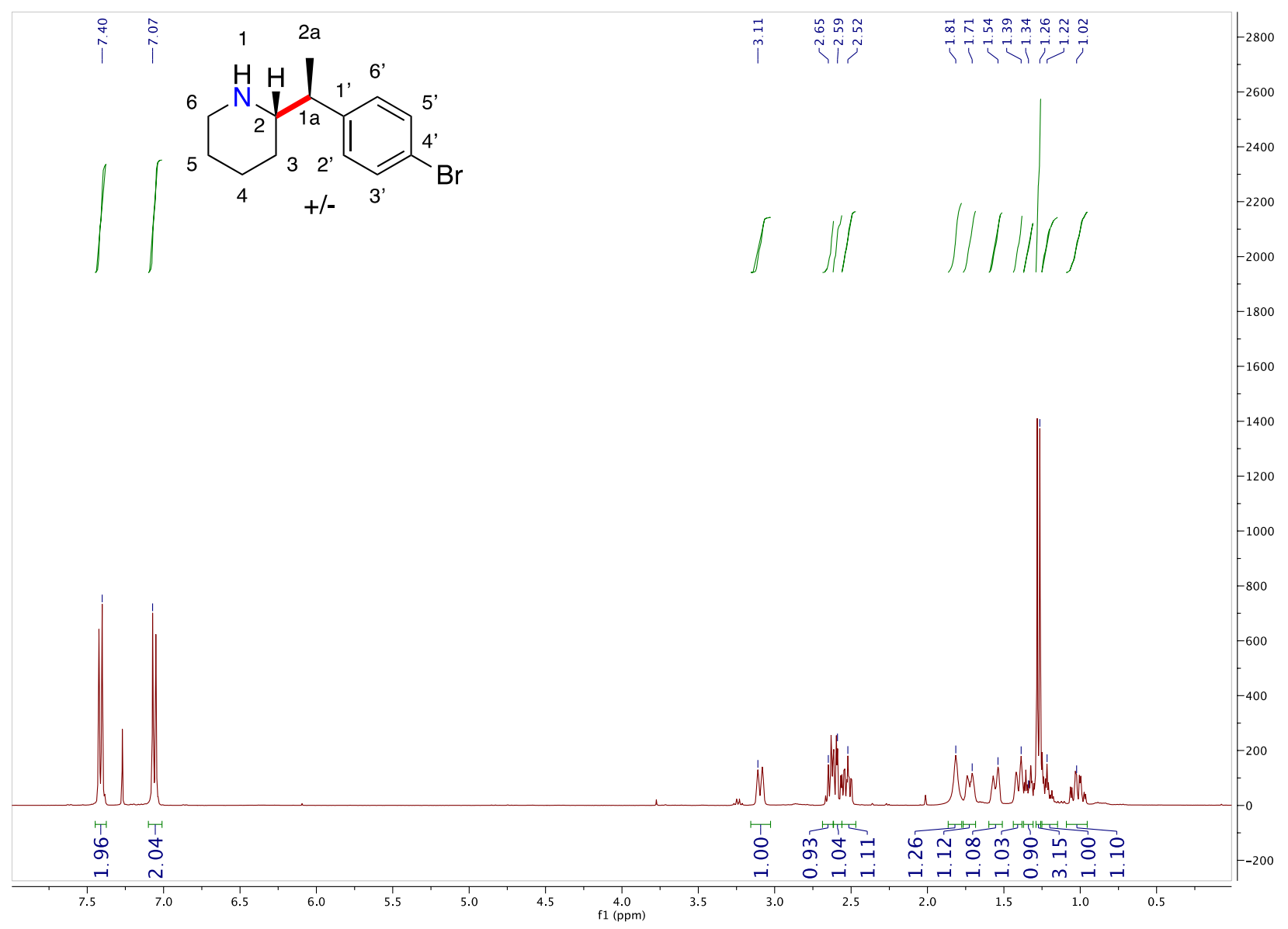

Figure S115: ${ }^{1} \mathrm{H}$ NMR spectrum $\left(400 \mathrm{MHz}, \mathrm{CDCl}_{3}, 298 \mathrm{~K}\right)$ of 2-(1-(4-bromophenyl)ethyl)piperidine. 


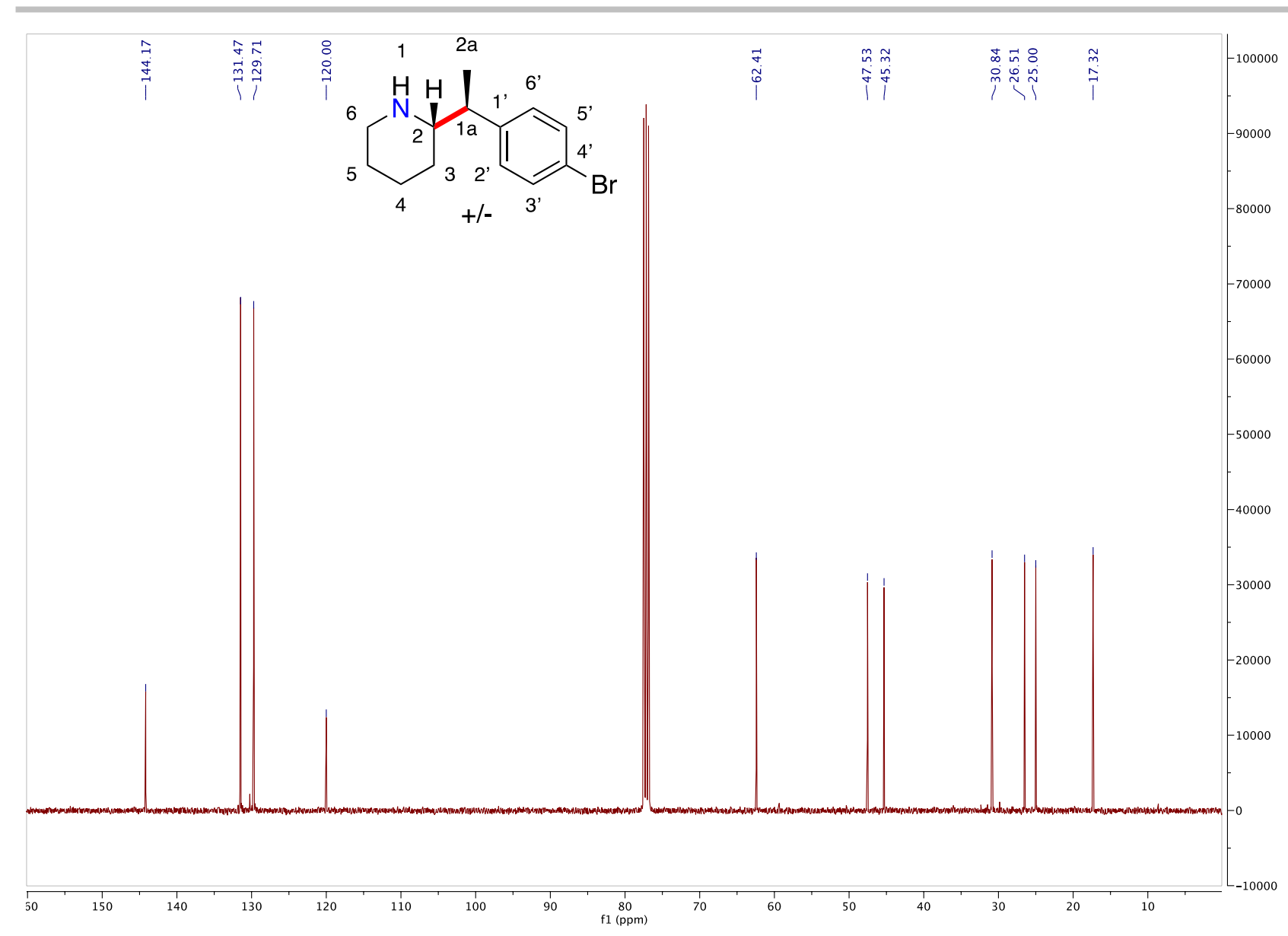

Figure S116: ${ }^{13} \mathrm{C}$ NMR spectrum (101 MHz, $\left.\mathrm{CDCl}_{3}, 298 \mathrm{~K}\right)$ 2-(1-(4-bromophenyl)ethyl)piperidine.

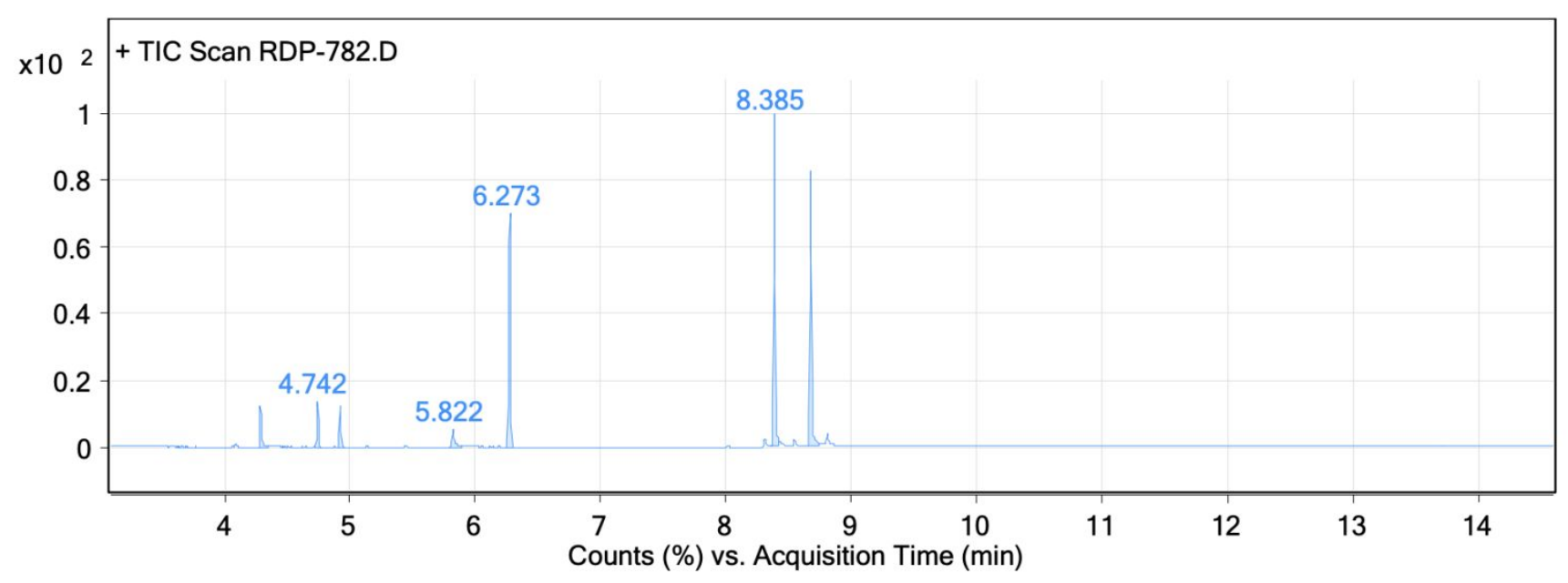

Figure S117: GC-MS for the crude reaction mixture between piperidine and para-bromostyrene. 


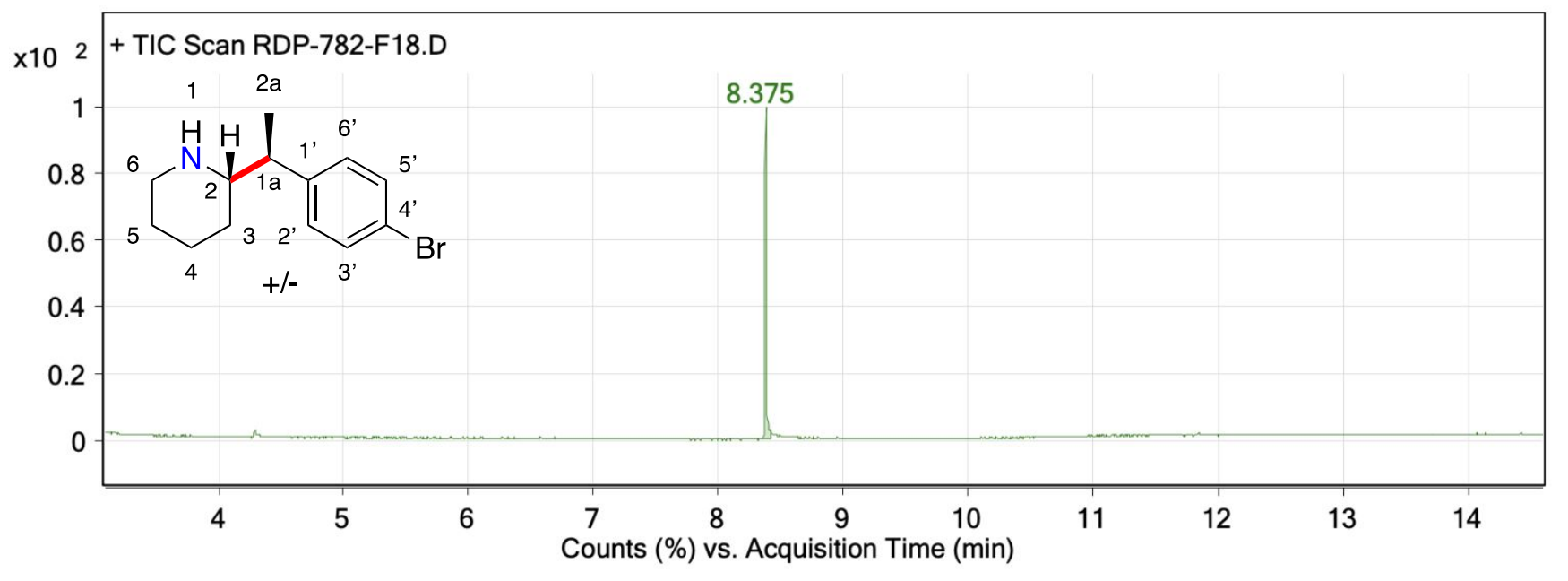

Figure S118: GC-MS report for 2-(1-(4-bromophenyl)ethyl)piperidine. 


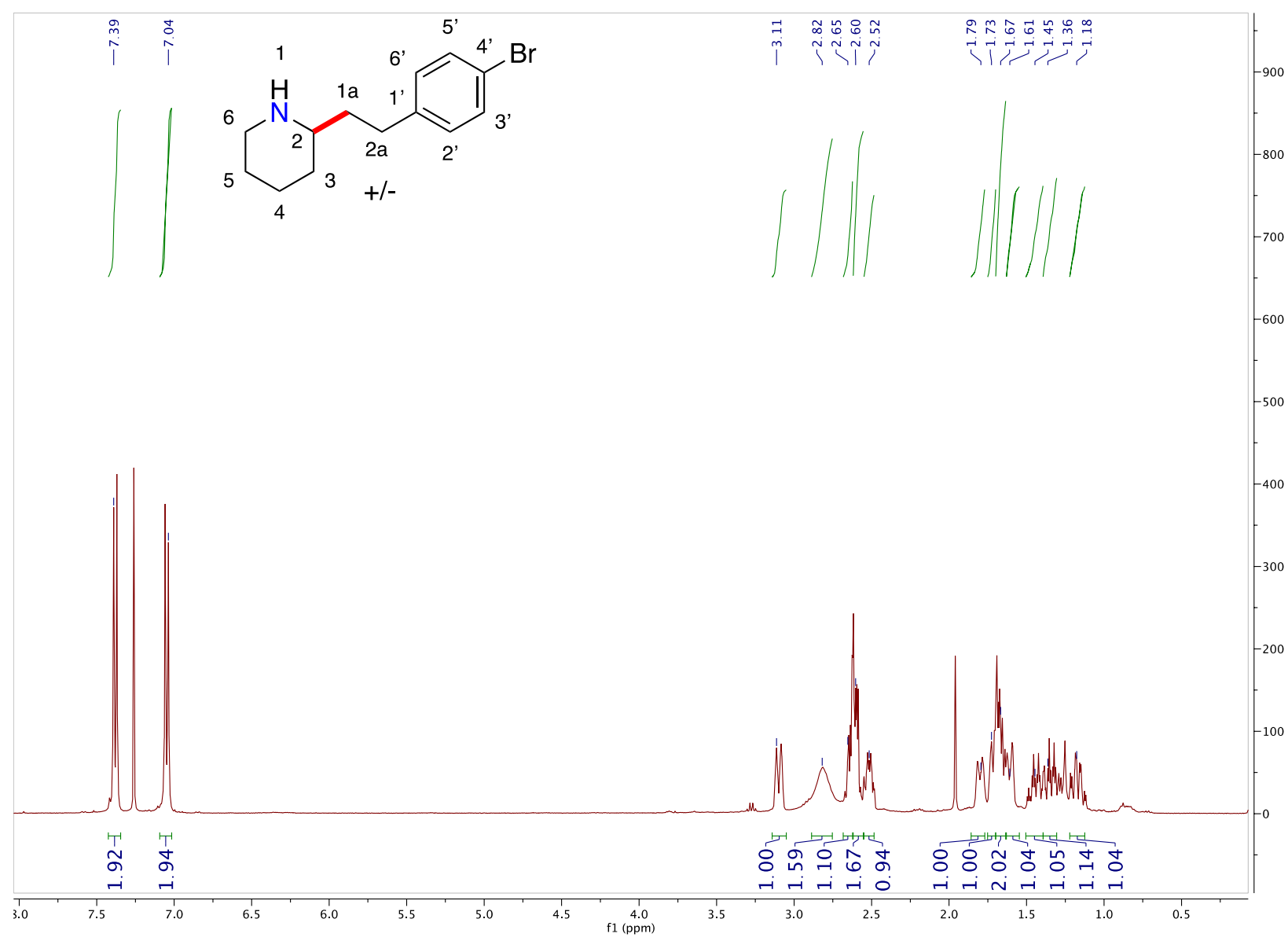

Figure S119: ${ }^{1} \mathrm{H}$ NMR spectrum (400 MHz, $\mathrm{CDCl}_{3}, 298 \mathrm{~K}$ ) of 2-(4-bromophenethyl)piperidine. 


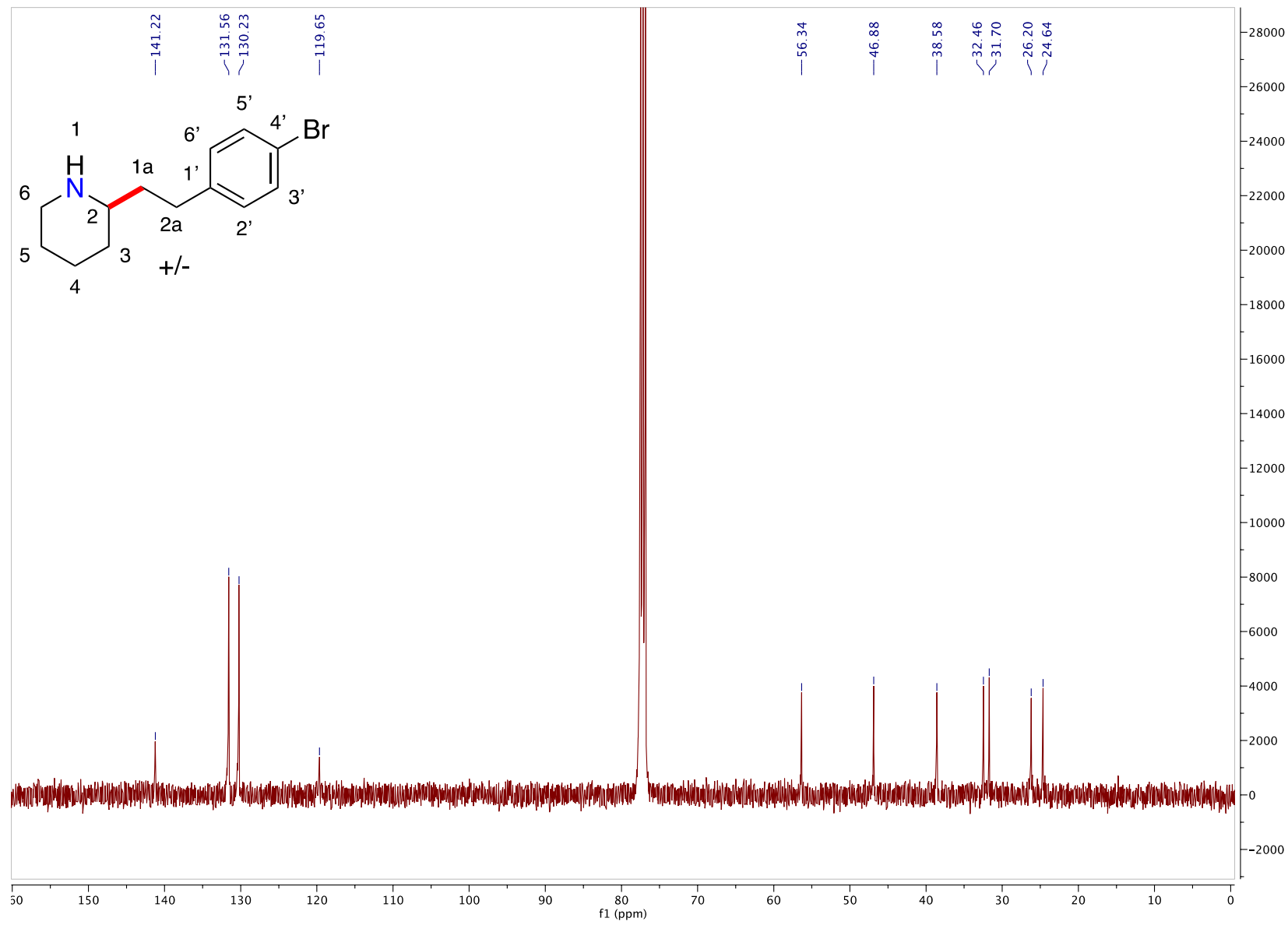

Figure S120: ${ }^{13} \mathrm{C}$ NMR spectrum (101 MHz, $\left.\mathrm{CDCl}_{3}, 298 \mathrm{~K}\right)$ 2-(4-bromophenethyl)piperidine.

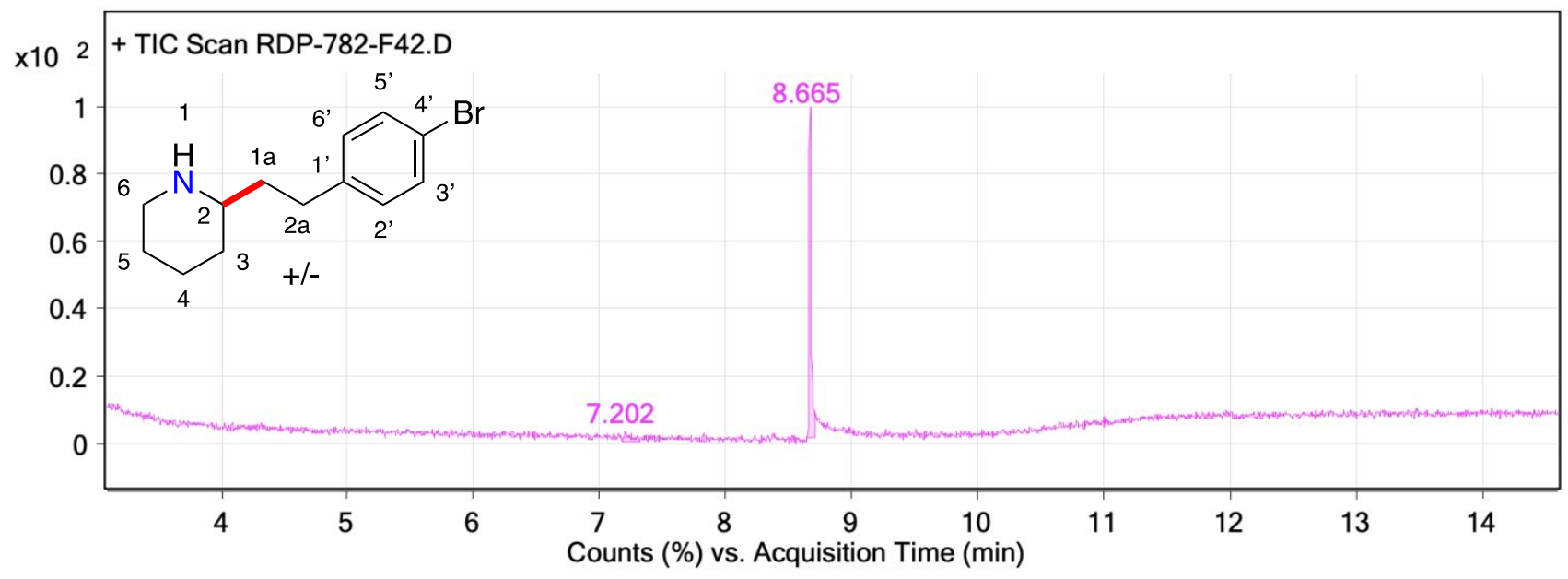

Figure S121: GC-MS report for 2-(4-bromophenethyl)piperidine.
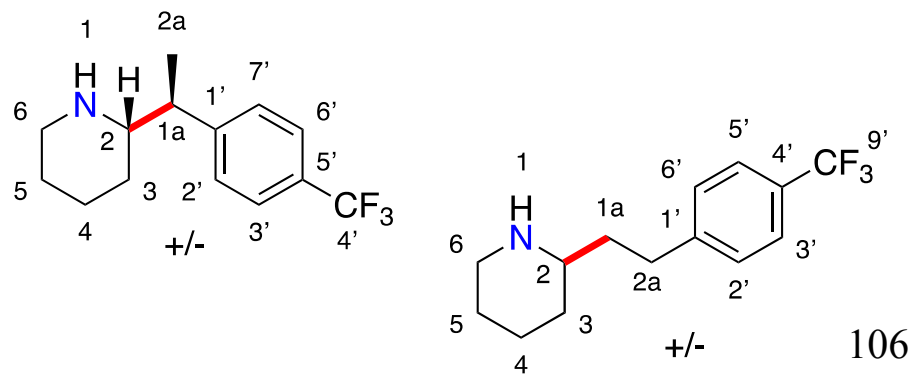

Synthesis

of

2-(1-(4-

(trifluoromethyl)phenyl)ethyl)piperidine and 
2-(4-(trifluoromethyl)phenethyl)piperidine (26 and 27): Prepared following the general procedure for branched and linear product mixtures outlined above: $26.0 \mathrm{mg}$ Ta, $15.2 \mathrm{mg}$ ligand $\mathbf{L} 4$, piperidine (85.15 $\mathrm{mg}, 1.0 \mathrm{mmol})$, para-trifluoromethylstyrene $(172.05 \mathrm{mg}, 1.0 \mathrm{mmol})$. The reaction was subsequently concentrated and the yield was determined to be $37 \%$ for 2-(1-(4(trifluoromethyl)phenyl)ethyl)piperidine and $55 \%$ for 2-(4-(trifluoromethyl)phenethyl)piperidine by NMR (1,3,5-trimethoxybenzene as a standard). Purification via column chromatography (7:2.5:0.5 hexanes : ethyl acetate : triethyl amine):

Branched Regioisomer: ${ }^{1} \mathrm{H}$ NMR $\left(\mathrm{CDCl}_{3}, 400 \mathrm{MHz}, 298 \mathrm{~K}\right): \delta 7.53(\mathrm{~m}, 2 \mathrm{H}, 3$ ' and 6'), $7.28(\mathrm{~m}, 2 \mathrm{H}, 2$ ' and $\left.7^{\prime}\right), 3.12(\mathrm{~m}, 1 \mathrm{H}, 1 / 2$ of 6$), 2.74(\mathrm{~m}, 1 \mathrm{H}, 1 \mathrm{a}), 2.61$ (overlapping dt, $1 \mathrm{H}, 1 / 2$ of 6$), 2.57(\mathrm{~m}, 1 \mathrm{H}, 2), 2.02$ (broad s, 1H, NH), $1.70(\mathrm{~m}, 1 \mathrm{H}, 1 / 2$ of 4$), 1.56(\mathrm{~m}, 1 \mathrm{H}, 1 / 2$ of 5$), 1.38(\mathrm{~m}, 1 \mathrm{H}, 1 / 2$ of 3$), 1.34(\mathrm{~m}, 1 \mathrm{H}, 1 / 2$ of 5), $1.31(\mathrm{~d}, \mathrm{~J}=1.31,3 \mathrm{H}, 2 \mathrm{a}), 1.22(\mathrm{~m}, 1 \mathrm{H}, 1 / 2$ of 4$), 1.02(\mathrm{~m}, 1 \mathrm{H}, 1 / 2$ of 3$)$ ppm. ${ }^{13} \mathrm{C}$ NMR $\left(\mathrm{CDCl}_{3}, 101\right.$ MHz, $298 \mathrm{~K}): \delta 149.24,128.76(\mathrm{q}, \mathrm{J}=32), 128.54,128.29(\mathrm{q}, \mathrm{J}=271.26), 125.36,63.33,47.45,45.73$, $30.78,26.32,25.88,17.42$ ppm. HRMS (ESI): $\mathrm{m} / z$ calcd for $\mathrm{C}_{14} \mathrm{H}_{18} \mathrm{~F}_{3} \mathrm{~N}\left[\mathrm{M}+\mathrm{H}^{+}\right]: 257.2391$ Found: 257.1395 .

Linear Regioisomer: ${ }^{1} \mathrm{H}$ NMR $\left(\mathrm{CDCl}_{3}, 400 \mathrm{MHz}, 298 \mathrm{~K}\right): \delta 7.53(\mathrm{~m}, 2 \mathrm{H}, 2$ ' and 3'), $7.29(\mathrm{~m}, 2 \mathrm{H}, 3$ ' and 5'), $3.09(\mathrm{~m}, 1 \mathrm{H}, 1 / 2$ of 6$), 2.72(\mathrm{~m}, 2 \mathrm{H}, 2 \mathrm{a}), 2.62(\mathrm{~m}, 1 \mathrm{H}, 1 / 2 \mathrm{of} 6), 2.50(\mathrm{~m}, 1 \mathrm{H}, 2), 2.00$ (broad s, $1 \mathrm{H}$, $\mathrm{NH}), 1.80(\mathrm{~m}, 1 \mathrm{H}, 1 / 2$ of 4$), 1.72(\mathrm{~m}, 1 \mathrm{H}, 1 / 2$ of 3$), 1.68(\mathrm{~m}, 2 \mathrm{H}, 1 \mathrm{a}), 1.60(\mathrm{~m}, 1 \mathrm{H}, 1 / 2$ of 5$), 1.41(\mathrm{~m}, 1 \mathrm{H}, 1 / 2$ of 5), $1.35(\mathrm{~m}, 1 \mathrm{H}, 1 / 2$ of 4$), 1.14(\mathrm{~m}, 1 \mathrm{H}, 1 / 2$ of 3$) \mathrm{ppm} .{ }^{13} \mathrm{C} \mathrm{NMR}\left(\mathrm{CDCl}_{3}, 101 \mathrm{MHz}, 298 \mathrm{~K}\right): \delta 146.63$, $128.75(\mathrm{q}, \mathrm{J}=32.42), 125.84(\mathrm{q}, \mathrm{J}=4.063), 125.44(\mathrm{q}, \mathrm{J}=272.85), 56.43,47.20,38.93,32.95,32.24$, 25.66, 24.85 ppm. HRMS (ESI): $m / z$ calcd for $\mathrm{C}_{14} \mathrm{H}_{18} \mathrm{~F}_{3} \mathrm{~N}\left[\mathrm{M}+\mathrm{H}^{+}\right]: 257.2391$ Found: 257.1394.

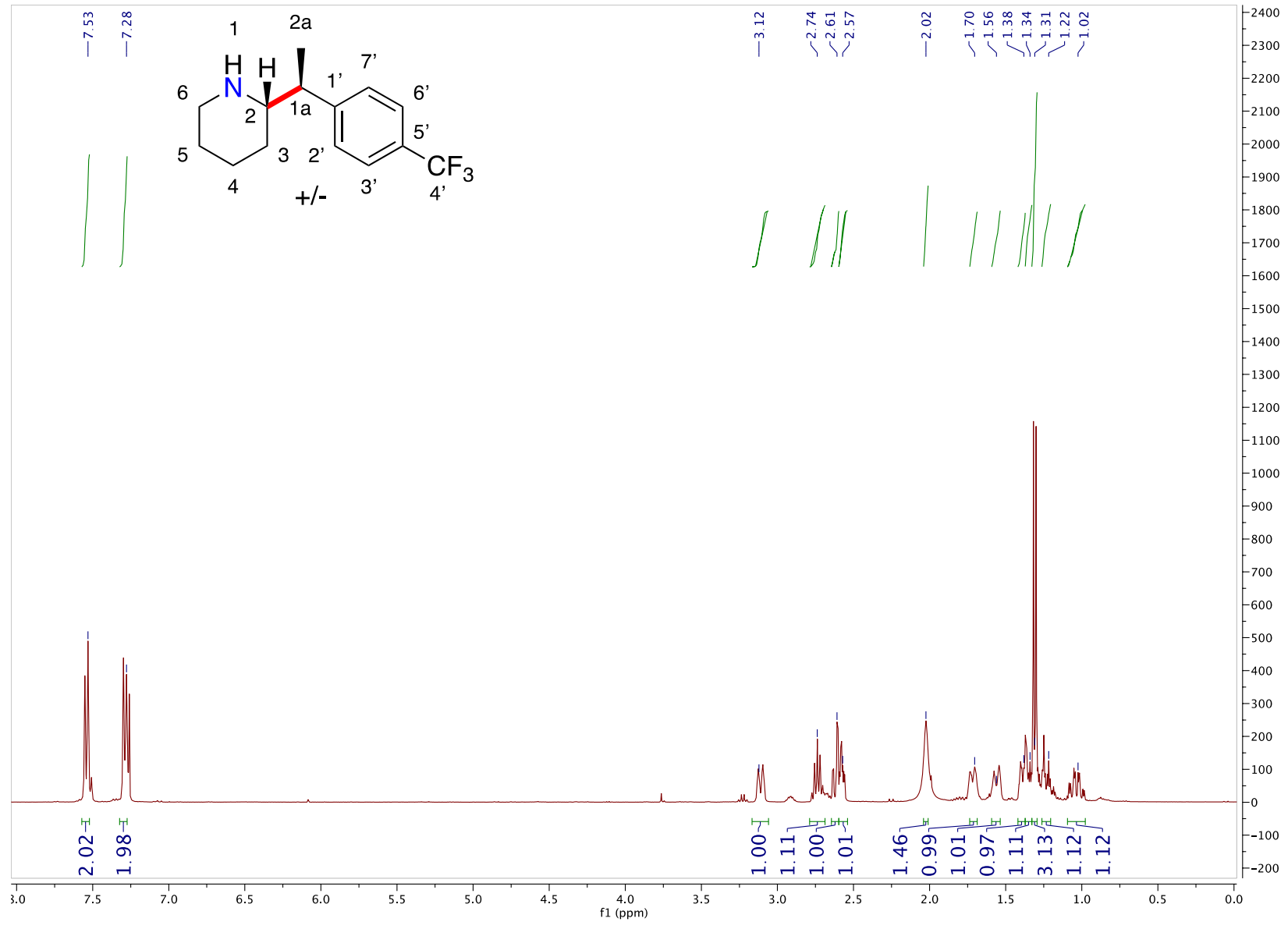


Figure S122: $\quad{ }^{1} \mathrm{H} \quad \mathrm{NMR} \quad$ spectrum $\quad\left(400 \quad \mathrm{MHz}, \quad \mathrm{CDCl}_{3}, \quad 298 \quad \mathrm{~K}\right) \quad$ of $\quad$ 2-(1-(4(trifluoromethyl)phenyl)ethyl)piperidine.

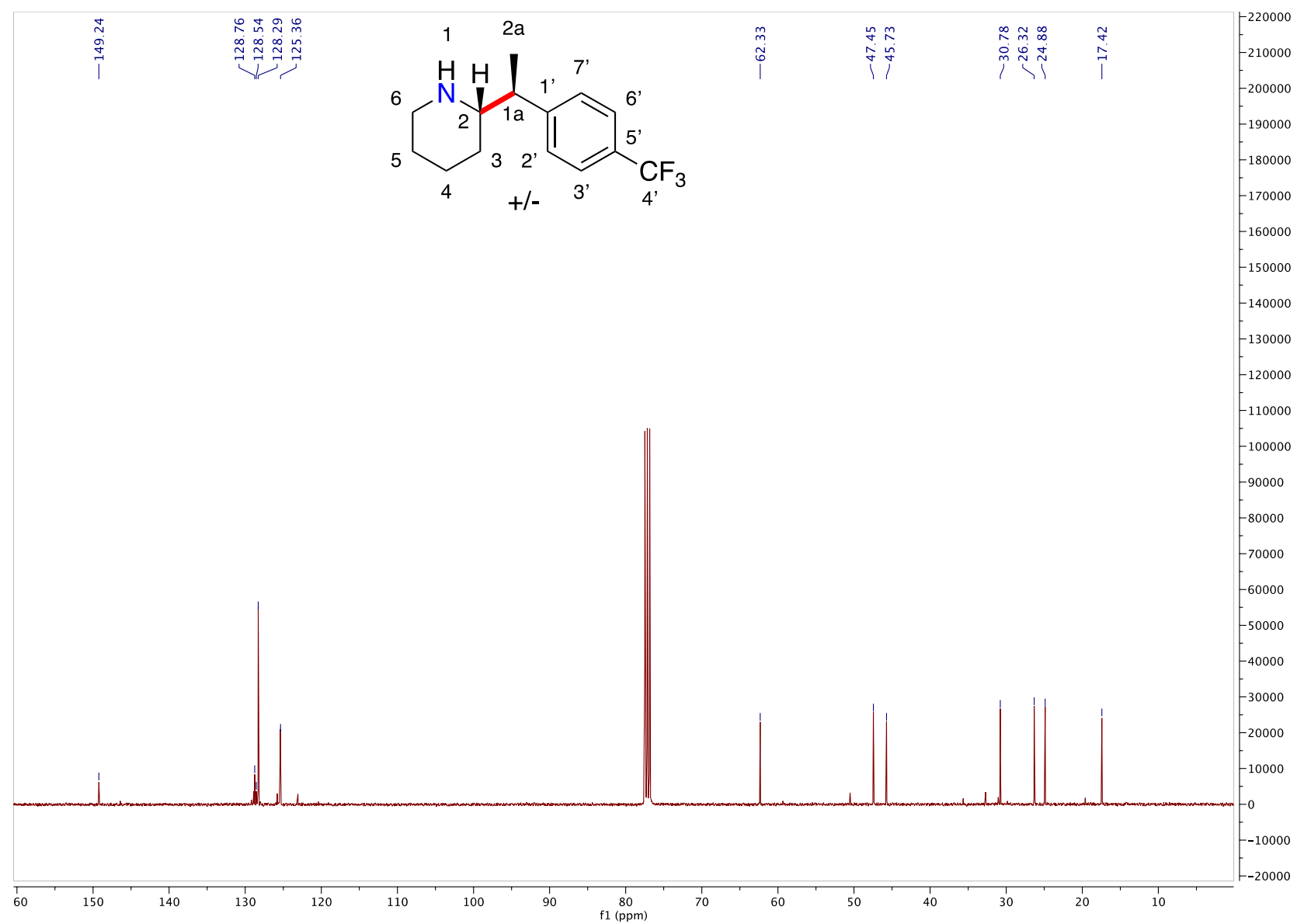

Figure $\quad$ S123: ${ }^{13} \mathrm{C} \quad \mathrm{NMR} \quad$ spectrum $\quad\left(101 \quad \mathrm{MHz}, \quad \mathrm{CDCl}_{3}, \quad 298 \quad \mathrm{~K}\right) \quad$ 2-(1-(4(trifluoromethyl)phenyl)ethyl)piperidine. 


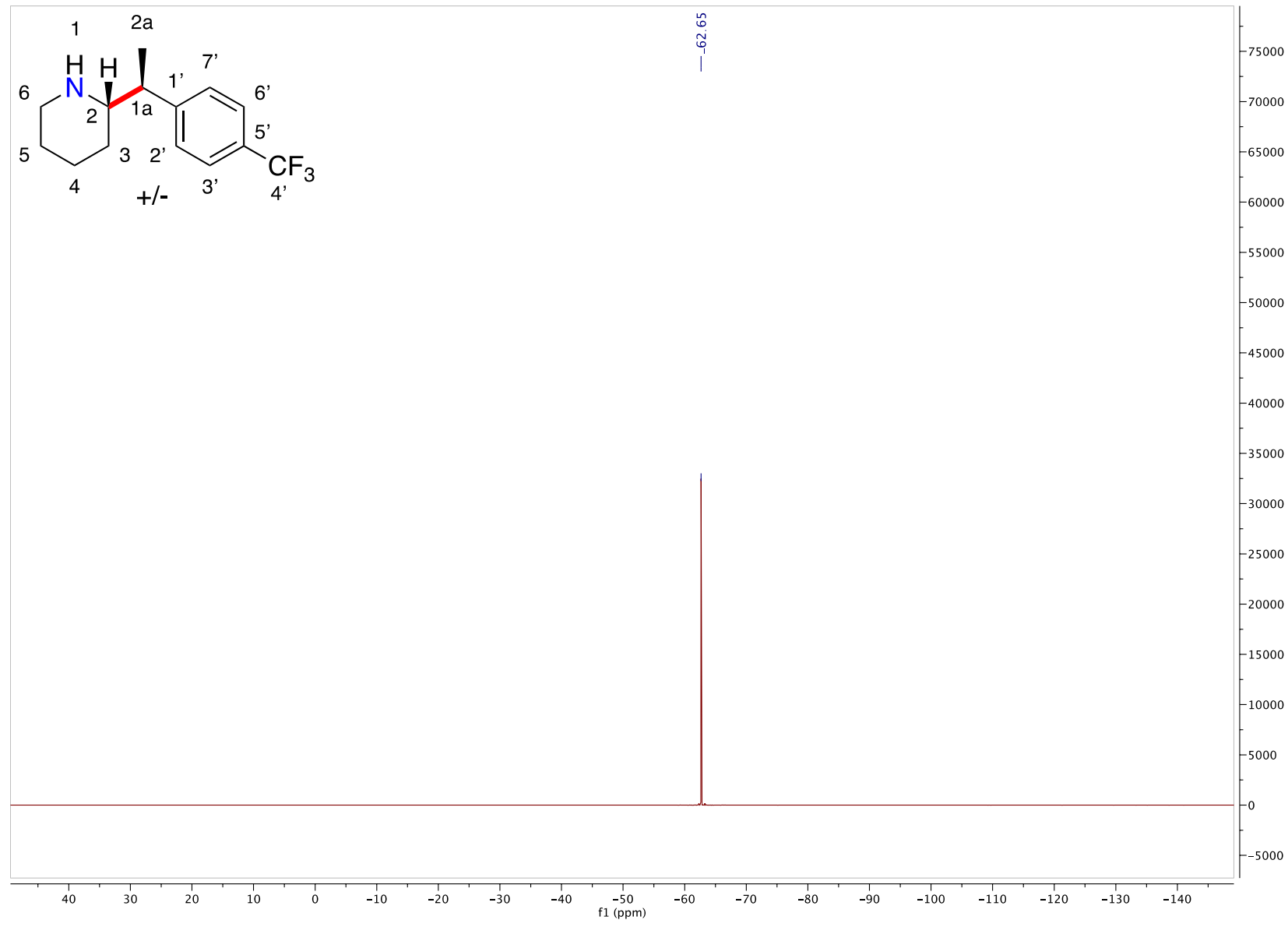

Figure $\quad$ S124: $\quad{ }^{19} \mathrm{~F} \quad \mathrm{NMR} \quad$ spectrum $\quad\left(101 \quad \mathrm{MHz}, \quad \mathrm{CDCl}_{3}, \quad 298 \quad \mathrm{~K}\right) \quad$ 2-(1-(4(trifluoromethyl)phenyl)ethyl)piperidine.

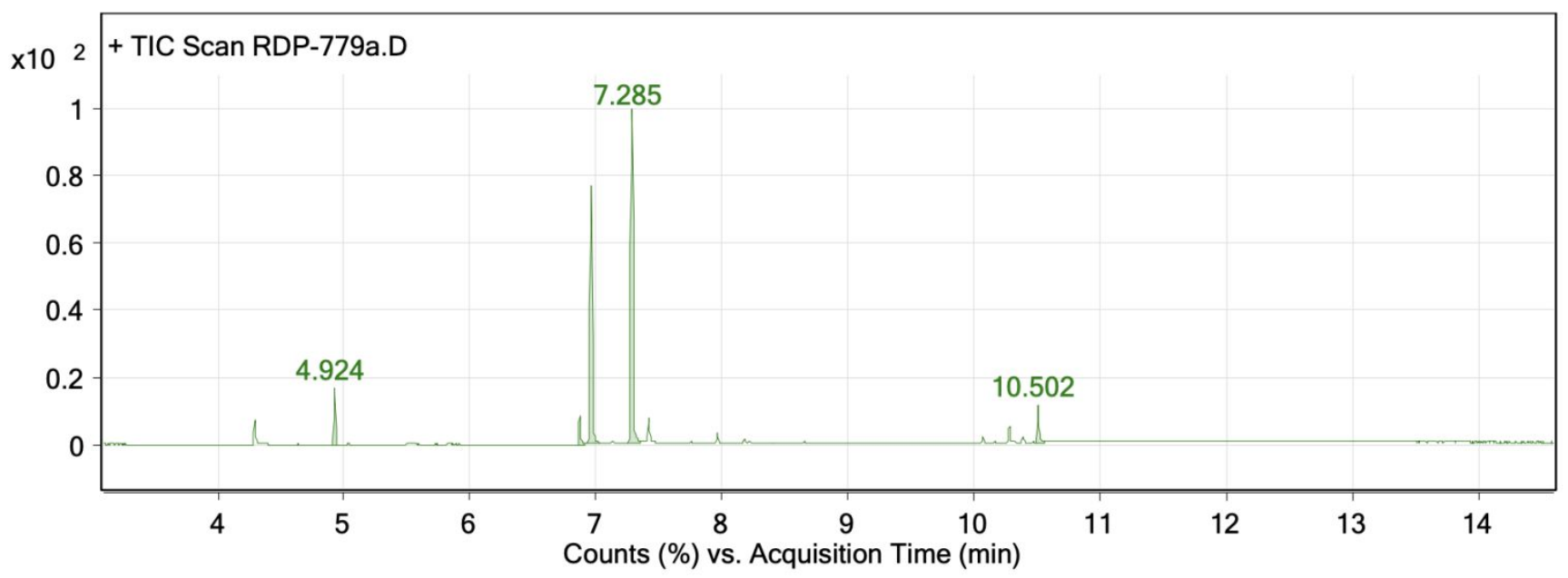

Figure S125: GC-MS for the crude reaction mixture between piperidine and para-trifluoromethylstyrene. 


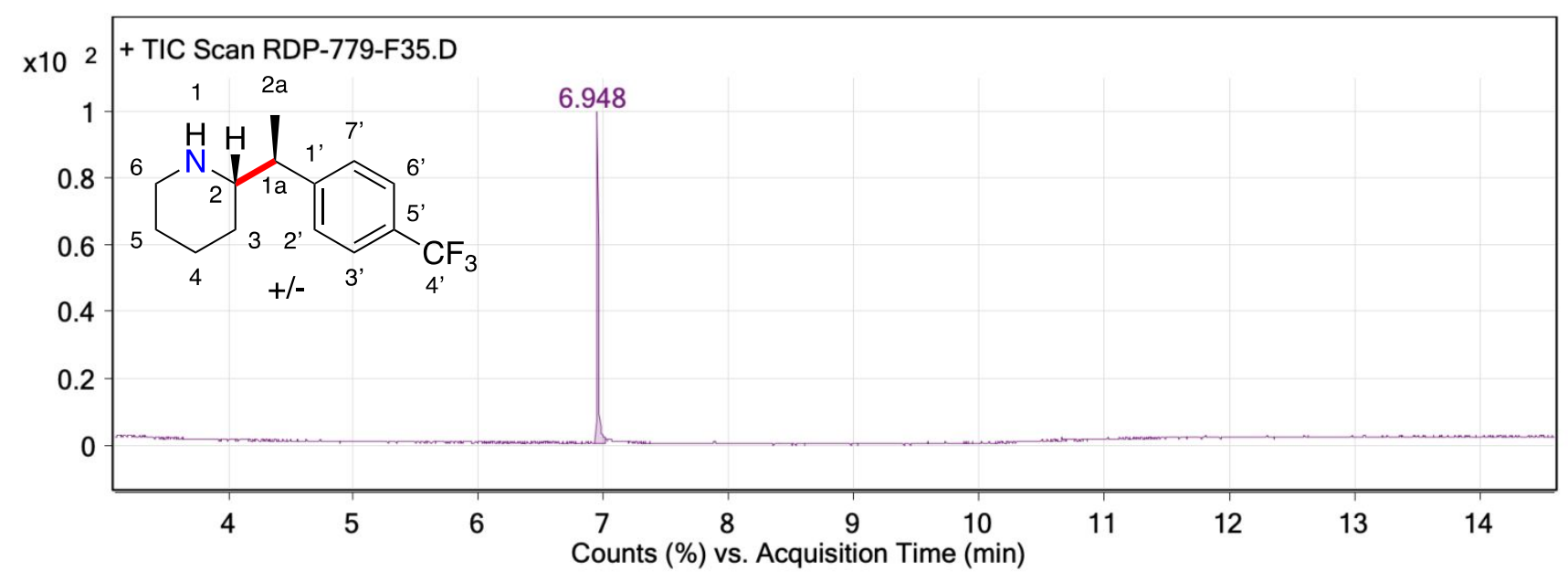

Figure S126: GC-MS report for 2-(1-(4-(trifluoromethyl)phenyl)ethyl)piperidine.

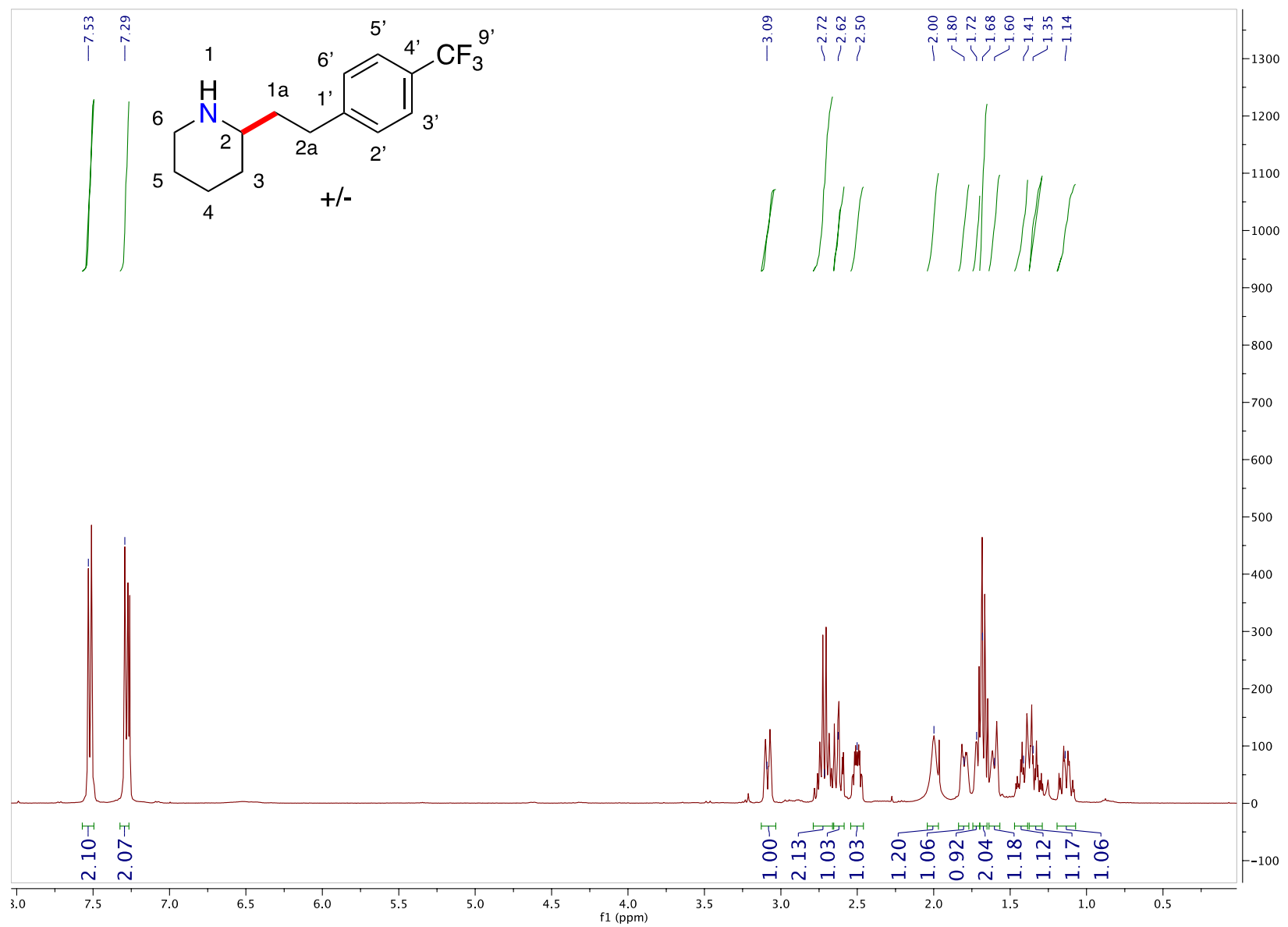


Figure S127: ${ }^{1} \mathrm{H}$ NMR spectrum (400 MHz, $\mathrm{CDCl}_{3}, 298 \mathrm{~K}$ ) of 2-(4-(trifluoromethyl)phenethyl)piperidine.

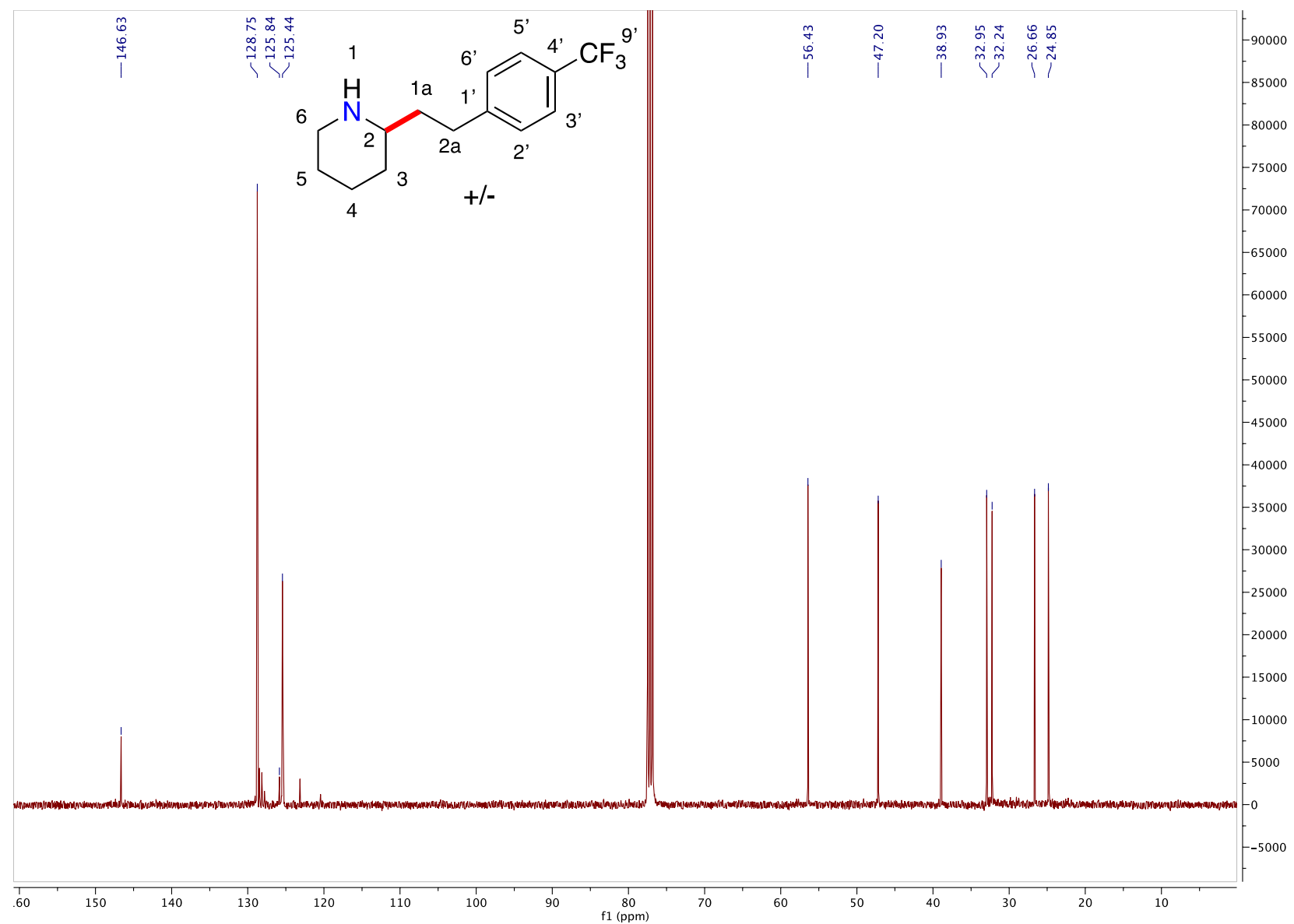

Figure S128: ${ }^{13} \mathrm{C}$ NMR spectrum $\left(101 \mathrm{MHz}, \mathrm{CDCl}_{3}, 298 \mathrm{~K}\right)$ 2-(4-(trifluoromethyl)phenethyl)piperidine. 


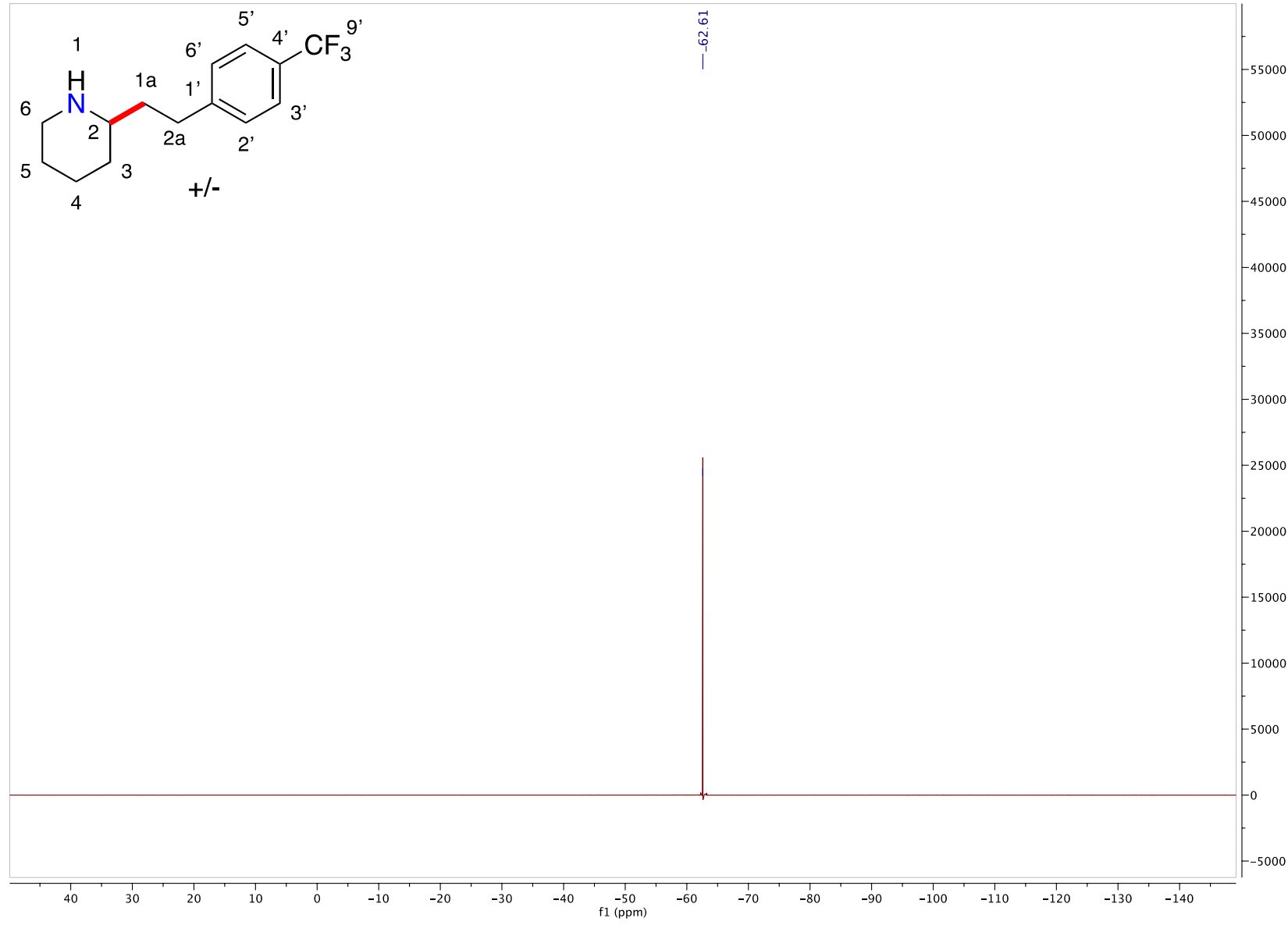

Figure S129: ${ }^{19} \mathrm{~F}$ NMR spectrum (400 MHz, $\mathrm{CDCl}_{3}, 298 \mathrm{~K}$ ) 2-(4-(trifluoromethyl)phenethyl)piperidine.

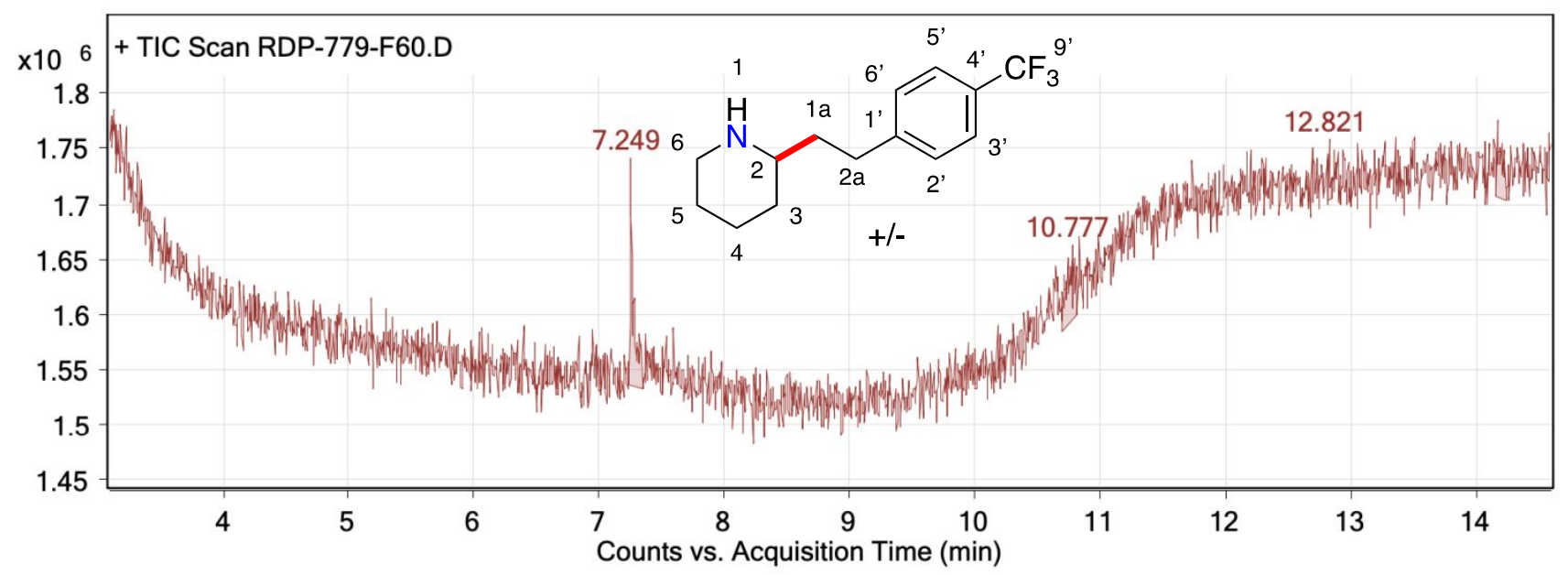

Figure S130: GC-MS report for 2-(4-(trifluoromethyl)phenethyl)piperidine. 


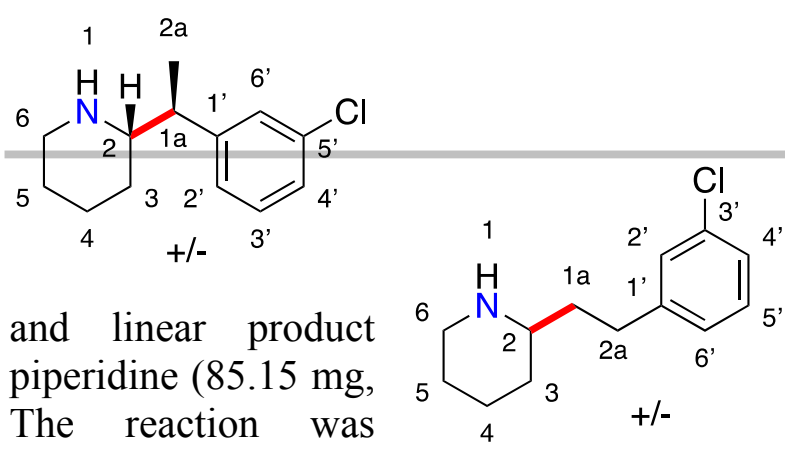

to be $45 \%$ for $2-(1-$
Synthesis of 2-(1-(3-chlorophenyl)ethyl)piperidine and 2-(3-chlorophenethyl)piperidine (28 and 29): Prepared following the general procedure for branched mixtures outlined above: $26.0 \mathrm{mg}$ Ta, $15.2 \mathrm{mg}$ ligand $\mathbf{L} 4$, $1.0 \mathrm{mmol})$, meta-chlorostyrene (138.59 $\mathrm{mg}, 1.0 \mathrm{mmol})$. subsequently concentrated and the yield was determined (3-chlorophenyl)ethyl)piperidine and $53 \%$ for 2-(3-

chlorophenethyl)piperidine by NMR (1,3,5-trimethoxybenzene as a standard). Purification via column chromatography (7:2.5:0.5 hexanes : ethyl acetate : triethyl amine):

Branched Regioisomer: ${ }^{1} \mathrm{H}$ NMR $\left(\mathrm{CDCl}_{3}, 400 \mathrm{MHz}, 298 \mathrm{~K}\right): \delta 7.23$ (m, 1H, 3'), $7.18\left(\mathrm{~m}, 1 \mathrm{H}, 4^{\prime}\right), 7.16$ (m, 1H, 6'), 7.05, (m, 1H, 2'), $3.09(\mathrm{~m}, 1 \mathrm{H}, 1 / 2$ of 6$), 2.63(\mathrm{~m}, 1 \mathrm{H}, 1 \mathrm{a}), 2.59(\mathrm{~m}, 1 \mathrm{H}, 1 / 2$ of 6$), 2.53(\mathrm{~m}, 1 \mathrm{H}$, 2), 2.00 (broad s, $1 \mathrm{H}, \mathrm{NH}), 1.72(\mathrm{~m}, 1 \mathrm{H}, 1 / 2$ of 4$), 1.54(\mathrm{~m}, 1 \mathrm{H}, 1 / 2$ of 5$), 1.41(\mathrm{~m}, 1 \mathrm{H}, 1 / 2$ of 3$), 1.34(\mathrm{~m}$, $1 \mathrm{H}, 1 / 2$ of 5$), 1.27(\mathrm{~d}, \mathrm{~J}=1.28,3 \mathrm{H}, 2 \mathrm{a}), 1.23(\mathrm{~m}, 1 \mathrm{H}, 1 / 2$ of 4$), 1.02(\mathrm{~m}, 1 \mathrm{H}, 1 / 2$ of 3$) \mathrm{ppm} .{ }^{13} \mathrm{C} \mathrm{NMR}\left(\mathrm{CDCl}_{3}\right.$, $101 \mathrm{MHz}, 298 \mathrm{~K}): \delta 147.20,134.12,129.55,127.90,126.41,126.13,62.24,47.37,45.54,30.76,26.30$, 24.83, 17.27 ppm. HRMS (ESI): $m / z$ calcd for $\mathrm{C}_{13} \mathrm{H}_{18} \mathrm{ClN}\left[\mathrm{M}+\mathrm{H}^{+}\right]: 223.1128$ Found: 223.1135 .

Linear Regioisomer: ${ }^{1} \mathrm{H}$ NMR $\left(\mathrm{CDCl}_{3}, 400 \mathrm{MHz}, 298 \mathrm{~K}\right): \delta 7.19\left(\mathrm{~m}, 1 \mathrm{H}, 4\right.$ ') $7.17\left(\mathrm{~m}, 1 \mathrm{H}, 2^{\prime} / 6\right.$ '), 7.16 (m, 1H, 2'/6'), $7.05\left(\mathrm{~m}, 1 \mathrm{H}, 5^{\prime}\right), 3.12(\mathrm{~m}, 1 \mathrm{H}, 1 / 2$ of 6$), 2.65(\mathrm{~m}, 2 \mathrm{H}, 2 \mathrm{a}), 2.63(\mathrm{~m}, 1 \mathrm{H}, 1 / 2$ of 6$), 2.54(\mathrm{~m}$, $1 \mathrm{H}, 2), 1.81(\mathrm{~m}, 1 \mathrm{H}, 1 / 2$ of 4$), 1.73(\mathrm{~m}, 1 \mathrm{H}, 1 / 2$ of 3$), 1.71(\mathrm{~m}, 2 \mathrm{H}, 1 \mathrm{a}), 1.60(\mathrm{~m}, 1 \mathrm{H}, 1 / 2$ of 5$), 1.47(\mathrm{~m}, 1 \mathrm{H}$, $1 / 2$ of 5), 1.35, (m, 1H, $1 / 2$ of 4), $1.20(\mathrm{~m}, 1 \mathrm{H}, 1 / 2$ of 3$) \mathrm{ppm} .{ }^{13} \mathrm{C} \mathrm{NMR}\left(\mathrm{CDCl}_{3}, 101 \mathrm{MHz}, 298 \mathrm{~K}\right): \delta 144.13$, 134.13, 129.65, 128.48, 126.54, 126.04, 56.31, 46.73, 38.25, 32.21, 31.82, 25.95, 24.44 ppm. HRMS (ESI): $m / z$ calcd for $\mathrm{C}_{13} \mathrm{H}_{18} \mathrm{ClN}\left[\mathrm{M}+\mathrm{H}^{+}\right]: 223.1128$ Found: 223.1137.

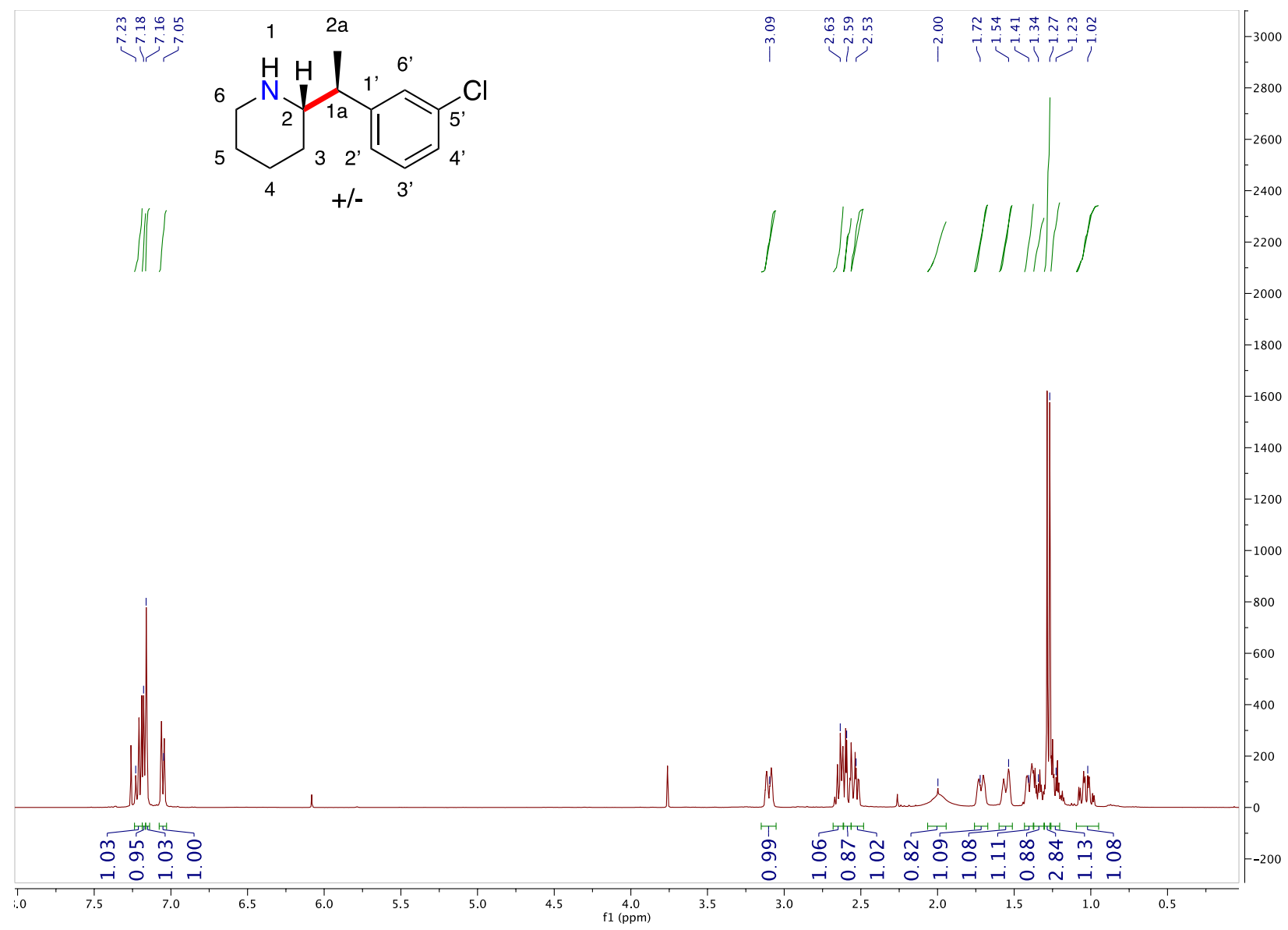


Figure S131: ${ }^{1} \mathrm{H}$ NMR spectrum $\left(400 \mathrm{MHz}, \mathrm{CDCl}_{3}, 298 \mathrm{~K}\right)$ of 2-(1-(3-chlorophenyl)ethyl)piperidine.

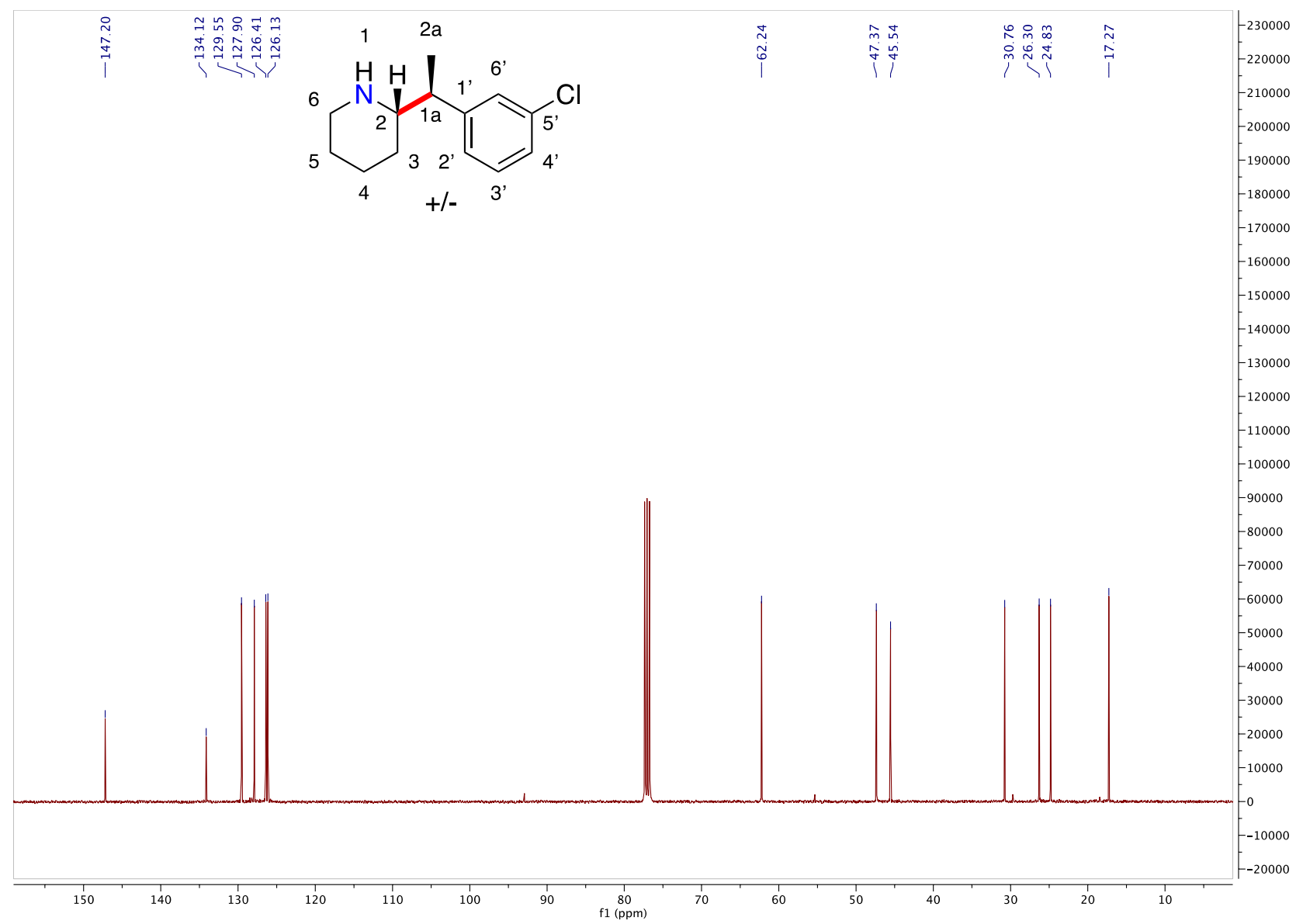

Figure S132: ${ }^{13} \mathrm{C}$ NMR spectrum (101 MHz, $\left.\mathrm{CDCl}_{3}, 298 \mathrm{~K}\right)$ 2-(1-(3-chlorophenyl)ethyl)piperidine.

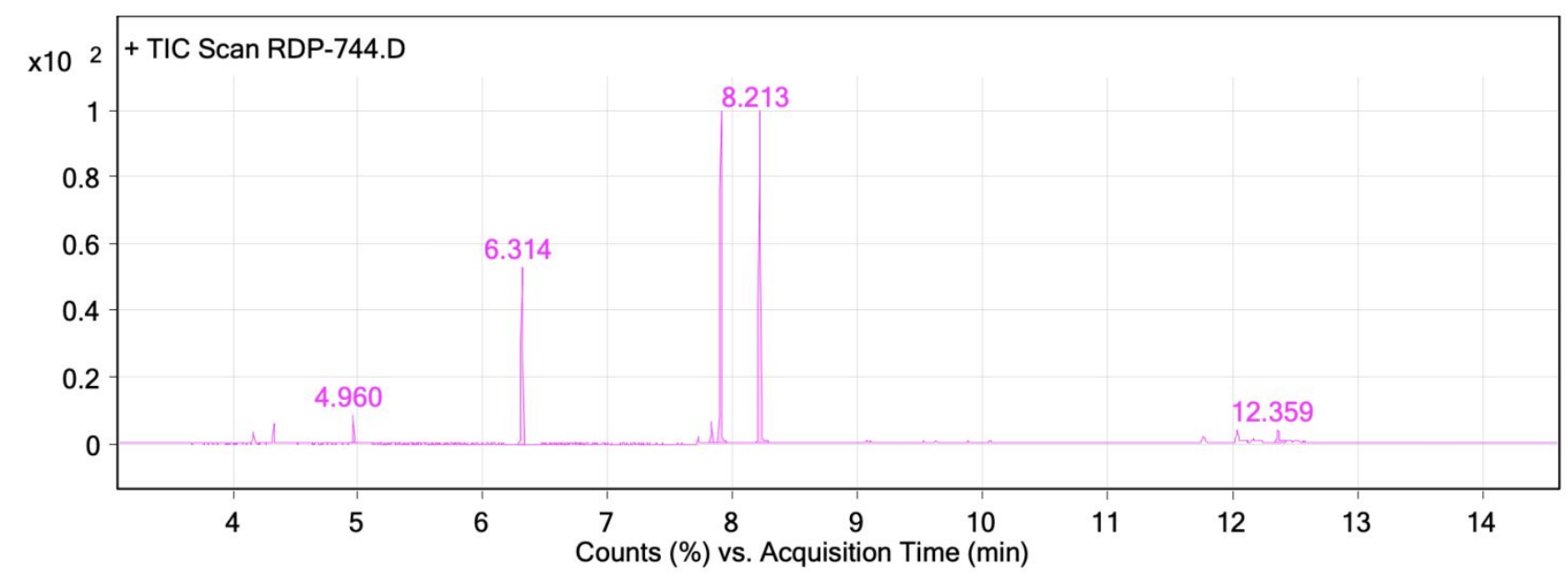

Figure S133: GC-MS for the crude reaction mixture between piperidine and meta-chlorostyrene. 


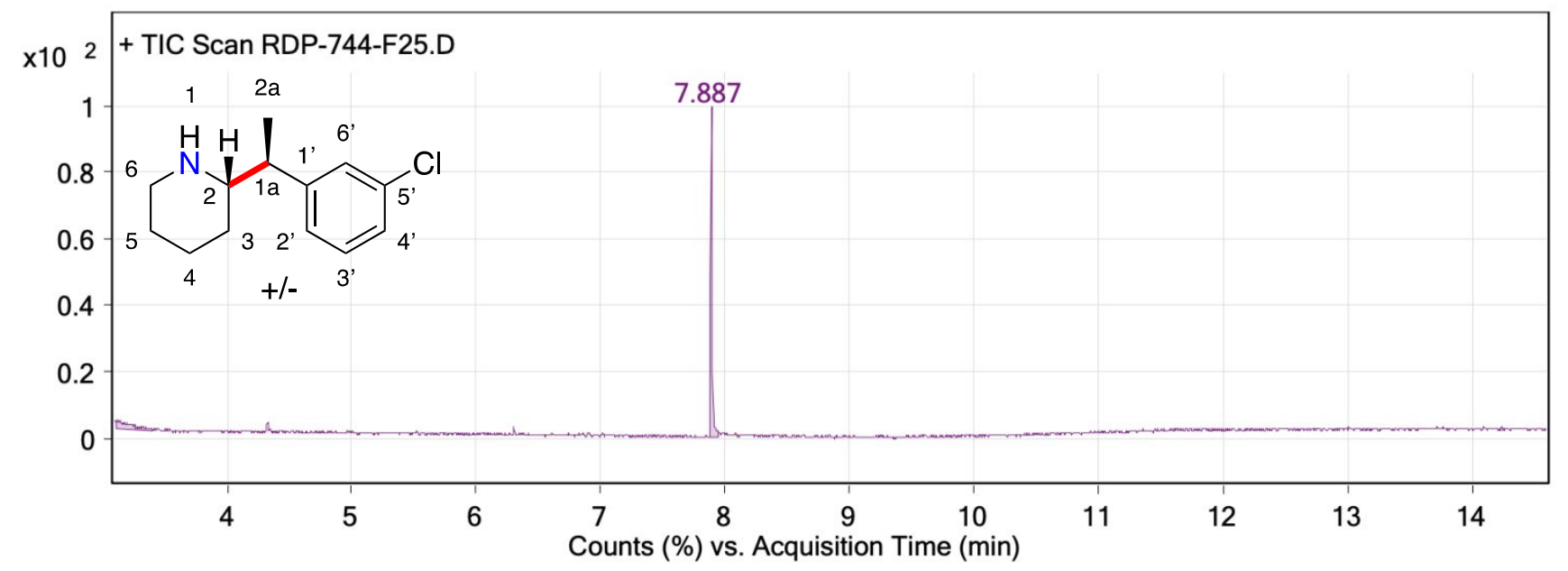

Figure S134: GC-MS report for 2-(1-(3-chlorophenyl)ethyl)piperidine.

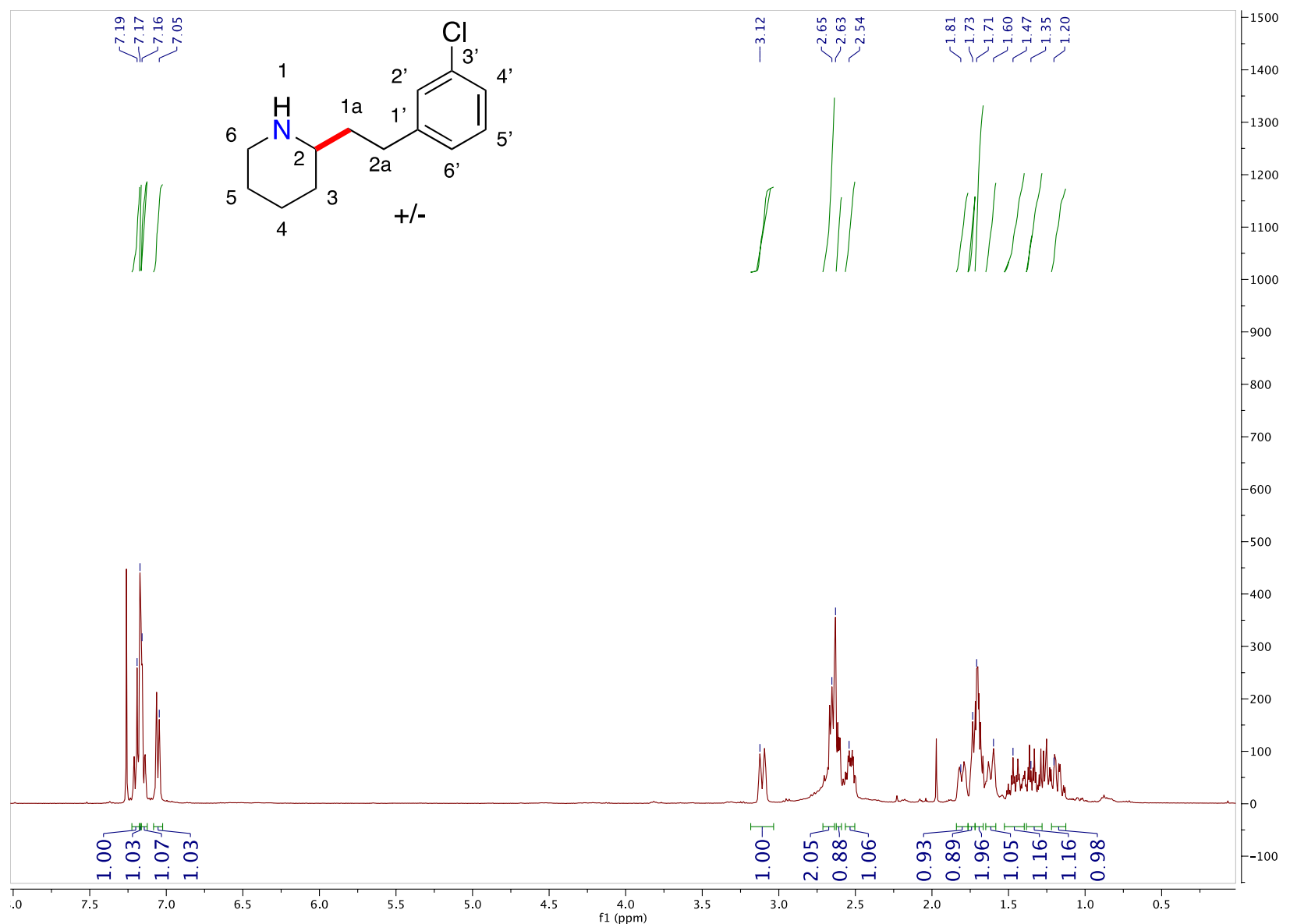


Figure S135: ${ }^{1} \mathrm{H}$ NMR spectrum (400 MHz, $\mathrm{CDCl}_{3}, 298 \mathrm{~K}$ ) of 2-(3-chlorophenethyl)piperidine.

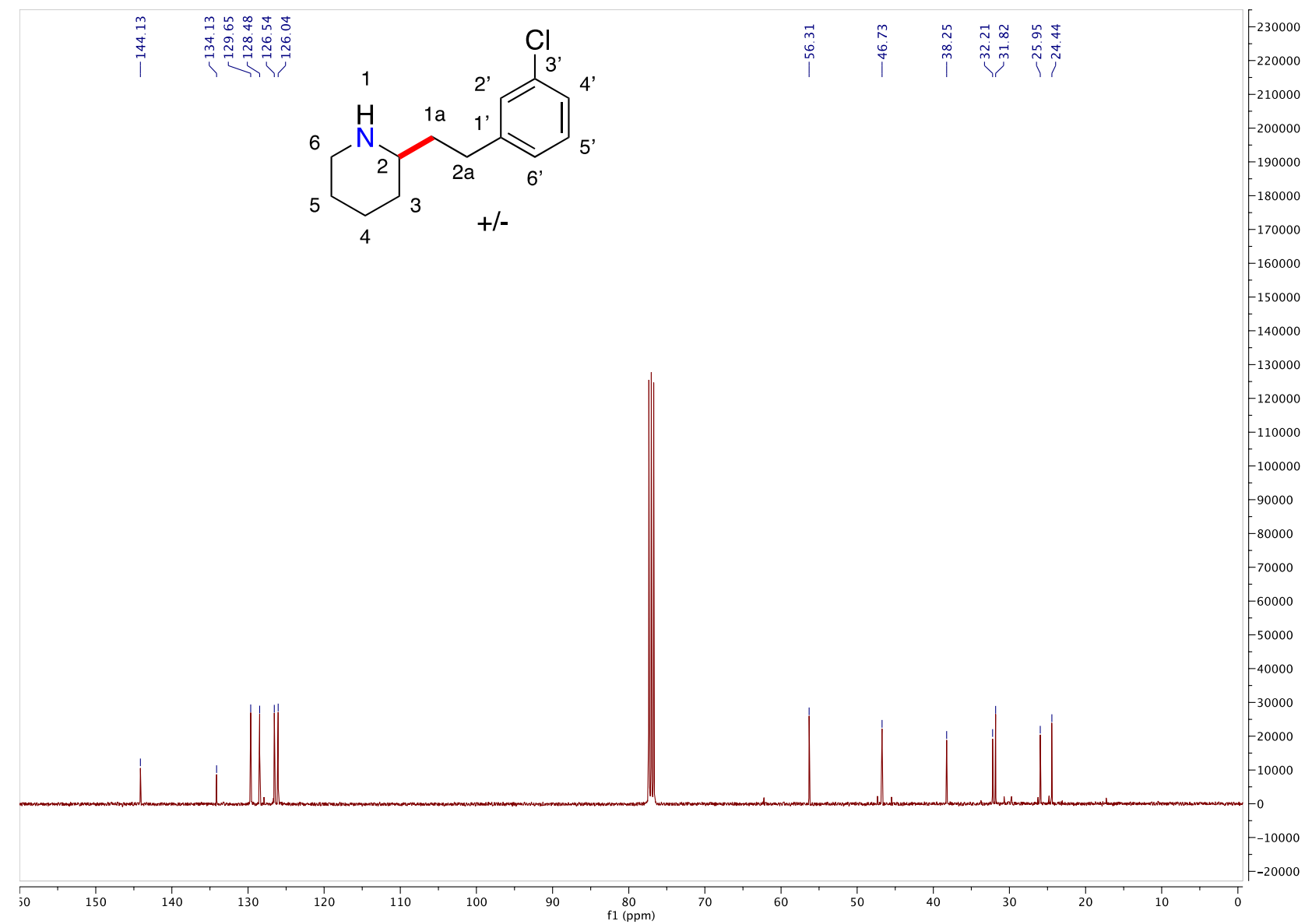

Figure S136: ${ }^{13} \mathrm{C}$ NMR spectrum (101 MHz, $\mathrm{CDCl}_{3}, 298 \mathrm{~K}$ ) 2-(3-chlorophenethyl)piperidine.

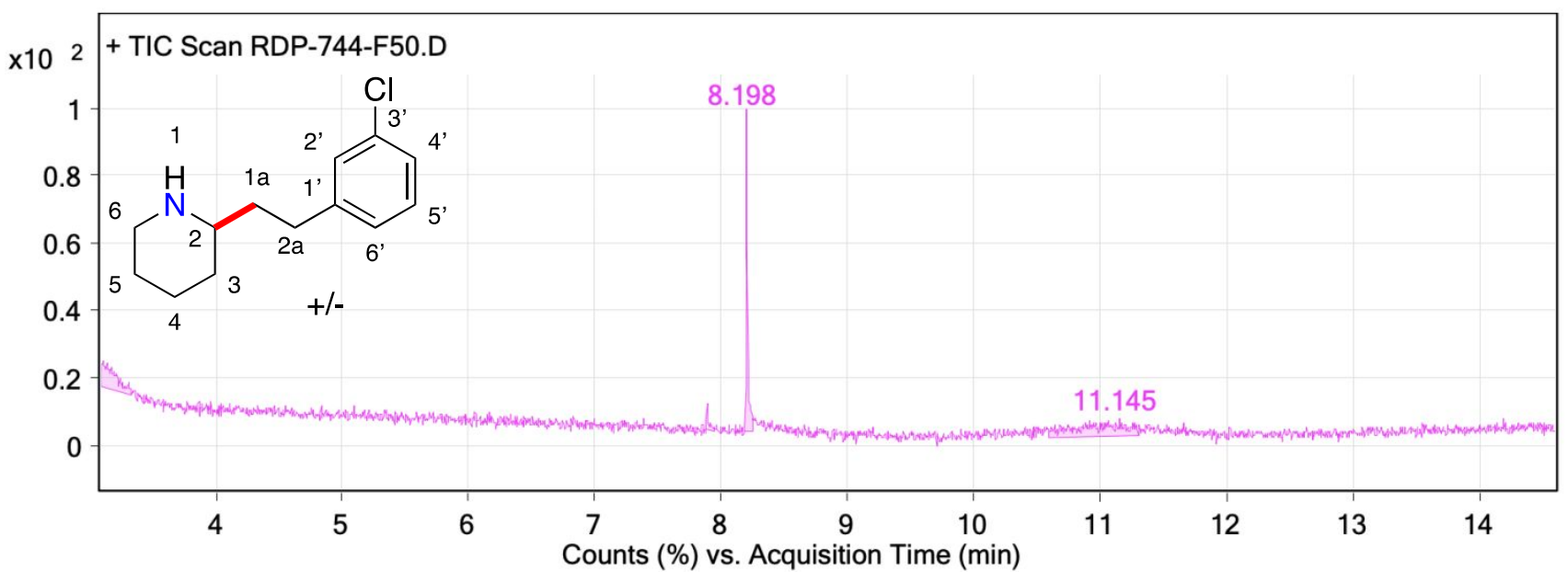

Figure S137: GC-MS report for 2-(3-chlorophenethyl)piperidine. 

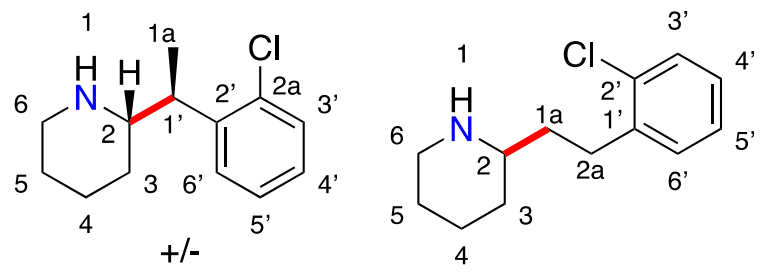

Synthesis of 2-(1-(2-chlorophenyl)ethyl)piperidine
and 2-(1-(2-chlorophenyl)ethyl)piperidine (30 and 31):
Prepared following the general procedure for branched
and linear product mixtures outlined above: $26.0 \mathrm{mg}$ Ta,
$15.2 \mathrm{mg}$ ligand $\mathbf{L} 4$, piperidine $(85.15 \mathrm{mg}, 1.0 \mathrm{mmol}), 2-$
chlorostyrene $(138.59 \mathrm{mg}, 1.0 \mathrm{mmol})$. The reaction was subsequently concentrated and the yield was determined to be $51 \%$ for 2-(1-(2chlorophenyl)ethyl)piperidine and $49 \%$ for )ethyl)piperidine and 2 by NMR (1,3,5-trimethoxybenzene as a standard). Purification via column chromatography (7:2.5:0.5 hexanes : ethyl acetate : triethyl amine):

Branched Regioisomer: ${ }^{1} \mathrm{H}$ NMR $\left(\mathrm{CDCl}_{3}, 400 \mathrm{MHz}, 298 \mathrm{~K}\right): \delta 7.57$ (m, 1H, 3'), 7.47 (m, 1H, 5'/6'), $7.43\left(\mathrm{~m}, 1 \mathrm{H}, 5^{\prime} / 6\right.$ ') 7.33 (m, 1H, 4'), $3.52\left(\mathrm{~m}, 1 \mathrm{H}, 1^{\prime}\right), 3.33$ (m, 1H, 1/2 of 6), $2.86(\mathrm{~m}, 1 \mathrm{H}, 2), 2.80(\mathrm{~m}$, $1 \mathrm{H}, 1 / 2$ of 6$), 2.00$ (broad s, $1 \mathrm{H}, \mathrm{NH}), 1.92(\mathrm{~m}, 1 \mathrm{H}, 1 / 2$ of 4$), 1.75(\mathrm{~m}, 1 \mathrm{H}, 1 / 2$ of 5$), 1.64(\mathrm{~m}, 1 \mathrm{H}, 1 / 2$ of 5$)$, $1.57(\mathrm{~m}, 1 \mathrm{H}, 1 / 2$ of 3$), 1.48(\mathrm{~d}, \mathrm{~J}=1.49,3 \mathrm{H}, 1 \mathrm{a}), 1.45(\mathrm{~m}, 1 \mathrm{H} .1 / 2$ of 4$), 1.38(\mathrm{~m}, 1 \mathrm{H}, 1 / 2$ of 3$) \mathrm{ppm} .{ }^{13} \mathrm{C}$ NMR $\left(\mathrm{CDCl}_{3}, 101 \mathrm{MHz}, 298 \mathrm{~K}\right): \delta$ ppm. HRMS (ESI): $\mathrm{m} / z$ calcd for $\mathrm{C}_{13} \mathrm{H}_{19} \mathrm{NCl}\left[\mathrm{M}+\mathrm{H}^{+}\right]: 224.1206$ Found: 224.1208 .

Linear Regioisomer: ${ }^{1} \mathrm{H}$ NMR $\left(\mathrm{CDCl}_{3}, 400 \mathrm{MHz}, 298 \mathrm{~K}\right): \delta 7.33\left(\mathrm{~m}, 1 \mathrm{H}, 3^{\prime}\right), 7.21(\mathrm{~m}, 1 \mathrm{H}, 6$ '), $7.14(\mathrm{~m}$, $2 \mathrm{H}, 4^{\prime}$ and 5'), $3.12(\mathrm{~m}, 1 \mathrm{H}, 1 / 2$ of 6$), 2.77(\mathrm{~m}, 2 \mathrm{H}, 2 \mathrm{a}), 2.65(\mathrm{~m}, 1 \mathrm{H}, 1 / 2$ of 6$), 2.55(\mathrm{~m}, 1 \mathrm{H}, 2), 2.11$ (broad $\mathrm{s}, 1 \mathrm{H}, \mathrm{NH}), 1.82(\mathrm{~m}, 1 \mathrm{H}, 1 / 2$ of 4$), 1.76(\mathrm{~m}, 1 \mathrm{H}, 1 / 2$ of 3$), 1.69(\mathrm{~m}, 2 \mathrm{H}, 1 \mathrm{a}), 1.62(\mathrm{~m}, 1 \mathrm{H}, 1 / 2$ of 5$), 1.47(\mathrm{~m}$, $1 \mathrm{H}, 1 / 2$ of 5$), 1.38(\mathrm{~m}, 1 \mathrm{H}, 1 / 2$ of 4$), 1.18(\mathrm{~m}, 1 \mathrm{H}, 1 / 2$ of 3$) \mathrm{ppm} .{ }^{13} \mathrm{C} \mathrm{NMR}\left(\mathrm{CDCl}_{3}, 101 \mathrm{MHz}, 298 \mathrm{~K}\right): \delta$ $140.01,134.01,130.39,129.61,127.41,126.95,56.74,47.19,37.39,32.77,30.15,26.51,24.83$ ppm. HRMS (ESI): $m / z$ calcd for $\mathrm{C}_{13} \mathrm{H}_{19} \mathrm{NCl}\left[\mathrm{M}+\mathrm{H}^{+}\right]: 224.1206$ Found: 224.1208 . 


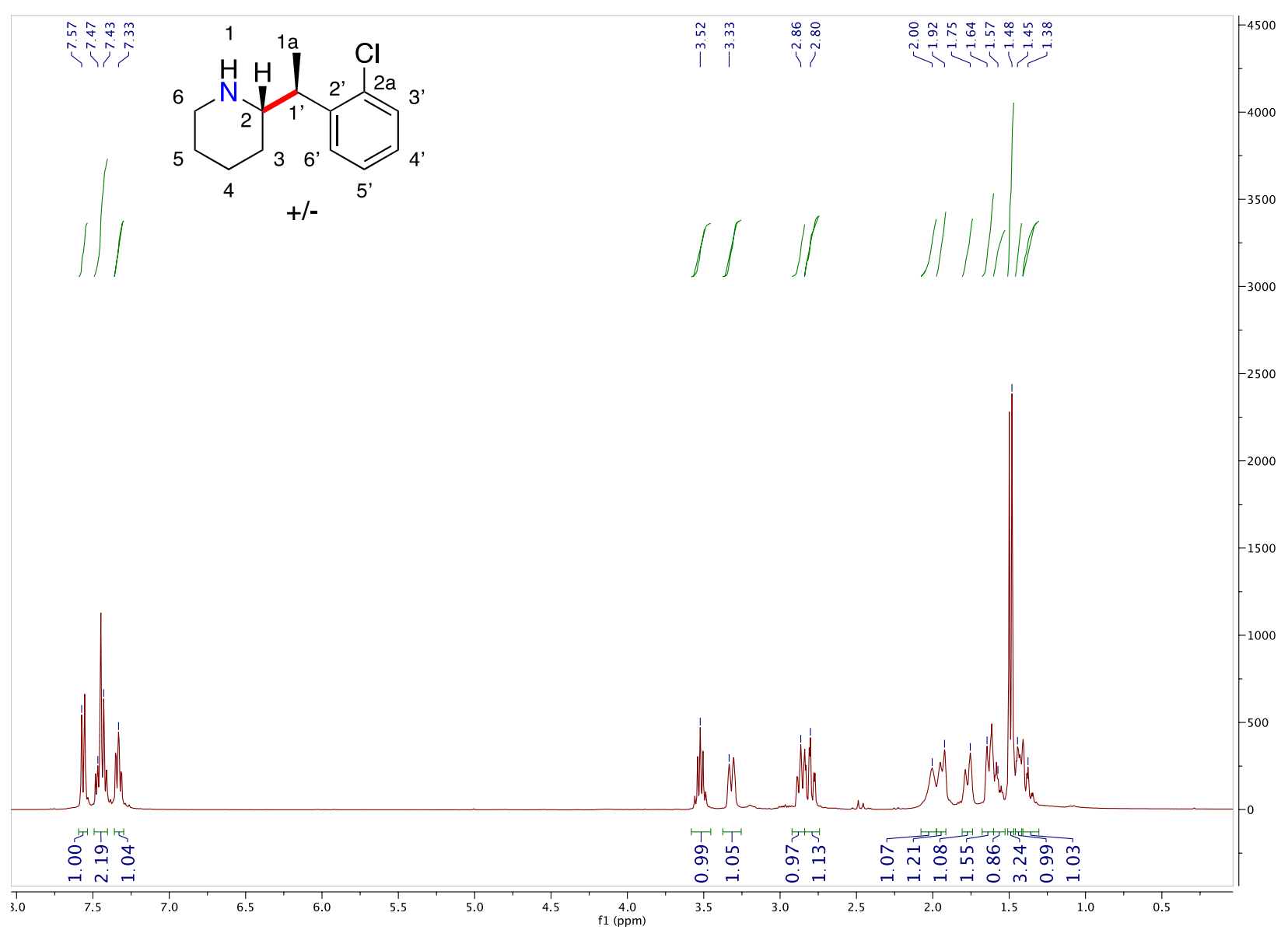

Figure S138: ${ }^{1} \mathrm{H}$ NMR spectrum $\left(400 \mathrm{MHz}, \mathrm{CDCl}_{3}\right.$, $298 \mathrm{~K}$ ) of 2-(1-(2-chlorophenyl)ethyl)piperidine. 


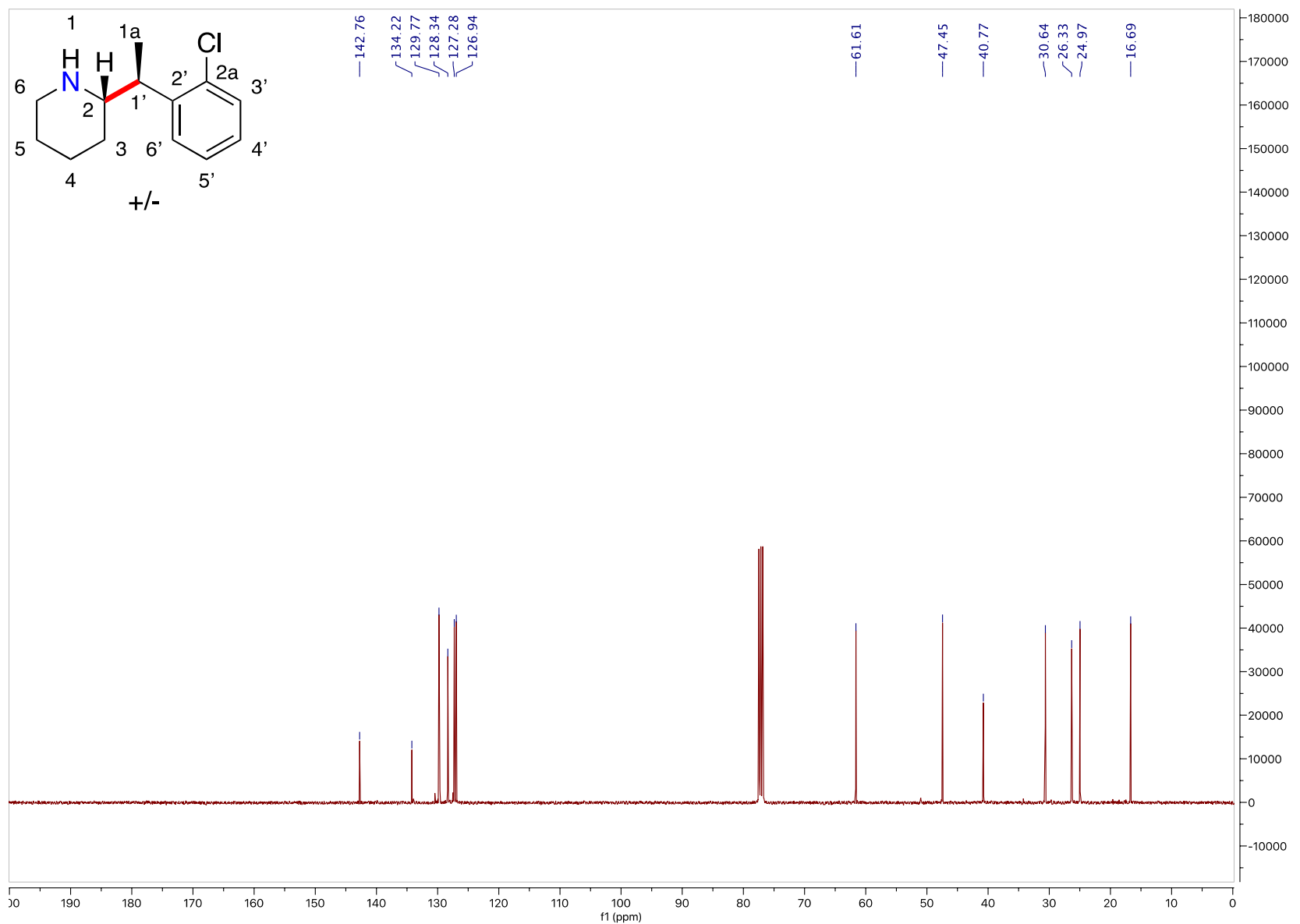

Figure S139: ${ }^{13} \mathrm{C}$ NMR spectrum $\left(101 \mathrm{MHz}, \mathrm{CDCl}_{3}, 298 \mathrm{~K}\right)$ of 2-(1-(2-chlorophenyl)ethyl)piperidine.

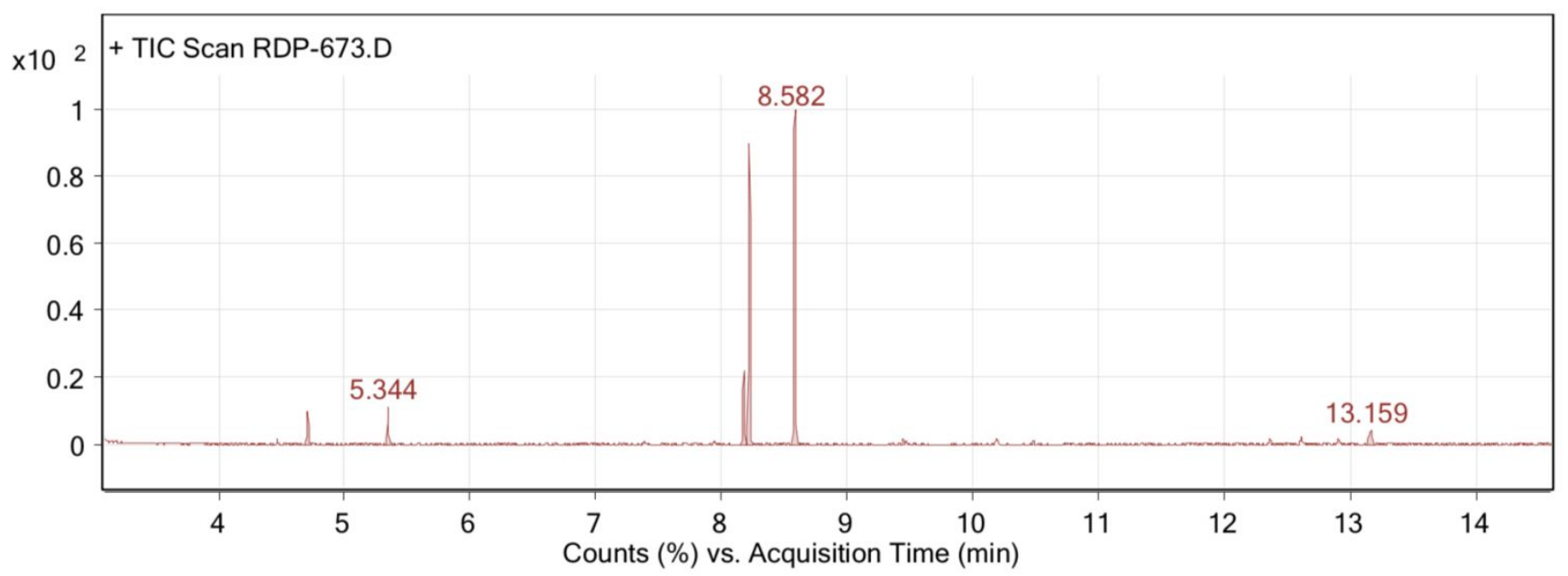

Figure S140: GC-MS for the crude reaction between 2-chlorostyrene and piperidine. 


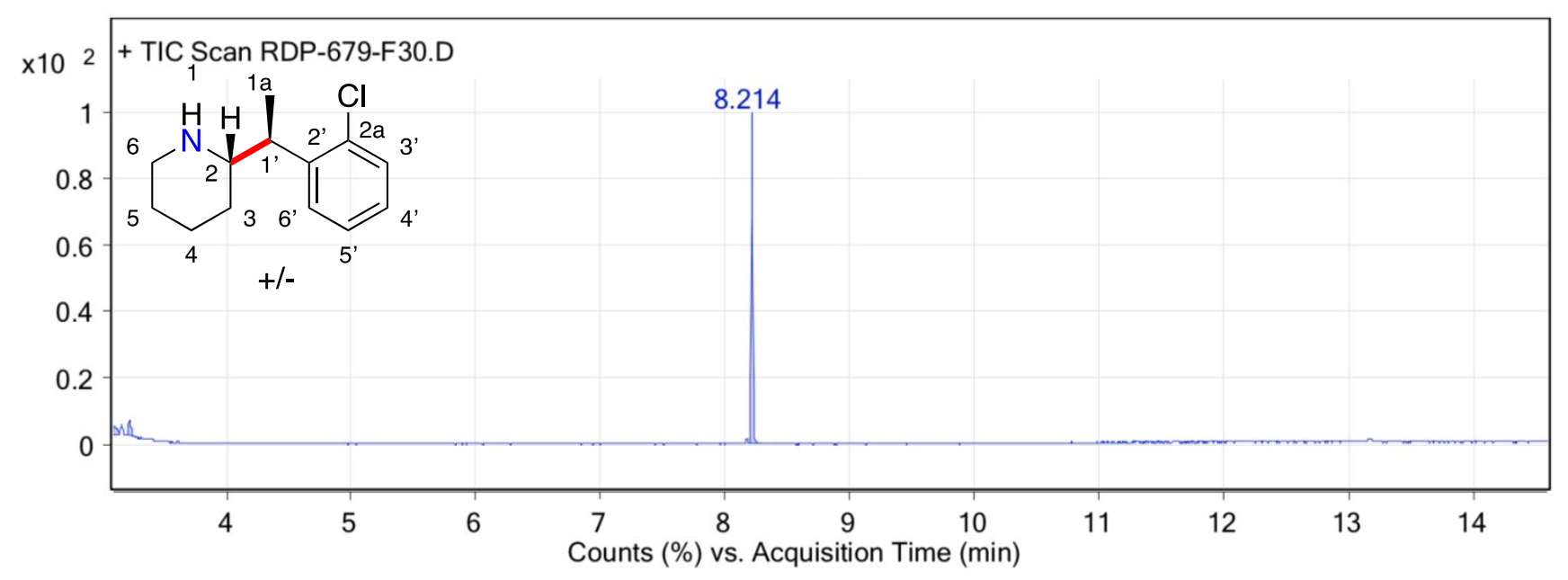

Figure S141: GC-MS report of 2-(1-(2-chlorophenyl)ethyl)piperidine. 


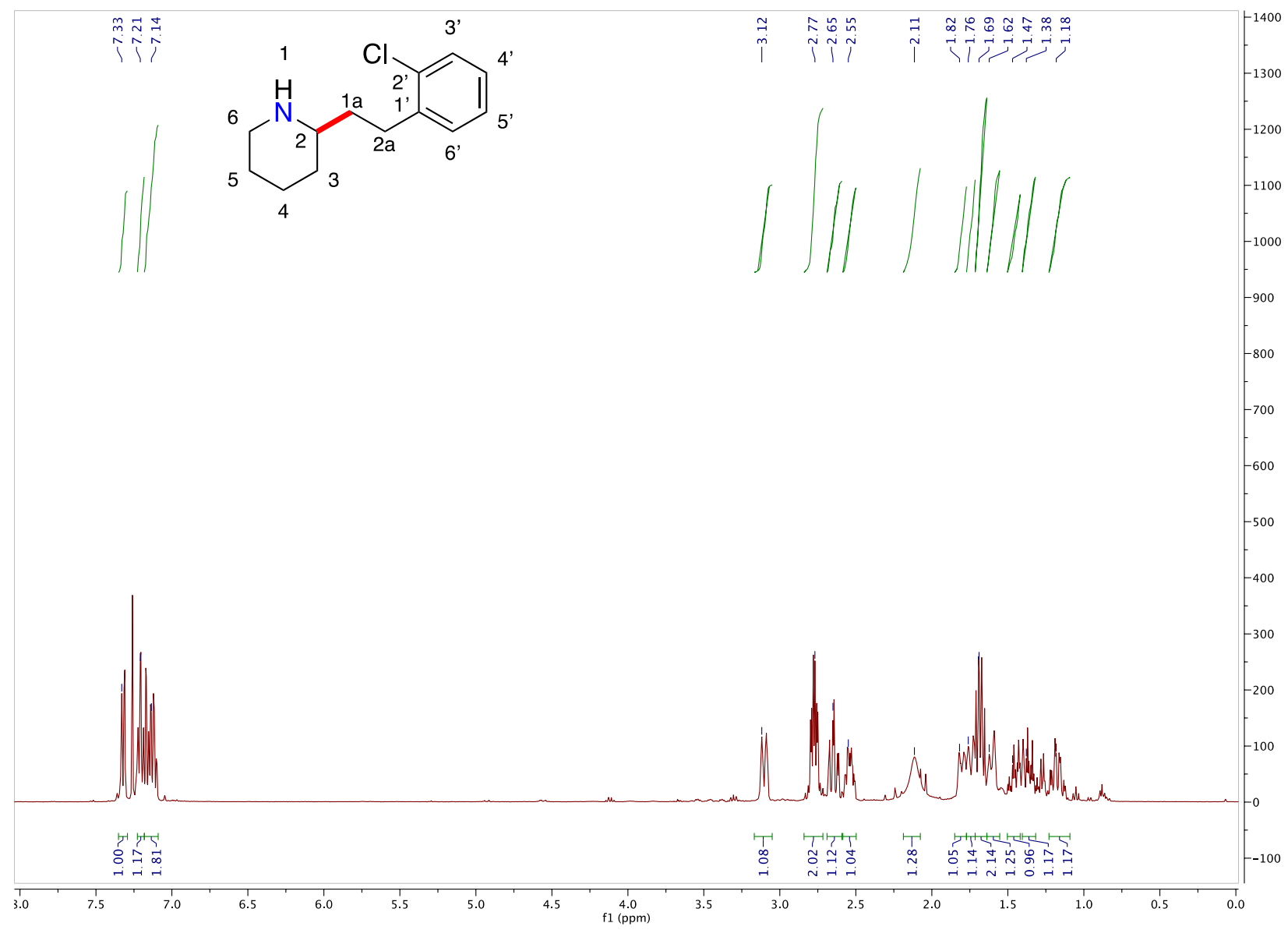

Figure S142: ${ }^{1} \mathrm{H}$ NMR spectrum $\left(400 \mathrm{MHz}, \mathrm{CDCl}_{3}, 298 \mathrm{~K}\right.$ ) of 2-(1-(2-chlorophenyl)ethyl)piperidine. 


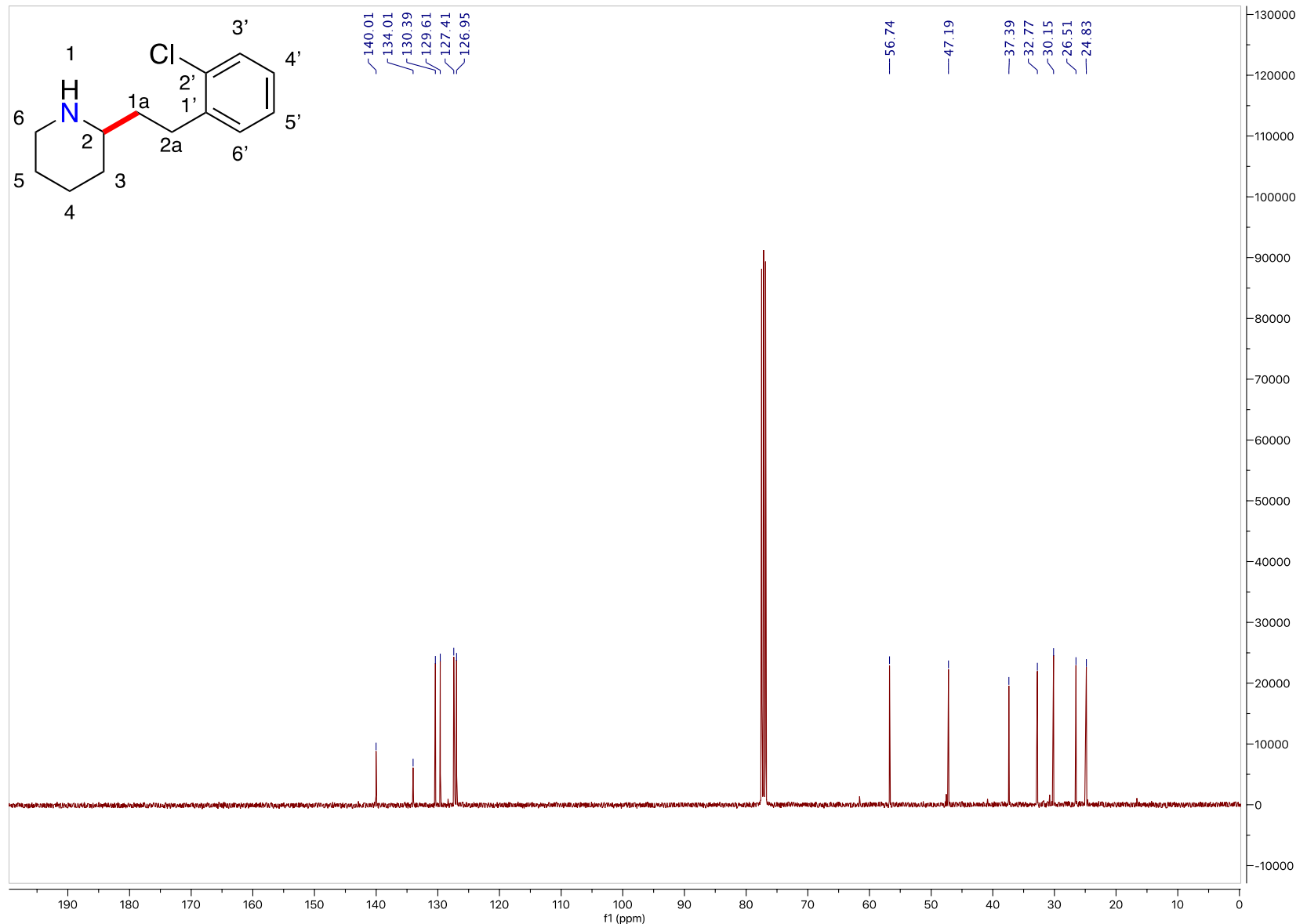

Figure S143: ${ }^{13} \mathrm{C}$ NMR spectrum $\left(101 \mathrm{MHz}, \mathrm{CDCl}_{3}, 298 \mathrm{~K}\right)$ of 2-(1-(2-chlorophenyl)ethyl)piperidine.

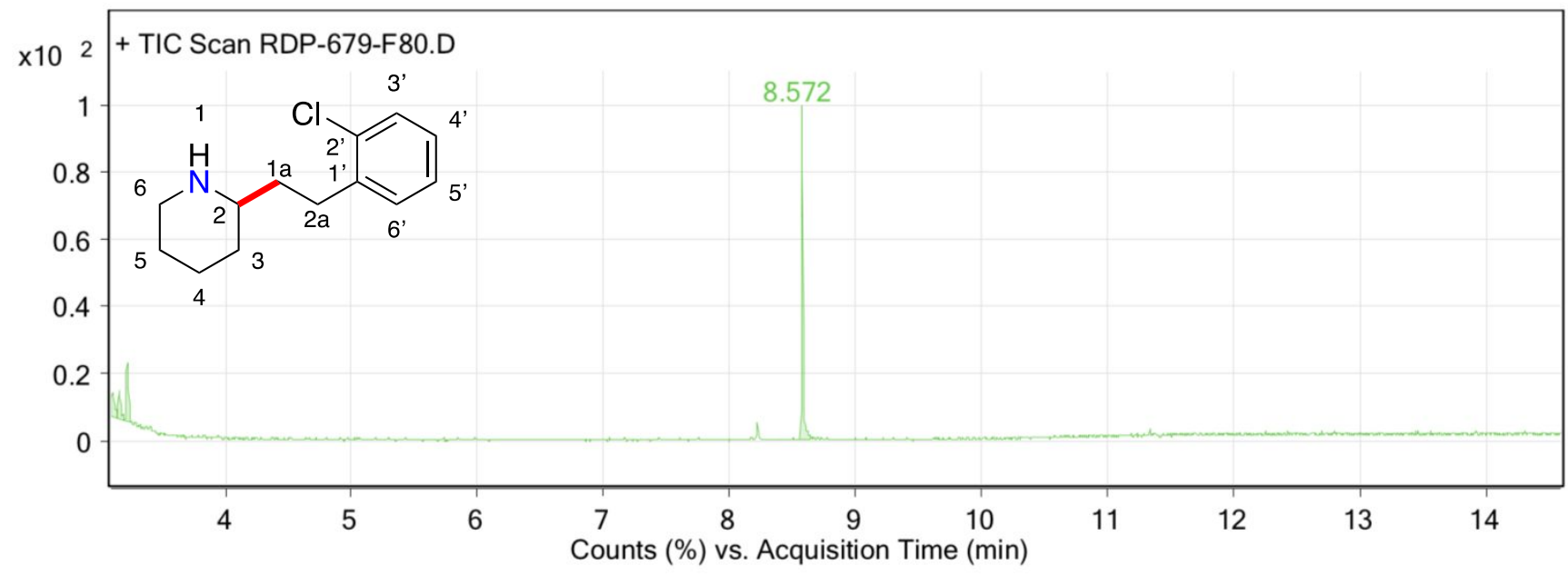

Figure S144: GC-MS report of 2-(1-(2-chlorophenyl)ethyl)piperidine. 
<smiles>C[C@@H](c1ccccc1Br)[C@H]1CCCCN1</smiles>

Synthesis of 2-(1-(2-bromophenyl)ethyl)piperidine and 2-(2-bromophenethyl)piperidine (32 and 33): Prepared following the general procedure outlined above: $26.0 \mathrm{mg}$ Ta, $15.2 \mathrm{mg}$ ligand $\mathbf{L} \mathbf{4}$, piperidine $(85.15 \mathrm{mg}, 1.0 \mathrm{mmol})$, 2-bromostyrene (181.9 $\mathrm{mg}, 1.0 \mathrm{mmol})$. The reaction was subsequently concentrated. Yield of the reaction mixture

could not be determined due to issues with this styrene polymerization during reaction. The unwanted polymerization resulted in broadened signals that could not be carefully integrated in the NMR spectrum. This could not be adequately improved with filtration. Total reaction NMR yield was $99 \%$. Purification via column chromatography (7:2.5:0.5 hexanes : ethyl acetate : triethyl amine):

Branched Regioisomer: ${ }^{1} \mathrm{H}$ NMR ( $\left.\mathrm{CDCl}_{3}, 400 \mathrm{MHz}, 298 \mathrm{~K}\right): \delta 7.56$ (m, 1H, 3'), 7.27 (m, 1H, 5'), 7.23 (m, 1H, 6'), $7.05\left(\mathrm{~m}, 1 \mathrm{H}, 4^{\prime}\right), 3.29(\mathrm{~m}, 1 \mathrm{H}, 1 \mathrm{a}), 3.11(\mathrm{~m}, 1 \mathrm{H}, 1 / 2 \mathrm{of} 6), 2.67(\mathrm{~m}, 1 \mathrm{H}, 2), 2.60(\mathrm{~m}, 1 \mathrm{H}, 1 / 2$ of 6), 1.95 (broad s, $1 \mathrm{H}, \mathrm{NH}), 1.74(\mathrm{~m}, 1 \mathrm{H}, 1 / 2$ of 4$), 1.55(\mathrm{~m}, 1 \mathrm{H}, 1 / 2$ of 5$), 1.44(\mathrm{~m}, 1 \mathrm{H}, 1 / 2$ of 3$), 1.38(\mathrm{~m}$, $1 \mathrm{H}, 1 / 2$ of 5$), 1.28(\mathrm{~d}, \mathrm{~J}=1.27,3 \mathrm{H}, 2 \mathrm{a}), 1.25(\mathrm{~m}, 1 \mathrm{H}, 1 / 2$ of 3$), 1.22(\mathrm{~m}, 1 \mathrm{H}, 1 / 2$ of 4$) \mathrm{ppm} .{ }^{13} \mathrm{C} \mathrm{NMR}\left(\mathrm{CDCl}_{3}\right.$, $101 \mathrm{MHz}, 298 \mathrm{~K}): \delta 144.51,133.15,128.36,127.65,127.61,125.29,61.70,47.50,43.46,30.70,26.38$, 25.02, $16.84 \mathrm{ppm}$. HRMS (ESI): $\mathrm{m} / z$ calcd for $\mathrm{C}_{13} \mathrm{H}_{19} \mathrm{NBr}\left[\mathrm{M}+\mathrm{H}^{+}\right]$: 268.0701 Found: 268.0704 .

Linear Regioisomer: ${ }^{1} \mathrm{H}$ NMR ( $\left.\mathrm{CDCl}_{3}, 400 \mathrm{MHz}, 298 \mathrm{~K}\right): \delta 7.49\left(\mathrm{~m}, 1 \mathrm{H}, 3^{\prime}\right), 7.19(\mathrm{~m}, 2 \mathrm{H}, 5$ ' and 6'), $7.02\left(\mathrm{~m}, 1 \mathrm{H}, 4^{\prime}\right), 3.08(\mathrm{~m}, 1 \mathrm{H}, 1 / 2$ of 6$), 2.77(\mathrm{~m}, 2 \mathrm{H}, 2 \mathrm{a}), 2.64$ (m, 1H, 1/2 of 6$), 2.54(\mathrm{~m}, 1 \mathrm{H}, 2), 2.28$ (broad s, $1 \mathrm{H}, \mathrm{NH}), 1.80(\mathrm{~m}, 1 \mathrm{H}, 1 / 2$ of 4$), 1.71(\mathrm{~m}, 1 \mathrm{H}, 1 / 2$ of 3$), 1.66(\mathrm{~m}, 1 \mathrm{H}, 1 \mathrm{a}), 1.57(\mathrm{~m}, 1 \mathrm{H}, 1 / 2$ of 5$)$, $1.44(\mathrm{~m}, 1 \mathrm{H}, 1 / 2$ of 5$), 1.35(\mathrm{~m}, 1 \mathrm{H}, 1 / 2$ of 4$), 1.16(\mathrm{~m}, 1 \mathrm{H}, 1 / 2$ of 3$)$ ppm. ${ }^{13} \mathrm{C} \mathrm{NMR}\left(\mathrm{CDCl}_{3}, 101 \mathrm{MHz}, 298\right.$ K): $\delta 141.71,132.86,130.31,127.60,127.56,124.48,56.66,47.17,37.57,32.79,32.70,26.53,24.82$ ppm. HRMS (ESI): $m / z$ calcd for $\mathrm{C}_{13} \mathrm{H}_{19} \mathrm{NBr}\left[\mathrm{M}+\mathrm{H}^{+}\right]$: 268.0701 Found: 268.0704 . 


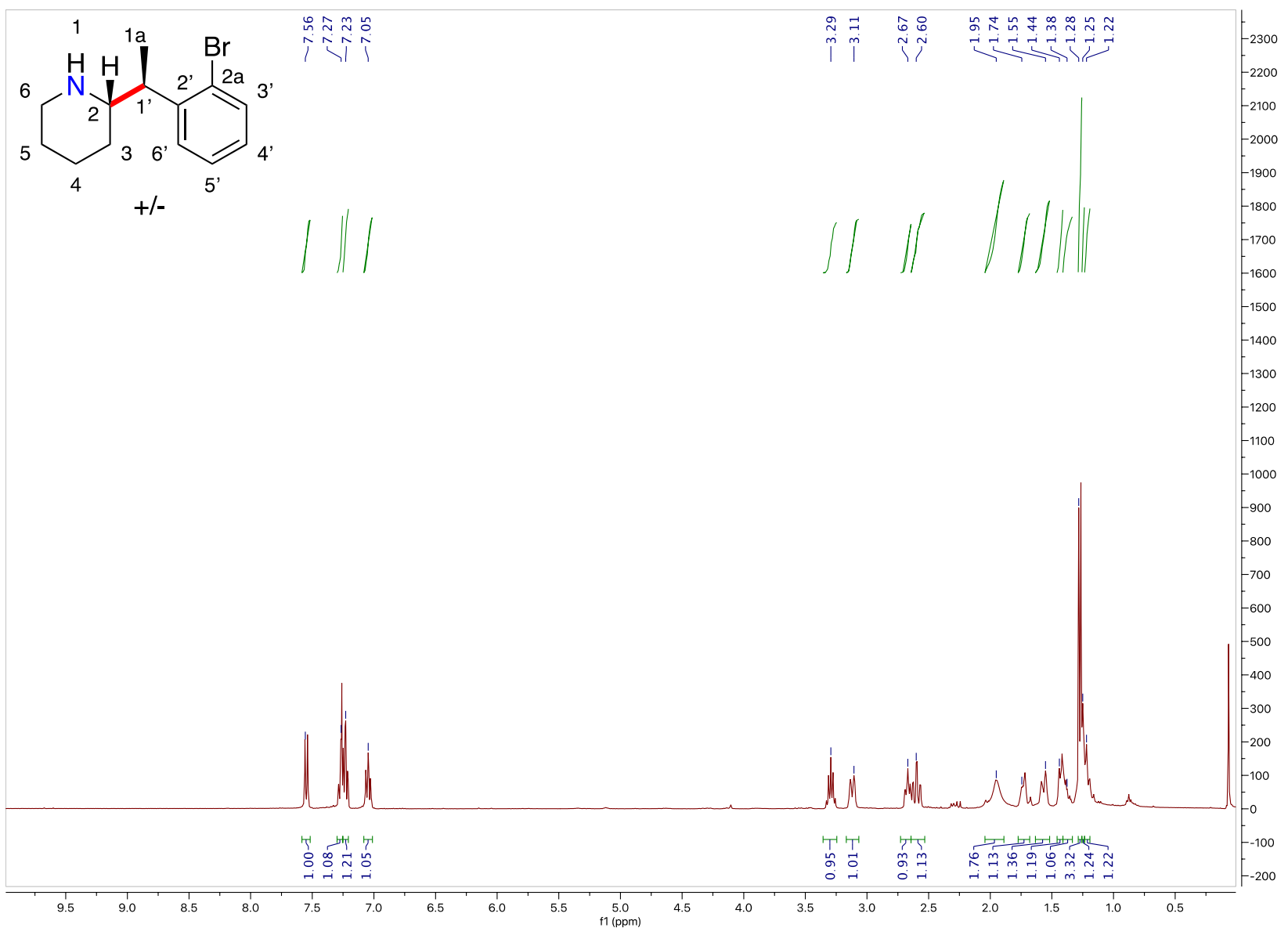

Figure S145: ${ }^{1} \mathrm{H}$ NMR spectrum (400 MHz, $\left.\mathrm{CDCl}_{3}, 298 \mathrm{~K}\right)$ of 2-(1-(2-bromophenyl)ethyl)piperidine.

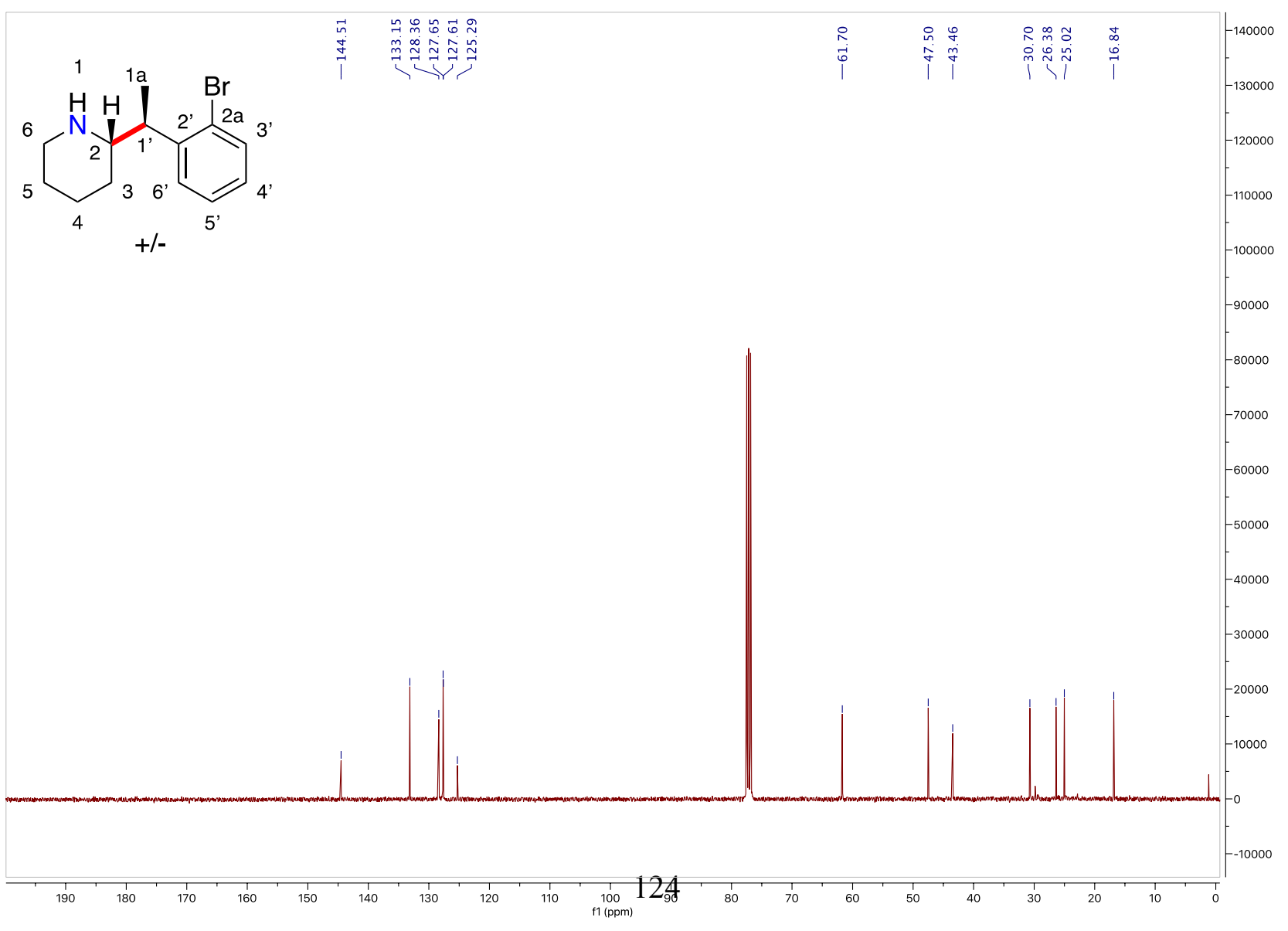


Figure S146: ${ }^{13} \mathrm{C}$ NMR spectrum $\left(101 \mathrm{MHz}, \mathrm{CDCl}_{3}, 298 \mathrm{~K}\right)$ of 2-(1-(2-bromophenyl)ethyl)piperidine.

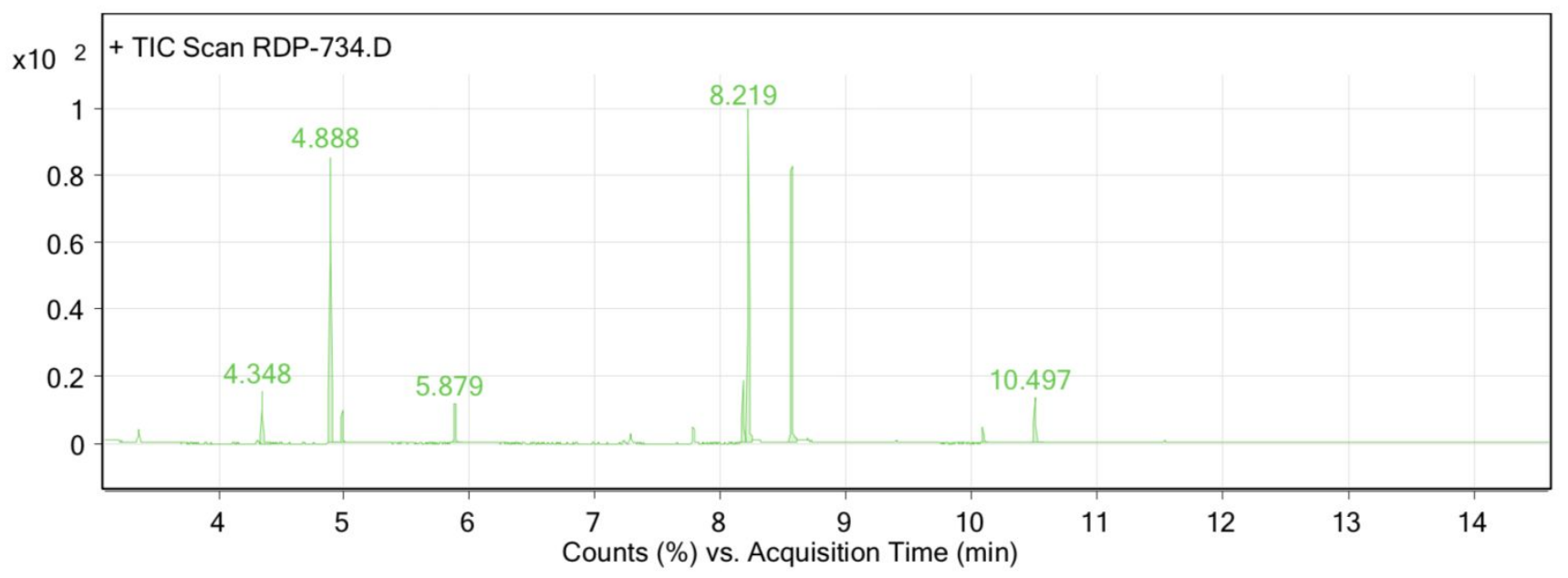

Figure S147: GC-MS for the crude reaction mixture between piperidine and 2-bromostyrene.

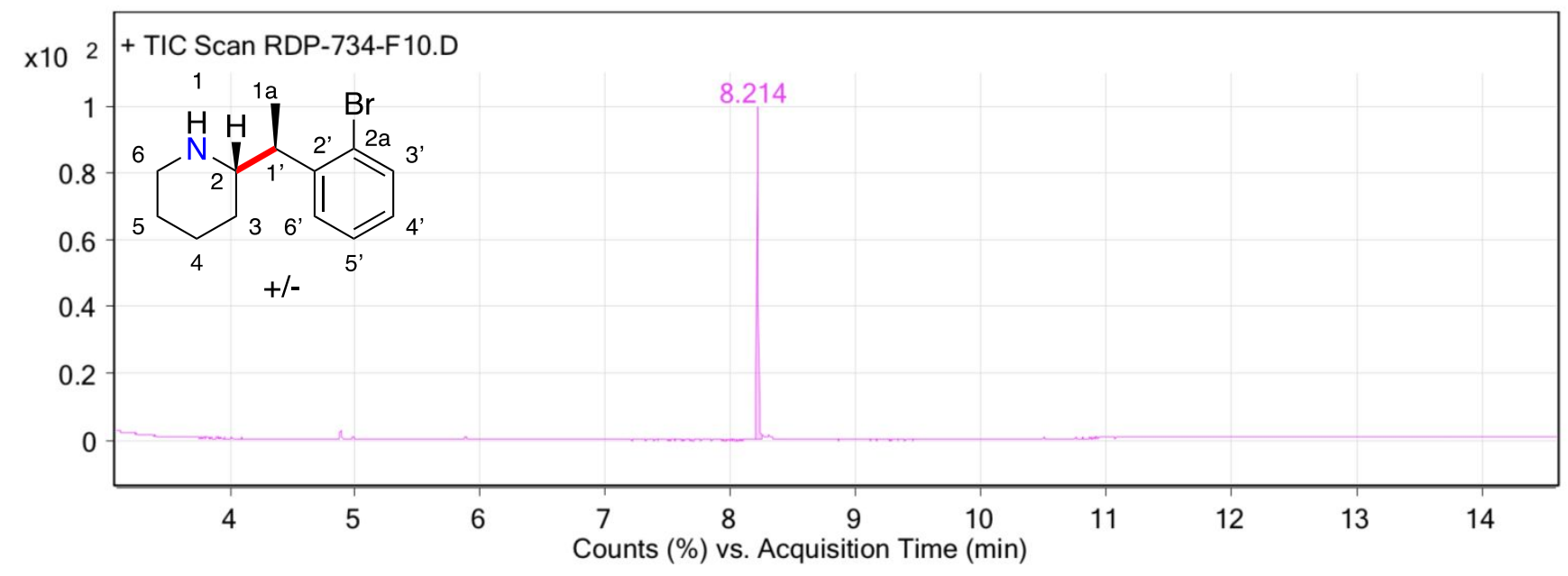

Figure S148: GC-MS spectrum of 2-(1-(2-bromophenyl)ethyl)piperidine. 


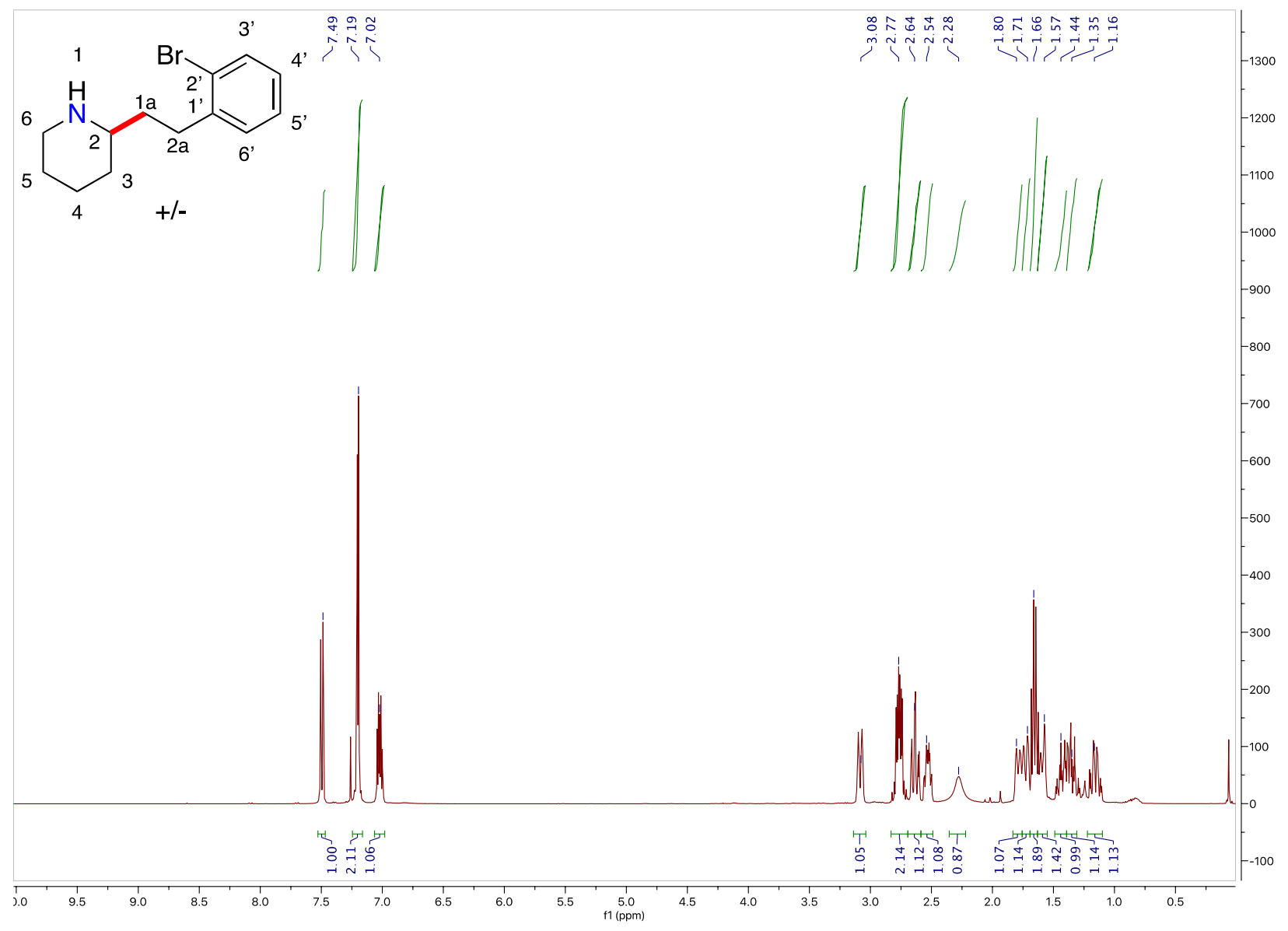

Figure S149: ${ }^{1} \mathrm{H}$ NMR spectrum (400 MHz, $\mathrm{CDCl}_{3}, 298 \mathrm{~K}$ ) of 2-(2-bromophenethyl)piperidine. 


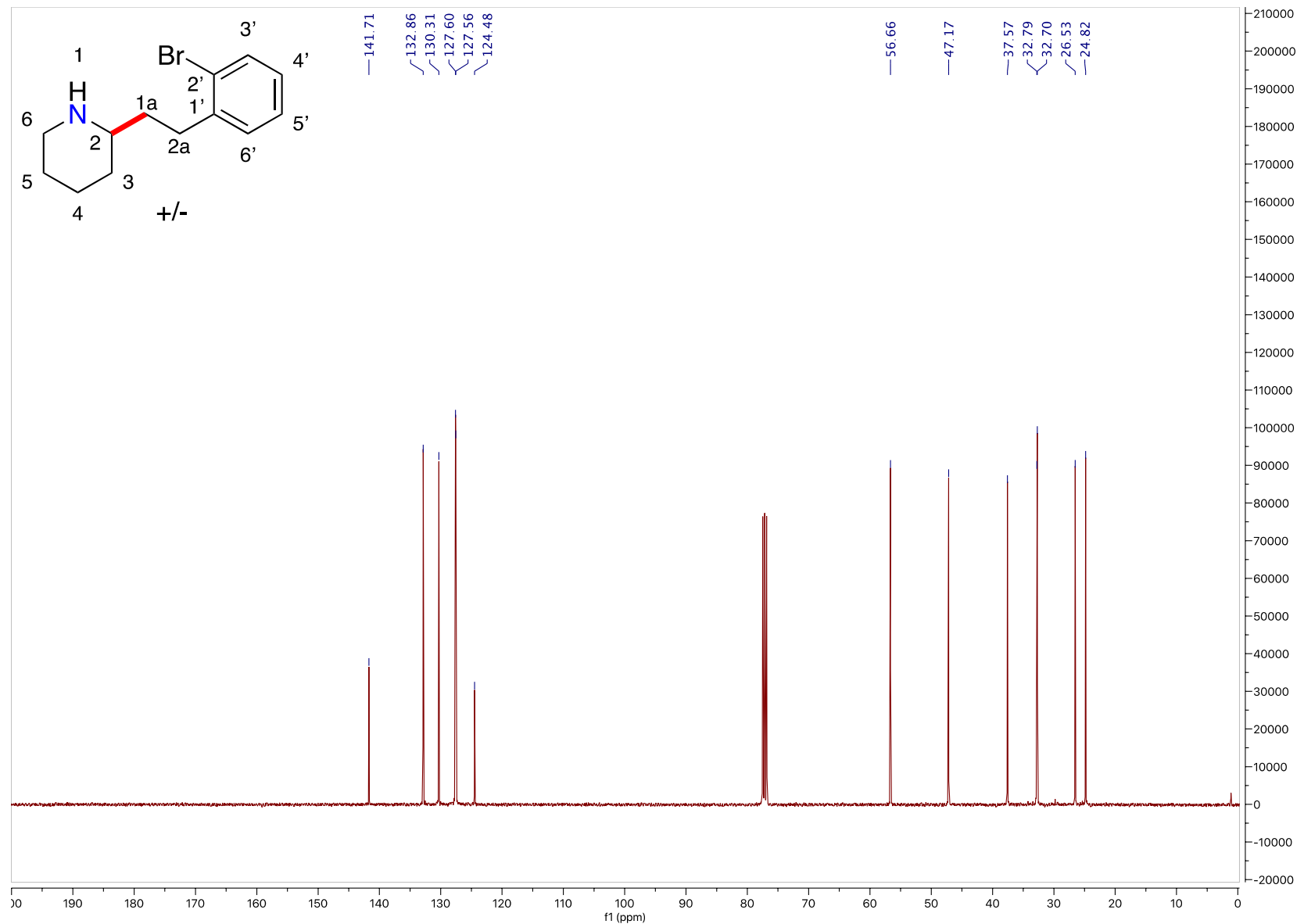

Figure S150: ${ }^{13} \mathrm{C}$ NMR spectrum $\left(101 \mathrm{MHz}, \mathrm{CDCl}_{3}, 298 \mathrm{~K}\right)$ of 2-(2-bromophenethyl)piperidine.

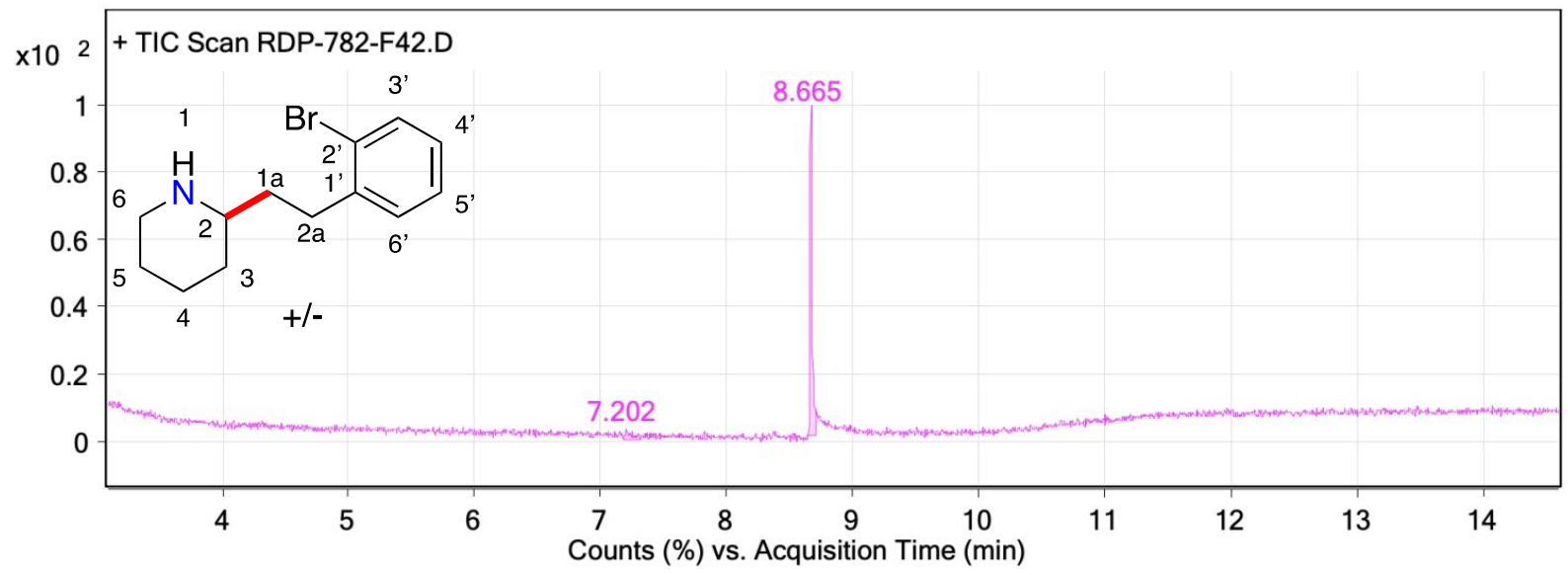

Figure S151: GC-MS report (101 MHz, $\mathrm{CDCl}_{3}, 298 \mathrm{~K}$ ) of 2-(2-bromophenethyl)piperidine.

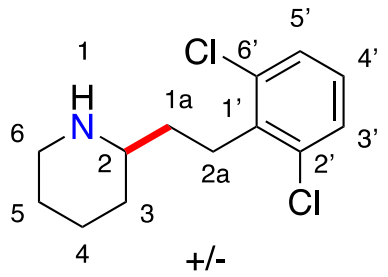

Synthesis of 2-(2,6-dichlorophenethyl)piperidine (34): Prepared following the general procedure for branched and linear product mixtures outlined above: 26.0 $\mathrm{mg} \mathrm{Ta}, 15.2 \mathrm{mg}$ ligand $\mathbf{L} 4$, piperidine $(85.15 \mathrm{mg}, 1.0 \mathrm{mmol}), 2,6-$ dichlorostyrene $(173.04 \mathrm{mg}, 1.0 \mathrm{mmol})$. The reaction was subsequently concentrated and the yield was determined to be $45 \%$ by NMR $(1,3,5-$ trimethoxybenzene as a standard). Purification via column chromatography 
(7:2.5:0.5 hexanes : ethyl acetate : triethyl amine): ${ }^{1} \mathrm{H}$ NMR $\left(\mathrm{CDCl}_{3}, 400 \mathrm{MHz}, 298 \mathrm{~K}\right): \delta 7.28(\mathrm{~m}, 2 \mathrm{H}$, $3^{\prime}$ and 5'), $7.07\left(\mathrm{~m}, 1 \mathrm{H}, 4^{\prime}\right), 3.19(\mathrm{~m}, 1 \mathrm{H}, 1 / 2$ of 6$), 2.98(\mathrm{~m}, 2 \mathrm{H}, 2 \mathrm{a}), 2.73(\mathrm{~m}, 1 \mathrm{H}, 1 / 2 \mathrm{of} 6), 2.66(\mathrm{~m}, 1 \mathrm{H}$, 2), 2.22 (broad s, $1 \mathrm{H}, \mathrm{NH}), 1.85(\mathrm{~m}, 1 \mathrm{H}, 1 / 2$ of 4$), 1.83(\mathrm{~m}, 1 \mathrm{H}, 1 / 2$ of 3$), 1.73(\mathrm{~m}, 2 \mathrm{H}, 1 \mathrm{a}), 1.66(\mathrm{~m}, 1 \mathrm{H}, 1 / 2$ of 5), $1.56(\mathrm{~m}, 1 \mathrm{H}, 1 / 2$ of 5$), 1.43(\mathrm{~m}, 1 \mathrm{H}, 1 / 2$ of 4$), 1.34(\mathrm{~m}, 1 \mathrm{H}, 1 / 2$ of 3$) \mathrm{ppm} .{ }^{13} \mathrm{C} \mathrm{NMR}\left(\mathrm{CDCl}_{3}, 101 \mathrm{MHz}\right.$, $298 \mathrm{~K}): \delta 138.08,135.38,128.31,127.73,57.00,46.78,34.78,31.95,28.00,25.82,24.46$ ppm. HRMS (ESI): $m / z$ calcd for $\mathrm{C}_{13} \mathrm{H}_{18} \mathrm{NCl}_{2}\left[\mathrm{M}+\mathrm{H}^{+}\right]$: 258.0815 Found: 258.0816 .

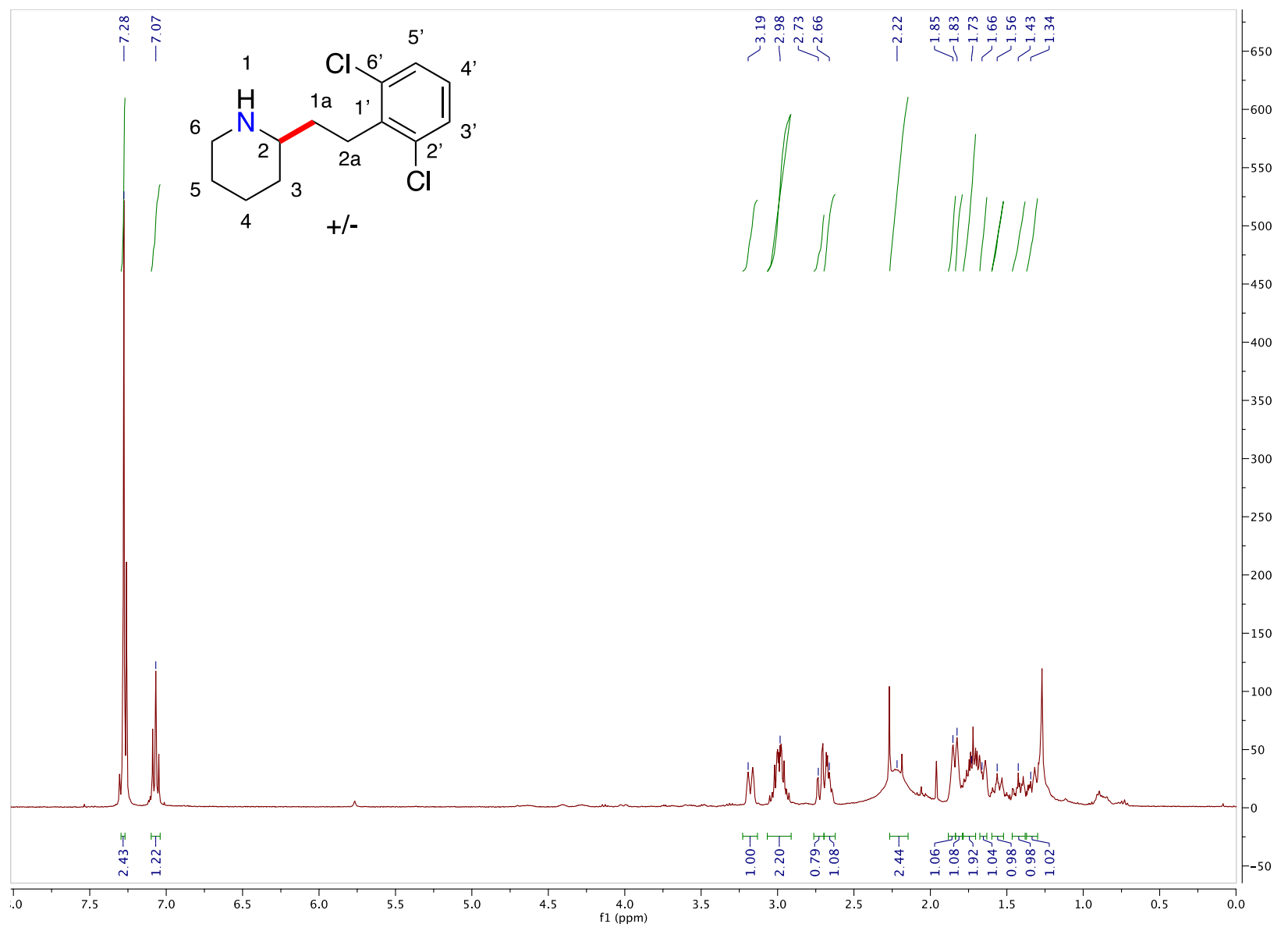

Figure S152: ${ }^{1} \mathrm{H}$ NMR spectrum (400 MHz, $\mathrm{CDCl}_{3}, 298 \mathrm{~K}$ ) of 2-(2,6-dichlorophenethyl)piperidine. 


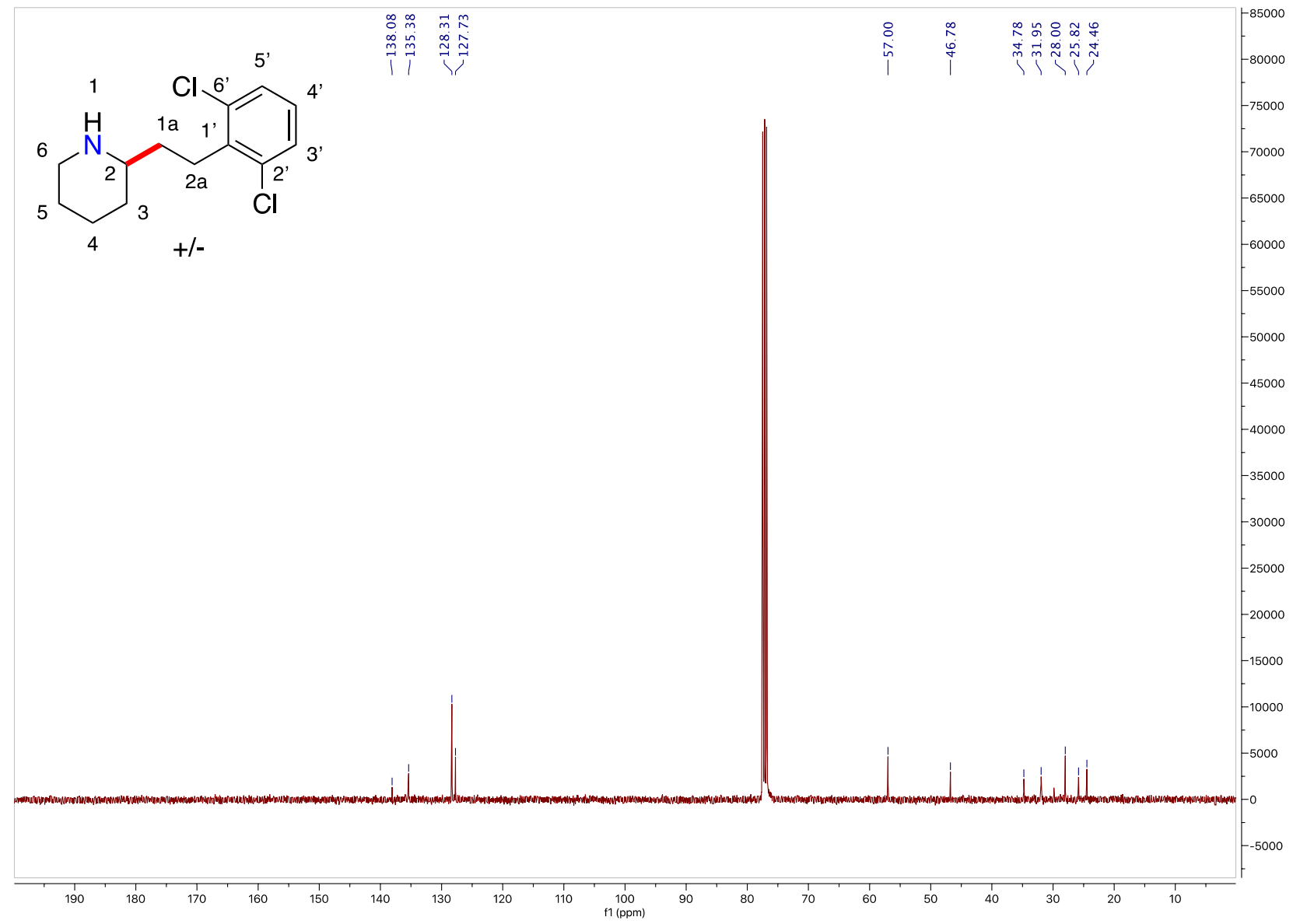

Figure S153: ${ }^{13} \mathrm{C}$ NMR spectrum (101 $\mathrm{MHz}, \mathrm{CDCl}_{3}, 298 \mathrm{~K}$ ) of 2-(2,6-dichlorophenethyl)piperidine.

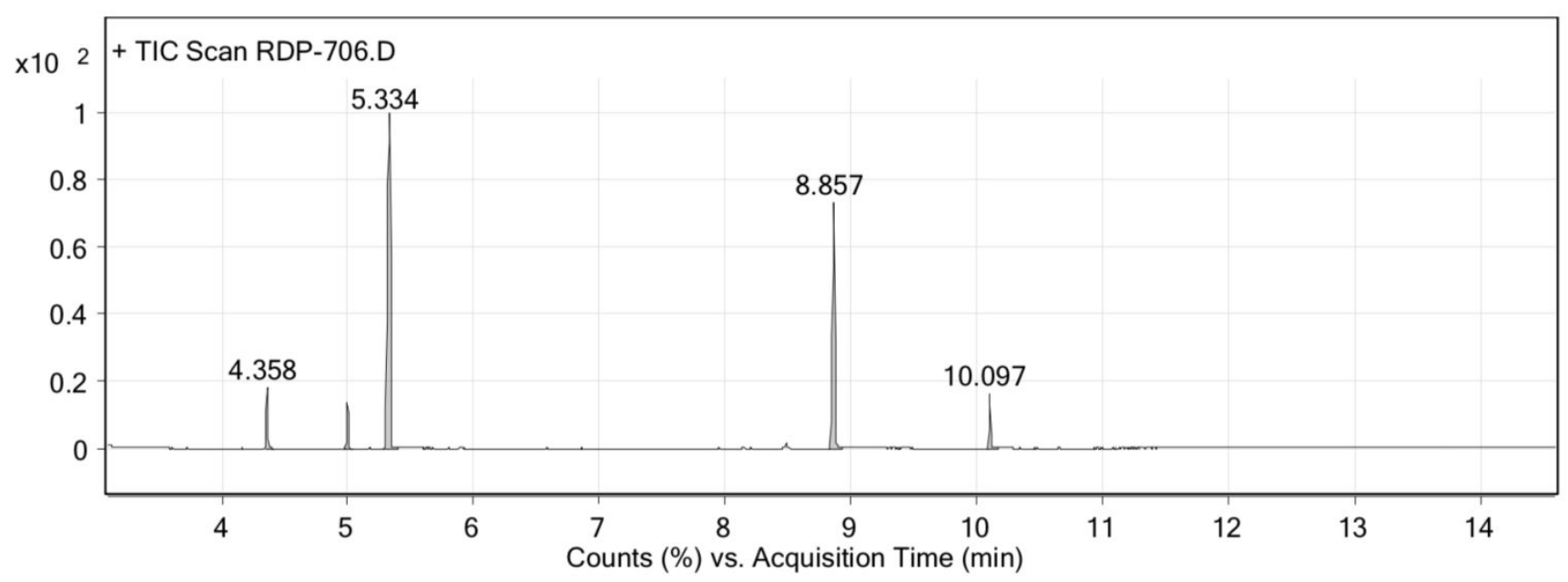

Figure 154: GC-MS for the crude reaction mixture between piperidine and 2-chlorosrtyrene. 


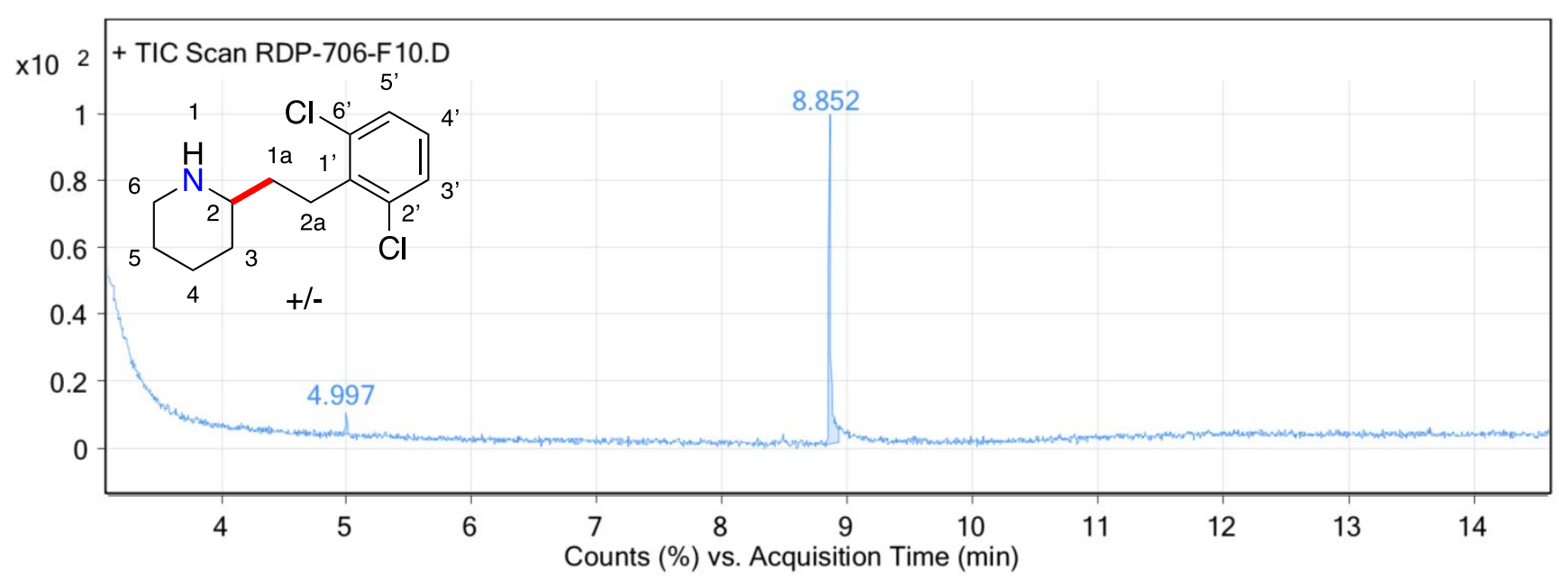

Figure S155: GC-MS report of 2-(2,6-dichlorophenethyl)piperidine.<smiles>C[Si](C)(C)CCC1CCCCN1</smiles>
$\left(\mathrm{CDCl}_{3}, 400 \mathrm{MHz}, 298 \mathrm{~K}\right): \delta 3.09(\mathrm{~m}, 1 \mathrm{H}, 1 / 2$ of 6$), 2.61(\mathrm{~m}, 1 \mathrm{H}, 1 / 2$ of 6$), 2.33(\mathrm{~m}, 1 \mathrm{H}, 2), 1.83$ (broad s, $1 \mathrm{H}, \mathrm{NH}), 1.79(\mathrm{~m}, 1 \mathrm{H}, 1 / 2$ of 4$), 1.69(\mathrm{~m}, 1 \mathrm{H}, 1 / 2$ of 5$), 1.57(\mathrm{~m}, 1 \mathrm{H}, 1 / 2$ of 5$), 1.41(\mathrm{~m}, 2 \mathrm{H}, 2), 1.32(\mathrm{~m}, 2 \mathrm{H}$, $\left.1^{\prime}\right), 1.04(\mathrm{~m}, 1 \mathrm{H}, 1 / 2$ of 3$), 0.52(\mathrm{~m}, 1 \mathrm{H}, 1 / 2$ of 4$), 0.43(\mathrm{~m}, 1 \mathrm{H}, 1 / 2$ of 3$), 0.03(\mathrm{~s}, 9 \mathrm{H}, 2 \mathrm{a}$ and $3 \mathrm{a}$ and $4 \mathrm{a}) \mathrm{ppm}$. ${ }^{13} \mathrm{C} \mathrm{NMR}\left(\mathrm{CDCl}_{3}, 101 \mathrm{MHz}, 298 \mathrm{~K}\right): \delta 47.40,32.74,31.61,26.78,25.07,12.65,-1.67 \mathrm{ppm}$. HRMS (ESI): $m / z$ calcd for $\mathrm{C}_{13} \mathrm{H}_{18} \mathrm{NCl}_{2}\left[\mathrm{M}+\mathrm{H}^{+}\right]: 258.0815$ Found: 258.0816 . 


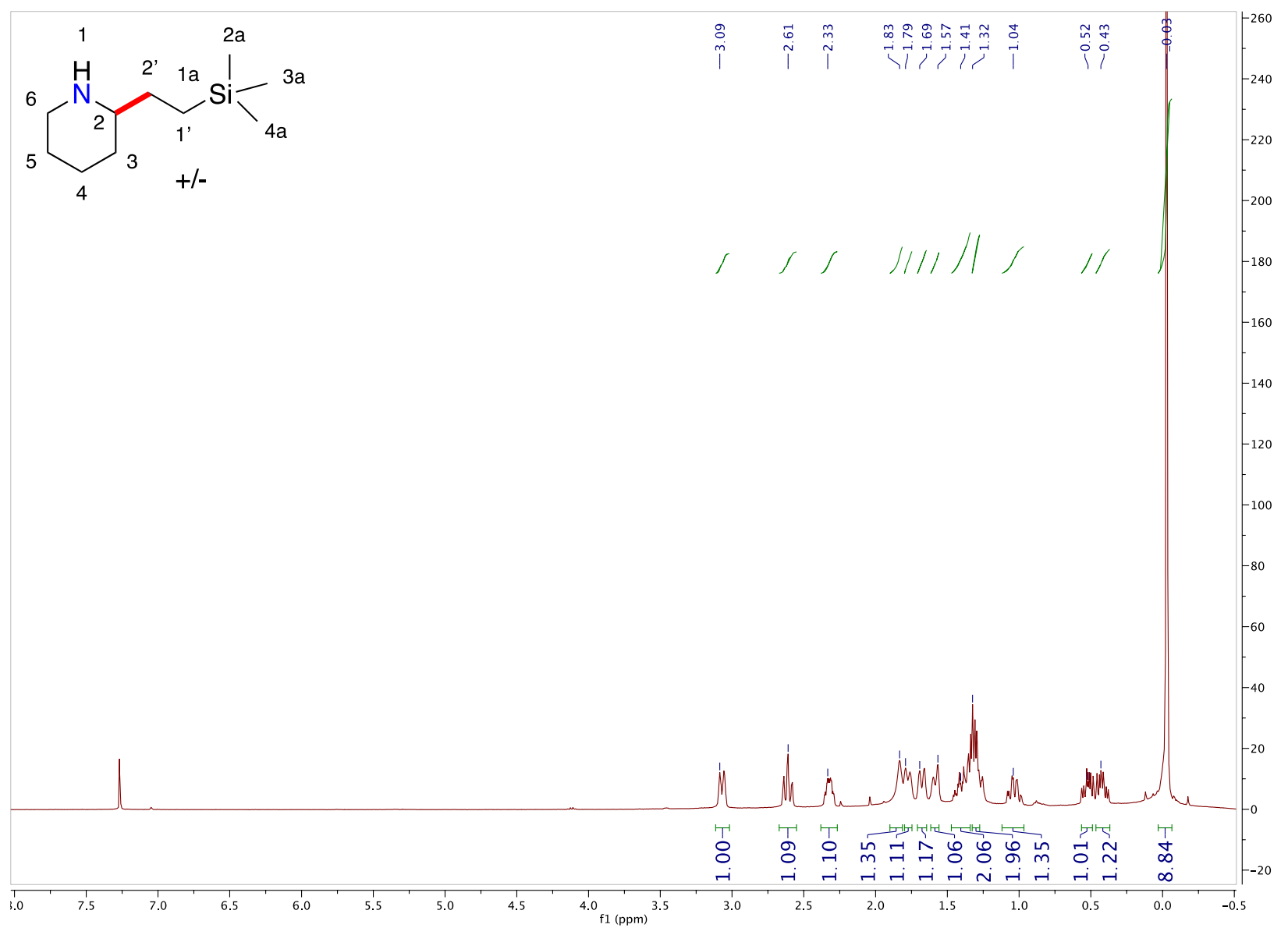

Figure S156: ${ }^{1} \mathrm{H}$ NMR spectrum $\left(400 \mathrm{MHz}, \mathrm{CDCl}_{3}, 298 \mathrm{~K}\right)$ 2-(2-(trimethylsilyl)ethyl)piperidine. 

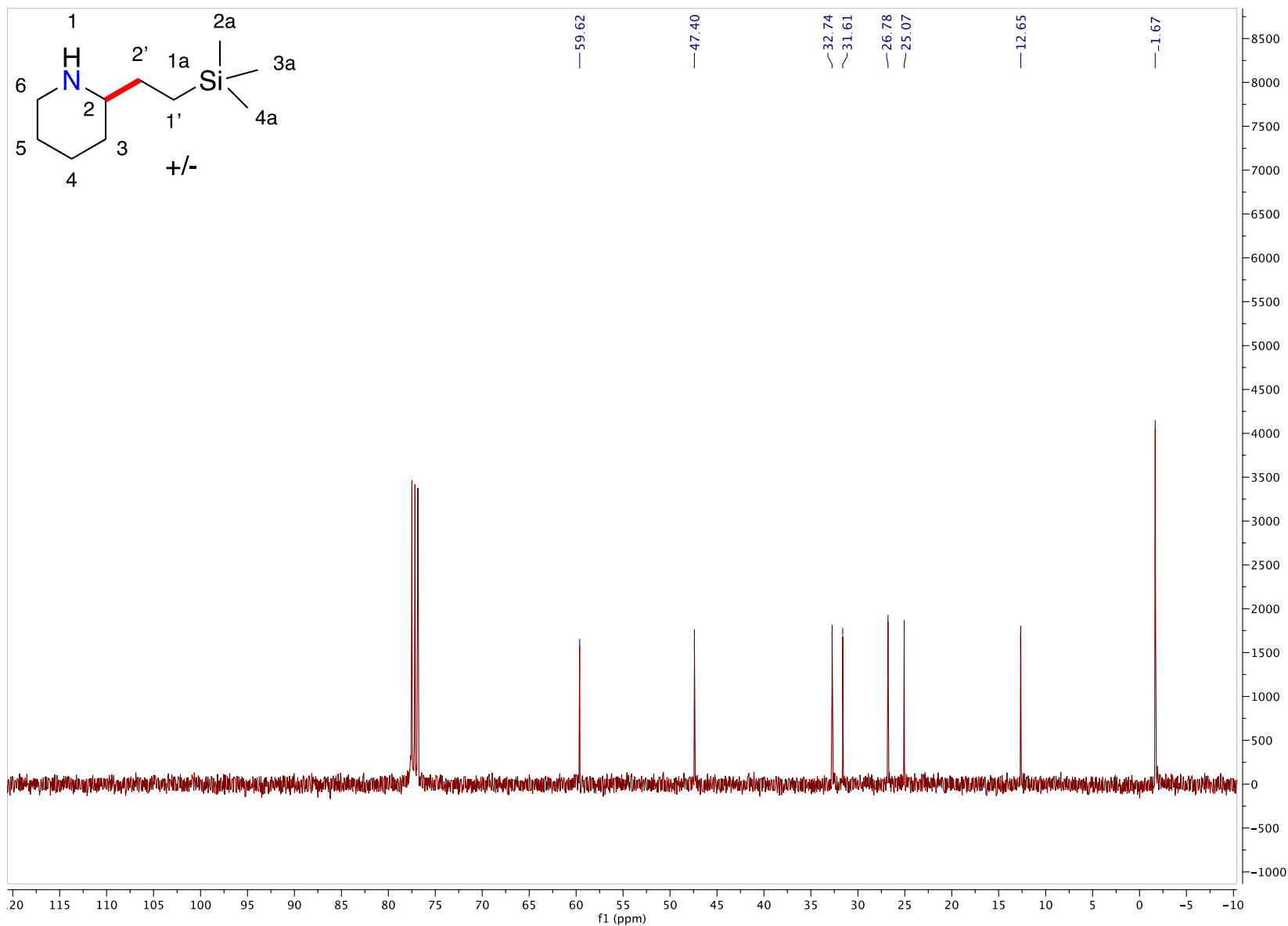

Figure S157: ${ }^{13} \mathrm{C}$ NMR spectrum $\left(101 \mathrm{MHz}, \mathrm{CDCl}_{3}, 298 \mathrm{~K}\right)$ of 2-(2-(trimethylsilyl)ethyl)piperidine.

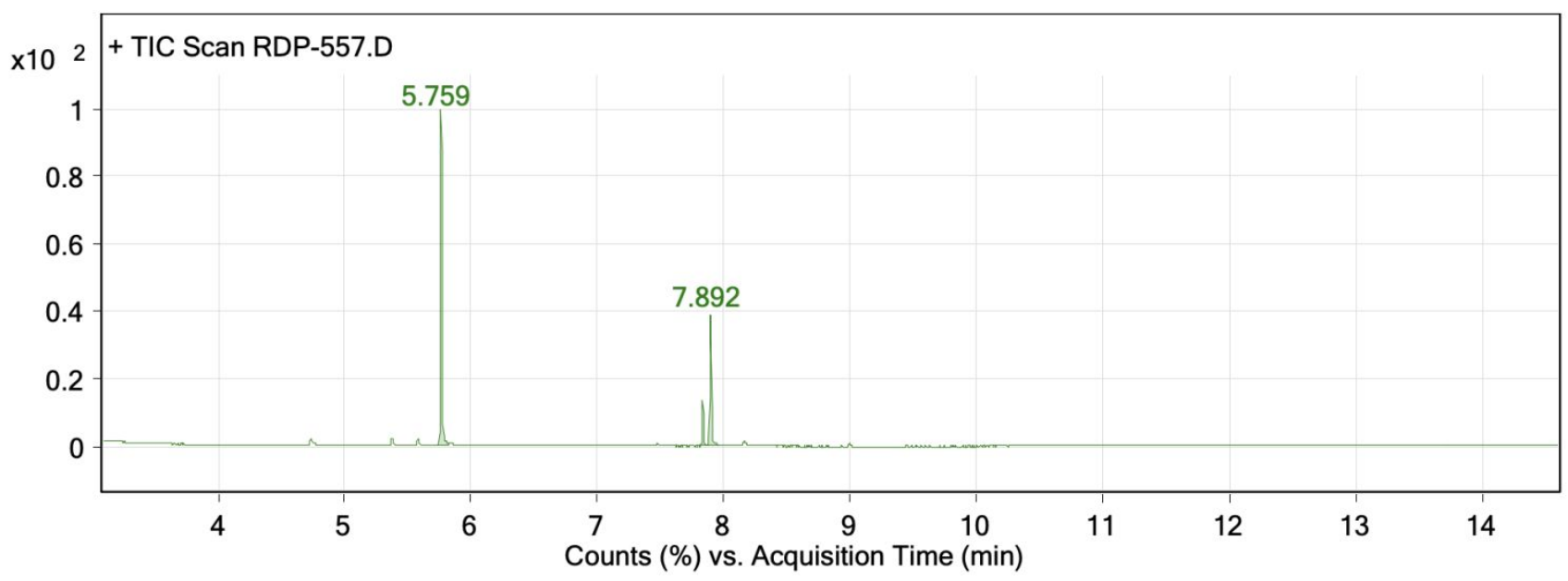

Figure S158: GC-MS for the crude reaction mixture between piperidine and trimethylvinylsilane. 


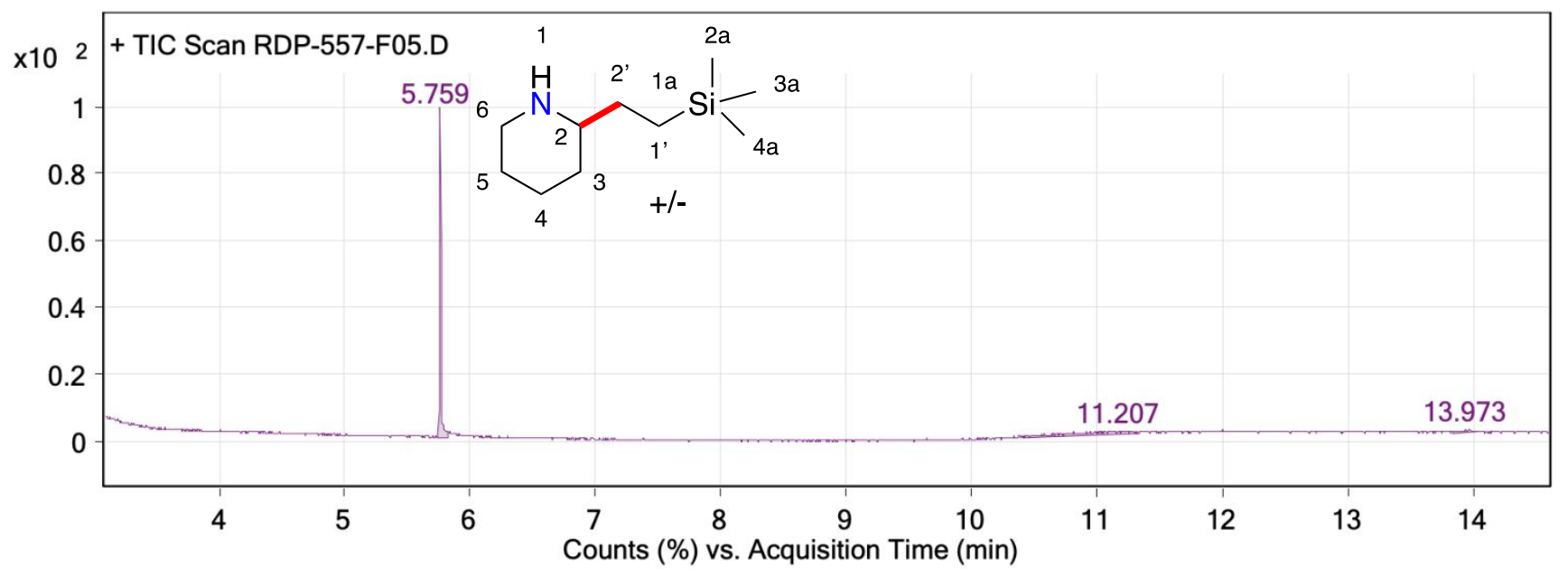

Figure S159: GC-MS report of 2-(2-(trimethylsilyl)ethyl)piperidine.<smiles>CC(CNc1ccccc1)c1ccccc1</smiles>

Synthesis of $N$-(2-phenylpropyl)aniline: Prepared following the general procedure outlined above: $12.8 \mathrm{mg}$ Ta, $7.6 \mathrm{mg}$ ligand $\mathbf{L 4}, N$-methylaniline (53.58 $\mathrm{mg}, 0.5 \mathrm{mmol})$, styrene $(52.08 \mathrm{mg}, 0.5 \mathrm{mmol})$. Both GC peaks below have molecular ion masses that match the target products. These branched and linear regioisomers have been previously published and published NMR spectroscopic and GC-MS data have been compared. ${ }^{0}$

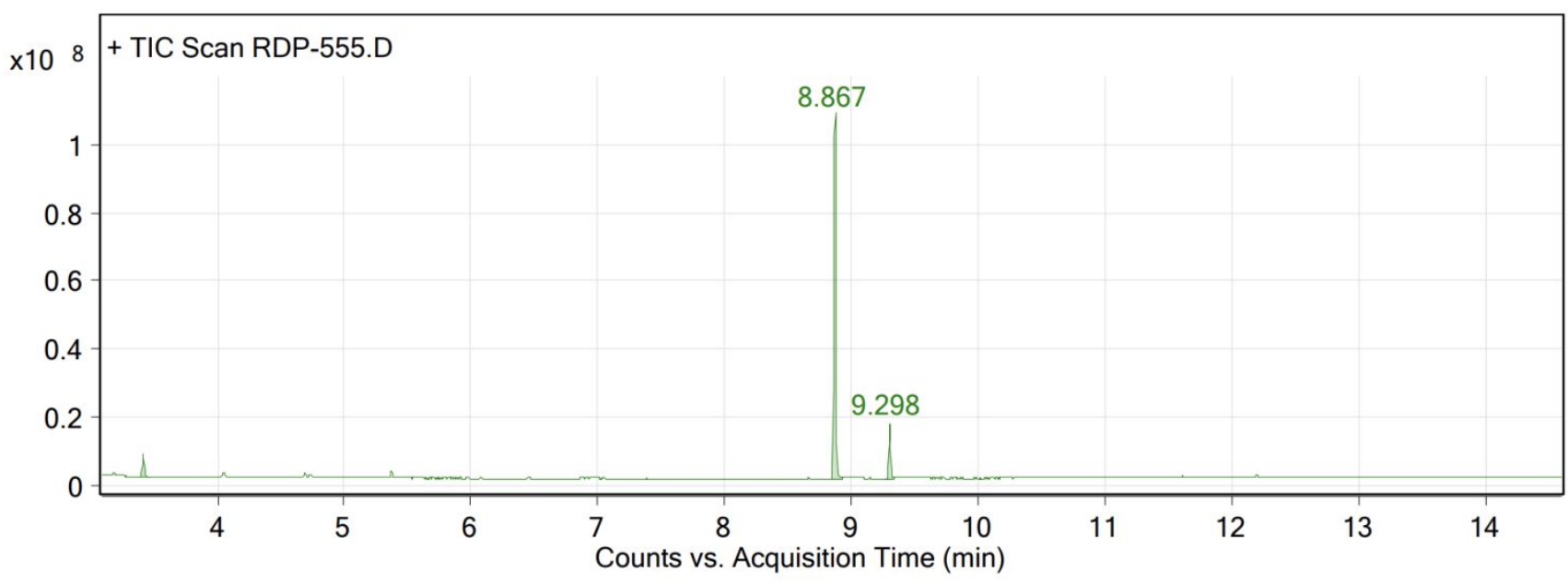

Figure S160: GC-MS report for the crude reaction mixture between $N$-methylaniline and styrene. Here, the peak at 8.867 minutes represents branched regioisomer and the peak at 9.928 minutes represents the linear regioisomer.

\section{S8. References}

(1) Chisholm, M. H.; Huffman, J. C.; Tan, L. S. Chloro(Dimethylamido) Compounds of Tantalum(V): Preparations, Properties, and Structures of [Ta(NMe2)3Cl2]2, $\mathrm{TaCl} 3(\mathrm{NMe} 2) 2(\mathrm{HNMe} 2), \mathrm{Ta}(\mathrm{NMe} 2) 3 \mathrm{Cl} 2(\mathrm{HNMe} 2)$, and [TaCl2(NMe2)2(HNMe2)]2O. Inorg. 
Chem. 1981, 20, 1859-1866.

(2) Chcme, M. C.; Schrock, R. R.; Fellmann, J. D. Multiple Metal-Carbon Bonds. Preparation, Characterization, and Mechanism of Formation of the Tantalum and Niobium Neopentylidene Complexes, M(CH2CMe3)3(CHCMe3). J. Am. Chem. Soc. 1978, 3, 3359.

(3) Moorhouse, B. S.; Wilkinson, G. Bis[(Trimethylsilyl)Methyl]- and Bis(Neopentyl)-Zinc and Tris[(Trimethylsilyl)Methyl]Aluminum-Diethyl Ether; Their Use as Alkylating Agents in Forming Niobium and Tantalum Alkyls. Dalt. Trans 1974, 2187-2190.

(4) DiPucchio, R. C.; Roşca, S. C.; Schafer, L. L. Catalytic and Atom-Economic Csp3-Csp3Bond Formation: Alkyl Tantalum Ureates for Hydroaminoalkylation. Angew. Chemie - Int. Ed. 2018, $57,3469-3472$.

(5) Daneshmand, P.; Roşca, S. C.; Dalhoff, R.; Kejun, Y.; DiPucchio, R. C.; Ivanovich, R. A.; Polat, D. E.; Beauchemin, A. M.; Schafer, L. L. A Cyclic Ureate Ta Catalyst for Preferential Hydroaminoalkylation with Aliphatic Amines. Mechanistic Insights into Substrate Controlled Reactivity. J. Am. Chem. Soc. 2020, 142, 15740-15750.

(6) DiPucchio, R. C.; Rosca, S. C.; Athavan, G.; Schafer, L. L. Exploiting Natural Complexity: Synthetic Terpenoid-Alkaloids by Regioselective and Diastereoselective Hydroaminoalkylation Catalysis. Chem CatChem 2019, 1-7.

(7) Sattler, A.; Ruccolo, S.; Parkin, G. Structural Characterization of TaMe3Cl2 and $\mathrm{Ta}(\mathrm{PMe} 3) 2 \mathrm{Me} 3 \mathrm{Cl}$,Apairof Five and Seven-Coordinate D0 Tantalum Methyl Compounds $†$. Dalt. Trans. 2011, 40, 7777-77782.

(8) Braun, C.; Nieger, M.; Bräse, S.; Schafer, L. L. Planar-Chiral [2.2]Paracyclophane-Based Pyridonates as Ligands for Tantalum-Catalyzed Hydroaminoalkylation. ChemCatChem 2019, 16.

(9) Chong, E.; Brandt, J. W.; Schafer, L. L. 2-Pyridonate Tantalum Complexes for the Intermolecular Hydroaminoalkylation of Sterically Demanding Alkenes. J. Am. Chem. Soc. 2014, 136, 10898-10901.

(10) Manßen, M.; Deng, D.; Zheng, C. H. M.; Dipucchio, R. C.; Chen, D.; Schafer, L. L. Ureate Titanium Catalysts for Hydroaminoalkylation: Using Ligand Design to Increase Reactivity and Utility. 2021, 11, 4550-4560. 